\title{
Genetische Untersuchungen zu den Voraussetzungen und Konsequenzen einer rezedenten Lebensweise am Beispiel der Vogelkirsche (Prunus avium L.)
}

\author{
Dissertation \\ zur Erlangung des Doktorgrades \\ der Fakultät für Forstwissenschaften und Waldökologie \\ der Georg-August-Universität Göttingen
}

vorgelegt von

Aki M. Höltken

geboren am 29.03.1971 in Oldenburg/Oldbg.

Göttingen 2005

Institut für Forstgenetik und Forstpflanzenzüchtung der Universität Göttingen 
BerichterstatterIn

1. Prof. Dr. H.-R. Gregorius

2. Prof. Dr. B. Ziegenhagen

3. Prof. Dr. F. Gruber

Tag der mündlichen Prüfung: 27.06.2005 


\section{Danksagung}

Die vorliegende Arbeit entstand am Institut für Forstgenetik und Forstpflanzenzüchtung in Göttingen in der Zeit vom 01.11.2001 bis zum 20.01.2005.

Mein besonderer Dank gilt Herrn Prof. H.-R. Gregorius für die Überlassung des Themas, die vielen Stunden mit kritischen Diskussionen thematischer Zusammenhänge und die wissenschaftliche Betreuung bei der Durchführung dieses Projektes. Ebenfalls möchte ich mich bei meinem Kollegen Herrn Dr. Kownatzki bedanken, der bei der Probenentnahme, der Durchsicht des Manuskriptes und durch die vielen Diskussionsbeiträge eine große Hilfe war.

Besonderer Dank gilt auch Frau Dr. Gillet, die mir stets beratend und unterstützend bei mathematisch-statistischen Fragen zur Seite stand.

Die Leiterin unseres Sekretariats, Frau Schwahn, war mir eine große Unterstützung hinsichtlich verwaltungstechnischer Fragen und der Formulierung von Textpassagen, wofür ich ihr sehr danken möchte.

Auch sei für die kollegiale Zusammenarbeit und die vielen anregenden Gespräche mit den zahlreichen Doktoranden gedankt. Ihnen und allen technischen MitarbeiterInnen wie Frau Artes, Frau Dolinska, Frau Nöring, Herrn Capelle, Herrn Seliger, Herrn Dinkel danke ich für die Unterstützung bei experimentellen Arbeiten sowie für ihre aufheiternde Stimmung während der vielen und langwierigen Routinearbeiten.

Meinen Eltern sowie meiner Freundin Kerstin bin ich ganz besonders verbunden. Ohne Ihre Geduld und Unterstützung wäre ein Gelingen dieser Arbeit nicht vorstellbar gewesen.

Allen meinen Freunden, die mir stets aufbauend zur Seite gestanden haben, bin ich ebenfalls zu besonderem Dank verpflichtet.

Dieses Forschungsprojekt wurde mit Mitteln der Deutschen Forschungsgemeinschaft (DFG) und der Georg-August-Universität Göttingen finanziert. 


\section{Inhaltsverzeichnis}

1.

1.1

1.2

1.3

Einführung $\ldots \ldots \ldots \ldots \ldots \ldots \ldots \ldots \ldots \ldots \ldots \ldots \ldots \ldots \ldots \ldots \ldots \ldots \ldots$

Rezedente Baumarten ................... 1

Die genetische Vielfalt: Biologische Bedeutung sowie

wissenschaftliche Nutzbarmachung ............ 2

Zielsetzung: Die Charakterisierung des Ver- und

Ausbreitungstyps der Vogelkirsche .............. 3

2.

Stand des problembezogenen Wissens . . . . . . . 7

2.1

2.2

2.2.1

2.2.2

2.2.2.1

2.2.2.2

2.2 .3

2.2.3.1

2.2.3.2

2.2 .4

2.2.4.1

2.2.4.2

2.2.4.3

2.2.4.4

2.2.4.5

2.3

Die Bedeutung von Beobachtungen an realen Systemen zur Hypotheseninduktion. .................... 7

Eigenschaften der Vogelkirsche . . . . . . . . . . . . . $\quad 7$

Morphologie .............................. 7

Verbreitung der Wildkirsche $\ldots \ldots \ldots \ldots \ldots \ldots \ldots \ldots$

Das natürliche Verbreitungsgebiet .................. 8

Die Standortansprüche ........................ 9

Bestäubung und Befruchtung ..................... 11

Insekten als Pollenvektoren .................... 11

Das gametophytische Selbstinkompatibilitätssystem ....... 12

Ausbreitungsmechanismen ........................ 16

Ornithochorie ............................... 17

Mammaliochorie ............................ 19

Keimung ................................ 19

Samenprädation ............................ 19

Der Einfluß der vegetativen Vermehrung . . . . . . . . . . . 20

Die Skalierung einer Untersuchung . ........... 20

3. Pflanzenmaterial und Labormethoden ........... 23

3.1 Auswahl des Pflanzenmaterials ................ 23

3.1.1 Der Kirschenbestand von Roringen als Beispiel für einen in Hochwald überführten ehemaligen Mittelwald .......... 24

3.1.2 Der Kirschenbestand von Wibbecke als Beispiel für einen durchgewachsenen Mittelwald ................... 27

3.1.3 Der Kirschenbestand von Settmarshausen als Beispiel für einen durchgewachsenen Mittelwald .................. 29

$3.2 \quad$ DNA-Analysen . . . . . . . . . . . . . . . . . 30

3.2.1 Isolierung der DNA aus Blattmaterial und Samen ......... 30

3.2.2 Agarose-Gelelektrophorese ..................... 31

3.2.3 DNA-Amplifizierung von Mikrosatelliten-Sequenzen........ 32

3.2.4 Die Kapillarelektrophorese . . . . . . . . . . . . . . . . . 32

4. Eigenschaften des gemischen Reproduktionssystems in adulten Vorkommen der Vogelkirsche .......... 34

4.1 Einführung in die Problematik zur Erfassung asexueller und sexueller Reproduktion bei der Vogelkirsche ...... . 34

4.1.1 Klonales Wachstum und asexuelle Vermehrung .......... 34 
4.1.2 Zum Problem der Identifizierung sexueller und asexueller Abstammung in adulten Vorkommen der Vogelkirsche . . . . . . 38

4.2

Konzeptionelle und statistische Vorgehensweise

Der Test auf klonale Vermehrung ................

Test auf Zugehörigkeit genetisch identischer Individuen zu

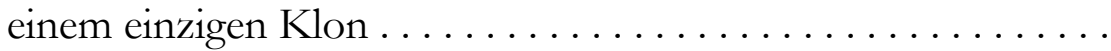

4.2.3 Nutzung des statistischen Fehlers 1. Art zur Abschätzung relativer Genassoziationen . . . . . . . . . . . . . . .

Maße zur Beschreibung der Anteile sexueller und asexueller

Vermehrung innerhalb von Populationen .............

Genetische Variation an sechs SSR-Loci innerhalb der drei Kirschenbestände .....................

Test auf Verklonung ohne Berücksichtigung von Genassozia-

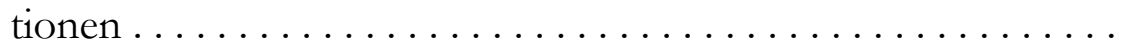

\subsubsection{Die Schätzung einer unteren Grenze relativer Genassoziation} nach Beobachtung statistischer Fehler 1. Art . . . . . . . . .

Anteile sexueller und asexueller Vermehrung innerhalb der

Kirschenvorkommen ......................

5.

Hinweise auf den Ver- und Ausbreitungstyp der Vogelkirsche durch gezielte Analysen räumlich-genetischer Strukturen in adulten Vorkommen . . . . . . . . . . . 61 Einleitung ........................ 61

Die Einordnung der Vogelkirsche im Ökosystem Wald . . . . . . . Die Bedeutung von Kenntnissen über die Verbreitung von Individuen und genetischer Information im Raum . . . . . . . . . . 62

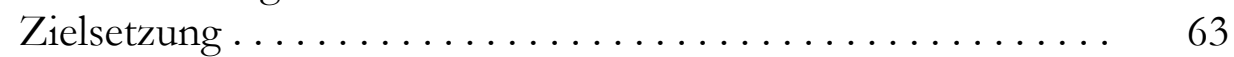
desstrukturen . . . . . . . . . . . . . . . .

Die Clusteranalyse zur Untersuchung räumlich sowie räumlichgenetischer Fragmentiertheit in Pflanzenvorkommen . . . . . . . Die Single-linkage Gruppierungsanalyse: Das Isolationsprinzip als Basis für eine hierarchische Ordnung von Elementen ... . 65 Die hierarchische Gruppierung von Individuen im Raum .... . Die Erzeugung des räumlich-genetischen Abstandsmaßes $d_{s g}$. Räumlich-genetische Gruppenbildung: Symmetrie/Asymmetrie, interne und externe Differenzierung sowie solitäre Objekte ............................ 71

Methoden der Erfassung räumlich-genetischer Kovariationtion

Moran's Index als distanzklassenbasiertes Verfahren ........

Distanzklassenbasierte räumlich-genetische Kovariation unter Verwendung des genetischen Abstandsmaßes $d_{0} \ldots \ldots \ldots \ldots$ Das statistische Testverfahren zu den distanzklassenbasierten

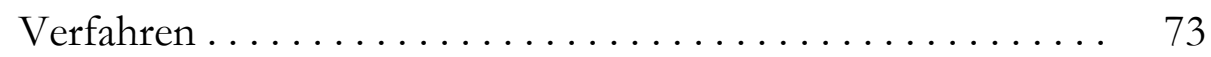

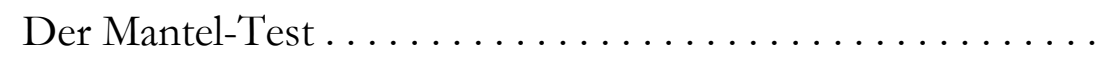

Ergebnisse ..................... 
5.3.1 Die räumliche Verteilung der Altbäume: Erfassung von Gruppenstrukturen, Gruppenisoliertheit sowie solitären Individuen . 74

5.3.2 Die räumlich-genetische Gruppierung der Individuen . . . . . . 82

$5.3 .3 \quad$ Die räumlich-genetische Kovariation . . . . . . . . . . . . 84

5.3.3.1 Die räumliche Autokorrelation ................. 84

5.3.3.2 Mantel-Test......................... 90

$5.4 \quad$ Diskussion $\ldots \ldots \ldots \ldots \ldots \ldots \ldots \ldots \ldots \ldots \ldots \ldots \ldots$

5.4.1 Vergleich der Ergebnisse der verwendeten Verfahren im Hinblick auf ihren Informationsgehalt . . . . . . . . . . . . 91

5.4.2 Hinweise auf den Ver- und Ausbreitungstyp der Vogelkirsche unter Berücksichtigung unterschiedlicher forstlicher Betriebs-

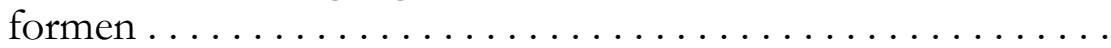

6. Erste explorative Untersuchungen zum reproduktiven Artzusammenhalt der Vogelkirsche ........... 97

$6.1 \quad$ Einleitung $\ldots \ldots \ldots \ldots \ldots \ldots \ldots \ldots \ldots \ldots \ldots \ldots \ldots$

6.1.1 Die Bedeutung und die Determinanten des reproduktiven Artzusammenhalts ........................ 97

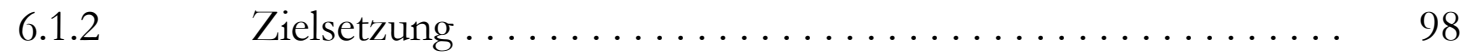

6.2 Materielle und methodische Vorgehensweise .......... 99

6.2.1 Das untersuchte Saatgut . . . . . . . . . . . . . . . . . 99

6.2.2 Vaterschaftsanalyse und Pollenverbreitungsdistanzen ....... 100

6.2.2.1 Das Ausschlußprinzip . . . . . . . . . . . . . . . . . . 100

6.2.2.2 Die Darstellung der potentiellen Väter und die Berechnung der mittleren Pollenausbreitungsdistanzen . . . . . . . . . . 101

6.2.3 Die genetische Diversität des männlichen gametophytischen Beitrags in den Nachkommenschaften einzelner Vogelkirschen 101

6.3 Ergebnisse ....................... 103

6.3.1 Die Pollenverbreitung innerhalb von Waldbeständen und in der freien Landschaft . . . . . . . . . . . . . . . . . 103

6.3.2 Die genetische Variation der Pollenbeiträge innerhalb der untersuchten Nachkommenschaften . . . . . . . . . . . . . . 107

6.3.2.1 Anzahl gefundener Allele in den Pollenbeiträgen der analysierten Samen im Vergleich zu den Altbeständen . . . . . . . . 107

6.3.2.2 Die genetische Diversität in den Pollenbeiträgen der analysierten Samen im Vergleich zu den Altbeständen . . . . . . . . . . 108

6.4 Diskussion . . . . . . . . . . . . . . . . . . . . . . 109

7. Abschließende Bemerkungen und Ausblick . . . . . . . 112

8. Zusammenfassung/Summary ............. 119

9. Literaturübersicht $\ldots \ldots \ldots \ldots \ldots \ldots \ldots \ldots \ldots \ldots$

$\begin{array}{ll}\text { Anhang } & 135\end{array}$ 


\section{Einführung}

\subsection{Rezedente Baumarten}

Das Baumartenspektrum mitteleuropäischer Laubwaldregionen wird von wenigen dominanten ${ }^{1.1}$ (Klimax-) Baumarten beherrscht. Im atlantischen und subatlantischen Klimabereich ist die Rotbuche (Fagus sylvatica L.) eine der vorherrschenden Arten (vgl. ELLENBERG 1986). Daneben gibt es aber auch zahlreiche zerstreut vorkommende, nicht bestandesbildende Baumarten. Diese sollen im folgenden als rezeden$t e^{1.1}$ Baumarten bezeichnet werden, da sie mit nur geringen Individuenzahlen in unseren Wäldern anzutreffen sind. Dabei soll aber nicht nur der geringe Anteil dieser Arten an der Waldfläche ein Charakteristikum darstellen, sondern auch ihr ausschließliches Vorkommen in Mischung mit anderen. Dies impliziert, daß für eine Reihe von Baumarten, die ebenfalls eine geringe Flächenrepräsentanz aufweisen, diese Definition nicht zutrifft. So vermag die Erle (Alnus glutinosa L.) Dominanz auf solchen Standorten erlangen, auf die ihr andere Baumarten nicht zu folgen vermögen (z.B. feuchte Bachtäler innerhalb ansonsten geschlossener Buchenwaldgebiete, vgl. Отто 1994).

Die Differenzierung der beteiligten Baumarten in dominante und rezedente erfolgt meist unter ökologischen Gesichtspunkten, wie z.B. nach deren Konkurrenzkraft (siehe auch KownATZKI 2002). Oft hängt die Präsenz vieler Baumarten in unseren Wäldern entscheidend davon ab, wie stark die Buche den Wettbewerb mit beeinflußt oder nicht. Sie stellt durch ihre hohe Schattentoleranz, ihre Langlebigkeit sowie aufgrund ihres bis ins hohe Alter beträchtlichen Höhenwachstums eine der konkurrenzkräftigsten Baumarten dar. Rezedente oder gar subrezedente Baumarten, zu denen viele aus der Familie der Rosaceae gerechnet werden können (z.B. Prunus avium L. (Vogel- oder Wildkirsche), Sorbus torminalis L. CRANTZ (Elsbeere), Sorbus domestica L. (Speierling), Malus sylvestris MiLL. (Holzapfel), Pyrus pyraster L. (Holzbirne) etc.) sind oft lichtbedürftiger, niedrigwüchsiger, kurzlebiger, weniger standortstolerant und/oder stärker durch Feinde wie Konsumenten und Krankheitserreger gefährdet (vgl. auch ОтTO 1994, ROTACH 1999). Dominanz bzw. Rezedenz und damit die Mischungsstrukturen der verschiedenen Baumartengruppen liegen somit in den unterschiedlichen Ansprüchen begründet, die sie an ihre Umwelt stellen.

Rezedente Arten waren von den Veränderungen der Waldwirtschaft in den letzten Jahrhunderten wahrscheinlich besonders betroffen. Das Vorkommen dieser Baumartengruppe dürfte im Rahmen der Nieder- und Mittelwaldwirtschaft seit dem

\footnotetext{
${ }^{1.1}$ vgl. SCHÄFER (2003): Dominanz ist die relative Menge einer Art in der Flächen- oder Raumeinheit im Vergleich zu den übrigen Arten, wobei nur in Körpergröße und Funktion vergleichbare Gruppen in Beziehung gesetzt werden. Dominanz kann u.a. bedingt sein durch ökologische Potenz oder Resistenz. Je nach Abundanz oder Biomasse der betreffenden Art innerhalb einer Lebensgemeinschaft werden Eudominante (stark Vorherrschende), Dominante (Vorherrschende), Rezedente (Zurücktretende) als auch Subrezedente (stark Zurücktretende) unterschieden.
} 
Beginn des Mittelalters zunächst gefördert worden sein. Denn diese zählten neben den beiden heimischen Eichenarten zu den „fruchtbaren“ im Oberholz der Mittelwälder gehaltenen Baumarten (SIEDER 2003). In den letzten Jahrhunderten dagegen führten Intensivierungen im Rahmen der geregelten Forstwirtschaft zur Auslöschung vieler lokaler und regionaler Vorkommen (SCHOPPA 2000). Die vergleichsweise geringe Populationsdichte oder -größe der rezedenten Arten ermöglicht einerseits zwar das Nebeneinander vieler verschiedener Arten auf kleiner Fläche, birgt andererseits aber, u.a. aus Gründen interspezifischer Konkurrenz, die permanente Gefahr lokaler Extinktionen. Vermutlich kommt ihnen im Hinblick auf ihre ökosystemaren Funktionen aber eine Schlüsselrolle zu, da sie die Fähigkeit besitzen, entstandene Waldöffnungen (Löcher, Freiflächen) schnell zu besiedeln und dadurch für Kontinuität im Nährstoffkreislauf zu sorgen bis diese Lücken wieder durch konkurrenzstärkere Arten besetzt werden. Diese Eigenschaften dürften unverzichtbar sein für die Stabilität von Waldökosystemen gegenüber kleinräumigen Störungen, insbesondere im Hinblick auf Klimaveränderungen (vgl. SCHOPPA 2000, KOWNATZKI 2002).

\subsection{Die genetische Vielfalt: Biologische Bedeutung sowie wissen- schaftliche Nutzbarmachung}

Da ein (Wald-)Ökosystem ein offenes, dynamisches Eingabe-Ausgabe-System darstellt, liegt seine Identität in der Gesamtheit aller Kennzeichen seines Stoff-, Energie- und Informationshaushalts. Der Informationshaushalt, der steuernd auf die Stoff- und Energieflüsse wirkt und auf die Schließung des Nährstoffkreislaufes abzielt, hat seine materielle Basis in der DNS (der genetischen Information). Da die genetischen Informationen nicht im Rahmen des Ökosystems sondern durch die Populationen der beteiligten Arten weitergegeben werden, ist der Zustand eines Ökosystems nicht nur durch das Artenspektrum, sondern auch durch die genetischen Strukturen der Populationen dieser Arten gegeben (HATTEMER und GREGORIUS 1996).

Angepaßtheit und Anpassungsfähigkeit der Populationen als die wichtigsten Komponenten der Ökosystemstabilität basieren also auf der Existenz und der Ausnutzung genetischer Variation. Insbesondere bei sessilen, langlebigen Organismen wie den Waldbäumen, deren Existenz unter zeitlich und räumlich sehr heterogenen Umweltbedingungen gesichert sein muß, ist das von größter Bedeutung (vgl. GREGORIUS 1996).

Genetische Inventuren mit Isoenzym-Genmarkern zeigen, daß die meisten Waldbaumpopulationen relativ schwach differenziert sind, so daß ein großer Teil der genetischen Variation einer Art also schon innerhalb einzelner Waldbestände gespeichert ist (HATTEMER et al. 1993). Der größte Teil der Untersuchungen basiert allerdings auf der genetischen Inventur dominanter Baumarten (Hauptbaumarten mit hoher Konkurrenzkraft). Aufgrund ihrer weitgehend zusammenhängenden Bestände besitzen sie die Fähigkeit, Störungen, die eine Gefahr für den Verlust geneti- 
scher Variation darstellen, leichter zu kompensieren. Indiz hierfür ist eine geringe räumlich-genetische Differenzierung, wie sie z.B. für die Rotbuche (STARKE et al. 1995, TUROK 1995) und die Rotfichte (BERGMANN 1991) beschrieben ist.

Die Anzahl an vergleichbaren Untersuchungen an rezedenten Arten ist jedoch, trotz ihres substantiellen Beitrags zur Biodiversität der meisten Waldökosysteme, sehr gering. Wegen ihrer räumlichen (sozialen) Isolation benötigen rezedente Arten für die Erhaltung der genetischen Variation innerhalb der Arten gut abgestimmte Mechanismen des genetischen Systems, welche in dieser Arbeit Gegenstand der Literatursichtung sowie experimenteller Untersuchungen sein sollen. Diese Mechanismen umfassen im allgemeinen neben der Organisation und Expression, die Reproduktion (einschließlich Replikation und Transmission), die Kombination sowie die zeitliche und räumliche Ausbreitung genetischer Information. Mutation (Bereitstellung neuartiger genetischer Information) und Selektion (Erprobung genetischer Information) sind solche Prozesse, die erst durch die Mechanismen des genetischen Systems ermöglicht werden. Damit werden die Voraussetzungen geschaffen, heterogenen Umweltbedingungen mit unterschiedlichen, an die jeweiligen Bedingungen besser angepaßten bzw. anpassungsfähigen Genotypen zu begegnen (vgl. GREGORIUS 2001, SCHOPPA 2000).

Eine nachhaltige Bewirtschaftung biologischer Ressourcen muß daher auch die genetische Vielfalt umfassen. Wirkungsvolle Maßnahmen sind allerdings nur durchführbar, wenn die populationsbiologischen Eigenschaften der fraglichen Arten bekannt sind. In diesem Zusammenhang kann genetische Variabilität auch als Indikator für die Erkennung dynamischer Prozesse innerhalb von Pflanzenvorkommen verwendet werden. $\mathrm{Zu}$ diesem Zwecke werden, wie auch in dieser Arbeit, meist hochvariable molekulare Marker eingesetzt. Auch wenn sich die DNA-Sequenzen der meisten Markersysteme (hier: Mikrosatelliten) meist außerhalb kodierender Abschnitte der Erbinformation befinden und somit adaptive Prozesse nur bedingt zu analysieren sind, so können doch mit Hilfe dieser Informationen eine Reihe von Mechanismen des genetischen Systems beschrieben werden. Insbesondere können aber die Einflüsse unterschiedlicher Umweltbedingungen auf die Funktion oder gar Intaktheit dieser Mechanismen näher untersucht werden.

\subsection{Zielsetzung: Die Charakterisierung des Ver- und Ausbrei- tungstyps ${ }^{1.2}$ der Vogelkirsche (Prunus avium L.)}

Als Modellbaumart zur Untersuchung populationsbiologischer Charakteristika einer rezedenten Lebensweise wurde die Vogelkirsche (Prunus avium L.) aus der Fami-

\footnotetext{
${ }^{1.2}$ Nach URBANSKA (1992) stellt die Ausbreitung einen Beförderungsvorgang von Ausbreitungseinheiten dar, während ihre Verbreitung Ausdruck und Folge davon ist, also ein Zustand, der die räumliche Verteilung der Pflanzen oder ihren Diasporen beschreibt. Dabei zitiert sie PRAEGER (1923), der schon Anfang letzten Jahrhunderts im englischen Sprachgebrauch die Begriffe distribution und dispersal im o.g. Sinne unterschied. Dies soll hier auch für die genetische Information als Indikator zur Beschreibung genetischer Mechanismen gelten.
} 
lie der Rosaceen herangezogen. Diese insektenbestäubte Baumart bildet aus waldbaulich-ökologischer Sicht keine zusammenhängenden Waldbestände, sondern kommt meist zerstreut (vereinzelt oder in Gruppen) in nährstoffreichen Buchenund Eichenmischwäldern wärmerer Standorte vor (SCHÜTT et al. 1992). Besonders häufig ist sie in ehemaligen Mittelwäldern anzutreffen (vgl. KOWNATZKI 2002). Der hohe Lichtbedarf, das ausgeprägte Jugendwachstum in Verbindung mit einem frühen Kulminationszeitpunkt verleihen ihr den Charakter einer Pionierbaumart. Im Laufe forstlicher Sukzessionsprozesse unterliegt die Vogelkirsche deshalb meistens konkurrenzstärkeren Baumarten (SPIECKER \& SPIECKER 1988, RÖÖS 1990, OBAL \& BARTSCH 2000), so daß Voraussetzungen vorliegen müssen, die ein Überleben unter Bedingungen ständiger Kolonisation und Extinktion gewährleisten.

Demgegenüber stehen aber Arteigenschaften dieser Baumart, die eine eher ungünstige Kombination zur schnellen, für eine Pionierart typischen Besiedlung geeigneter und in diesem Fall meist sehr fragmentierter Habitate vermuten lassen. Ihre geringe Flächenrepräsentanz und die Tatsache, daß die Vermehrung über Samen erstaunlicherweise wenig wirksam zu sein scheint (siehe auch RÖHRIG \& BARTSCH 1992), stellen eher ein ökologisches Paradoxon dar. In diesem Zusammenhang sind auch Charakteristika wie die Fähigkeit zur asexuellen Vermehrung, die gametophytische Selbstinkompatibilität (GSI) als auch die Abhängigkeit von Insekten zur Blütenbestäubung zu nennen. Die Vermutung, daß sich eine Bestäubung durch Insekten im wesentlichen auf die engeren Nachbarschaften beschränkt (DUCCI \& SANTI 1997, Perry \& KNOWles 1991), und somit eher limitierte, effektive Pollenausbreitungsdistanzen zu erwarten sind, stehen kaum im Einklang mit den übrigen genannten Eigenschaften. Denn DUCCI \& SANTI (1997), insbesondere aber FRASCARIA et al. (1993) berichten in verschiedenen Vogelkirschenbeständen von größeren, vegetativ aus Wurzelbrut entstandenen Klongruppen. Damit wäre möglicherweise eine stark verminderte Fekundität als Folge des GSI verbunden, woraus auch die waldbaulichen Beobachtungen einer eher geringen Beteiligung der generativen Vermehrung erklärbar wären.

Deshalb wirft die Fähigkeit der Vogelkirsche, sich sowohl generativ als auch vegetativ (Wurzelbrut, Stockausschlag) fortzupflanzen, im Bereich des gemischten Reproduktionssystems eine Reihe von zu beantwortenden Fragen auf. Aus Sicht eines systemanalytischen Ansatzes ist zur Formulierung geeigneter, problembezogener Hypothesen zunächst eine intensive Literatursichtung notwendig. Deshalb wird in Kapitel 2 eine eingehende Auseinandersetzung mit dem bisherigen Erkenntnisstand bezüglich der Eigenschaften der Vogelkirsche vorgenommen (Morphologie, natürliche Verbreitung, Biologie der Bestäubung und Befruchtung, Ausbreitungsmechanismen). Da insbesondere anthropogen geprägte Umweltbedingungen die Populationsbiologie rezedenter Arten möglicherweise stark beeinflußt haben und dieses eines der zentralen Themen dieser Arbeit darstellen soll, werden in Kapitel 3 Untersuchungsbestände ausgewählt und beschrieben, deren Entstehung auf verschiedene forstliche Betriebsarten mit unterschiedlichen ökologischen Rahmenbedingungen zurückgeht. Aufgrund der Komplexität der hiesigen Problematik kann in dieser Einführung noch keine Festlegung der Hypothesenstruktur erfolgen. Diese wird in 
den experimentellen Kapiteln 4 bis 6 fortlaufend entwickelt. Die dort gewonnenen Ergebnisse werden im Gesamtzusammenhang in Kapitel 7 diskutiert.

Eine zwingende Voraussetzung für die Analyse populationsgenetischer Zusammenhänge stellt zunächst die Unterscheidung der Art der Reproduktion (sexuell vs. asexuell) innerhalb der Untersuchungsbestände in Kapitel 4 dar. Da dies bislang ausschließlich auf wahrscheinlichkeitstheoretischen Modellen basiert, wird in diesem Abschnitt ein neues statistisches Verfahren auf einer neuen konzeptionellen Grundlage von GrEgorius (2005) verwendet. Dabei sollen nicht nur die Anteile sexueller und asexueller Vermehrung beschrieben werden, sondern auch mögliche historische und gegenwärtige Ereignisse, die diese Zusammensetzung bestimmt haben.

Es ist allgemein bekannt, daß innerhalb einzelner Populationen Kräfte bestehen, welche einerseits verstärkt die genetische Kohärenz (den reproduktiven Zusammenhalt), andererseits aber auch die genetische Separation (genetische Differenzierung) fördern und begünstigen können (STEINER \& GREGORIUS 1997). Gerade dieser Sachverhalt ist bei der populationsbiologischen Untersuchung rezedenter Arten wie der Vogelkirsche von entscheidender Bedeutung. Welche der oben aufgeführten evolutiven Kräfte durch welche Mechanismen des genetischen Systems gestützt wird, soll ein zentrales Objekt dieser Untersuchung sein. Insbesondere die geringe Flächenrepräsentanz der Vogelkirsche und die in Verbindung damit stehenden geringen Stichprobengrößen sind als problematisch einzuschätzen. Deshalb soll in Kapitel 5 eine Evaluation des Informationsgehalts vorhandener Verfahren der Analyse räumlich-genetischer Strukturen erfolgen, die zu einem besseren Verständnis der Ver- und Ausbreitungsstrukturen der Vogelkirsche beitragen können.

In Kapitel 6 wird ferner angestrebt, Kenntnisse über die Mechanismen der Kombination (dies betrifft hauptsächlich das Paarungssystem) als auch des Genflußsystems (Pollenausbreitung) zu gewinnen. Es sollen erste explorative Untersuchungen durchgeführt werden, welche Entfernungen kompatible Pollenkörner mittels Insekten als Vektoren zurücklegen können, da dies (neben der Samenverbreitung) einen der wichtigsten Faktoren darstellt, welcher den reproduktiven Zusammenhalt dieser Art bestimmt. Von Interesse ist in dem Zusammenhang nicht nur die Frage von Pollenausbreitungsdistanzen und dem Anteil bestandesinterner und -externer Pollenbeiträge im Wald, sondern auch die Bedeutung solitärer Vorkommen in der freien Landschaft für die Vernetzung hiesiger Vogelkirschenvorkommen. Dieses sind möglicherweise wichtige Faktoren, welche die genetische Variation innerhalb und zwischen Vorkommen einer Art und damit auch die nötigen adaptive Prozesse unter räumlich und zeitlich heterogenen Umweltbedingungen beeinflussen.

In den meisten populationsgenetischen Untersuchungen war insbesondere die Variation innerhalb und zwischen Populationen von Bedeutung. Diese Fragestellung soll bei der Analyse der Vogelkirsche zunächst weniger relevant sein, da für rezedente Baumarten eine Populationsabgrenzung und damit die Bestimmung von effektiven Populationsgrößen kaum jemals möglich sind. Deshalb beschränkt sich diese Arbeit auf die Untersuchung von Reproduktionsprozessen, die innerhalb von 
ausgewählten, rein räumlich abgrenzbaren Vorkommen herleitbar sind. Die Konzentration auf gruppenweise Vorkommen unter weitgehender Vernachlässigung solitärer Bäume findet ihre Rechtfertigung darin, daß diese Verbreitungsform aus einer für die Vogelkirsche typischen Besiedlungsstrategie folgt. 


\section{Stand des problembezogenen Wissens}

\subsection{Die Bedeutung von Beobachtungen an realen Systemen zur Hypotheseninduktion}

Die vorliegende Untersuchung beschäftigt sich mit der Analyse des Ver-und Ausbreitungstyps der Vogelkirsche unter verschiedenen (meist anthropogen bedingten) Umweltbedingungen. Für die Untersuchung möglicher Ursachen charakteristischer Verbreitungsmuster sind diejenigen Prozesse zu berücksichtigen, die vor, während und nach dem eigentlichen Ausbreitungsvorgang wirksam sein können. Als wichtige Vorgänge vor der Samenausbreitung sind die Bestäubung und die Befruchtung zu nennen, denen eine bedeutsame Rolle für den reproduktiven Zusammenhalt einer Population zukommt und die schon im Vorfeld maßgeblich die genetische Struktur der Folgegeneration bestimmt. Deshalb ist der derzeitige Wissensstand über die Biologie der die Wildkirsche bestäubenden Insekten als auch die Wirkung ihres gametophytischen Inkompatibilitätssystems näher zu durchleuchten. Da die fleischig-fruchtigen Samen von Tieren (frugivore Vögel, herbi- und omnivore Säuger) erstens als Nahrungsquelle genutzt, von diesen aber auch gleichzeitig ausgebreitet werden, sind während der Samenausbreitung insbesondere die Habitatpräferenzen und die daraus resultierenden Bewegungsmuster der Vektoren von besonderem Interesse (vgl. BONN \& POSCHLOD 1998). Aber nicht nur die Strukturen des durch tierische Verbreiter erzeugten „Samenregens“ sind für die spätere Verbreitung von Individuen einschließlich ihrer genetischen Information von Bedeutung, sondern auch Vorgänge nach der Ausbreitung. So sind z.B. das Auftreten von Samenprädatoren zu nennen als auch Prozesse von eher mikrostandörtlicher Bedeutung, die die Keimung und die Etablierung der Jungpflanzen beeinflußt.

Ein weiterer großer Bereich ist das Potential der Vogelkirsche zur asexuellen Vermehrung durch Wurzelbrut. Über die Bedeutung und die Konsequenzen für populationsbiologische und -genetische Eigenschaften ist in der gängigen Literatur nur recht wenig bekannt. Dieser Sachverhalt wirft, insbesondere in Verbindung mit dem Selbstinkompatibilitätssystem dieser Art eine Reihe von zu beantwortenden Fragen auf, so daß dieser Bereich hier nur kurz, dafür aber in den folgenden (analytischen) Kapiteln (insb. Kap. 4) sehr intensiv bearbeitet wird.

\subsection{Eigenschaften der Vogelkirsche}

\subsubsection{Morphologie}

P. avium (Familie der Rosaceae, Unterfamilie der Prunoideae) ist ein im Mittel $20 \mathrm{~m}$, in Ausnahmefällen aber sogar ein bis zu über $30 \mathrm{~m}$ hoher Baum. Im Freistand ist die Wildkirsche rundkronig und kurzstämmig, im Bestand auf zusagenden Standorten gerade, vollholzig und meist mit hoch- ansetzender Krone. 
Das Holz ist halbringporig, mittelschwer, ziemlich hart und zäh. Neben einem schmalen, gelblichen Splint verleiht insbesondere der rötlich-braune Kern dieser Baumart einen hohen Holzwert. Das sicherte der Kirsche seit Jahrhunderten einen Platz bei der Herstellung hochwertiger Innenausstattung (Möbel), wobei die wertvollsten Stämme zu Furnieren verarbeitet werden.

Die Rinde älterer Bäume ist ringelartig und läßt sich oft streifenartig wie Papier ablösen, in jungen Jahren ist sie glatter und glänzend. Sie ist mit waagerechten Korkwarzen (Lenticellen) versehen.

Die Blätter sind grob doppelt gesägt mit vorwärts gerichteten Zähnen, länglich-eiförmig und nach vorne hin zugespitzt. Am Blattstiel befinden sich 2-4 unsymmetrisch verteilte Nektarien, die ein zuckerhaltiges Sekret absondern. Die Herbstfärbung ist hellgelb bis rot.

Die Blüten sind weiß und erscheinen in 2- bis 5-blütigen, doldigen Büscheln unmittelbar vor dem Austrieb der Blätter (Blütezeit April/Mai). An jungen Bäumen befinden sich die Blüten meist entlang der Triebe in kurz gestielten Büscheln, bei älteren Bäumen sind sie dichter gebüschelt aber länger gestielt. Die Blüten der Gattung Prunus beinhalten fünf Blütenblätter, zahlreiche Staubblätter, einen Griffel sowie einen unterständigen Fruchtknoten bestehend aus einem Fruchtblatt und zwei Samenanlagen. Sehr gerne wird die Kirsche, insbesondere die Kulturformen, zur Bienenweide verwendet, denn die Blüten sind reich an Nektar, Zucker und Pollen.

Die Vogelkirsche besitzt Steinfrüchte, deren Kerne von kugeligen bis herzförmigen, verholzten Schalen aus Endokarp umschlossen sind. Die wiederum sind von Fruchtfleisch, bestehend aus Exo- und Mesokarp, eingehüllt. Im Reifezustand sind die Früchte glänzend rot bis schwarz-rot und das Fruchtfleisch bittersüß.

Die Wurzel der Vogelkirsche ist sehr anpassungsfähig an die Bodentiefe und bildet meist ein Pfahl- oder Herzwurzelsystem aus. Das gesamte Wurzelsystem besteht außerdem aus weit streichenden, faserreichen Seitenwurzeln, welche eine entscheidende Rolle bei der Möglichkeit zu vegetativer Vermehrung (Wurzelbrut) spielt (siehe unter anderem BECK 1977, KLEINSCHMit et al. 2000, MitCHELL 1979, SCHÜTT et al. 1992).

Wie die meisten Lichtbaumarten, hat auch die Vogelkirsche ihr stärkstes Höhenwachstum in der Jugendphase. Nach KLEINSCHMIT et al (2000) kulminiert das Höhenwachstum bereits nach 7 bis 15 Jahren, um dann ab Mittelhöhen von 20 bis 23 $\mathrm{m}$ bzw. Altern von 30 bis 40 Jahren deutlich nachzulassen.

\subsubsection{Verbreitung der Wildkirsche}

\subsubsection{Das natürliche Verbreitungsgebiet}

Das natürliche Verbreitungsareal der Wildkirsche wird in Abb. 2.1 dargestellt. Auch wenn sie nicht so weit nach Norden vordringt wie beispielsweise Fagus sylvatica, so weist sie insgesamt dennoch ein recht großes Verbreitungsgebiet auf. Sie ist (außer in Skandinavien) in nahezu ganz Europa heimisch. Außerdem wächst sie in NordAfrika, im Kaukasus und dringt sogar bis ans Kaspische Meer vor. 
Das große Verbreitungsareal läßt vermuten, daß die Vogelkirsche eine sehr große Anpassungsfähigkeit sowie eine Fülle von Herkünften aufweist. In Deutschland befinden sich bedeutendere Vorkommen im Steigerwald, im Bodenseegebiet, im Kottenforst sowie im Raum Göttingen (SCHÜTT et al. 1992).

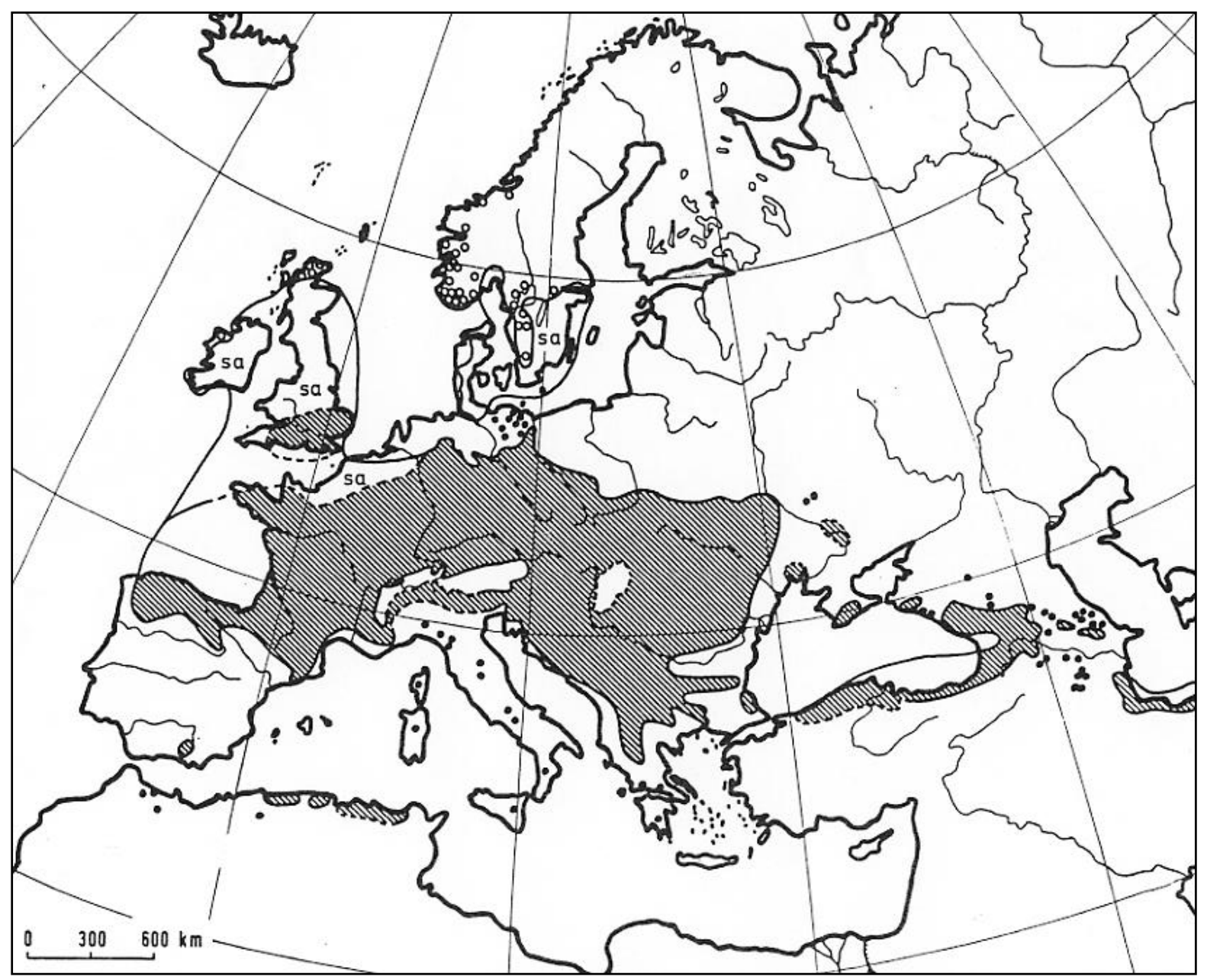

Abb. 2.1: Das natürliche Verbreitungsareal der Vogelkirsche, verändert nach MEUSEL et al. $(1965)^{2.1} ; \mathrm{o}=$ synanthrop (sa)

\subsubsection{Die Standortansprüche der Vogelkirsche als Waldbaumart}

Bedeutendere Vorkommen der Vogelkirsche sind in Mitteleuropa überwiegend in der planaren bis submontanen Stufe zu finden. Nach SPIEKER (1994) bevorzugt $P$. avium sommerwarme, frische und kalkreiche Standorte, wobei mittlere bis große Ansprüche an Nährstoff sowie Basenreichtum gestellt werden. Diese Bedingungen sind aber eher als das physiologische Optimum dieser Art und damit auch als die optimalen Standortverhältnisse im waldbaulichen Sinne zu verstehen, da mit zunehmender Frische auch das Wachstum (insbesondere das Höhenwachstum) steigt. Nach KLEINSCHMIT et al. (2000) allerdings beschränkt sich das natürliche Vorkom-

${ }^{2.1}$ Diese Verbreitungskarte stammt aus einem Vorlesungsskriptum der TU München (Institut für Forstbotanik) und sollte urprünglich im Lexikon für Forstbotanik (SCHÜTT et al. 1992) veröffentlicht werden. 
men der Vogelkirsche meist auf den Bereich der thermophilen Kalkbuchenwälder, wo sie einzelstammweise oder in kleineren Gruppen anzutreffen ist. Das auf diesen trockenen Standorten teilweise gehäufte Auftreten von $P$. avium ist demzufolge eher auf das ökologische Optimum dieser Baumart zurückzuführen, da auf solchen Standorten die Wuchskraft konkurrierender Baumarten, insbesondere der Buche, meist stark vermindert ist. Deshalb ist die Vogelkirsche in diesen Beständen auch oft mit Lichtbaumarten wie der Elsbeere (Sorbus torminalis) und dem Feldahorn (Acer campestre) vergesellschaftet. Auf basischen, frischeren Standorten beschränkt sich ihr natürliches Vorkommen auf frühe Sukzessionsstadien (KLEINSCHMIT et al. 2000). Aufgrund ihrer Lichtbedürftigkeit ist die Existenz der Vogelkirsche bis ins höhere Alter meist auf intensive Pflege (Freistellung) angewiesen.

Wie den Ergebnissen eines Kirschenanbauversuchs nach OBAL \& BARTSCH (2000) in Tab. $2.1 \mathrm{zu}$ entnehmen ist, gedeiht die Vogelkirsche unter im Bestand unter Teilschirm sowie auf der Freifläche am besten, auch wenn ihre Entwicklung hinsichtlich einiger Teilaspekte zum Teil große Unterschiede zeigen.

\begin{tabular}{|c|c|c|c|}
\hline Kirschenanbau-Versuch & Freifläche & Teilschirm & Vollschirm \\
\hline \multicolumn{4}{|l|}{ Beschreibung der Versuchsvarianten bei Veruchsbeginn } \\
\hline Hiebseingriff in \% der Ausgangsgrundfläche von $27 \mathrm{~m}^{2}$ ha ${ }^{-1}$ & 100 & 50 & 0 \\
\hline Überschirmungsprozent & 0.0 & 57.74 & 88.94 \\
\hline relative Beleuchtungsstärke in \% der Freilandstrahlung & 90.0 & 14.2 & 2.4 \\
\hline \multicolumn{4}{|l|}{ Ausfälle* } \\
\hline Mortalitätsraten N/ha (\%) & $41(10.3)$ & $13(3.3)$ & $74(19)$ \\
\hline \multicolumn{4}{|l|}{ Wachstum $^{*}$} \\
\hline mittlere Höhen der $20 \%$ höchsten Kirschen in cm & 288.5 & 326.5 & 224.2 \\
\hline mittlerer Höhenzuwachs im Vgl. zu Vorjahr in \%: Kir (Bu) & $26(25)$ & $24(8)$ & $12(6)$ \\
\hline \multicolumn{4}{|l|}{ Blattausbildung* } \\
\hline Fläche pro Blatt in $\mathrm{cm}^{2}$ & 71.5 & 93.6 & 60.8 \\
\hline Trockengewicht pro Blatt (mg) & 597 & 479 & 184 \\
\hline \multicolumn{4}{|l|}{ Wurzelausbildung $^{*}$} \\
\hline Maximale mittlere Horizontalausbreitung $(\mathrm{cm})$ & 310 & 249 & 67 \\
\hline Wurzeltrockengewicht (g) & 616 & 303 & 51 \\
\hline Sproß/Wurzel-Verhältnis & 1.24 & 2.01 & 1.26 \\
\hline
\end{tabular}

Tab. 2.1: Ergebnisse eines Kirschenanbauversuches mit 2-jährigen Pflanzen nach OBAL \& BARTSCH (2000); dargestellt sind hier die Resultate 4 Jahre nach Pflanzung bezogen auf Mortalität, Wachstum sowie Blatt- und Wurzelausbildung auf einer Freifläche sowie unter Teil- und Vollschirm 
So war das Wachstum der 20\% höchsten Kirschen im Vergleich zur Buche unter Teilschirm am höchsten und die Mortalitätsrate am geringsten. Anders verhält es sich mit der Wurzelausbildung. Hier wiesen die Kirschen der Freifläche mit über drei Metern die größte maximale Horizontalausbreitung sowie auch das größte Wurzeltrockengewicht auf. Unter Vollschirm hingegen vielen die Kirschen bezüglich Mortalität, Wachstum sowie Blatt- und Wurzelausbildung deutlich zurück. Dieses Experiment zeigt aber, daß die Vogelkirsche in der Jugendphase durchaus als Halblicht- bzw. Halbschattbaumart bezeichnet werden kann, da sie in gewissem Maße Überschirmung verkraften kann. Es ist allerdings darauf hinzuweisen, daß bei diesem Experiment andere Bedingungen herrschen als unter natürlichen Gegebenheiten (Keimungs- und erste Etablierungsphasen sind hier unbeachtet geblieben). Die Resultate bestätigen aber im wesentlichen die Einordnung der in der waldökologischen Literatur nur sehr selten erwähnten Vogelkirsche in Waldgesellschaften, in denen die Buche konkurrenzbedingt lichtdurchlässigeren Baumarten wie den Eichen unterlegen ist. Nach FISCHER (2003) und HÄRDTLE et al. (2004) beispielsweise werden natürliche Vorkommen der Vogelkirsche den Carpinion betuli (EichenHainbuchenwäldern) zugerechnet. Allerdings wird darauf hingewiesen, daß diese Vegetationsformen sehr oft aus Nieder- und Mittelwaldbewirtschaftung hervorgegangen sind und nur selten die natürliche Waldgesellschaft dieser Standorte darstellen.

\subsubsection{Bestäubung und Befruchtung}

\subsubsection{Insekten als Pollenvektoren}

Die Wildkirsche wird vorwiegend durch Insekten bestäubt, da ihre Pollen meist schwer und in kleinen Gruppen verklebt sind. Windtransport tritt sehr selten auf, so daß Flugpollen, wenn überhaupt, nur in unmittelbarer Nähe des Pollenspenders effektiv wird (BERGER 1963, SANTI 1988). Andererseits ist bekannt, daß die Pollen auf die Narbenoberfläche gedrückt werden müssen, bevor eine für die Keimung benötigte Haftung gewährleistet ist (FREE 1993).

Bis zum heutigen Zeitpunkt sind die meisten Untersuchungen allerdings an Kultursorten durchgeführt worden, da die Bestäuberaktivität wesentlichen Einfluß auf den Fruchtertrag ausübt (siehe u.a. Kap. 2.2.3.2 zum Thema der Selbstinkompatibilität). Die meisten Erhebungen zeigen, daß Honigbienen den höchsten Prozentsatz an Blütenbesuchen aufweisen. Allerdings sind auch andere Insekten an diesen Blütenbesuchen beteiligt wie z.B. Hummeln (Bombus ssp.) oder auch solitäre Bienen der Gattungen Andrena (in Mitteleuropa wegen ihrer Bautätigkeit im Boden auch als Erdbienen bekannt) und Megachile (Blattschneiderbienen) (siehe FREE 1993, SANTI 1988, CHINERY 1984). FREE \& WILLLIAMS (1972) ermittelten, daß auf den Körpern der Honigbienen während ihrer Flüge zum Zwecke des Nahrungserwerbs zwischen 1600 und 43000 Pollenkörner haften. Ähnliche Zahlen fanden sie auch für einige Hummelarten. FREE \& BUTLER (1959) weisen allerdings in diesem Zusammenhang darauf hin, daß Hummeln, auch wenn sie in nicht so großer Zahl präsent sind, als 
Bestäuber meist unterschätzt werden. Sie arbeiten schneller, unter unbeständigeren Witterungsbedingungen und meist auch über längere Zeiträume als die Honigbiene.

Verläßt eine Biene zum Nahrungserwerb ihre Kolonie, so haften an ihrem Körper oft noch mehrere Tausend Pollenkörner. Untersuchungen an einigen Kulturobstarten ergaben, daß eine Fremdbestäubung auch dann noch erfolgte, obwohl ein Teil der Bienen einer Kolonie nur eine Kultursorte über längere Zeiträume anflog. Nach Free \& Williams (1972) liegt der Grund darin, daß kompatibler Pollen innerhalb der Kolonie durch Kontakt der Bienen zueinander übertragen wird. DEGRANDI-HOFFMAN et al. (1984) konnten mittels Elektronenmikroskopie nachweisen, daß Bienen, welche bevorzugt eine bestimmte Kultursorte besuchten, sogar mit einem wesentlich höheren Anteil an Fremdpollen ausgestattet waren als mit dem Eigenpollen der entsprechenden Kultursorte. Interessant dabei ist, daß die Quelle der Fremdpollen teilweise in über $300 \mathrm{~m}$ Entfernung stand. Für die oben genannten Autoren sind diese Ergebnisse ein Beweis für sehr intensiven Pollentransfer von Biene-zu-Biene innerhalb einer Kolonie und es verstärkt die Vermutung, daß dieser Vorgang wesentlich zur Fremdbestäubung innerhalb von Obstplantagen beiträgt. Die Effektivität einer auf diese Weise erfolgreichen Fremdbestäubung hängt folglich im wesentlichen davon ab, wie viele kompatible Kultursorten vorhanden sind und ob sich kompatible Paarungspartner auch innerhalb der Reichweite einer Bienenkolonie befinden (FREE 1993).

Über die Wildkirsche sind diesbezüglich allerdings kaum Daten verfügbar. Es wird zwar berichtet, daß Honigbienen und Hummeln mehrere Kilometer zum Zwecke des Nahrungserwerbs zurücklegen können (FERNANDEZ et al. 1994, SANTI 1988), aber über die Effektivität für die Bestäubung und Befruchtung ist nur sehr wenig bekannt.

\subsubsection{Das gametophytische Selbstinkompatibilitätssystem}

Schon DARWIN (1876) machte die Beobachtung, daß manche Pflanzen nach der Bestäubung durch Eigenpollen vollständige Sterilität aufweisen. EAST \& PARK (1918) fanden an Nicotiana sp., daß Eigenpollen gegenüber Fremdpollen ein stark verlangsamtes Pollenschlauchwachstum zeigen und den Fruchtknoten bis zum Zeitpunkt des Abblühens nicht erreichen können. Erste Versuche, dieses Phänomen zu erklären, lauteten wie folgt:

„These results appear us to show that the pollen tubes in a selfed pistil are not inhibited in their growth by substances secreted in the pistil, but rather that a substance or substances are secreted in the pistil after a compatible cross which accelerate growth, and that the direct cause of this secretion is a catalyser which the pollen-tube nucleus is able to produce because the zygotic constitution of the plant producing it is different in certain particular hereditary factors from that of the plant on which it is placed.“ (EAST \& PARK 1918)

Auch wenn die biochemischen Vorgänge noch nicht korrekt dargestellt werden konnten, so sind doch Unterschiede in den erblichen Eigenschaften des Pollens gegenüber dem weiblichen Griffelgewebe als mögliche Ursache der erfolgreichen Fremdbestäubung richtig erkannt worden. Seit diesen Entdeckungen fand man 
Selbstinkompatibilität in fast der Hälfte aller blühenden Pflanzenarten (DE NETTANCOURT 1977).

Auch viele Gattungen der Familie der Rosaceae sind mit einem Selbstinkompatibilitätsmechanismus ausgestattet. Insbesondere aufgrund des wirtschaftlichen Interesses (Fruchtertrag) wurde eine Analyse der Vererbung dieser Eigenschaft bei den Arten der Gattung Prunus in einer Reihe von Untersuchungen in Angriff genommen. Die Erkenntnis, daß nicht nur Selbstung, sondern auch gewisse Fremdbefruchtungen ausgeschlossen waren, führte dazu, daß eine Reihe von Kultursorten der Kirsche durch Beobachtungen des Fruchtertrages nach kontrollierten Kreuzungen in verschiedene Inkompatibilitätsgruppen eingeteilt werden konnten. Für diese Art der Inkompatibilität wurde erstmals ein hochvariabler Genlocus, der sogenannte S-Locus, verantwortlich gemacht (CRANE \& LAWRENCE 1929, 1931). Außerdem wurde diese Art der Selbstinkompatibilität als 'gametophytisch' bezeichnet, da hier einerseits die Haplophase (des männlichen Gametophyten) und die Diplophase (Pollenempfänger, weibliches Blütengewebe) in Wechselwirkung treten. Stimmt dabei der S-Haplotyp des haploiden Pollenschlauches mit einem der beiden S-Haplotypen des diploiden Griffelgewebes überein, so wird das Pollenschlauchwachstum gehemmt und der Pollenschlauch geht schließlich zugrunde. Besteht keine Übereinstimmung, wächst dieser zur Samenanlage hin und es kann die Befruchtung erfolgen.

Daraus ergaben sich zwei grundlegende Fragestellungen bezüglich der Funktionswiese der gametophytischen Selbstinkompatibilität (im folgenden GSI): (1) Welche Mechanismen führen zur Verhinderung der Befruchtung von Eigen- bzw. nichtkompatiblen Fremdpollen? (2) Wie unterscheidet das weibliche Blütengewebe zwischen kompatiblen und nicht-kompatiblen Pollen?

Es war schon lange klar, daß sowohl eine weibliche als auch eine männliche Determinante an dem Zustandekommen der Inkompatibilitätsreaktion beteiligt sein muß. Auf der Suche nach der weiblichen Determinante der GSI wurden zwei Eigenschaften dieses S-Locus vorausgesetzt: Dieser Locus muß allelspezifische Unterschiede aufweisen und dessen Produkte müssen auf jeden Fall im weiblichen Blütengewebe (dem Griffel) exprimiert sein. So identifizierten BREDEMEIJER \& BLASS (1981) an Nicotiana alata griffelspezifische Proteine (Glycoproteine), welche bezüglich ihres Molekulargewichts und/oder isoelektrischen Punktes allelspezifische Unterschiede zeigten. MCCLuRE et al. (1989) fand, daß die Aminosäuresequenzen dieser S-Proteine Homologien zur RNase aufwiesen, welche aus Aspergillus oryzae gewonnen wurden. Die nahe liegende Schlußfolgerung, daß die S-spezifischen Proteine auch RNase-Aktivität besitzen, wurde schon im folgenden Jahr an N. alata durch MCCLURE et al. (1990) nachgewiesen, wonach diese S-Proteine auch die Bezeichnung S-RNase erhielten. Es konnte experimentell gezeigt werden, daß bei inkompatiblen Kreuzungen ribosomale RNA in den Pollenschläuchen stark degradiert wurde, wobei kompatible Kreuzungen von diesem Phänomen nicht betroffen waren.

Weitere Bestätigung fand die Rolle der S-RNase bei Experimenten mit transgenen Pflanzen: Die Einführung fremder Allele für S-RNase in den weiblichen Kreu- 
zungspartner führte bei denjenigen Fremdpollen zu einer Inkompatibilitätsreaktion, welche Träger des zuvor eingeführte Allels waren. Außerdem waren Pflanzen, die durch künstlich erzeugte Mutation an einem der beiden S-Allele inaktivierte SRNasen produzierten, zur Selbstung befähigt (HUANG et al. 1994).

Nach der Extraktion von S-RNasen aus dem Griffelgewebe einer Reihe von Kultursorten der Kirsche konnten BošKOVIĆ \& TOBUTT $(1996,1998)$ sowie BošKOVIĆ et al. (1997) durch elektrophoretische Methoden mehrere aktive S-Loci identifizieren. Diese Arbeit wurde u.a. von KownATZKI (2001) fortgesetzt, der Griffelextrakte von Wildkirschenklonen einer Samenplantage elektrophoretisch auftrennte und dabei insgesamt 13 verschiedene S-Allele bestimmen konnte.

Mit der Entdeckung der S-RNasen war zwar die Frage beantwortet, wie eine Befruchtung durch inkompatiblen Pollen verhindert wird, aber welche Mechanismen bei der Erkennung eine Rolle spielen, konnte so noch nicht geklärt werden. In diesem Zusammenhang wurde schon lange vermutet, daß es ein Pollen-S-Gen geben muß, welches sehr eng mit dem S-RNase Gen gekoppelt ist. Diese enge Kopplung ist notwendig, um eine mögliche Rekombination zwischen diesen beiden Genen zu verhindern, da dieser Vorgang unausweichlich zum Zusammenbruch des Inkompatibilitätssystems führen würde (siehe u.a. KAO \& TsUкAмото 2004). Solche Rekombinanten konnten nach DENETTANCOURT (2001) allerdings noch nicht beobachtet werden.

ENTANI et al. (2003) fand an Prunus mume noch weitere Gene (F-Box Gene) in der Region des S-Locus, wovon eines möglicherweise die Pollen-S-Determinante des GSI darstellt. Dieses Gen wurde als SLF-Gen (S-Locus F-Box Gen) bezeichnet. Dieses SLF-Gen erfüllt eine Reihe von Eigenschaften, die dafür sprechen, daß es in dem Erkennungsprozeß (kompatibel vs. inkompatibel) involviert ist: (1) Wie oben erwähnt, befindet sich dieses Gen innerhalb der Region des S-Locus, ist demnach eng gekoppelt mit dem S-RNase Gen, (2) es enthält eine Aminosäuresequenz-Diversität, die spezifisch für S-Haplotypen ist und (3) dieses Gen wird nur im Pollen, nicht aber in anderen pflanzlichen Geweben wie Griffel oder Blätter, exprimiert. Es wird aber darauf hingewiesen, daß experimentelle Arbeiten, die einen eindeutigen Beweis erbringen sollen, noch nicht für Prunus durchgeführt wurden. Bei Petunia inflata hingegen ist mittels Kreuzungs-experimenten mit transgenen Pflanzen das Pollen-S-Gen (SLF-Gen) identifiziert worden. Das SLF-Protein hemmt bei Vorliegen von Kompatibilität die Wirkung der S-RNase (SIJACIC et al. 2004).

Allerdings ist es noch ungeklärt, ob das SLF-Protein bei kompatiblen Kreuzungen direkt den Abbau von S-RNasen fördert oder ob deren Wirkung im Cytoplasma verhindert wird. Dazu gibt es bereits mehrere Modelle, von denen das InhibitorModell den Mechanismus vermutlich am besten erklärt (siehe diesbezügliches Experiment bei LuU et al. 2000). Es wird unter anderem vermutet, daß die S-RNase zwei separate Domänen ${ }^{2.2}$ enthält: Eine S-allelspezifische sowie eine katalytische Domäne, welche für alle S-RNasen mehr oder weniger identisch ist. Analog dazu soll das Produkt des Pollen-S-Gens auch zwei solche separate Funktionen beinhalten, nämlich ebenfalls eine S-allelspezifische Domäne sowie in diesem Fall einen S-

2.2 Abschnitt der Aminosäuresequenz eines Proteins mit einer besonderen Funktion 
RNase-Inhibitor. Die Funktionsweise dieser beiden Genprodukte bei Inkompatibilität wird wie folgt beschrieben: Nach dem Eintritt eines Pollenschlauches mit dem Haplotyp $S_{1}$ in das zentrale Leitgewebe des Griffels des weiblichen Paarungspartners (Genotyp $\mathrm{S}_{1} \mathrm{~S}_{2}$ ), kommt es zu einer unterschiedlichen Wechselwirkung des Pollen- $\mathrm{S}_{1}$-Genproduktes mit den $\mathrm{S}_{1}$ - und $\mathrm{S}_{2}$-RNasen, welche im Griffelgewebe exprimiert werden. Das Pollen- $S_{1}$-Genprodukt würde in diesem Fall mit der S-allelspezifischen Domäne der $\mathrm{S}_{1}-\mathrm{RNase}$ in der Weise interagieren, daß die katalytische Funktion nicht beeinflußt und die enzymatische Aktivität (Abbau von rRNA im Pollenschlauch) beibehalten wird. Andererseits reagiert das Pollen-S $\mathrm{S}_{1}-$ Genprodukt mit der $\mathrm{S}_{2}$-RNase anders. Hier passen die S-allelspezifischen Domänen nicht zusammen, so daß hier die Domäne des S-RNase-Inhibitors des Pollen-S-Gens mit der katalytischen Domäne der $\mathrm{S}_{2}$-RNase in Wechselwirkung tritt und somit dessen enzymatische Funktion unterdrückt.

Bei einer Inkompatibilitätsreaktion würde also die $\mathrm{S}_{1}$-RNase ihre Aktivität beibehalten, die Funktion der $\mathrm{S}_{2}$-RNase allerdings würde unterdrückt. Bei diesem Ablauf muß allerdings folgendes vorausgesetzt werden: Die Bindung zwischen der $S_{1}$-allelspezifischen Domäne des Pollen- $S_{1}$-Allelproduktes und der entsprechenden $S_{1}$ RNase-Bindungsstelle muß größer sein als zwischen der Domäne des RNase-Inhibitors des Pollen- $\mathrm{S}_{1}$-Allelproduktes und der katalytischen Domäne der entsprechenden $\mathrm{S}_{1}$-RNase. Eine zweite Voraussetzung wäre, daß die Bindung an eine Domäne der S-RNase die Bindung an die andere ausschließt. Eine Bindung des Pollen-SAllelprodukts an die S-allelspezifische Domäne der S-RNase würde damit die Inaktivierung der S-RNase vollständig ausschließen (KAO \& MCCUBBIN 1996, KAO \& TSUKAMOTO 2004).

Populationsgenetisch ist bezüglich des GSI nur selten experimentell gearbeitet worden und es soll auch nicht Ziel dieser Arbeit sein. Dennoch ist der Selbstinkompatibilitätsmechanismus der Vogelkirsche ein wichtiger Bestandteil der Populationsbiologie dieser Art und wird deshalb in den folgenden Kapiteln auch Gegenstand der Diskussionen sein.

Voraussetzung für den sexuellen Reproduktionserfolg einer Population ist auf jeden Fall das Vorhandensein von drei S-Allelen, um zumindest Semikompatibilität zu erreichen. In natürlichen Populationen sind in der Regel aber wesentlich mehr SAllele zu verzeichnen (siehe Review von CASTRIC \& VeKEMANS 2004). So fanden Kato \& Mukai (2004) in Prunus lannesiana 21 S-Allele und ähnliche Anzahlen werden auch von $P$. avium (noch unveröffentlichte Angaben ${ }^{23}$ ) gemeldet.

Schon Wright (1939) vermutete, daß die wesentliche evolutionäre Kraft, die auf die Häufigkeiten der S-Allele innerhalb einer Population einwirkt, eine negativ häufigkeitsabhängige Funktion ist. Denn für Pollen mit seltenen Allelen ist die Wahrscheinlichkeit zur Befruchtung zu gelangen und die genetische Information in die Folgegeneration einzubringen größer als für Pollen, die häufige S-Allele tragen. Demzufolge gehen aus Mutation hervorgegangene neue S-Allele auch seltener durch Drifteffekte verloren als seltene Allele von Genorten, die anderen Selektions-

\footnotetext{
${ }^{2.3}$ nach Untersuchungen von SCHÜLER (persönliche Mitteilung) an der BFH

(Bundesforschungsanstalt für Holz- und Forstwirtschaft)
} 
mechanismen unterliegen. STEINER \& GREGORIUS (1994) konnten unter anderem zeigen, daß die S-Allelhäufigkeiten immer einen Gleichgewichtszustand anstreben, der durch die höchste Äquität (Eveness, Gleichverteilung der Allele) und damit auch der höchsten allelischen Diversität charakterisiert ist. Die ersten o.g. noch unveröffentlichten Ergebnisse zeigen aber, daß dieser Gleichgewichtszustand bei $P$. avium nicht gegeben ist, woraus möglicherweise interessante Zusammenhänge zur Lebensweise dieser Art abgeleitet werden können. Vermutlich unterliegen die Populationen der Vogelkirsche als rezedente Baumart starker Fluktuationen, so daß ein solches Gleichgewicht möglicherweise nie erreicht werden kann.

\subsubsection{Samenausbreitungsmechanismen}

Abgesehen von wenigen hoch spezialisierten Arten, verfügen die meisten Pflanzen über eine Ausbreitungsstrategie, auch wenn Wirksamkeit und Ausbreitungsdistanz sehr verschieden sein können. Eine Vielzahl von Untersuchungen hat sich mit den Ausbreitungstypen, ihren Ausbreitungsmedien und den dafür speziell entwickelten morphologischen Mechanismen der Pflanzen beschäftigt (URBANSKA 1992). Der Sinn und Zweck der Ausbreitung wird unter anderem ausführlich von HOWE \& SMALLWOOD (1982) diskutiert:

So kann durch die Samenausbreitung beispielsweise der intraspezifische Konkurrenzdruck um lebenswichtige Ressourcen gemindert werden (zwischen Sämlingen bzw. Sämlingen und Mutterpflanze). Außerdem verbessert sich die Chance, einer erhöhten Mortalität durch Prädatoren und Pathogene zu entkommen, da Samenansammlungen meist häufiger betroffen sind als verstreute Einzelsamen (vgl. auch JANZEN 1971); $\rightarrow$ Fluchthypothese.

Ausbreitung bietet zudem die Möglichkeit der Besiedlung anderer potentieller oder tatsächlich vorhandener, geeigneter Standorte. Sind passende Lebensräume selten, instabil, zufällig verteilt oder nur vorübergehend verfügbar, so ist eine effektive Samenausbreitung für die Arterhaltung zwingend erforderlich. Ein Vorteil effektiver Ausbreitungsstrategien besteht darin, daß Diasporen auf Mikrostandorten deponiert werden können, die aufgrund ihrer physikalischen sowie biologischen Eigenschaften die Wahrscheinlichkeit einer erfolgreichen Keimung und Etablierung verbessern; $\rightarrow$ Besiedlungshypothese.

Auch die Ausbreitung mit Hilfe spezieller Vektoren kann zu einem (nicht zufälligen) Samentransport zu speziellen Standorten führen, wo die Wahrscheinlichkeit einer erfolgreichen Keimung und Etablierung hoch ist. Frugivore Vögel dienen hier als Modellbeispiel, die den natürlichen Streubereich von Samen und Früchten möglicherweise deutlich erweitern und einen gerichteten Transport zu Bestandeslücken hin gezielt ausformen (siehe Kap. 2.2.5.1) (vgl. auch STIMM \& BÖSWALD 1994); $\rightarrow$ Hypothese der gericbteten Ausbreitung.

Es wird deutlich, daß der Verbreitungstyp einer Pflanzenart das Ergebnis eines komplexen Systems dynamischer Prozesse darstellt. Da nach KollmanN (2000) die meisten der mit der Etablierung assoziierten Prozesse (Samenprädation, Einfluß 
von Herbivoren, intraspezifische Konkurrenz etc.) dichteabhängig sind, zeigen sie für gewöhnlich eine ähnliche räumliche Variation wie sie auch für die Samenausbreitung beschrieben werden. Unter Freilandbedingungen ist dies aber nicht unbedingt eine abnehmende Funktion zu der Entfernung von der Samenquelle, da Habitatheterogenität sehr oft spezifische und unerwartete Effekte mit sich bringt (siehe Abb. 2.2).

Im folgenden sollen spezifische Samenausbreitungsmechanismen der Vogelkirsche beschrieben werden, wobei auch Kenntnisse über Keimungsbedingungen, Samenprädation als auch die mögliche Bedeutung der vegetativen Vermehrung mit berücksichtigt sollen. Es sei allerdings darauf hingewiesen, daß viele der oben genannten komplexen Prozesse, welche zu einem spezifischen Verbreitungsmuster der Vogelkirsche führen (also die „effektive“ Ausbreitung im eigentlichen Sinne), mit Hilfe dieser Erkenntnisse kaum voraussagbar sind. Erste Ansätze zur Problemlösung sollen Gegenstand dieser Arbeit (insb. Kap. 4 bis 6) sein.

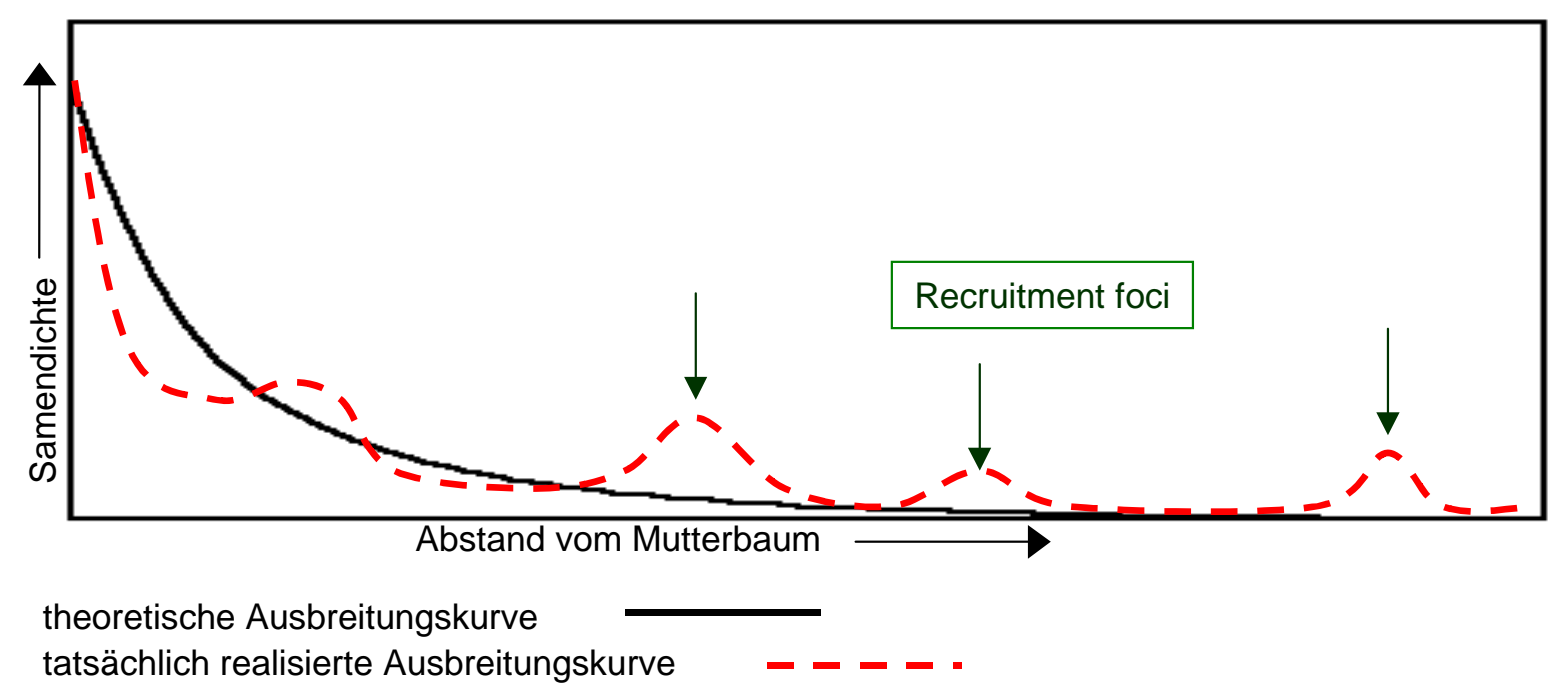

Abb. 2.2: Theoretisch erwartete und tatsächlich realisierte Samenausbreitungskurve von Gehölzarten mit fleischig-fruchtigen Samen: Der Verlauf der theoretischen Kurve ist distanzabhängig, der Verlauf der tatsächlichen Samenausbreitung wird durch lokale Unterschiede in der Vegetationsstruktur bestimmt; ähnliche Strukturen werden auch für diejenigen Prozesse angenommen, die mit der Samenausbreitung assoziiert sind, wie z.B. Samenprädation, Keimung und Etablierung der Jungpflanzen (verändert nach KOLLMANN 2000)

\subsubsection{Ornithochorie}

Saftig-fleischige Früchte treten gehäuft - wenn auch nicht ausschließlich - bei Gehölzarten auf und sind auffallend stark bei den Rosaceen (Crataegus spp., Prunus spp., Rosa spp., Rubus spp.) verbreitet. Die Wildkirsche besitzt kohlenhydrat- und mineralstoffreiche Samen von geringer bis mittlerer Größe mit einem eßbaren äußeren Teil ohne harte Schale (Fruchtfleisch) sowie mit Signalfarben bei der Reife. Damit können die Früchte von Vögeln, die einen fehlenden oder nur schwach aus- 
geprägten Geruchssinn haben, optisch wahrgenommen und als Nahrungsquelle genutzt werden (BONN \& POSCHLOD 1998). Dieses Verhältnis ist von mutualistischer Natur, denn die Avifauna ist ein wichtiger Ausbreitungsvektor von Kirschensamen. Außerdem nehmen nach KolLmanN (1994) die Vögel durch das Entfernen des Fruchtfleisches Einfluß auf die Keimung, da das Fruchtfleisch keimhemmend wirkt. Auf der anderen Seite hat die Kirsche ihrerseits verschiedene Schutzmechanismen entwickelt, die die Embryonen vor der Verdauung oder vor zu frühem Gefressenwerden schützen, wie z.B. eine harte Samenschale sowie im unreifen $\mathrm{Zu}$ stand saure und toxische Früchte mit unauffälliger Farbe (vgl. BONN \& POSCHLOD 1998, TURĈEK 1967).

Bei der Verfrachtung durch Vögel sind Endozoochorie ${ }^{2.4}$ und Synzoochorie ${ }^{2.5}$ für die Samen der Wildkirsche am bedeutendsten. Von den Früchten der Wildkirsche ernähren sich nach TURĈEK (1968) etwa 48 Vogelarten. Die wichtigsten Vertreter sind Rabenvögel, Drossel- und Grasmückenarten. Während die Rabenvögel (Elster, Eichelhäher, Dohle) als auch Pirol, Star und Ringeltaube die Früchte der Wildkirsche über Entfernungen von teilweise über $1 \mathrm{~km}$ ausbreiten, wurden für Drosseln und Grasmücken meist nur kürzere Distanzen festgestellt (unterhalb $1 \mathrm{~km}$, meist jedoch in einem Radius von nur ca. 30m). TURĈEK (1961) berichtet weiterhin von Amseln und Singdrosseln, die Kirschen zu ihren Schlafplätzen verfrachtet haben, wobei die Samenbäume $50-400 \mathrm{~m}$ entfernt waren. Auch für die Jungenfütterung wiederum werden teilweise größere Distanzen zurückgelegt als bei gewöhnlichem Verzehr (TURĈEK 1968). Außerdem werden Blaumeise, Kleiber als auch der Haussperling als Fruchtfleischfresser beschrieben (JORDANO 1995), was allerdings keine nennenswerten Ausbreitungsdistanzen zur Folge hat, da meist nur die gestielten Kerne am Baum zurückbleiben und später auch direkt am Baum herunterfallen (eigene Beobachtung).

Das durch die Avifauna nach dem Fraß erzeugte Verbreitungsmuster als auch die Ausbreitungsdistanz im Wald hängt im wesentlichen von den durch die Habitatpräferenzen der Vögel erzeugten Bewegungsmustern als auch von der Retentionszeit der gefressenen Früchte ab. Der höchste ornithochore Diasporenniederschlag wurde meist in Lichtungen und an Waldrändern beobachtet, nicht aber im geschlossenen Wald. Nach HERRERA (1985) sind je nach Entfernung der nächsten Bestandeslücke auch sehr große Ausbreitungsdistanzen möglich, womit auch eine Einwanderung der für solche Sukzessionsstadien typischen Arten erleichtert wird. Die meisten Bestandeslücken bieten eine große Zahl an Rast- und Nistmöglichkeiten für Vögel. So werden isolierte Einzelbäume oder Sträucher innerhalb solcher Bestandeslücken in der Literatur häufig als "recruitment foci" bezeichnet, da besonders dort ein hoher Diasporenniederschlag durch frugivore Vögel zu verzeichnen ist (KOLLMANN 2000).

Es ist jedoch nicht zu vernachlässigen, daß die Kirsche als Waldpionier insbesondere auch in der freien Landschaft auf nicht bewaldeten Standorten anzutreffen ist. Besonders im Schutz von Dornsträuchern im Inneren von Gebüschen (wie z.B.

\footnotetext{
${ }^{2.4}$ Ausbreitung von Diasporen über den Verdauungstrakt von Tieren

${ }^{2.5}$ Ausbreitung von Diasporen durch Anlage von Nahrungsvorräten in Verstecken
} 
Prunus spinosa) können sich unbewehrte Strauch- und Baumarten wie die Vogelkirsche ansiedeln, wo sie dem Verbiß durch Herbivore entgehen können. In bestimmten sukzessionalen Stadien solcher Gebüschgesellschaften konnte zudem von KOLLMANN (1994) sehr hoher ornithochorer Diasporenniederschlag festgestellt werden. So zählte er für $P$. avium stellenweise bis zu 23 Samen pro $\mathrm{m}^{2}$.

\subsubsection{Mammaliochorie}

Herbivore als auch carni- und omnivore wildlebende Säuger tragen im wesentlichen durch das Fressen heruntergefallener Kirschen zur Ausbreitung dieser Art bei. Nach BONN \& POSCHLOD (1998) konnten in Winterlosungen von Feldhasen und Kaninchen Kirschkerne nachgewiesen werden, wobei die Retentionszeit (das Passieren der Samen durch den Verdauungstrakt) im Allgemeinen mit etwa 6 Std. angegeben wird, wobei direkte Angaben über die Ausbreitung auf diesem Wege wenig bekannt ist. Kleine herbivore Säuger wie die Feldmaus oder das Eichhörnchen hingegen neigen zur Synzoochorie, also der Verschleppung von Samen zur Vorratshaltung. Insbesondere bei der Feldmaus sind die unterirdischen Vorräte in ihrer Ausdehnung jedoch eingeschränkt (10 bis $20 \mathrm{~m}$ um den Mutterbaum) (siehe u.a. SANTI 1988, TURĈEK 1967). Effektiver scheint die Ausbreitung durch Fuchs und Marder zu sein. Nach MATEjKA et al. (1997) sind im Sommer und Herbst zahlreiche fleischig-fruchtige Samen, so auch die Kirsche, ein regelmäßiger Bestandteil der Fuchsnahrung. Auch Dachs und Marder befressen recht häufig heruntergefallene Früchte. KOLLMANN (1994) fand sogar, daß P. avium zusammen mit Vitis vinifera das Gros der Kerne im Fuchskot ausmachte, wobei er den Füchsen für die Ausbreitung von Wildpflanzen eine eher geringere Rolle zuschreibt. Obwohl sie eine deutlich längere Retentionszeiten, größere Aktionsradien als auch eine größere Menge an Diasporen im Kot aufweisen als Vögel, so werden Fuchslosungen meist auf Mesobrometen und Wegen vorgefunden, nur wenige aber in Gebüschen (von Wald ist hier keine Rede).

\subsubsection{Keimung}

Nach STEPHEN et al. (2003) ist der Grund für die Dormanz von Kirschensamen im wesentlichen im Emryo zu finden, obwohl auch die Samenschale in gewissem Umfang keimhemmend wirkt. Bemerkenswert dabei ist, daß der Embryo seine Dormanz zu einem Zeitpunkt erhält, bevor die Früchte ihre volle Reife haben, aber nachdem die Samen schon die Fähigkeit zur Keimung erlangt haben. Werden die Embryonen der noch unreifen Samen präpariert, so können sie zwar keimen, entwickeln aber meistens Abnormalitäten. Mit zunehmender Entwicklungsphase nimmt das Keimpotential stetig ab und die Embryonen voll ausgereifter Früchte benötigen über gewisse Zeiträume niedrige Temperaturen, um diese Dormanz wieder abzulegen. Perioden mit höheren Temperaturen während dieser Zeit können wiederum eine sekundäre Keimruhe induzieren. Durch diese sekundäre Keimruhe wird ein neues Kältebedürfnis aufgebaut, das erst mit einer neuen vollständigen Kälteperiode von 12 bis 16 Wochen wieder abgebaut wird (SUSZKA et al. 1996). 


\subsubsection{Samenprädation}

Als Samenprädatoren der Vogelkirsche werden im wesentlichen Nagetiere sowie Vögel genannt. Nach Beobachtungen von PIRL (2000) ist für den Schadfraß an Kirschensamen innerhalb der Baumkrone der Kernbeißer zu nennen, obwohl kletterfähige Mäuse wie die Rötel- und Gelbhalsmaus teilweise noch viel größeren Schaden anrichten können. Beobachtungen von TURĈEK (1968) ergaben aber auch, daß der Kernbeißer die Kirschkerne nicht nur in situ an Bäumen, sondern auch bis zum Spätherbst am Boden befrißt. Nach KollmanN (1994) sind die Kerne von $P$. avium mit Abstand dem stärksten Schadfraß unterworfen, wobei er zusätzlich noch die Waldmaus als Schädiger mit einbezieht. Er fand unter anderem, daß 87\% der Kirschensamen durch Prädatoren vernichtet wurden. Auch in diesem Zusammenhang sei noch einmal auf Abb. 2.2 verwiesen, denn auch die Samenprädation wird in vielen Arbeiten als dichteabhängiger Prozeß verstanden und kann ähnliche Muster wie die durch Tiere erzeugte Samenausbreitung aufweisen.

\subsubsection{Einfluß der vegetativen Vermebrung}

Nach RÖHRIG \& BARTSCH (1992) verjüngt sich die Vogelkirsche trotz häufiger und in manchen Jahren sehr ergiebiger Fruktifikation nur wenig auf generativem Wege. Das Gros des Vogelkirschen-Nachwuchses im Walde soll aus Wurzelbrut stammen, welches als Ursache dafür gewertet wird, daß Vogelkirschen in Mischbeständen oft in Trupps oder Gruppen auftreten. Als ein Grund wird die bessere Regenerationsfähigkeit der vegetativen Verjüngung nach biotischer Schädigung genannt. Das liegt möglicherweise in physiologischen Vorteilen für vegetativ entstandene Verjüngung, wie z.B. Wurzelverbindungen zu Altbäumen, die die Jungpflanzen vermutlich mit lebenswichtigen Ressourcen versorgen. Aus vegetativer Vermehrung hervorgegangene Pflanzen können so längere Zeiträume auch unter ungünstigen Bedingungen überdauern und somit lokal bessere Überlebensmöglichkeiten besitzen als generative Nachkommen.

Erste Hinweise ergeben Untersuchungen von FrASCARIA et al. (1993), die mittels Isoenzymgenmarkern identische Multilocus-Genotypen auf einer Fläche von über 0.5 ha fanden. Allerdings wird betont, daß noch weitere Marker mit höheren Polymorphiegraden Anwendung finden sollten, da manche Klongruppen nur an einem Genlocus Heterozygotie aufwiesen und damit auch die Möglichkeit gegeben ist, daß eine Rekombination wiederum identische Genotypen erzeugt.

Welche Umweltbedingungen (incl. verschiedener forstlicher Bewirtschaftungsarten) die Anteile sexueller zu asexueller Vermehrung bestimmen und wie diese Anteile zu quantifizieren sind, bleibt allerdings meist offen. Auch die statistische Auswertung populationsgenetischer Daten bedarf diesbezüglich einer umfassenden Analyse.

\subsection{Die Ebene der Untersuchungsskala}

Zur zielgerichteten Analyse der Verbreitung von Pflanzen und ihrer genetischen Information im Raum sind neben einer geeigneten Methode zur Erkennung von Strukturen sowie der Analyse möglicher Prozesse, welche die beobachteten Muster 
erzeugen, zunächst die geeignete räumliche Skalierung zu wählen (siehe DALE 2000). Dies ist deshalb von entscheidender Bedeutung, da in Zusammenhang mit der zu untersuchenden Fragestellung eine bestimmte Auflösung (oder auch Körnung) bezüglich einer modellhaften Abbildung der Realität gewünscht wird. Dazu werden meist Kenntnisse über Zusammenhänge zwischen biotischen und abiotischen Struktureigenschaften benötigt, welche ausführlich in Abb. 2.3 aufgeführt sind.

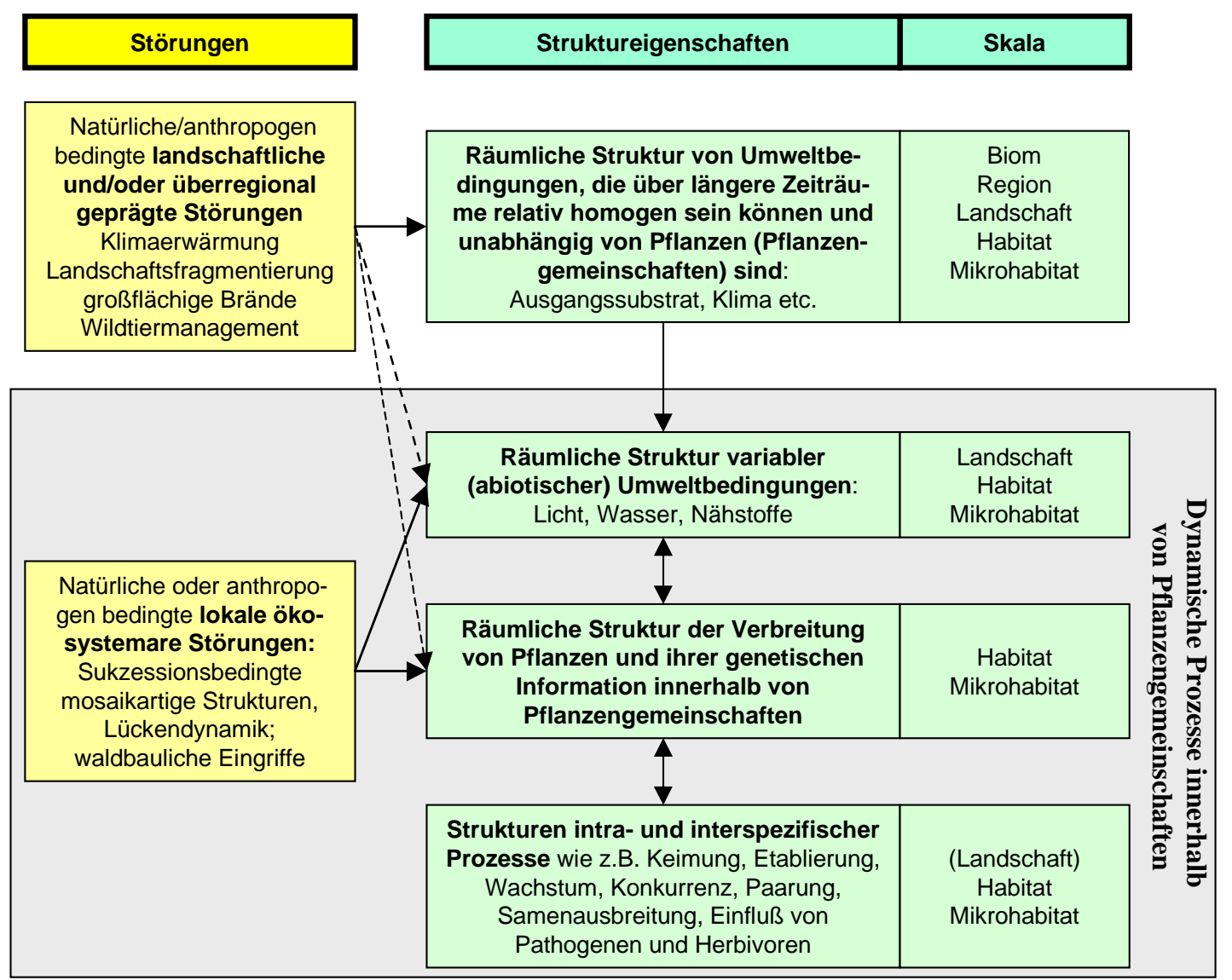

Abb. 2.3: Der Einfluß von Störungen auf räumliche Strukturen von Umweltbedingungen und damit auch auf die Verbreitung von Pflanzen und ihrer genetischen Information (modifiziert nach HERBEN \& HARA 2003)

Es soll hier gezeigt werden, daß bestimmte räumliche Muster von Umweltbedingungen über größere Zeiträume hinweg unabhängig von darauf stockenden Pflanzengemeinschaften hohe Stabilität aufweisen können (Ausgangssubstrat, großräumiges Klima, Topographie). Andererseits aber gibt es auch sehr variable räumliche Strukturen an Umweltbedingungen, welche innerhalb deutlich kürzerer zeitlicher Abstände sehr großen Schwankungen unterliegen können (z.B. die Verfügbarkeit von Licht, Wasser und Nährstoffen innerhalb von Pflanzengemeinschaften). Letztere stehen in enger Wechselbeziehung zu der aktuell vorhandenen Artenzusammensetzung und deren Dynamik. Störungen, welche die räumliche Verbreitung von Arten und damit die Strukturen innerhalb solcher Pflanzengemeinschaften verändern, sind meist lokaler Natur (HERBEN \& HARA 2003). 
Soll das Mosaik von Pflanzengesellschaften in einer Landschaft oder sogar die Vegetationsformen einer Region das Ziel der Untersuchung sein, so ist ein deutlich größeres Beobachtungsfenster zu wählen als beispielsweise bei der Verbreitung von Pflanzenarten innerhalb von Pflanzengemeinschaften. Landschaftliche oder (über-) regionale Vegetationsuntersuchungen beziehen sich meist auf über längere Zeiträume stabilere Strukturen von Umweltbedingungen. Sollen, wie etwa in der vorliegenden Arbeit, Verbreitungsmuster bestimmter Pflanzenarten und dessen Ursachen innerhalb charakteristischer Pflanzengemeinschaften untersucht werden, so bestehen komplexe Wechselbeziehungen zwischen der (klein-)räumlichen Verbreitung von Individuen, den kleinräumig sehr variablen (abiotischen) Umweltstrukturen sowie den zugrundeliegenden intra- und interspezifischen dymischen Prozessen. Wird das Beobachtungsfenster hierbei zu groß bemessen, so ist es naheliegend, daß a) kleinräumige Muster möglicherweise nicht erkannt werden können und b) die räumliche Verbreitung der Arten das Resultat unterschiedlicher Umweltbedingungen widerspiegelt, die unabhängig von den dynamischen Prozessen innerhalb charakteristischer Pflanzengemeinschaften sind (siehe u.a. HERBEN \& HARA 2003).

KOLLMANN (2000) stellte eine Übersicht der wichtigsten Einheiten räumlicher Skalierung, der dort ablaufenden Ausbreitungsprozesse und der Art der bisher durchgeführten populationsbiologischen Untersuchungen zusammen (bezüglich der Skaleneinheiten vgl. auch WIENS et al. 1986 und SCHÄFER 2003). Wie groß die Flächen der einzelnen Einheiten sind, hängt im Einzelfall von den entsprechenden Vegetationstypen ab:

Die kleinste Einheit ist das Mikrohabitat, dessen Fläche kaum die Ausdehnung der größten Pflanze innerhalb der Vegetation überschreitet $\left(0.01 \mathrm{~m}^{2}\right.$ in Graslandschaften bis über $100 \mathrm{~m}^{2}$ in Waldökosystemen). Die Thematik der meisten Untersuchungen der letzten Jahrzehnte beschränkte sich hier im wesentlichen auf Prozesse wie Keimung und Etablierung einzelner Pflanzen.

Die nächste Ebene, das Habitat, ist gekennzeichnet durch spezifische Pflanzengemeinschaften, in denen charakteristische Prozesse in Bezug auf Diasporenniederschlag, Samenprädation als auch Sukzession zu beobachten sind. Die Größe eines Habitats wird nach KolLmanN (2000) auf 10 bis über $10000 \mathrm{~m}^{2}$ eingestuft. Deshalb werden Lücken bestimmter Größe innerhalb geschlossener Wälder auch als spezifische Habitate (nicht als Mikrohabitate) gekennzeichnet, da sich hier im Vergleich zur umliegenden forstlichen Vegetation differenzierte Pflanzengemeinschaften (zumindest für gewisse Zeiträume) einstellen können. Die Ebene der Landschaft $\left(0.01\right.$ bis $\left.1000 \mathrm{~km}^{2}\right)$ ist wiederum durch ein Mosaik verschiedener Pflanzengemeinschaften und abiotischer Habitatstrukturen geprägt, die sich in ähnlicher Form über viele Quadratkilometer wiederholen können.

Da insbesondere auf Habitatebene und möglicherweise auch noch auf Landschaftsebene wichtige Ursachen für spezifische Ver- und Ausbreitungsmuster einer Art zu suchen sind (Zusammenhang zwischen der räumlichen Struktur variabler Umweltbedingungen und Strukturen intra- und interspezifischer Prozesse, siehe Abb. 2.3), soll hier auf höhere Skalenebenen (wie z.B. regionale Strukturen) verzichtet werden. Letztere sind durch großräumige topographische und/oder klimatische Eigenschaften charakterisiert. 


\section{Pflanzenmaterial und Labormethoden}

In Kapitel (3.1) werden die Altbestände mit unterschiedlicher forsthistorischer Entwicklung und damit unterschiedlichen Ausgangsbedingungen für die Besiedlung durch die Vogelkirsche ausgewählt werden. Da populationsbiologisch über die Vogelkirsche nur sehr wenig bekannt ist, sollen diese Informationen in Verbindung mit spezifischen Verfahren zur Analyse des gemischten Reproduktionssystems $\frac{\text { 3.1 }}{\text {. }}$ und der räumlich-genetischen Strukturen, die in den folgenden Kapiteln 4 und 5 detailliert vorgestellt werden, erste Hinweise über den Zusammenhang zwischen gegebenen Umweltbedingungen und dem Ver- und Ausbreitungstyp dieser Baumart liefern (siehe auch Kapitel 2.3). Explorative Untersuchungsmethoden an Saatgut zum Zwecke der Analyse des reproduktiven Artzusammenhalts werden in Kapitel 6 erläutert. In Kapitel 3.2 werden die ausgewählten genetischen Marker sowie deren labortechnischen Analysenmethoden vorgestellt.

\subsection{Auswahl des Pflanzenmaterials}

Die Charakterisierung des Ver- und Ausbreitungstyps der Vogelkirsche als rezedente Baumart mit Hilfe populationsgenetischer Methoden gestaltet sich deshalb schwierig, weil die Artenzusammensetzung der Waldbestände nicht mehr natürlich, sondern nahezu vollständig anthropogen geprägt ist (KÜSTER 1998). Die Entwicklung des Waldbestands ohne menschliche Einwirkung ist historisch und gegenwärtig nahezu unbekannt. Deshalb ist die Untersuchung der lokalen Verbreitung von Individuen und ihrer genetischen Information unter verschiedenen (durch anthropogene Einflüsse verursachten) Umweltbedingungen der vermutlich einzige Lösungsansatz.

Deshalb wurden bei der Auswahl der Vogelkirschenbestände unterschiedliche forstliche Betriebsarten berücksichtigt. Die durch unterschiedliche anthropogene Störungen hervorgerufene Variation an Umweltbedingungen kann auch als langfristig angelegtes, großräumiges Experiment angesehen werden, das wichtige Aufschlüsse über das Verhalten einer Art liefern kann.

Viele der heutigen Vogelkirschenbestände sind aus ehemaliger Nieder- und Mittelwaldwirtschaft hervorgegangen. Diese Bestände sind oft daran zu erkennen, daß die Buche in diesen Beständen auch heute noch eine meist untergeordnete Rolle spielt und die ihr im natürlichen Konkurrenzkampf unterlegenen Typen (wie z.B. die Vogelkirsche) bis in die heutige Zeit vertreten sind. Diese stellen aufgrund der hier praktizierten forstlichen Betriebsart meist schon über längere Zeiträume besiedelte Standorte und damit auch ältere Bestände dar (siehe die im folgenden beschriebenen Bestände Wibbecke und Settmarshausen).

Im Gegensatz dazu ist die Vogelkirsche auch vereinzelt in Hochwäldern vertreten, vorausgesetzt ihr sind aufgrund ihrer geringen Schattentoleranz überhaupt Mög-

${ }^{3.1}$ gemischtes Reproduktionssystem = Fähigkeit der Vogelkirsche zu sexueller und asexueller Vermehrung 
lichkeiten der Besiedlung gegeben. Deshalb sind oft femelartig bewirtschaftete Flächen von Bedeutung, da hier eine mittlere raum-zeitliche Variation ökologischer Bedingungen (Lückendynamik) und damit eine gute Steuerbarkeit der Verjüngung von Mischbeständen (Licht-, Halbschatt- und Schattbaumarten) gegeben ist (SCHOPPA 2000). Diese Bestände sind vermutlich meist jünger, da die Vogelkirsche dem Konkurrenzdruck anderer Baumarten aufgrund ihres raschen Jugendwachstums, ihres frühen Kulminationszeitpunktes als auch ihrer geringen Schattentoleranz meist nur in frühen Sukzessionsstadien gewachsen ist und damit einer anderen Kolonisations-Extinktionsdynamik unterliegt (siehe Bestand Roringen).

\subsubsection{Der Kirschenbestand von Roringen als Beispiel für einen hochwald- bewirtschafteten Bestand}

Fagus sylvatica (Rotbuche) ist die dominante Baumart in diesem Bestand mit einem Flächenanteil von ca. 60\%. Zweitwichtigste Baumart ist Fraxinus excelsior (Esche) mit knapp 30\% Flächenanteil. Acer pseudoplatanoides (Bergahorn) und P. avium (Wildkirsche) sind stamm- bis gruppweise beigemischt und vereinzelt finden sich auch Acer campestre (Feldahorn) und Sorbus torminalis (Elsbeere) (siehe auch Tabelle 3.1 und Abbildung 3.1).

Insgesamt waren in diesem Waldbestand 56 adulte Kirschbäume vertreten. Zum Zwecke der DNA-Analyse wurde der Bestand vollständig beerntet und kartiert (Abbildung 3.2).

Der Bestand erstreckt sich über die Abteilungen 14 (5.1 ha) und 16a (3.5 ha) des Realgemeindeforstes von Roringen. Der Standort wird im aktuellen Forsteinrichtungswerk als mesophiler Kalkbuchenwald eingestuft (mäßig frischer bis kaum frischer Standort der Ebenen mit gut versorgten steinigen Kalkverwitterungslehmböden). Im Betriebswerk von 1957 werden die Standortseigenschaften wie folgt kurz zusammengefaßt: „Ebene, Mullrendzina bis braune Rendzina, tonig, Kalkflora“.

Genauere und verwertbare Aufzeichnungen der Forsteinrichtung bestehen seit dem Ende des II. Weltkrieges, die hier im folgenden nun näher beschrieben werden sollen. Im Betriebswerk von 1946 heißt es:

„...Endnutzung durch langsamen Auszug der breitkronigsten Mittelwaldoberständer. Begünstigung und weitere Auflichtung über Naturverjüngungshorsten, evtl. femelartig. Aushieb vor allem des dämmenden Zwischenstandes, besonders Hainbuche, soweit er nicht als zukünftiger Bestand geeignet ist. Fortsetzung der Verjüngung von oben. Ausroden der verdämmenden Lonicera xylosteum..."

Der Wortlaut läßt also vermuten, daß dieser, wie so mancher siedlungsnaher Bestand, aus ehemaliger Mittelwaldbewirtschaftung stammt und hier Maßnahmen für eine Überführung in Hochwald getroffen wurden.

Dabei ist hier eine horstweise Naturverjüngung über femelartige Eingriffe als Überführungsmethode gewählt worden. Allerdings ist zu bemerken, daß schon damals die typischen Baumarten der Mittelwälder, wie z.B. die Eiche und die Hainbuche, in 
diesem Bestand nicht vorherrschend waren. Die dominierende Baumart im Jahre 1946 war die Buche, gefolgt von der Eiche und anderen Laubholzarten (alle 96- bis 126-jährig). Die Vogelkirsche fand damals noch keine Erwähnung und war (falls überhaupt) vermutlich nur sehr vereinzelt in diesem Bestand vertreten.

Nachdem die ersten femelartigen Eingriffe in den ersten zehn Jahren durchgeführt worden waren, wurde gemäß der Forsteinrichtung von 1957 die Endnutzung der restlichen Überhälter (hauptsächlich kurzschäftige und breitkronige Buche und Hainbuche) in Angriff genommen. Weitere Maßnahmen betrafen die Verjüngung des Bestandes. Das Betriebsziel wurde auf Buche/Edellaubholz festgelegt. Neben der Naturverjüngung wurden die Blößen teilweise auch durch Pflanzungen mit Buche und Esche aufgeforstet. Auch im Betriebswerk von 1957 findet die Kirsche novh keine Erwähnung. Sie hatte aber vermutlich aufgrund der femelartigen Lichtungshiebe gute Anwuchsbedingungen. Denn heute ist die Vogelkirsche in diesem Bestand erfaßt und wird auf ungefähr das gleiche Alter geschätzt wie die übrigen Baumarten. Die Altersdatierung fällt genau auf die Jahre, in denen diese ersten femelartigen Verjüngungshiebe eingeleitet wurden (vor ca. 55 Jahren). Das belegen die Zahlen der aktuellen Forsteinrichtungsdaten (siehe Bestandesbeschreibung in Tab. 3.1).

Heute werden die hochdurchforstungsartigen Eingriffe in diesem Bestand meist in Form von einzelstammweisen Nutzungen durchgeführt. Die letzte Maßnahme fand nach der Probenentnahme für diese Untersuchung im Jahre 2003 statt. Dabei wurden meist die Bedränger der qualitativ besten Stämme entfernt. Dies ist forstwirtschaftlich in diesem Bestand auch als sinnvoll zu betrachten, da der Konkurrenzdruck durch die Buche immer stärker wird und in absehbarer Zeit viele wertvolle Edellaubhölzer zurückdrängen würde.

\begin{tabular}{ll}
\hline Forstamt/Abteilung & FA Bovenden Abt. 14a und 16; Realgemeinde-Forst Roringen \\
\hline Standort & Mesophiler Kalkbuchenwald, 301-350 m über NN; \\
& Mäßig frischer bis kaum frischer Standort der Ebenen mit gut versorgten \\
& steinigen Kalkverwitterungslehmböden \\
Bestandesbeschreibung & Buche mit Edellaubholz, geringes Baumholz (bis Stangenholz), verein- \\
& zelt Überhalt \\
$>$ & in Hochwald überführter ehemaliger Mittelwald \\
Hauptbestand & Buche ca. 55-jährig, meist aus Naturverjüngung (NV) (teilweise auch aus \\
& Pflanzung) gemischt mit Esche (ca. 55-jährig) aus NV und Pflanzung, \\
$>$ & langschaftig, gleichwüchsig \\
$>$ & stamm- bis truppweise Bergahorn aus NV, gleichwüchsig, langschaftig; \\
$>$ & stamm- bis gruppweise Kirsche (ca. 55 Jahre) aus NV, gleichwüchsig, \\
& stellenweise auch vorwüchsig \\
$>$ & ganze Fläche stammweise Elsbeere, Feldahorn, Eberesche, Sandbirke \\
$>$ & ganze Fläche Hainbuche 40-jährig aus NV, geringwüchsig, astig kurz- \\
& schaftig \\
$>$ & stamm- bis truppweise Buche 40-jährig aus NV, geringwüchsig, kurz- \\
& schäftig \\
\hline
\end{tabular}

Tab. 3.1: Bestandesbeschreibung der Abteilungen 14 und 16a in Roringen 


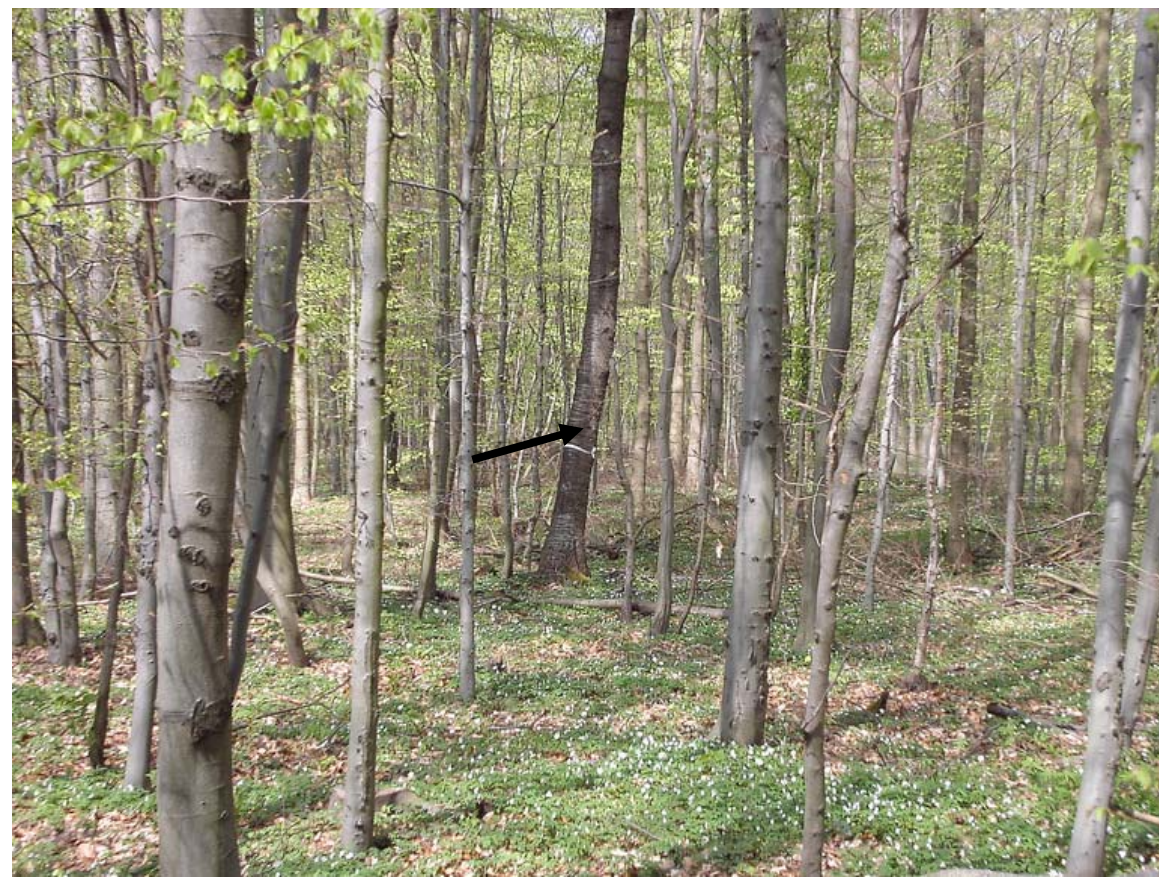

Abb. 3.1: Der Buchen-Edellaubholzbestand von Roringen; hier eine der stamm- bis gruppenweise beigemischten vorwüchsigen Kirschen (Pfeil) umgeben von meist unterständigen, aber aufholenden Buchen

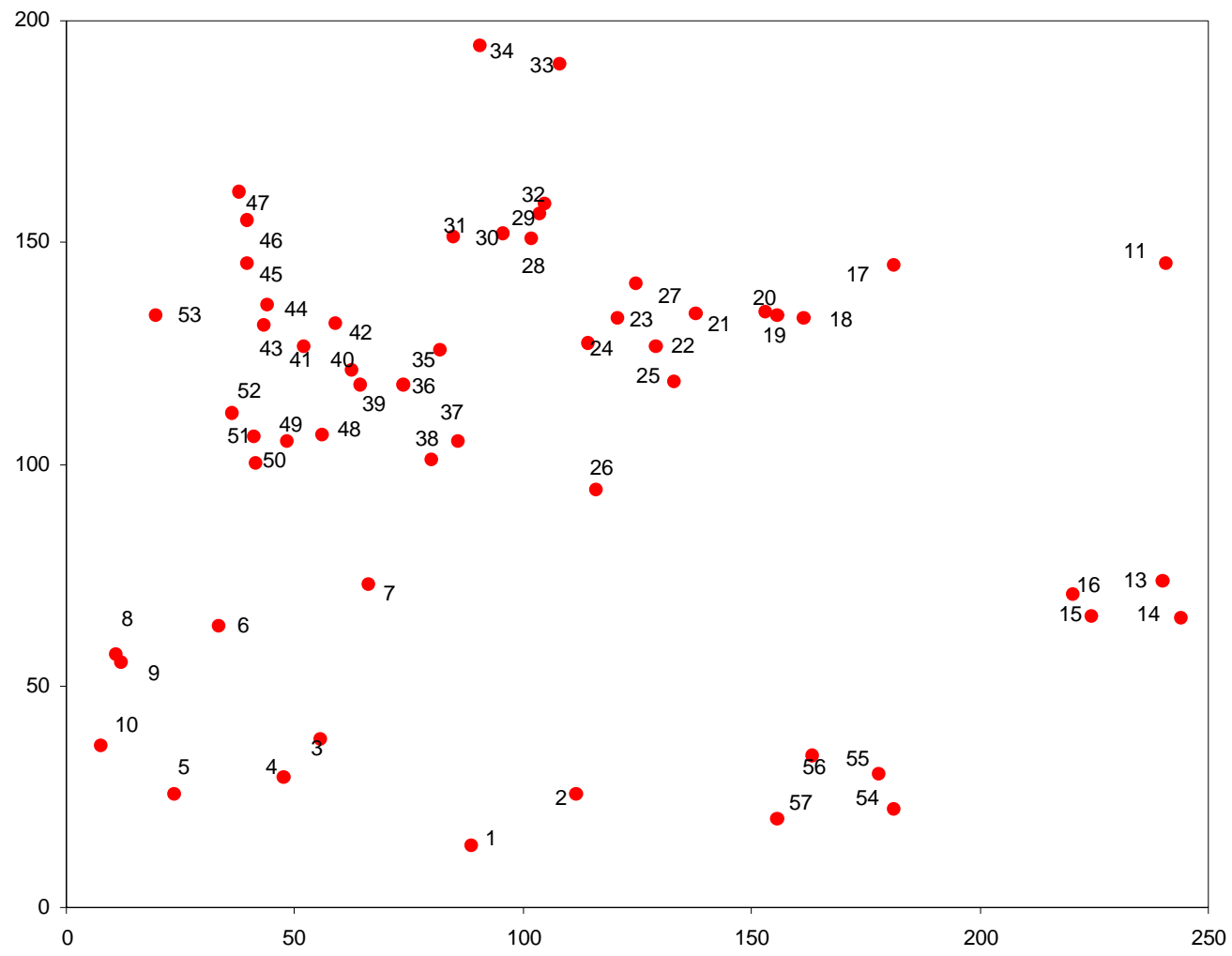

Abb. 3.2: Kartenübersicht über die einzelnen Vogelkirschen im Bestand Roringen 


\begin{tabular}{ll}
\hline Forstamt/Abteilung & FA Bramwald Abt. 1a und 2a; Genossenschafts-Forst Wibbecke \\
\hline Standort & Mesophiler Kalkbuchenwald, über 101-150 m über NN; \\
& Mäßig frischer bis kaum frischer Standort der Ebenen mit gut versorgten \\
& steinigen Kalkverwitterungslehmböden \\
Bestandesbeschreibung $>$ & Buche mit Eiche, geringes bis mittleres Baumholz, zweischichtig, un- \\
& gleichaltrig, stellenweise Naturverjüngung, mit Altbestandsrest; locker \\
& mit Lücken \\
$>$ & ehemaliger Mittelwald \\
$>$ & Hainbuche 103-jährig aus Stockausschlag, mäßig wüchsig \\
$>$ & stammweise Traubeneiche 163-jährig aus Stockausschlag, gering- \\
& wüchsig, kurzschafttig und breitkronig \\
$>$ & stammweise bis truppweise Kirsche (103-jährig) aus Stockausschlag, \\
& zurückbleibend \\
$>$ & stammweise Esche (107-jährig) aus Stockausschlag, vorwüchsig und \\
& kurzschäftig, zwieselig \\
$>$ & stammweise Bu 164-jährig aus Naturverjüngung, vorwüchsig, kurz- \\
& schaftig \\
$>$ & stammweise ganze Fläche Feldahorn, Spitzahorn, Elsbeere, Bergulme, \\
Linde & ganze Fläche Hainbuche 103-jährig aus Stockausschlag, geringwüchsig \\
\hline Unterstand
\end{tabular}

Tab. 3.2: Bestandesbeschreibung der Abteilungen 1a1 und 2a1 im Genossenschafts-Forst Wibbecke

\subsubsection{Der Kirschenbestand von Wibbecke als Beispiel für einen durchge- wachsenen Mittelwald}

Der Bestand von Wibbecke (Abteilungen 1a1 und 2a1 des Wuchsbezirkes Bramwald-Brackenberg) unterscheidet sich grundlegend von dem Bestand in Roringen, obwohl auch dieser in der Forsteinrichtung als mesophiler Kalkbuchenwald angesprochen wird. Hier dominiert Carpinus betulus (Hainbuche) mit über 40\% gefolgt von Quercus petraea (Traubeneiche) mit 20-30\% Flächenanteil. Fagus sylvatica (Rotbuche) ist mit nur wenigen, sehr starken und breitkronigen Exemplaren im Oberstand vertreten und nimmt hier einen Flächenanteil von nur knapp über 10\% ein. Neben der stamm- bis truppweise eingemischten $P$. avium (Wildkirsche) finden sich auch Acer campestre (Feldahorn), A. platanoides (Spitzahorn), Tilia cordata (Winterlinde) und Sorbus torminalis (Elsbeere) (siehe Bestandesbeschreibung in Tabelle 3.2).

Das gesamte Erscheinungsbild, insbesondere die Baumartenzusammensetzung sowie auch der sehr große Anteil an aus Stockausschlägen hervorgegangenen Bäumen läßt auf einen durchgewachsenen Mittelwald schließen, denn insbesondere Hainbuche, Esche, Ahorn und Linde sind gut auf ein regelmäßiges „auf den Stock setzen“ angepaßt (siehe Abbildung 3.3). 


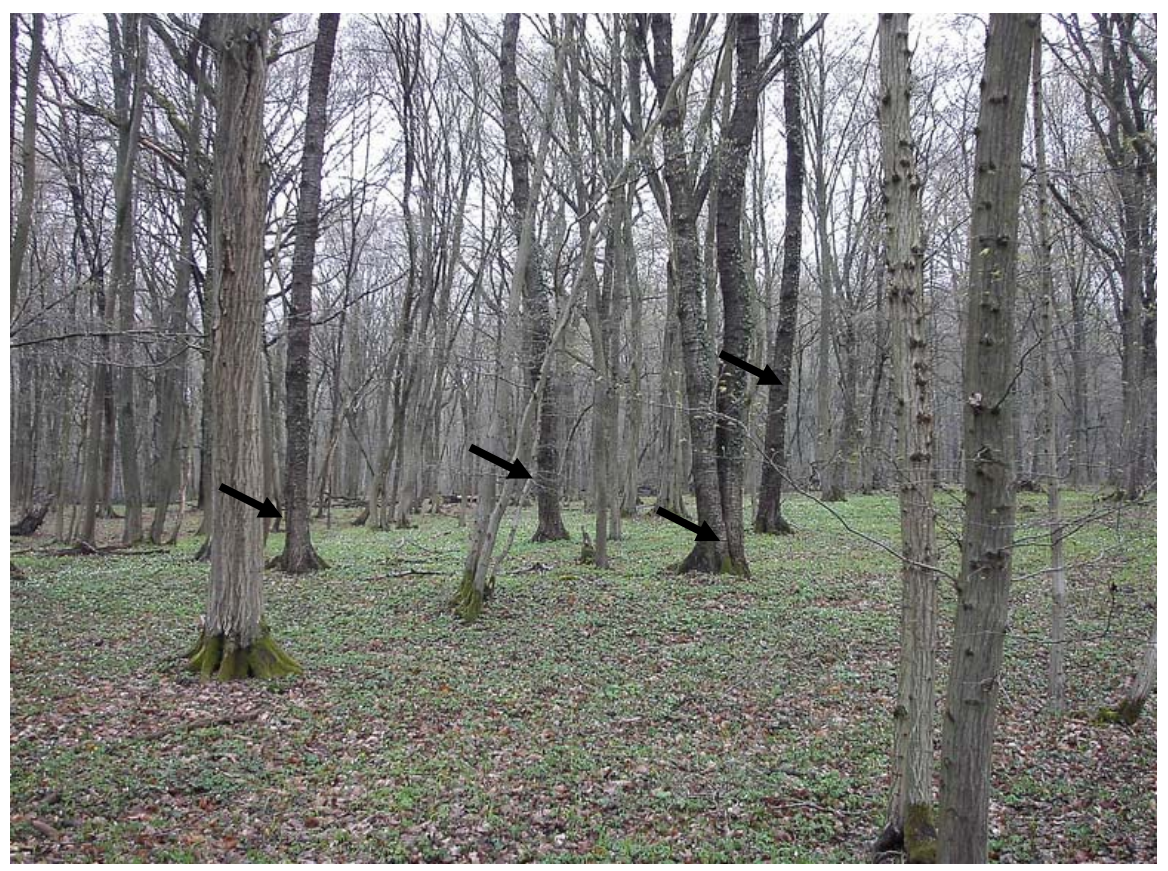

Abb. 3.3: Der Bestand von Wibbecke; hier gruppenweise begemischte Kirschbäume (Pfeile) umgeben von unterständiger Hainbuche, teilweise auch Winterlinde und Esche

Nach SIEDER (2003) werden die Grundzüge der Mittelwaldwirtschaft wie folgt zusammengefaßt:

- Zweischichtbetrieb, der in einer Art Schirmschlag den Unterstand in Form eines kurzumtriebigen Niederwaldbetriebes, den Oberstand in Form eines ungleichaltrigen, lockeren Oberstandes bewirtschaftete

- Verjüngung auf vegetative (Stockausschlag und Wurzelbrut) und generative Weise (Samen, teilweise Pflanzung).

Die Oberschicht bestand aus meist 20 bis 30 fruchtbaren Bäumen je ha. Zu den Hauptbaumarten der Oberschicht zählten insbesondere die Trauben- oder Stieleiche (Q. petraea oder Q. robur) (Bauholz, Früchte zur Schweinemast, Brennund Kohlholz, Rinde zum Ledergerben). Waldbaulich günstig wirkte sich auch die relativ lichtdurchlässige Krone der Eichen aus, die die kontinuierliche Verjüngung der Bestände gewährleistete. Weitere Baumarten der Oberschicht waren weitere „fruchtbaren" Arten, wie z.B. die Wildkirsche (auch Wildbirne und Wildapfel), die Elsbeere, die Vogelbeere, die Rotbuche sowie auch die Linde (Bienenweide und Bastnutzung) (siehe SIEDER 2003, S. 108).

Die Unterschicht (oder auch Hauschicht genannt) nahm den Charakter einer Dickung oder eines Gertenholzes an und wurde kahlschlagartig ca. alle 5-40 Jahre je nach Produktionsziel und Baumverjüngung genutzt (siehe auch SCHOPPA 2000, S. 35). Besonders gut geformte Stämme (Laßreiser oder Kernwüchse) wurden meist belassen, da sie in die zukünftige Oberschicht hineinwachsen sollten.

Die Positionen der Kirschenaltbäume sind in Abbildung 3.4 dargestellt. Insgesamt wurde der Bestand aus 78 Kirschen vollständig beerntet. 


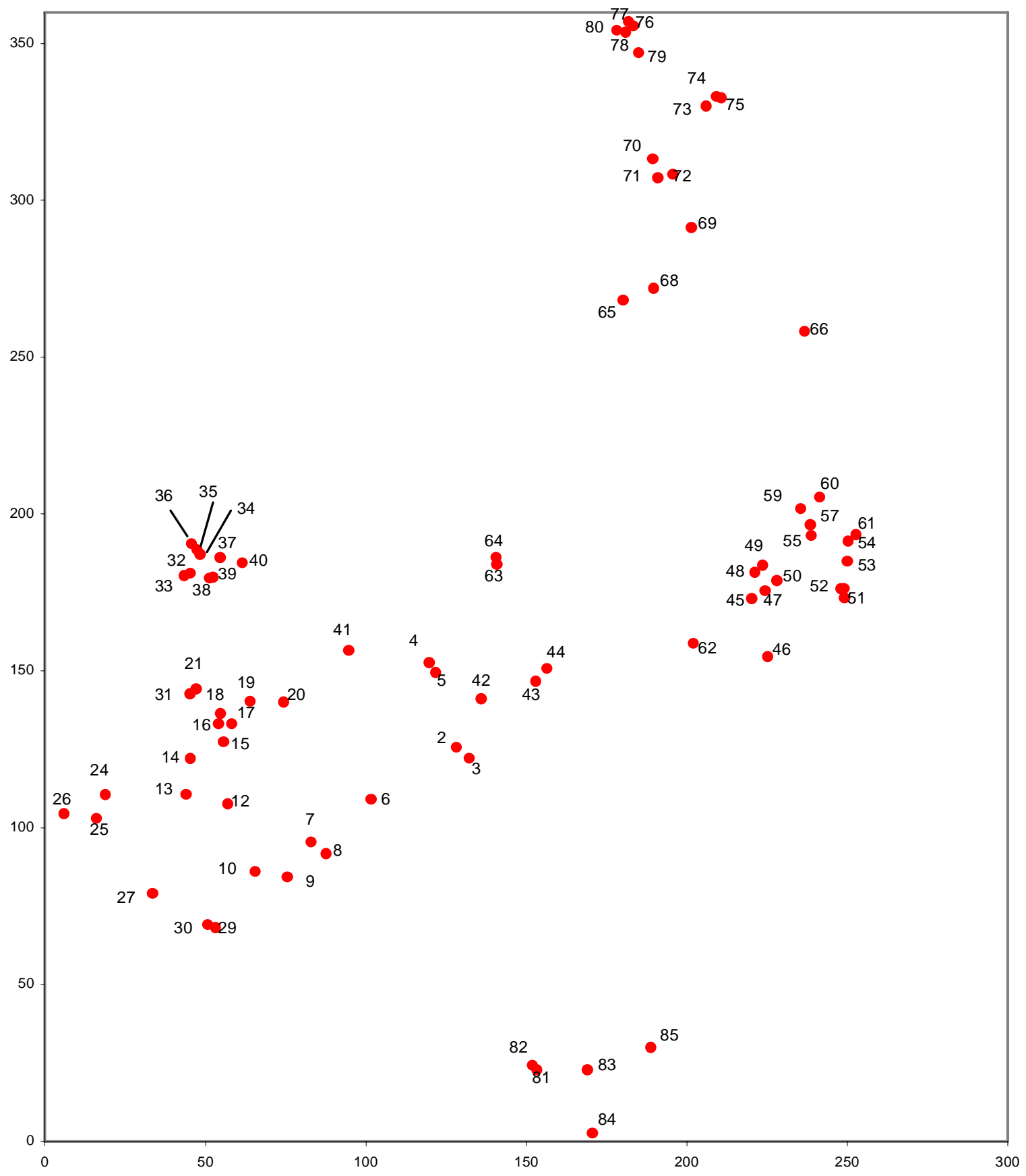

Abb. 3.4: Kartenübersicht des Vogelkirschenvorkommens im Bestand von Wibbecke

\subsubsection{Der Kirschenbestand von Settmarshausen}

Der Bestand von Settmarshausen ähnelt dem von Wibbecke. Der größte Flächenanteil wird auch hier von Carpinus betulus (Hainbuche) mit ca. $40 \%$ als auch von Quercus petraea (Traubeneiche) mit ungefähr 30\% eingenommen. Auch dieser Bestand zeigt typische Eigenschaften eines durchgewachsenen Mittelwaldes. Insgesamt ist dieser Bestand aber noch älter (ca. 130-jährig) und der Anteil von Fraxinus excelsior (Esche) sowie von Acer campestre (Feldahorn) sind hier mit zusammen ca. 
20\% höher als in Wibbecke (siehe Bestandesbeschreibung in Tabelle 3.3 und Abbildung 3.5).

Auch hier wurden alle Kirschen kartiert und frisches Blattmaterial zum Zwecke der DNA-Analyse geerntet. Die Karte mit den Positionen der Kirschen sind in Abbildung 3.5 dargestellt.

\begin{tabular}{ll}
\hline Forstamt/Abteilung & FA Bramwald Abt. 6; Realgemeinde-Forst Settmarshausen \\
\hline Standort & Mesophiler Kalkbuchenwald, über 2511-300 m über NN; \\
& Mäßig frischer bis kaum frischer Standort der Ebenen mit gut versorgten \\
& steinigen Kalkverwitterungslehmböden \\
Bestandesbeschreibung $>$ & Buche (Hainbuche) mit sonstigen Baumarten, geringes bis starkes Baum- \\
& holz, stufig ungleichaltrig, verbreitet Naturverjüngung (NV) in Femeln (diese \\
& teilweise gegattert) \\
$>$ & ehemaliger Mittelwald \\
Hauptbestand $>$ & Hainbuche 130-jährig, Entstehung unbekannt, vermutlich aus Stockaus- \\
& schlag, mäßig wüchsig \\
$>$ & gemischt mit stammweiser Traubeneiche 175-jährig, Entstehung unbe- \\
& kannt, vorwüchsig, astig, kurzschäftig, breitkronig \\
$>$ & stamm- bis truppweise Feldahorn 100-jährig, gleichwüchsig, kurzschaftig, \\
& zahlreiche Wasserreiser, Klebäste \\
$>$ & stammweise bis truppweise Esche (130-jährig), vorwüchsig, lang- und \\
& geradschaftig \\
$>$ & stammweise ganze Fläche Kirsche, Elsbeere, Winterlinde, Bergahorn \\
$>$ & geschlossen mit Lücken und Löchern \\
$>$ & ganze Fläche Hainbuche 103-jährig aus Stockausschlag, geringwüchsig \\
\hline Unterstand &
\end{tabular}

Tab. 3.3: Bestandesbeschreibung der Abteilung 6 im Realgemeinde-Forst von Settmarshausen

\subsection{DNA-Analysen}

Die Wahl des Markers fiel in dieser Untersuchung auf Mikrosatelliten (simple sequence repeats $=$ SSRs), da Kodominanz und eine (z.B. gegenüber Isoenzymen) hohe Variation zur Identifikation sexueller und asexueller Vermehrung, zur Analyse populationsgenetischer Bestandesstrukturen als auch für Genflußuntersuchungen (Kapitel 6) äußerst vorteilhafte Eigenschaften darstellen.

\subsubsection{Isolierung der DNA aus Pflanzenmaterial}

Die DNA wurde mit dem QIAGEN DNeasy96 Plant Kit aus frischen, gerade ausgetriebenen Blättern sowie (für Untersuchungen in Kapitel 6) aus präparierten Embryonen des Saatgutes der Vogelkirsche extrahiert. Dabei wurde darauf geachtet, daß die für dieses Verfahren optimierte Menge von ca. 50 bis $75 \mathrm{mg}$ Material (Frischgewicht) pro Probe für die Extraktion nicht überschritten wurde. Vor dem eigentlichen Isolationsprozeß wurde das Pflanzenmaterial in flüssigem Stickstoff 
eingefroren und im tiefgefrorenen Zustand zunächst in der Retschmühle pulverisiert. Das Isolationsverfahren des QIAGEN DNeasy96 Plant Kit erfolgt durch folgende Schritte: (1) Zerkleinerung und Lösen von Zellwand- und Zellmembranbestandteilen, (2) Ausfällung von Proteinen und Polysacchariden, (3) Mehrere Waschprozesse, um die restlichen Verunreinigungen zu entfernen (u.a. Polyphenole) und (4) Lösen der DNA in Wasser und Konservierung bei $-20^{\circ} \mathrm{C}$.

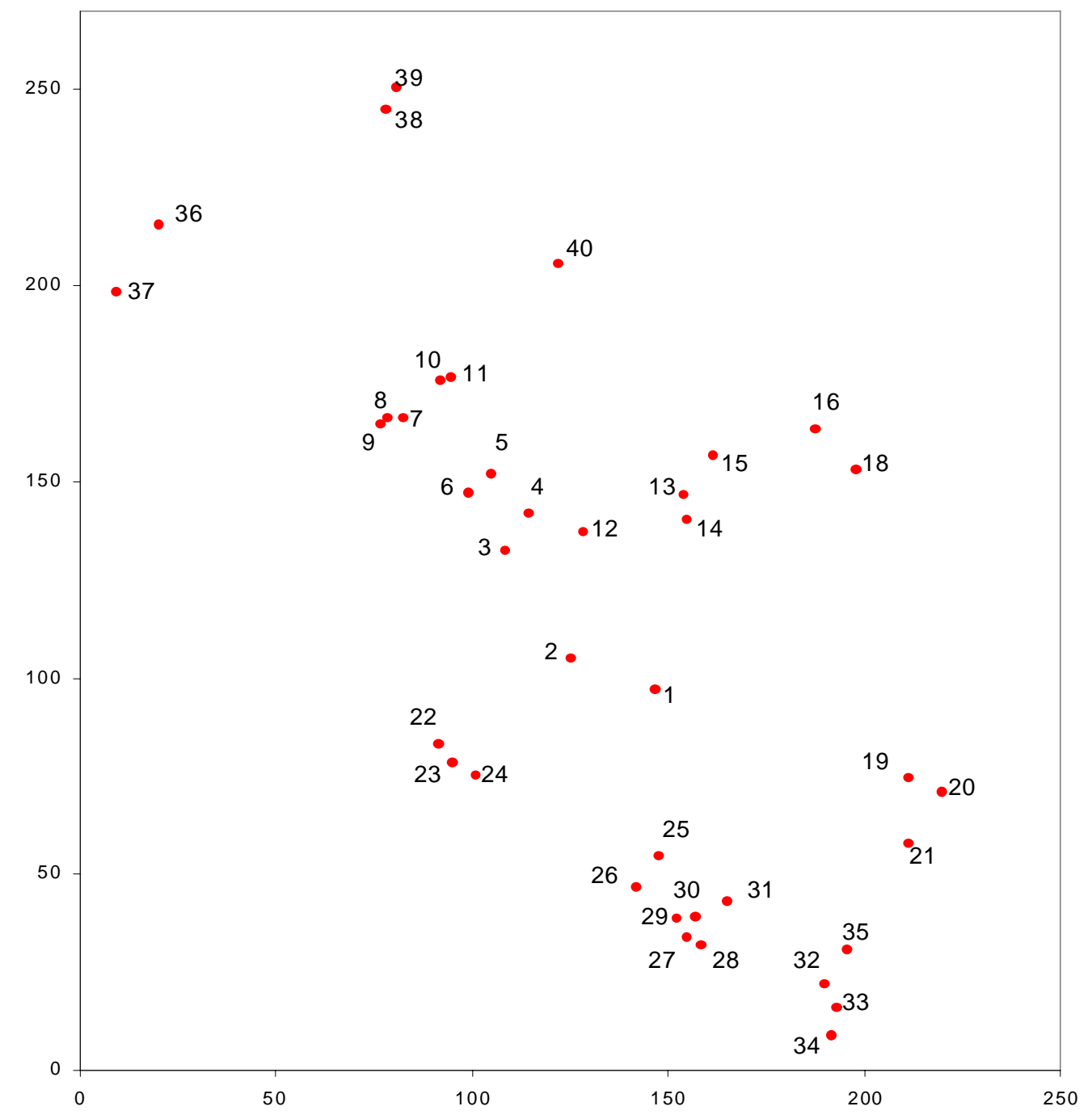

Abb. 3.5: Kartenübersicht des Vogelkirschenvorkommens im Bestand von Settmarshausen

\subsubsection{Agarose-Gelelektrophores}

Zur Bestimmung der Menge und der Qualität der isolierten DNA wurde eine Agarose-Gelelektrophorese durchgeführt. Dabei wurde die gelöste DNA in $0.8 \%$ igen Agarosegelen mit 1 X TAE (40mM Tris-Acetat pH 7.8, 1mM EDTA) als Elektrodenpuffer aufgetrennt. Nachdem die Gele über ca. 10 min in einer Ethidiumbromidlösung geschwenkt und damit die isolierte DNA angefärbt worden war, wurde 
das Resultat unter UV-Licht begutachtet und mit einer Digitalkamera dokumentiert.

Auch die DNA-Amplifizierungsprodukte wurden gemäß obigem Schema mit Hilfe der Agarose-Gelelektrophorese kontrolliert, bevor die Fragmentlängenbestimmung erfolgte. Aufgrund der geringen Größe der Amplifizierungsprodukte betrug die Agarose-Konzentration hier nur ca. 2\%.

\subsubsection{Amplifizierung von Mikrosatelliten-Sequenzen}

Insgesamt wurden acht derzeit verfügbare und erprobte Mikrosatelliten-Marker für die Untersuchung der Vogelkirsche verwendet. Dabei wurden sechs SSRs (UDP96005, UDP98-021, UDP98 -410, UDP98-412, ВРРCT034 und ВРРCT040) zur Beschreibung populationsgenetischer Strukturen und weitere zwei SSRs (UDP96-001 und UDP98-411) bei Bedarf bei Vaterschaftsanalysen eingesetzt. Die Primer-Sequenzen, die Wiederholungssequenzen sowie die Anlagerungstemperaturen sind in Tabelle 3.4 dargestellt.

Die Amplifikation wurde in einem PTC-200 (MJ Research) durchgeführt. Für die später erfolgende rechnergestützte Kapillarelektrophorese wurden floureszenzmarkierte Primer mit zwei Farbstoffen (grün (HEX) und blau (FAM)) verwendet (siehe Tabelle 3.4). Dadurch war es möglich, die Amplifizierungsprodukte zweier Mikrosatelliten-Loci gleichzeitig zu analysieren (Multiplex-System). Die Polymerase-Kettenreaktion (PCR) erfolgte in einem Reaktionsvolumen von $10 \mu$ l. Darin enthalten waren $10 \mathrm{ng}$ DNA-Templat, $1.5 \mathrm{mM} \mathrm{MgCl}, 10 \mathrm{mM}$ Tris- $\mathrm{HCl} \mathrm{pH} 9.0,50 \mathrm{mM} \mathrm{KCl}$, $0.15 \mathrm{mM}$ der einzelnen Nucleotide (dNTPs) (QIAGEN), 0.5 Einheiten des Enzyms HotStar-Taq ${ }^{\text {TM }}$ DNA-Polymerase (QIAGEN) sowie $0.2 \mu \mathrm{M}$ der jeweiligen Primer. Der Ablauf der Amplifizierungsreaktion sah wie folgt aus:

\begin{tabular}{|c|c|c|}
\hline Zykluszahl & Temperatur & Dauer \\
\hline $1 X$ & $95^{\circ} \mathrm{C}$ & $15 \mathrm{~min}$ \\
\hline $30 \mathrm{X}$ & $\begin{array}{l}94^{\circ} \mathrm{C} \\
\text { Annealing-Temp. } \\
72^{\circ} \mathrm{C}\end{array}$ & $\begin{array}{l}1 \mathrm{~min} \\
0.5-1 \mathrm{~min} \\
1 \mathrm{~min}\end{array}$ \\
\hline $1 \mathrm{X}$ & $72{ }^{\circ} \mathrm{C}$ & $12 \min$ \\
\hline
\end{tabular}

\subsubsection{Die Kapillarelektrophorese}

Die PCR-Produkte wurden zunächst verdünnt im Verhältnis von 1:250 bis 1:500. $\mathrm{Zu} 2 \mu \mathrm{l}$ dieser Verdünnung wurden $12 \mu \mathrm{l} \mathrm{Hi-Di}$ Formamid gegeben, worin ein interner Längenstandard (GS 500 ROX) enthalten war. Die Proben wurden anschließend bei $95^{\circ} \mathrm{C}$ für 2 min denaturiert und auf Eis gestellt.

Danach wurden die Amplifizierungsprodukte auf dem ABI PRISM 3100 Genetic Analyser (Applied Biosystems/HITACHI) visualisiert und mit den Computerprogrammen GeneScan 3.7 und Genotyper 3.7 analysiert. 


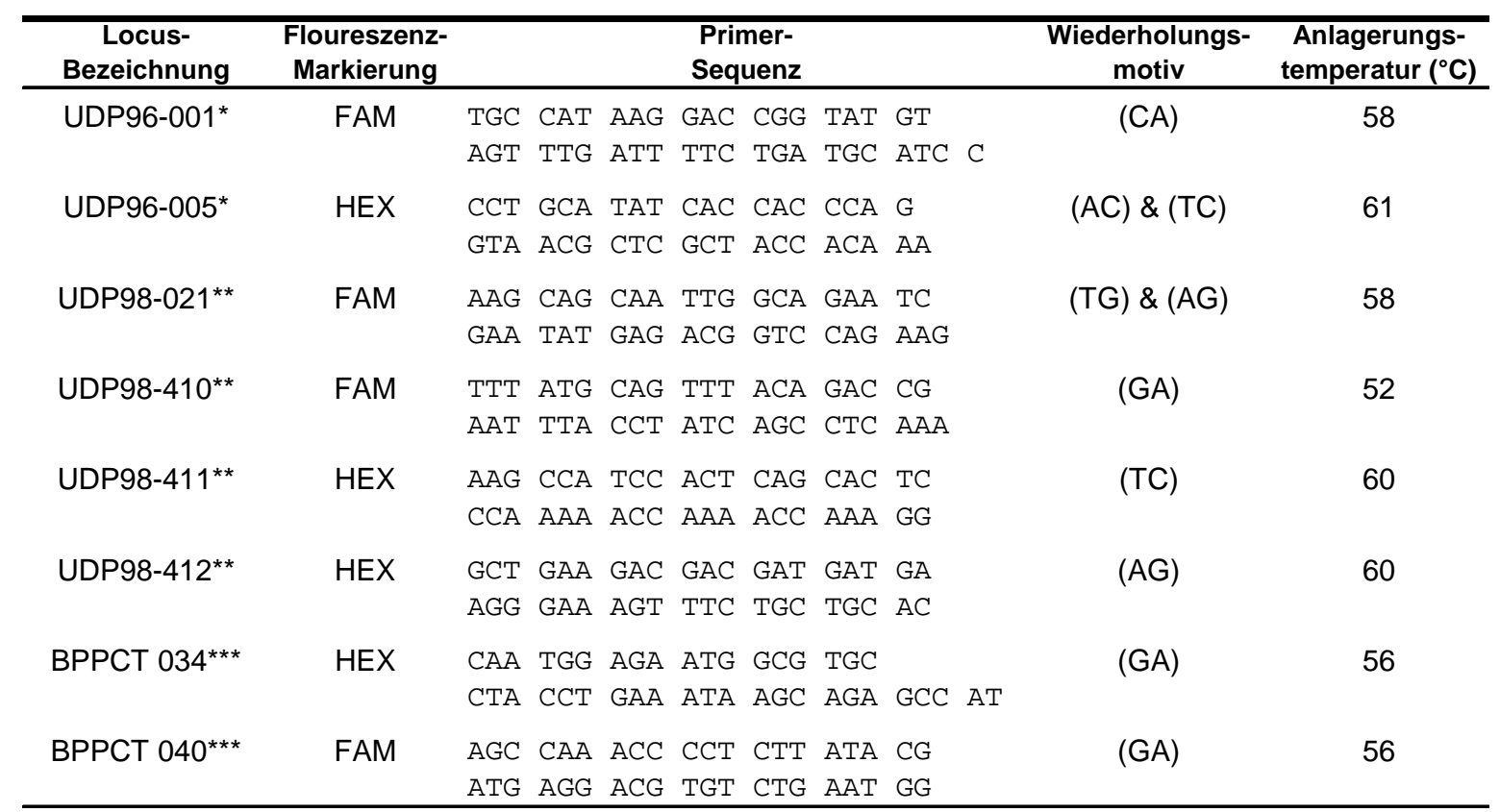

Tab. 3.4: Die Locus-Bezeichnung der verwendeten Mikrosatellitenmarker (CIPRIANI et al. 1999; TESTOLIN et al. 2000, DIRLEWANGER et al. 2002, siehe auch SCHÜLER et al. 2003), die Floureszenzmarkierung für die Kapillarelektrophorese, die Primersequenz $\left(5^{\prime} \rightarrow 3^{\prime}\right.$-Ende), das Wiederholungsmotiv des Mikrosatellitenfragments sowie die Anlagerungstemperatur der Primer 


\section{Eigenschaften des gemischten Reproduktionssystems in adulten Vorkommen der Vogelkirsche}

\subsection{Einführung in die Problematik zur Erfassung asexueller und sexueller Reproduktion bei der Vogelkirsche}

Das gemischte Reproduktionssystem dieser Baumart, d.h. die Fähigkeit sowohl zu sexueller als auch zu asexueller Vermehrung, wirft eine Reihe von zu beantwortenden Fragen auf. In diesem Kapitel soll der Einfluß verschiedener (meist anthropogen geprägter) Umweltbedingungen auf das Verhältnis der beiden Reproduktionsmodi als auch auf die genetische Variation in drei adulten Vorkommen der Wildkirsche (siehe Kapitel 3) quantifiziert werden. Dabei soll insbesondere auf Probleme sowie die konzeptionellen Grundlagen der Identifikation der beiden Reproduktionsmodi eingegangen werden, was eine Analyse hinsichtlich der Entstehung von Genotypen unumgänglich macht. Da diese Analyse die zwingende Grundlage für die weiteren Untersuchungen ist, werden Aspekte wie z.B. die Verteilung von Individuen und genetischer Information im Raum erst Gegenstand der folgenden Kapitel sein.

Da der Klon-Begriff hier eine zentrale Rolle spielt, bedarf es vorerst einer Klärung seiner Terminologie. Das ursprüngliche Klon-Konzept stammt aus dem Pflanzenbau und der Genetik. Demnach ist ein Klon als eine genetisch einheitliche Gruppe pflanzlicher Organismen zu betrachten, die durch asexuelle Vermehrung aus einer einzigen Pflanze hervorgegangen ist (siehe auch COOK 1985). Diese (genetische) Interpretation des Klon-Konzeptes unterscheidet sich aber oft grundlegend von denen in der Pflanzenpopulationsbiologie und -ökologie verwendeten. Ein Klon wird hier in vielen Ausführungen als eine einheitliche Struktur aufgefaßt, die erst später in Teile zerfällt oder auch ungeteilt bleibt. Damit wird der Begriff Klon als „Quasi-Synonym“ für eine einzige Pflanze verwendet und so ins genaue Gegenteil des genetischen Konzeptes verkehrt. Einige Autoren sehen klonales Wachstum und Fortpflanzung sogar als einen einzigen biologischen Vorgang an (URBANSKA 1992).

Um Verwirrungen zu vermeiden und eine durchgehend übereinstimmende Terminologie in dieser Arbeit zu gewährleisten, sind in der Definitionsbox (Box 4.1) die wesentlichen Begriffe zusammengefaßt, welche in diesem und auch in den folgenden Kapiteln Verwendung finden sollen. Mit dieser Terminologie sollen im folgenden zunächst die wesentlichen Unterschiede zwischen modularem und klonalem Wachstum sowie asexueller Vermehrung unter besonderer Berücksichtigung der Vogelkirsche als heimische Waldbaumart vorgenommen werden.

\subsubsection{Klonales Wachstum und asexuelle Vermehrung}

Die Anzahl und die Verteilung meristematischer Gewebe auf einer Pflanze bestimmen meistens dessen Wuchseigenschaften sowie (im Ergebnis) auch dessen gesam- 
te Struktur. Der modulare Aufbau höherer Pflanzen bildet die Grundlage für eine große Vielfalt an Möglichkeiten räumlichen Wachstums (Harper 1985). Diese finden auch in den meisten Wachstums- und Populationsmodellen Berücksichtigung.

\section{Definitionen}

Adventivknospe: Knospe, die nicht endständig oder in einer gesetzmäßigen Bindung an die Blattachseln steht, wie z.B. Wurzelknospen, aus denen sich Wurzelsprosse entwickeln können. Die Vermehrung durch Wurzelsprosse wird auch als Wurzelbrut bezeichnet

Agamospermie: Form der asexuellen Vermehrung durch Samen, wobei die Samenbildung auf ungeschlechtlichem Wege unter Umgehung der Meiose erfolgt (ohne vorausgehende Reduktionsteilung)

Genet: Ein genetisches Individuum, d.h. die Pflanze oder der Klon, der aus einer Zygote hervorgegangen ist

Guerilla-Strategie: Form der vegetativen Vermehrung bei Pflanzen, die als Module eines Klons mittels langer Rhizome oder Ausläufer einen weiten Bereich besiedeln können; Beispiel: Lianen, Trifolium repens

Klon: Gruppe von Organismen, die durch ungeschlechtliche oder vegetative Fortpflanzung von einem Elternindividuum abstammen und deshalb genetisch identisch sind (abgesehen von seltenen vegetativen Mutationen)

Klonales Wachstum: Durch iterative Bildung von Ramets erkennbare Form des expansiven Wachstums eines Individuums, womit eine klonal wachsende Pflanze also aus Ramets besteht, welche miteinander verbunden und damit physiologisch integriert sind

Klonierung: Erfolgt durch Fragmentation von der Mutterpflanze, womit als Ergebnis die endgültige vegetative oder asexuelle Reproduktion vollzogen und die physiologische Unabhängigkeit der einzelnen Ramets gegeben ist

Modul: Funktionseinheit; sich mehrmals wiederholendes, grundlegendes Bauelement einer Pflanze mit Apikalmeristem

Phalanx-Strategie: Form der vegetativen Vermehrung bei Pflanzen, bei denen die Module eines Klons dicht zusammenbleiben; Beispiel: Horstgräser

Ramet: Eine vegetative Einheit eines Genet, z.B. ein Sproß, der sich aus Wurzelgewebe entwickelt und der durch Abtrennung von der Mutterpflanze physiologisch selbständig werden kann (Klonierung)

Ressourcentranslokation: Der Austauch von Ressourcen (Assimilate, Nährstoffe, Wasser) von einem Teil eines Klons zu einem an deren über spezifische pysiologische Verbindungen. Das „solidarische Verhalten“ von Ramets klonal wachsender Pflanzen kann zwei Bereiche umfassen: (1) Bei der Bildung neuer Ramets unterstützen ältere Strukturen die Neuentwickelten; (2) unter Streßbedingungen helfen sich die Ramets gegenseitig

Rhizom: Unterirdischer, waagerechter oder aufsteigender Sproßteil mit gestauchten Internodien, der Speicherfunktion hat und nichtgrüne, schuppenförmige Niederblätter trägt. Weit kriechende und verzweigte R. können der vegetativen Vermehrung dienen, in dem die älteren Teile absterben

Stolo, pl. Stolonen: Seitensprosse mit verlängerten Internodien und sproßbürtiger Bewurzelung, der der vegetativen Vermehrung dient

vgl. SCHÄFER (2003), URBANSKA (1992), WAGENITZ (2003); siehe Glossar in DE KROON und VAN GROENENDAL (1997) 
Viele Pflanzenarten beispielsweise wachsen durch das Hinzufügen von Modulen hauptsächlich in vertikaler, andere durch die Erzeugung neuer Module an ihrer Basis bevorzugt in horizontaler Richtung (SILVERTOWN \& CHARLESWORTH 2001, S. 10, 290). Bäume besitzen nach JENIK (1994) im Vergleich zu den meisten krautigen Pflanzen eine größere Vielzahl verschiedener meristematischer Gewebe, woraus eine Fülle von Möglichkeiten des Wachstums entsteht. Ist mit der vegetativen Erzeugung von Modulen potentiell auch deren physiologische Unabhängigkeit gegeben, kann von klonalem Wachstum und in der Folge oft auch von Klonierung bzw. asexueller Vermehrung gesprochen werden (MOGIE \& HuTCHINGS 1990). Neben der Agamospermie bietet auch modulares Wachstum vielen Pflanzenarten die Möglichkeit, Ramets zu erzeugen, welche sowohl untereinander als auch im Vergleich zu ihren klonalen Vorfahren genetische Identität besitzen.

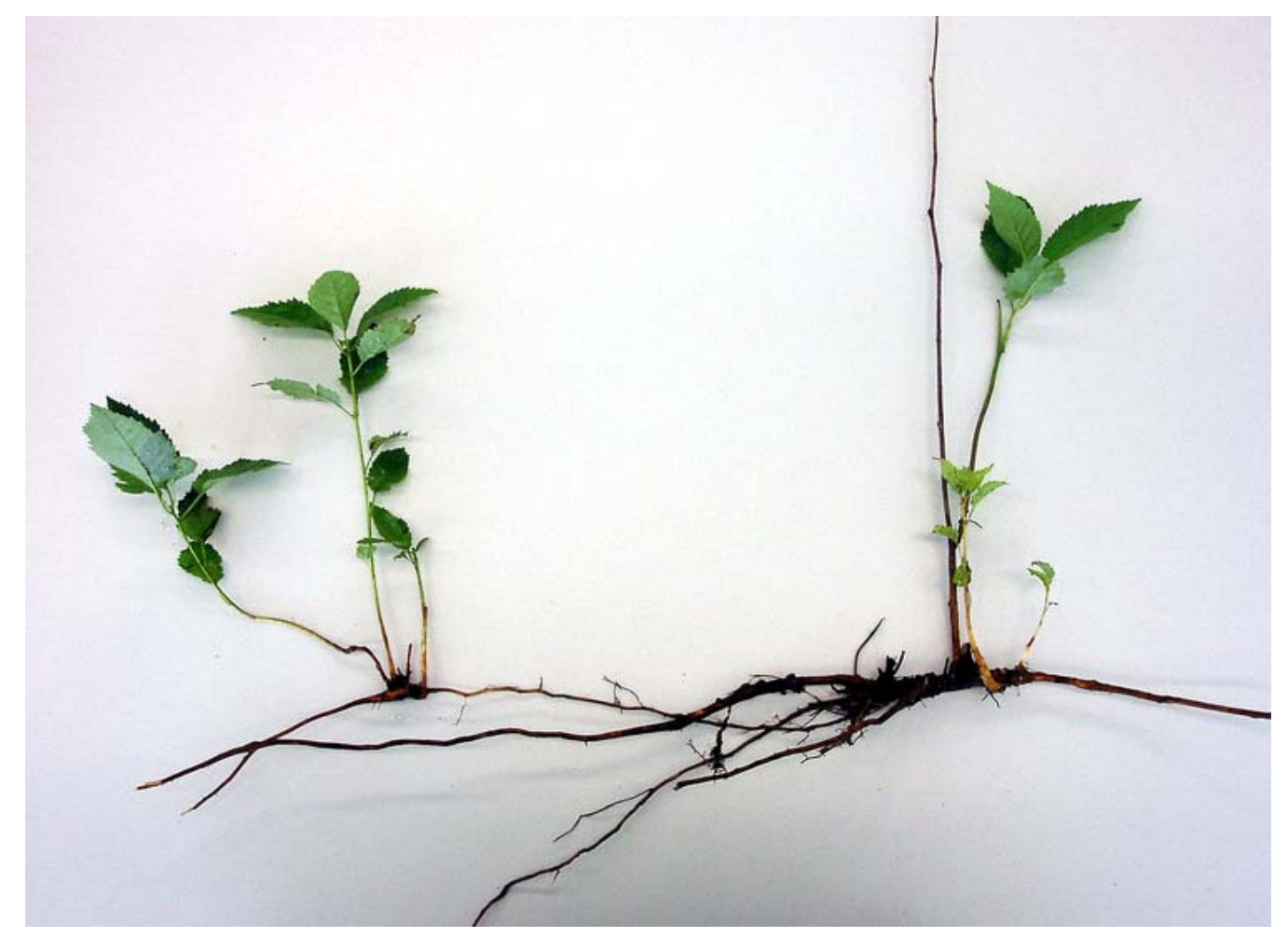

Abb. 4.1: Bildung von Wurzelbrut an Verdickungen des flach streichenden Feinwurzelsystems der Vogelkirsche

Wie die meisten Pflanzen, die zu asexueller Vermehrung befähigt sind, ist auch $P$. avium mit zwei Reproduktionsmodi ausgestattet. Sie ist in der Lage, sich sowohl generativ über die Produktion von Samen als auch vegetativ über die Bildung von Wurzelbrut fortzupflanzen. Letzteres geschieht über Adventivknospen, welche an Wurzelverdickungen eines flach unter der Erdoberfläche verlaufenden Feinwurzelsystems zu beobachten sind (siehe Abb. 4.1 und 4.2).

Nach FISCHER \& VAN KLEUNEN (2002) können die populationsbiologisch relevanten Arteigenschaften klonal wachsender und reproduzierender Pflanzen durch folgende Kriterien zusammengefaßt werden: (1) Durch das Verhältnis von vegetativen 
zu sexuellen Nachkommen, (2) die Form der vegetativen Ausbreitung (Phalanxoder Guerilla-Strategie) und (3) durch die Bedeutung und die zeitliche Dauer der physiologischen Verbindungen zwischen den einzelnen Ramets. Bei einigen Pflanzenarten kann darüber hinaus (4) eine starke Variation der Länge der Internodien im Bereich von Stolonen oder Rhizomen und damit eine unterschiedliche Verzweigungshäufigkeit beobachtet werden. Damit ist vermutlich die Möglichkeit gegeben, ressourcen- und standortsabhängig die Anzahl der zu etablierenden Ramets zu beeinflussen (im englischen Sprachgebrauch „foraging behaviour“, eine den Ressourcen zugewandte Entwicklungsstrategie, siehe CAIN (1994)).

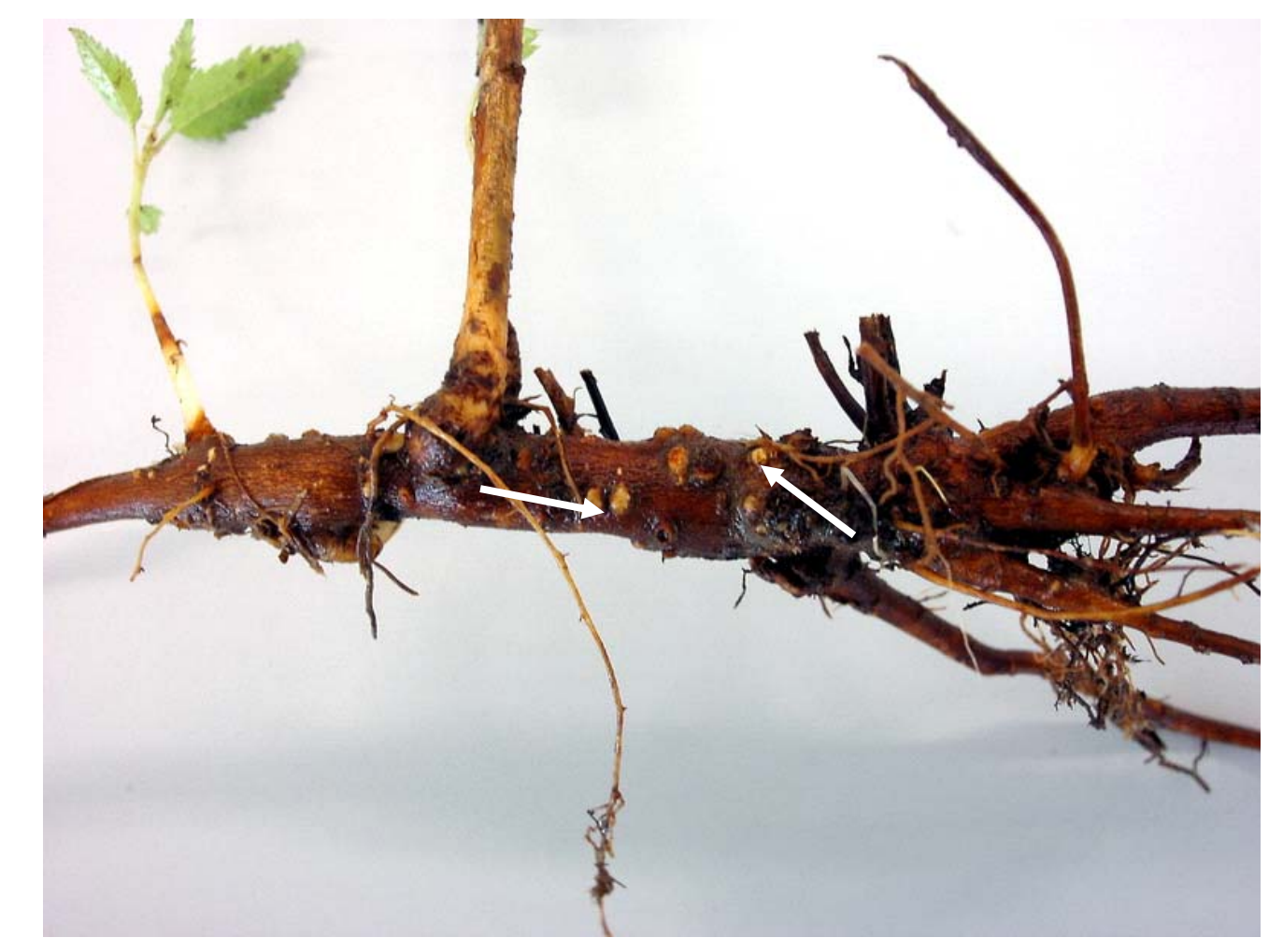

Abb. 4.2: Junger Sproß sowie meristematische Gewebe (Adventivknospen, siehe Pfeile) an Verdickungen des flach streichenden Feinwurzelsystems der Vogelkirsche

Vegetative Vermehrung kann also auf sehr unterschiedliche Art und Weise erfolgen, wobei die immense Variationsbreite an unterschiedlichen Entwicklungsstrategien und -zyklen nicht unbedingt nur zwischen Arten zu finden ist. Diese können auch innerhalb einer Pflanzenart unter verschiedenen Umweltbedingungen zu unterschiedlichen Ausprägungen gelangen (FISCHER \& VAN KLEUNEN 2002).

Die meisten Untersuchungen der vergangenen Jahrzehnte befaßten sich allerdings mit krautigen Pflanzen. Hier zeigte sich, daß Ressourcentranslokation klonal wachsender Pflanzen und damit eine Art Arbeitsteilung zwischen den einzelnen Ramets offensichtlich eine sehr effektive Strategie darstellt, Standorte mit starker Umweltheterogenität zu besiedeln (HuTCHINGS \& WijESINGHE 1997). STUEFER et al. (1994) beobachteten an den Fingerkrautarten Potentilla reptans sowie $P$. anserina, daß stark heterogene Verhältnisse sogar höhere Biomasseproduktion ermöglichen können als 
homogene Umweltbedingungen. Sie erklärten es damit, daß Unterschiede im Bodenwasserhaushalt aufgrund sehr unterschiedlicher Belichtungsverhältnisse über physiologische Verbindungen (hier: Stolonen) ausgeglichen werden können. So erhalten diejenigen Ramets, welche starker Belichtung und damit hoher Evapotranspiration ausgesetzt sind, Wasser von denjenigen, die einem geringeren Trockenstreß unterliegen. Im Gegenzug werden Photosyntheseassimilate verstärkt in umgekehrter Richtung transportiert. Ähnliches wurde von HUTCHINGS (1999) auch an Klonen von Glechoma hederacea (Gundermann) in Böden mit stark heterogenen Nährstoffverhältnissen gefunden.

Während ein wichtiger Vorteil klonalen Wachstums bei krautigen Pflanzen die optimale Ausnutzung der Standortsressourcen ist, hat klonales Wachstum bei Baumarten vermutlich andere Vorzüge. PETERSON \& JONES (1997) vermuten, daß das geklumpte Auftreten vegetativer Verjüngung eher einer erhöhten Mortalität durch Faktoren wie z.B. Wildverbiß (oder auch Feuer und Wind) entgegenwirken soll („damage buffering“). Nach RÖHRIG \& BARTSCH (1992) verjüngt sich die Vogelkirsche in unseren Wälder nur selten durch Ansamung, da die vegetative Vermehrung nach einer Beschädigung durch Wild eine stärkere Regenerationsfähigkeit aufweist als Sämlinge aus generativer Vermehrung. Auch ist zu erwähnen, daß vegetative Nachkommen eher die Möglichkeit haben über längere Zeit im Schatten älterer Bäume zu überleben als generative Nachkommen, bis die Entstehung von Lücken im Kronendach die Chance für die eigene Entwicklung gewährleistet (PETERSON \& JONES 1997). Auch dies wäre wieder mit Ressourcentranslokation verbunden, die hier aber vermutlich eher einseitigen Charakter aufweist. Der Mutterbaum versorgt die Tochterramets solange mit Wasser, Nährstoffen und Assimilaten, bis bessere Umweltbedingungen das selbständige Überleben der Tochterramets ermöglichen.

Ein weiterer wesentlicher Aspekt ist im Bereich der intraspezifischen Konkurrenz zu finden. Während klonal wachsende krautige Pflanzen die Produktion neuer Ramets sowie ihre räumliche Verteilung und Dichte meist kontrollieren und somit intraspezifischer Konkurrenz bessser ausweichen können, setzt bei Baumarten aufgrund ihres immensen Volumenzuwachses schon sehr früh eine natürliche Auslese und damit eine Reduktion der Stammzahlen (=Selbstverlichtung) ein (PETERSON \& JONES 1997, PITELKA 1984).

\subsubsection{Zum Problem der Identifizierung sexueller und asexueller Abstam- mung in adulten Vorkommen der Vogelkirsche}

Falls die gemeinsame klonale Abstammung eines Pflanzenkollektivs durch direkte Beobachtungsmöglichkeiten (ober- und unterirdische physiologische Verbindungen wie etwa Wurzelausläufer, Stolonen oder Rhizome) nicht bestimmt werden kann, ist der Nachweis vegetativer Vermehrung in Pflanzenpopulationen abhängig von der Analyse der genetischen Identität der Individuen. Insbesondere bei $P$. avium ist eine solche direkte Determinierung über das Entdecken von Wurzelverbindungen zwischen Ramets (wenn überhaupt) nur in frühen Entwicklungsstadien möglich. 
Zu einem späteren Zeitpunkt entwickeln sich diese Ramets meist zu physiologisch vollständig unabhängigen Individuen, auch wenn dieser Prozeß bei Baumarten Zeiträume von mehreren Jahrzehnten in Anspruch nehmen kann (PETERSON \& JONES 1997). Da insbesondere Forstpflanzen durch inter- und intraspezifische Konkurrenz (natürliche Stammzahlreduktion, Selbstverlichtung, "forest self-thinning") unterschiedlichen Überlebenswahrscheinlichkeiten ausgesetzt sind, bleibt es somit meist unklar, wie viele Ramets desselben Klons unter jeweils gegebenen Umweltbedingungen das reproduktive Alter erreichen und inwieweit klonale Reproduktion zur Bildung der nächsten Generation beiträgt, falls nicht geeignete Verfahren der Klonidentifikation im adulten Stadium zur Verfügung stehen. In Abb. 4.3 ist ein Beispiel für im folgenden analysierte Baumgruppen dargestellt.

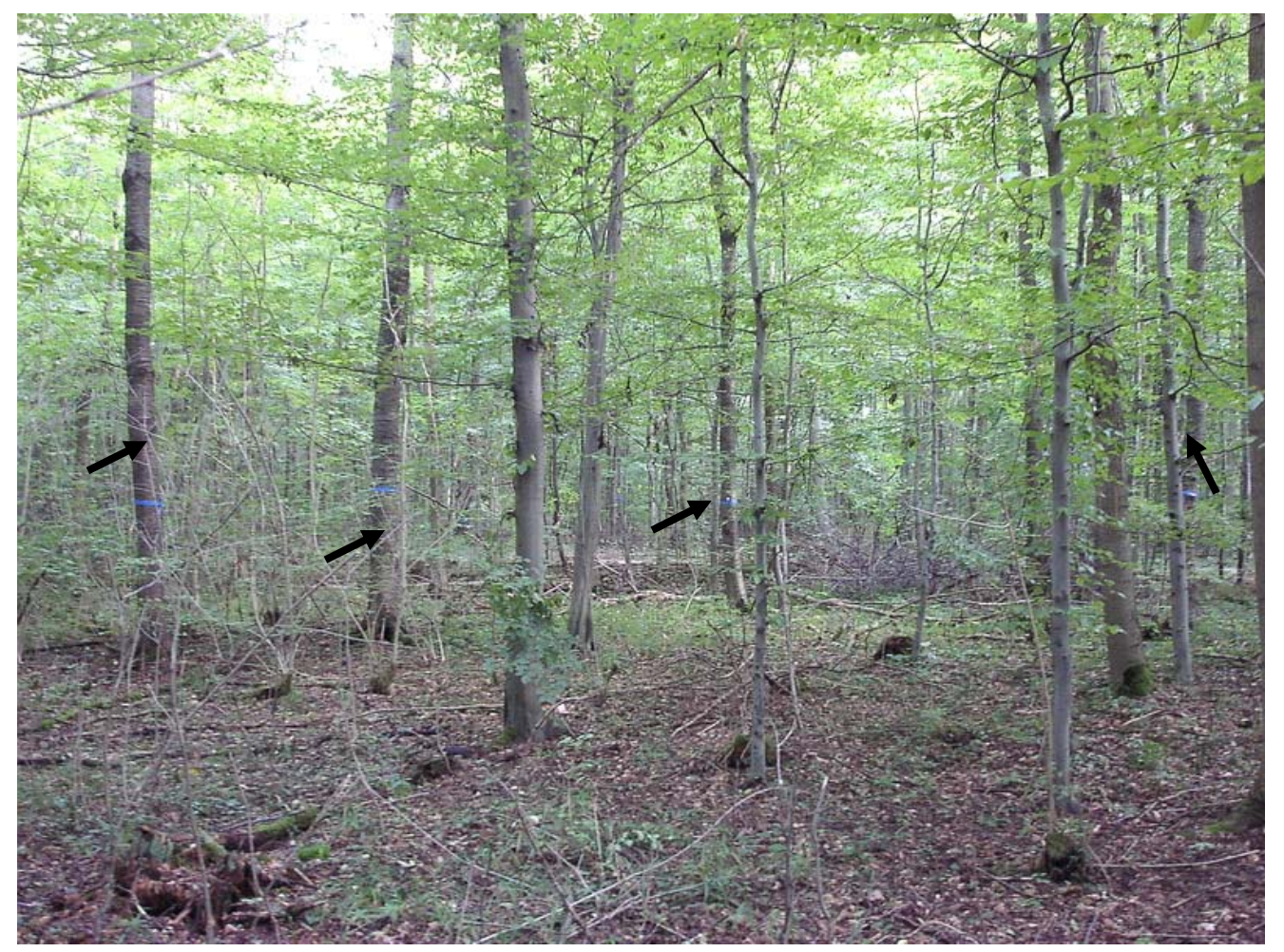

Abb. 4.3: Gruppe von Kirschenaltbäumen im Altbestand Roringen (Individuen mit Pfeilen gekennzeichnet)

Die meisten Methoden der Klonidentifikation sind von der Existenz geeigneter genetischer Marker abhängig. Dabei wird im allgemeinen versucht, die Hypothese, daß Individuen gleichen Multilocus-Genotyps (im folgenden MLG) aus sexueller Reproduktion stammen, zugunsten der Annahme asexueller Vermehrung als der einzigen Alternative zu verwerfen. Die gängigen statistischen Testverfahren basieren in der Regel auf der Berechnung der Wahrscheinlichkeit, $n$ Individuen mit gleichem MLG in einer Zufallsstichprobe der Größe $N$ vorzufinden. Dabei gilt die Annahme, daß die Häufigkeit eines MLG in der Grundgesamtheit das Ergebnis einer stochastisch unabhängigen Weitergabe von Genen und somit fehlender Genassoziationen darstellt (siehe FrASCARIA et al. 1993, PARKS \& WERTH 1993, IVEY \& RICHARDS 2001). Werden für den sexuellen Reproduktionsvorgang derartige Ei- 
genschaften angenommen, lassen geringe Erwartungshäufigkeiten eines zwei- oder mehrfach beobachteten MLG folglich vegetative Vermehrung vermuten.

Offensichtlich beruht diese Methode auf Annahmen, die nur für im Gleichgewicht befindliche, panmiktische Populationen gelten. Genau genommen können Genassoziationen aber nicht nur aufgrund asexueller Vermehrung, sondern auch im Zuge aller bedeutsamen evolutionären und adaptiven Prozesse erwartet werden. Diese Überlegung wird gestützt durch Ergebnisse einer kürzlich veröffentlichten Arbeit, die konzeptionelle und methodische Aspekte der Klonanalyse behandelt (GREGORIUS 2005).

So betreffen Anpassungen in der Regel eine Vielzahl von Merkmalen, welche in unterschiedlichen physiologischen oder adaptiven Beziehungen zueinander stehen. Neben diesem, im allgemeinen mit den Begriffen Koevolution und Koadaptation angesprochenen Sachverhalt, können auch Paarungssysteme bzw. Sexualsysteme genische Assoziationen auf- oder abbauen. Letzteres ist auch schon bei Problemen der individuellen Identifikation in Tierpopulationen (WAITS et al. 2001) als auch in der Forensik bekannt (DonNELly 1995). In Pflanzenvorkommen konnte unter anderem gezeigt werden, daß partielle Selbstbefruchtung den Aufbau von stochastischen Assoziationen zwischen homozygoten bzw. heterozygoten Genloci fördert (BENNET \& BINET 1956, ZIEHE 2003). Im speziellen Fall der Vogelkirsche mit ihrem gametophytischen Selbstinkompatibilitätssystem und ihrer rezedenten Lebensweise sind Erkenntnisse, die aus Modelluntersuchungen in panmiktischen oder Selbstbefruchtung erlaubenden Reproduktionssystemen stammen, bezüglich einer Einschätzung der für die Art typischen Genassoziationen vermutlich wenig hilfreich. Auch fehlen eindeutige Informationen über den reproduktiven Zusammenhalt und damit die effektiven Populationsgrößen dieser Art.

Es ist daher von grundlegender Bedeutung zu erfahren, welche Ausmaße Genassoziationen in natürlichen Populationen erreichen und inwieweit herkömmliche Verklonungsanalysen dadurch verfälscht werden können. Solche Maße existieren bislang im wesentlichen nur für zwei genetische Merkmale und nur in Verbindung mit Haplotypen (Gameten). Aus diesem Grunde wird hier ein kürzlich entwickeltes und allgemein anwendbares $\mathrm{Ma} ß$ für relative Genassoziation auf der Ebene von Genotypen und für eine beliebige Anzahl von Genloci verwendet (siehe GrEGORIUS 2004a). Da die Schätzung solcher Assoziationen für eine größere Anzahl genetischer Merkmale Stichprobengrößen von kaum realisierbarem Umfang erforderlich machen würden, sind hier alternative Methoden der Schätzung von Genassoziationen entwickelt worden.

\subsection{Konzeptionelle und statistische Vorgehensweise}

Bei Verwendung variabler Genmarker, wie z.B. SSRs (Mikrosatelliten), läßt die Beobachtung zweier oder mehrerer Kopien eines Multilocus-Genotyps (MLG) in einer Stichprobe zunächst meist asexuelle Vermehrung vermuten. Ein geeignetes statistisches Testverfahren zur Überprüfung der Hypothese, daß die beobachteten genetischen Strukturen auch tatsächlich auf klonale Reproduktion zurückzuführen 
sind, hängt nach GREGORIUS (2005) aber entscheidend von den Eigenschaften des sexuellen Reproduktionssystems einer Art bzw. einer Population ab.

Ist Panmixie charakteristisch für sexuelle Reproduktion, können Genotyphäufigkeiten erwartet werden, die aus dem Produkt der jeweiligen Allelhäufigkeiten resultieren. Wie schon erwähnt, scheint das bei Klonanalysen die vorherrschende Grundannahme darzustellen (siehe FrASCARIA et al. 1993, PARKS \& WERTH 1993, IVEY \& RICHARDS 2001). Verhältnisse dieser Art sind in natürlichen Pflanzenvorkommen aber kaum realisiert. Abweichungen der so erwarteten Genotyphäufigkeiten aufgrund nicht zufallsmäßiger Paarung zeigen sich meist in Abweichungen von Hardy-Weinberg-Proportionen oder auch in stochastischen Assoziationen zwischen Loci.

Im Verhältnis zu sexueller Reproduktion wird aufgrund klonaler Vermehrung ein Ansteigen der Häufigkeiten einiger MLG erwartet. Andererseits impliziert dies, daß die relativen Häufigkeiten anderer MLG möglicherweise abnehmen, falls der Prozeß der sexuellen Vermehrung alle möglichen Kombinationen von Genen hervorgebracht hat. Bei hohen Verklonungsgraden würde dies sogar die vollständige Abwesenheit einiger Genotypen bedeuten. Nach GREGORIUS (2005) werden zum Testen auf klonale Vermehrung folgende Informationen vorausgesetzt:

(1) Erkenntnisse über relative Genassoziationen als Ergebnis art- oder populationsspezifischer Mechanismen sexueller Reproduktion, wobei idealerweise zygotennahe Stadien zu untersuchen sind, da genetische Strukturen in späteren Stadien durch Viabilitätsselektion oder asexuelle Vermehrung modifiziert werden können;

(2) Beobachtungen genetischer Strukturen in späteren Entwicklungsstadien des Pflanzenvorkommens;

(3) Unterscheidbarkeit sexueller von klonaler Vermehrung auf der Grundlage von Häufigkeitsverteilungen von Genotypen.

Sind die für sexuelle Reproduktion im zygotennahen Stadium charakteristischen Genassoziationen bekannt, können diese unter Berücksichtigung der Allelhäufigkeiten späterer (vegetativer) Entwicklungsstadien weiterverwendet werden. Damit besteht die Möglichkeit, realistischere Hypothesen über Genotyphäufigkeiten, die für ausschließliche sexuelle Vermehrung anzunehmen sind, für jedes beliebige Stadium näherungsweise herzuleiten. Diese Häufigkeiten sollen dann auch die Grundlage eines statistischen Tests darstellen, welcher Abweichungen von hypothetisch angenommenen und tatsächlich beobachteten Häufigkeiten bestimmter MLG prüft und möglicherweise die sexuelle zugunsten der klonalen (asexuellen) Vermehrung falsifiziert (siehe Punkt (1) und (2)). Da diese Methode aber meist Stichprobengrößen von nicht realisierbarem Umfang erforderlich machen würde, wurden hier alternative Methoden der näherungsweisen Schätzung der unteren Grenze möglicher Genassoziationen auf der Grundlage von tatsächlich beobachteten Allelhäufigkeiten entwickelt.

Eine notwendige Unterscheidbarkeit der sexuellen von der asexuellen Vermehrung (siehe Punkt (3)) ist aber nicht mehr möglich, wenn alle Multilocus-Genotypen mit Häufigkeiten vertreten sind, wie sie auch für sexuelle Reproduktion erwartet werden können, und jeder Genotyp zusätzlich noch mit jeweils gleichem Faktor multi- 
pliziert (verklont) ist. Bei Einsatz variabler Genmarker ist dieses Problem allerdings zu vernachlässigen, da diesbezüglich unrealistisch hohe Stichprobengrößen zu untersuchen wären (siehe GREGORIUS 2005)

\subsubsection{Der Test auf klonale Vermehrung}

Das Testverfahren zur Überprüfung klonaler Vermehrung basiert auf dem Gedanken, daß die ausschließliche Abstammung eines bestimmten MLG aus sexueller Reproduktion unwahrscheinlich ist, wenn seine Häufigkeit eine hypothetisch erwartete Häufigkeit $H(g)$ überschreitet. Folglich kann die Hypothese, daß alle Kopien eines in einer Stichprobe beobachteten MLG aus sexueller Reproduktion stammen, falsifiziert werden, wenn die Anzahl der Kopien zu hoch ist. Die präzise Formulierung lautet:

Die Hypothese, daß alle $n$ beobachteten Kopien eines Genotyps in einer Stichprobe der Größe $N$ sexueller Abstammung sind, wird abgelehnt, wenn die Wahrscheinlichkeit $C_{n}^{N}$ (unter Berücksichtigung einer (hypothetischen) Häufigkeit $H(g)$ ), kleiner ist als das gewählte Signifikanzniveau $\varepsilon$. Dies wird durch folgende Binomialgleichung ausgedrückt:

$$
C_{n}^{N}(H)=\sum_{i=n}^{N}\left(\begin{array}{c}
N \\
i
\end{array}\right) H^{i}(1-H)^{N-i}<\varepsilon
$$

Im wesentlichen wird mit $C_{n}^{N}<\varepsilon$ die Hypothese falsifiziert, daß die relative Häufigkeit des betrachteten Genotyps in der Stichprobe kleiner oder gleich der hypothetisch angenommenen Häufigkeit $H(g)$ ist. Die Ablehnung der Hypothese besagt, daß nicht alle Individuen aus sexueller Reproduktion stammen; folglich müssen aber noch wenigstens zwei der Individuen einen Klon bilden. Werden weitere Markergenloci an den Individuen dieses MLG analysiert und es stellt sich heraus, daß an diesen zusätzlichen Loci nur noch $n$ - 1 der ursprünglichen $n$ Individuen genetisch identisch sind, stimmt dies folglich noch immer mit der Ablehnung der Hypothese ausschließlicher sexueller Reproduktion überein. Ein statistischer Febler 1. Art würde aber dann aufgedeckt, wenn nun alle Individuen, die für die ursprünglich untersuchten Markerloci Identität aufwiesen, sich an den zusätzlich analysierten Loci unterscheiden würden. Definitionsgemäß wird die Hypothese ausschließlicher sexueller Reproduktion der Individuen mit identischem MLG für alle Grenzhäufigkeiten $H(g)$, für welche die Wahrscheinlichkeit $C_{n}^{N} \geq \varepsilon$ ist, nicht verworfen. Das schließt auch die Fälle mit ein, in denen ein statistischer Fehler 1. Art durch die Analyse weiterer Genloci entdeckt worden ist. Um diesen statistischen Fehler 1. Art zu vermeiden, ist der ursprünglich angenommene Wert $H(g)$, für den $C_{n}^{N}(H)<\varepsilon$, auf den Wert anzuheben, bis $C_{n}^{N}(H) \geq \varepsilon$. 


\subsubsection{Test auf Zugehörigkeit genetisch identischer Individuen zu einem einzigen Klon}

In den meisten Arbeiten (wie auch in dieser) liegt das Hauptinteresse darin, zu erfahren, ob alle Kopien eines MLG auch Ramets eines einzigen Klonkomplexes darstellen. Die Hypothese der Zugehörigkeit zu einem einzigen Klon kann nicht abgelehnt werden, wenn je zwei Träger identischer Kopien eines MLG mit hoher Wahrscheinlichkeit nicht zu verschiedenen Genets gehören, also $C_{2}^{N}(H)<\varepsilon$ ist [vgl. "Arbeitsschritte für ein statistisches Testverfahren bezüglich klonaler Vermehrung" in Box 4.2 und die zugrunde liegende Theorie in GREGORIUS (2004a)]. Folglich impliziert $C_{2}^{N}(H) \geq \varepsilon$ das Gegenteil. In diesem Fall kann die Annahme, daß die beobachteten Kopien eines MLG aus (mindestens zwei) verschiedenen Zygoten hervorgegangen sind und demnach zu verschiedenen Genets gehören, nicht falsifiziert werden. Das schließt auch den Fall mit ein, daß alle Kopien des fraglichen MLG das Ergebnis sexueller Reproduktion sind. Für das Entdecken eines statistischen Fehlers 1. Art reicht es also aus, wenn nach der Analyse von zusätzlich untersuchten Genloci wenigstens ein Individuum sich von den übrigen unterscheidet. Dieser Fehler hätte nur dann vermieden werden können, wenn die (hypothetische) Häufigkeit $H(g)$ für die ursprünglich untersuchten Genloci wenigsten so hoch gewählt worden wäre, daß $\operatorname{sich} C_{2}^{N}(H) \geq \varepsilon$ ergeben hätte.

In der gegenwärtigen Literatur gilt bei der Überprüfung von Hypothesen, in denen sexuelle gegen klonale Vermehrung getestet werden sollen, nahezu ausschließlich die Annahme vollständig zufallsmäßiger Genassoziationen als Charakteristika des sexuellen Reproduktionssystems. Folglich resultiert die Grenzhäufigkeit eines bestimmten MLG $(H(g))$ aus der Multiplikation der Häufigkeiten derjenigen Allele, welche im fraglichen MLG vertreten sind. Aus diesem Grunde beginnen wir, bezüglich dieser Grenzhäufigkeit $H(g)$, unsere Analyse mit der gleichen Annahme, welche wir dann später auf Haltbarkeit überprüfen wollen.

\subsubsection{Nutzung des statistischen Fehlers 1. Art zur Abschätzung relativer Genassoziationen}

Die Möglichkeit, einen statistischen Fehler 1. Art zu begehen, sowie dessen informativer Nutzen sollen in diesem Kapitel näher betrachtet werden. Dabei wird zunächst von der klassischen Hypothese zufallsmäßiger Genassoziation ausgegangen. Zu diesem Zweck wurden zu den ursprünglich untersuchten sechs Mikrosatelliten-Loci noch weitere Marker hinzugezogen. In den Beständen Roringen und Settmarshausen wurden zusätzlich zwei weitere Mikrosatelliten (UDP96-001 und UDP98-411) und im Bestand Wibbecke sechs polymorphe Isoenzymsysteme (PGM, IDH, 6-PGDH, SKDH, AAT und ACO; siehe KOWNATZKI 2002) untersucht. Das Entdecken eines statistischen Fehlers 1. Art mit Hilfe dieser zusätzlichen Marker auf der Basis von $C_{2}^{N}(H)$ gibt Anlaß, die Annahme vollständig zufallsmäßiger Genassoziation als zuverlässige Grundlage für die Berechnung der (hypothetischen) Genotyphäufigkeit $H(g)$ neu zu überdenken. 
Um einen solchen Fehler zu vermeiden, ist der Wert für $H(g)$ mindestens so hoch zu wählen, daß $C_{2}^{N}(H) \geq \varepsilon$ sichergestellt ist (s. Kapitel 4.2.2). Dabei gilt, daß die Häufigkeit $H(g)$ innerhalb eines unteren $[\alpha(g)]$ und oberen $[\omega(g)]$ Grenzwertes liegen muß, welche durch die Allelhäufigkeiten innerhalb der Population bestimmt werden [siehe Box 4.2, Gleichung (1)]. Unter Berücksichtigung dieser Grenzen, sind die erwarteten Genotyphäufigkeiten von folgenden Parametern abhängig [siehe Box 4.2, Gleichungen (2) bis (4)]:

(a) Von den relativen Häufigkeiten derjenigen Allele innerhalb der Population, welche im fraglichen Genotyp $(g)$ vertreten sind, und

(b) von einem relativen $\mathrm{Ma} \beta$ der Genassoziation $A_{r}(\mathrm{~g})$, welches zwischen -1 und +1 variiert. Der Wert 0 gilt für den Fall vollständig zufallsmäßiger Genassoziation. Der Extremwert von -1 wird nur dann auftreten, wenn ein Genotyp innerhalb einer Population nicht beobachtet werden kann, obwohl er aufgrund der Allelhäufigkeiten hätte gebildet werden können. Dabei ist allerdings zu beachten, daß unter Verwendung hochvariabler Marker (wie z.B. SSRs) immens große Stichproben zu untersuchen wären, um sicherzustellen, daß alle nicht gefundenen Genotypen auch nicht in der Grundgesamtheit vertreten sind. Der Wert +1 ist für den Fall denkbar, in dem die beobachtete Genotyphäufigkeit gleich der oberen Grenze der möglichen Genotyphäufigkeit ist.

Der kausale Zusammenhang zwischen den einzelnen Parametern und ihre biologische Bedeutung soll nun im folgenden näher erläutern werden:

Bei steigendem $\mathrm{Ma} ß$ der relativen Genassoziation $A_{r}(g)$ steigt auch die (hypothetisch erwartete) Häufigkeit eines Genotyps $H(g)$, vorausgesetzt die Allelhäufigkeiten innerhalb einer Population bleiben konstant. Gleichzeitig steigt auch die Wahrscheinlichkeit $C_{n}^{N}(H)$ bei konstanten $n$ und $N$. Bewegt sich der Wert $A_{r}(g)$ von -1 in Richtung +1 und überschreitet die Wahrscheinlichkeit $C_{2}^{N}(H)$ dabei irgendwann das Signifikanzniveau $\varepsilon$, so kann für kleine $A_{r}(g)\left(\rightarrow C_{2}^{N}(H)<\varepsilon\right)$ ausschließlich klonale und für ausreichend hohe Werte $\left(\rightarrow C_{2}^{N}(H) \geq \varepsilon\right)$ auch sexuelle Reproduktion an dem Zustandekommen der jeweiligen Kopien des beobachteten MLG beteiligt sein. Wenn die Hypothese ausschließlicher klonaler Vermehrung (z.B. unter der klassischen Annahme von $\left.A_{r}(g)=0\right)$ nicht abgelehnt werden kann und falls die Hinzunahme weiterer Genmarker genetische Variation zwischen den Ramets des zunächst angenommenen Klons entdeckt, dann wurde ein statistischer Fehler 1. Art begangen.

Folglich ist ein höherer Wert für $A_{r}(g)$ anzunehmen, um diesen statistischen Fehler 1. Art zu vermeiden. Dieser Wert muß mindestens so hoch gewählt werden, daß man eine (hypothetisch erwartete) Genotyphäufigkeit $H(g)$ erhält, für welche $C_{2}^{N}(H) \geq \varepsilon$ gilt. Der so erhaltene Wert $A_{r}(g)$ stellt damit gewissermaßen die untere Grenze des Schätzwertes für relative Genassoziation dar (mit einer Wahrscheinlichkeit von $1-\varepsilon$ ), welcher charakteristisch für den beobachteten MLG ist.

$H(g)$ kann nach Umformung der Gleichung (5) in Box 4.2 und nach Einsatz des gewählten Signifikanzniveaus $\varepsilon$ sowie der Stichprobengröße $N$ berechnet werden. Durch Umformung von Gleichung (4) kann nun diejenige untere Grenze für $A_{r}(g)$ ermittelt werden, durch die ein statistischer Fehler 1. Art hätte vermieden werden können (modifiziert nach GREGORIUS 2005). 
Die untere $(\alpha(g))$ und obere $(\omega(g))$ Grenze der relativen Häufigkeit eines Genotyps $g$, welche durch die Häufigkeiten derjenigen Allele innerhalb der Population bestimmt werden, die in Genotyp $g$ vertreten sind. Die Häufigkeit $P(g)$ des Genotyps $g$ liegt damit innerhalb des Intervals $\alpha(\boldsymbol{g}) \leq \boldsymbol{P}(\boldsymbol{g}) \leq \boldsymbol{\omega}(\boldsymbol{g})$.

$$
\begin{gathered}
\alpha(g)=\max \left\{\sum_{l=1}^{L}\left[\delta_{i j ; l} \cdot \max \left\{p_{i ; l}+p_{j ; l}-1,0\right\}\right]-(L-1), 0\right\} \\
\omega(g)=\min _{l}\left[\left(2-\delta_{i j ; l}\right) \cdot \min \left\{p_{i ; l}, p_{j ; l}\right\}\right]
\end{gathered}
$$

i;/ und $j ; /$ kennzeichnen die beiden Allele, die an Locus / vertreten sind;

$p_{i j,}$ bezeichnet die Häufigkeit des Allels $i$ am Locus / innerhalb der Population;

$\delta_{i j ;}=0$, wenn $i \neq j$ (heterozygoter Locus), andernfalls $\delta_{i j ;}=1$ (homozygoter Locus)

Häufigkeit $\widetilde{P}(g)$ des Genotyps $g$ unter der Annahme stochastischer Unabhängigkeit der beteiligten genetischen Einheiten:

$$
\tilde{P}(g)=\prod_{l=1}^{L}\left(2-\delta_{i j ; l}\right) \cdot p_{i ; l} \cdot p_{j ; l}
$$

$\boldsymbol{A}_{\boldsymbol{r}}(\boldsymbol{g})$ ist ein Maß für relative Genassoziation, das die zufallsmäßige Assoziation von Allelen in den Mittelpunkt eines Intervalls zwischen -1 und +1 stellt. Die Extremwerte stellen jeweils die obere und die untere Grenze der Häufigkeit eines Genotyps $g$ dar (siehe (1))

$$
A_{r}(g)= \begin{cases}\frac{P(g)-\widetilde{P}(g)}{\omega(g)-\widetilde{P}(g)} & \text { if } P(g) \geq \widetilde{P}(g) \\ \frac{P(g)-\widetilde{P}(g)}{\widetilde{P}(g)-\alpha(g)} & \text { if } P(g) \leq \widetilde{P}(g)\end{cases}
$$

$P(g)=$ beobachtete relative Häufigkeit des betrachteten Multilocus-Genotyps ( $g$ )

$\boldsymbol{H}(\boldsymbol{g})$ ist die Häufigkeit des Genotyps $\boldsymbol{g}$ als eine Funktion der relativen

Genassoziation. Dieser Wert berechnet sich durch Ersetzen von $P(g)$ durch $H(g)$ in Gleichung (3) und durch anschließendes Umformen zu $H(g)$ :

$$
H(g)=\left\{\begin{array}{l}
\tilde{P}(g)+(\omega(g)-\widetilde{P}(g)) \cdot A_{r}(g) \text { if } A_{r}(g) \geq 0 \\
\widetilde{P}(g)+(\widetilde{P}(g)-\alpha(g)) \cdot A_{r}(g) \text { if } A_{r}(g) \leq 0
\end{array}\right.
$$

Arbeitsschritte für ein statistisches Testverfahren bezüglich klonaler Vermehrung Hypothese: Stammen alle $n$ Kopien des Genotyps $g$, die in einer Stichprobe vom Umfang $N$ beobachtet wurden, aus klonaler Vermehrung?

1. Bestimme die Allelhäufigkeiten $p_{i, 1}$ in der Stichprobe

2. Bestimmung von $A_{r}(g)$ durch begründete Annahme

3. Berechne $H$ gemäß Gleichung (4)

4. Berechne $\mathrm{C}_{2}{ }^{N}=1-(1-H)^{N-1}(1+(N-1) H)$

5. Falls $\mathrm{C}_{2}{ }^{N}<\varepsilon$ [z.B. $\left.=0.05\right]$, kann die Hypothese der Zugehörigkeit aller

Träger eines Genotyps $g$ zu einem einzigen Klon nicht falsifiziert werden.

Das Prinzip dieses Verfahrens der Abschätzung des Ausmaßes von relativen Genassoziationen ist im übrigen auch folgendermaßen verwendbar: Es ist z.B. möglich, aus einem Satz von untersuchten Genloci ein oder mehrere herauszusuchen, um diese dann als "zusätzliche" Marker im obigem Sinne zu verwenden, während die übrigen Loci dazu verwendet werden, eine vorläufige Charakterisierung der MLG 
vorzunehmen. Falls einer der Genotypen mit einer Anzahl von $n \geq 2$ beobachtet wird, die Individuen dieses vermuteten Klons sich aber an einem oder mehreren dieser "zusätzlichen" Genloci unterscheiden, kann wiederum die untere Grenze der relativen Genassoziation für einen ausgewählten Satz von Genloci geschätzt werden. Sind evtl. artspezifische Rahmenwerte relativer Genassoziationen ermittelt, können Schätzungen der Verklonung möglicherweise mit weniger Genmarkern und damit auch mit weniger Aufwand betrieben werden.

\subsubsection{Maße zur Beschreibung der Anteile sexueller und asexueller Vermeh- rung innerhalb von Populationen}

Um mögliche Einflüsse verschiedener anthropogen verursachter Umweltbedingungen (hier: waldbauliche Verfahren) auf die beiden Reproduktionsmodi der Vogelkirsche analysieren zu können, ist die Bestimmung des Anteils der aus asexueller Vermehrung hervorgegangenen Individuen in den jeweiligen Beständen von großer Bedeutung. CHUNG et al. (2000) beschreiben klonale Anteile innerhalb von Populationen mit dem Quotienten G/N (siehe auch ELLSTRAND \& RoOSE 1987), wobei $G$ die Anzahl unterschiedlicher Genotypen und $N$ die Gesamtzahl an Individuen darstellt.

Dieser Parameter mißt einerseits zwar den Anteil unterscheidbarer Genotypen bezogen auf die Gesamtzahl an Individuen eines Kollektivs, andererseits zeigt sich aber, daß bei sehr ähnlichen Werten für diesen Parameter durchaus sehr unterschiedliche Situationen zutreffen können.

Deshalb sollen hier eine Reihe weiterer Parameter Verwendung finden, wobei folgende Annahmen gelten (siehe auch KOWNATZKI 2002):

Annahme (1): Bäume mit einmaligem MLG sind das Ergebnis sexueller Reproduktion. $N_{S}$ repräsentiert die Anzahl derjenigen Individuen, deren Genotypen nur einmal vertreten und somit nach Annahme generativ reproduziert sind.

Annahme (2): Individuen mit einem MLG, der mit einer absoluten Häufigkeit $>1$ vorkommt, sind aus asexueller Vermehrung hervorgegangen.

Damit stellt der Parameter $N_{C}=N-N_{S}$ die Anzahl asexuell entstandener Individuen in einem Kollektiv der Größe $\mathrm{N}$ dar. $G_{C}=G-N_{S}$ quantifiziert die Anzahl asexuell reproduzierter MLG. Der Anteil an Individuen innerhalb der Kollektive, der aus asexueller Vermehrung stammt, kann demzufolge durch den Quotienten $N_{C} / N$ dargestellt werden.

Da Gene das grundlegende genetische Potential für die Erzeugung genotypischer Vielfalt und damit auch Anpassungsfähigkeit in Populationen darstellen, soll in dem Zusammenhang auch die genische Diversität innerhalb der Bestände näher betrachtet werden. Dabei sind die Bestände aber nicht nur in ihrer Gesamtheit zu untersuchen. Es soll insbesondere die Bedeutung der asexuellen und sexuellen Komponente bezüglich der genischen Diversität getrennt analysiert werden. Die genische Diversität (=effektive Anzahl Allele) wird durch jeweils folgende Parameter bestimmt (vgl. GREGORIUS 1978): 


$$
\begin{gathered}
v_{k}=\left[\sum_{i=1}^{n_{k}}\left(p_{i}{ }^{k}\right)^{2}\right]^{-1} \\
\begin{array}{l}
v_{k}=\text { allelische Diversität eines Kollektivs am k-ten Genlo- } \\
\text { cus; } n_{k}=\text { Anzahl der Allele am k-ten Locus; } p_{i}{ }^{k}=\text { Häufig- } \\
\text { keit des i-ten Allels am k-ten Genlocus; } v_{\text {Genpool }}=\text { mittlere } \\
\text { effektive Anzahl von Allelen }(=\text { harmonisches Mittel von }
\end{array} \\
v_{\text {Genpool }}=m \cdot\left[\sum_{k=1}^{m} \frac{1}{\left.v_{k}\right) ; m=\text { Anzahl untersuchter Loci (GREGORIUS 1978) }}\right.
\end{gathered}
$$

Damit ist aber noch nicht die klonale Diversität innerhalb der Bestände bestimmt. Dies soll analog zur genischen (allelischen) Diversität durch die effektive Anzahl an MLG $\left(v_{\text {Klon }}\right)$ unter den asexuell entstandenen charakterisiert werden.

Ein zentrales Problem dabei ist allerdings die Tatsache, daß nur diejenigen MLG, welche in mindestens zweifacher Kopie beobachtet wurden, mit den in den vorhergehenden Kapiteln hergeleiteten Methoden als asexuell entstandene identifiziert werden können. Es ist beispielsweise nicht mehr nachvollziehbar, ob ein Individuum mit einmaligem MLG nicht auch das Ergebnis asexueller Vermehrung sein kann. Dies wäre nämlich dann Fall, wenn dieses Individuum als einziges einer Gruppe klongleicher Ramets bis zum heutigen Zeitpunkt überlebt hätte. Deshalb ist es hier nur möglich, eine untere Grenze des Anteils asexueller Individuen zu bestimmen. Es ist daher davon auszugehen, daß dieser Wert eher eine Unterschätzung des wahren Anteils Asexueller darstellt.

\subsection{Ergebnisse}

\subsubsection{Genetische Variation an sechs SSR-Loci innerhalb der drei Kirschen- altbestände}

In drei Altbeständen der Wildkirsche, in denen typische Strukturen verschiedener forstlicher Betriebstypen (heutige Hochwald- und ehemalige Mittelwaldwirtschaft) erkennbar sind, wurden nach der Analyse von zunächst sechs nuklearen Mikrosatelliten folgende genetische Variationsparameter berechnet: Die mittlere Anzahl von Allelen pro Locus, die Genpool-Diversität sowie die hypothetische gametische Multilocus-Diversität.

Die Anzahl gefundener Allele variierte von 5,5 pro Locus in Roringen und Wibbecke bis 6,3 in Settmarshausen. Die Bestände unterschieden sich insbesondere auch in ihren Diversitätsmaßen. Bei Betrachtung aller Individuen, also auch derjenigen, die in mindestens zwei Kopien innerhalb der Kollektive beobachtet wurden, konnte in Roringen eine Genpooldiversität von 2,88 (zwischen 2,01 bis 4,02 an den einzelnen Loci) und in Wibbecke von 3,00 (1,51 bis 4,86) ermittelt werden. In Settmarshausen war die größte Genpooldiversität von 3,60 effektiven Allelen pro Locus (in einem Bereich von 2,60 bis 6,81 an den einzelnen Loci) zu verzeichnen. Die daraus folgenden hypothetischen gametischen Multilocus-Diversitäten der einzelnen Bestände betragen 694,66 [Roringen] < 1.261,16 [Wibbecke] < 2.885,49 [Settmarshausen](siehe Tab. 4.2). 


\begin{tabular}{|c|c|c|c|c|c|c|c|}
\hline \multirow{2}{*}{$\begin{array}{c}\text { SSR-Bezeichnung/ } \\
\text { Allele }\end{array}$} & \multicolumn{3}{|c|}{ Allelhäufigkeiten } & \multirow{2}{*}{$\begin{array}{l}\text { SSR-Bezeichnung/ } \\
\text { Allele }\end{array}$} & \multicolumn{3}{|c|}{ Allelhäufigkeiten } \\
\hline & Ror & Wib & Set & & Ror & Wib & Set \\
\hline \multicolumn{2}{|l|}{ UDP96-005 } & \multicolumn{6}{|c|}{ UDP98-021 } \\
\hline 2 & 0.393 & 0.160 & 0.231 & 2 & 0.000 & 0.032 & 0.077 \\
\hline 3 & 0.286 & 0.019 & 0.154 & 3 & 0.205 & 0.167 & 0.192 \\
\hline 5 & 0.071 & 0.019 & 0.192 & 5 & 0.134 & 0.006 & 0.154 \\
\hline \multicolumn{2}{|l|}{ UDP98-410 } & \multicolumn{6}{|c|}{ UDP98-412 } \\
\hline 2 & 0.214 & 0.308 & 0.372 & 1 & 0.134 & 0.071 & 0.013 \\
\hline 4 & 0.571 & 0.237 & 0.154 & 2 & 0.009 & 0.019 & 0.000 \\
\hline 5 & 0.062 & 0.288 & 0.333 & 3 & 0.045 & 0.141 & 0.064 \\
\hline 6 & 0.009 & 0.000 & 0.013 & 5 & 0.232 & 0.224 & 0.346 \\
\hline \multicolumn{2}{|l|}{ ВРРСТ 034} & \multicolumn{6}{|c|}{ ВРРСТ 040} \\
\hline 1 & 0.018 & 0.064 & 0.051 & 1 & 0.045 & 0.090 & 0.013 \\
\hline 2 & 0.375 & 0.321 & 0.115 & 2 & 0.143 & 0.276 & 0.205 \\
\hline 3 & 0.134 & 0.167 & 0.128 & 3 & 0.571 & 0.064 & 0.333 \\
\hline 4 & 0.009 & 0.250 & 0.115 & 4 & 0.232 & 0.231 & 0.064 \\
\hline 5 & 0.000 & 0.000 & 0.038 & 5 & 0.000 & 0.000 & 0.026 \\
\hline 6 & 0.071 & 0.026 & 0.141 & 6 & 0.000 & 0.000 & 0.179 \\
\hline 7 & 0.134 & 0.141 & 0.179 & 7 & 0.009 & 0.340 & 0.179 \\
\hline 8 & 0.259 & 0.032 & 0.218 & & & & \\
\hline 9 & 0.000 & 0.000 & 0.013 & & & & \\
\hline
\end{tabular}

Tab. 4.1: An sechs Mikrosatelliten-Genloci beobachtete Allelhäufigkeiten in den Kirschenbeständen Roringen (Ror), Wibbecke (Wib) und Settmarshausen (Set);

Kalkulation unter Einbezug aller Individuen, also auch jener, welche identische Multilocus-Genotypen aufweisen

\begin{tabular}{cccccccc}
\hline $\begin{array}{c}\text { Locus- } \\
\text { Bezeichnung }\end{array}$ & $\begin{array}{c}\text { Längenbereiche der } \\
\text { beobachteten Allele }\end{array}$ & \multicolumn{3}{c}{$\begin{array}{c}\text { Anzahl } \\
\text { beobachteter Allele }\end{array}$} & \multicolumn{4}{c}{ Anzahl } \\
& & Ror & Wib & Set & Ror & Wib & Set \\
\hline UDP96-005 & $110-156$ & 5 & 5 & 5 & 3.47 & 2.49 & 3.67 \\
UDP98-021 & $100-114$ & 3 & 4 & 5 & 2.01 & 1.51 & 2.60 \\
UDP98-410 & $116-138$ & 6 & 5 & 6 & 2.56 & 3.85 & 3.54 \\
UDP98-412 & $87-129$ & 7 & 7 & 6 & 3.90 & 4.88 & 2.78 \\
BPPCT 034 & $222-260$ & 7 & 7 & 9 & 4.02 & 4.57 & 6.81 \\
BPPCT 040 & $116-142$ & 5 & 5 & 7 & 2.48 & 3.89 & 4.49 \\
& & & & & 2.88 & 3.00 & 3.60 \\
& Genpool-Diversität & & & & & & \\
& Hypothetische gametische Multilocus-Diversität & 694.66 & 1261.16 & 2885.49 \\
\hline
\end{tabular}

Tab. 4.2: Genetische Variationsparameter ermittelt an sechs SSR-Loci für drei Kirschenbestände (Roringen (Ror), Wibbecke (Wib) und Settmarshausen (Set)); der Bereich der gefundenen Längenvariation der gefundenen Allele in Basenpaaren (bp), die Anzahl der beobachteten Allele an den einzelnen Loci, die genische Diversität (Anzahl effektiver Allele an den einzelnen Loci) sowie die Genpool- und die hypothetische gametische Multilocus-Diversität. 
Im allgemeinen läßt das eine höhere Effizienz bei der Klonidentifikation in Settmarshausen als beispielsweise in Roringen vermuten. Die Allelhäufigkeiten der einzelnen Bestände sind in Tab. 4.1 aufgelistet. Deren Kalkulation erfolgte unter Berücksichtigung aller Individuen (einschließlich klongleicher Ramets).

\subsubsection{Test auf Verklonung ohne Berücksichtigung relativer Genassoziatio- nen}

In Bezug auf die Fragestellung inwieweit identische MLG nun auch demselben Klon angehören, wurde das unter 4.2.2 vorgestellte Testverfahren $C_{2}^{N}(H)$ verwendet. Dabei wurde zunächst angenommen, daß das Zustandekommen der MLG aus sexueller Reproduktion die Folge zufallsmäßiger Genassoziation darstellt. Deshalb wurde für das $\mathrm{Ma} \beta$ der relativen Genassoziation $A_{r}(g)$ auch der Wert Null gewählt (siehe Tabellen 4.3). Das statistische $\mathrm{Maß} C_{2}^{N}(H)$ wurde für alle MLG ermittelt, welche in mindestens zwei Kopien in den Beständen beobachtet werden konnten. Die durchweg höchst signifikanten Werte variierten zwischen $1,8033 \cdot 10^{-6}$ und $2,4647 \cdot 10^{-11}$ in Roringen, zwischen $7,9074 \cdot 10^{-6}$ und $3,1075 \cdot 10^{-13}$ in Wibbecke sowie zwischen $1,3239 \cdot 10^{-5}$ und $7,7284 \cdot 10^{-12}$ in Settmarshausen. Noch erheblich niedrigere Werte konnten für $C_{n}^{N}(H)$ kalkuliert werden. Dies bedeutet, daß die Wahrscheinlichkeit ausschließlich sexueller Reproduktion innerhalb von Individuengruppen mit identischem MLG gegen Null tendiert. Unter o.g. Annahmen kann demnach wegen der kleinen Werte von $C_{2}^{N}(H)$ und $C_{n}^{N}(H)$ vermutet werden, daß alle Kopien der beobachteten MLG das Ergebnis klonaler Vermehrung sind.

\subsubsection{Die Schätzung einer unteren Grenze relativer Genassoziation nach Be- obachtung statistischer Fehler 1. Art}

Die höchst signifikanten Werte, welche für $C_{2}^{N}(H)$ ermittelt wurden, stellten sich aber teilweise als irreführend heraus, als zusätzliche Genmarker analysiert wurden (zwei weitere nukleare Mikrosatelliten in den Beständen Roringen und Settmarshausen sowie sechs polymorphe Isoenzyme in Wibbecke). So konnten für insgesamt fünf MLG (Ror1, Wib1, Wib3, Wib4 und Wib6) durch die Hinzunahme wieterer Marker gezeigt werden, daß nicht alle Kopien eines MLG auch Ramets eines einzigen Klonkomplexes darstellten. In Bezug auf die oben gemachten Ausführungen (siehe Kap. 4.1.2 und Kap. 4.2.2) ist es somit sehr wahrscheinlich, daß eine stochastisch unabhängige Weitergabe von Genen und somit fehlende Genassoziationen keine geeignete Annahme für die oben gemachten statistischen Kalkulationen darstellen. Wie schon im konzeptionellen Ansatz hervorgehoben wurde, kann ein so entstandener statistischer Fehler 1. Art vermieden werden, in dem der Parameter für relative Genassoziation $A_{r}(g)$ auf ein bestimmtes Mindestmaß angehoben wird. Dabei sollte garantiert sein, daß $C_{2}^{N}(H) \geq \varepsilon$ zumindest für diejenigen MLG gilt, bei denen o.g. Fehler aufgetreten ist. Dieser (untere) Grenzwert für $A_{r}(g)$ wurde nun bei der Kalkulation des statistischen Testwertes $C_{2}^{N}(H)$ eingesetzt, und zwar für alle diejenigen MLG, die in mindestens zwei Kopien in den untersuchten Kirschenaltbeständen beobachtet wurden. 


\begin{tabular}{|c|c|c|c|c|}
\hline $\begin{array}{l}\text { Multilocus- } \\
\text { Genotyp }\end{array}$ & $\begin{array}{c}\text { Anzahl } \\
\text { Individuen }\end{array}$ & $C_{n}^{N}$ & $C_{2}{ }^{N}$ & $\begin{array}{l}\text { Fehler 1. Art entdeckt an } \\
\text { Marker (Locus) }\end{array}$ \\
\hline Ror1 & 3 & $1.3793 \cdot 10^{-10}$ & $2,2898 \cdot 10^{-07}$ & SSR (UDP96-001, UDP98-411) \\
\hline Ror2 & 3 & $2.2205 \cdot 10^{-15}$ & $2,4674 \cdot 10^{-11}$ & \\
\hline Ror3 & 2 & $3.8747 \cdot 10^{-07}$ & $3,8747 \cdot 10^{-07}$ & \\
\hline Ror4 & 4 & $5.0660 \cdot 10^{-13}$ & $1,8033 \cdot 10^{-06}$ & \\
\hline Wib1 & 8 & $3,8858 \cdot 10^{-15}$ & $3,8320 \cdot 10^{-06}$ & Isoenzyme (PGM, IDH, 6-PGDH, SKDH, ACO) \\
\hline Wib2 & 2 & $3.8320 \cdot 10^{-11}$ & $3.8320 \cdot 10^{-11}$ & \\
\hline Wib3 & 7 & $2.6645 \cdot 10^{-15}$ & $1,9343 \cdot 10^{-07}$ & Isoenzyme (6-PGDH, PGM, SKDH) \\
\hline Wib4 & 6 & 0 & $3,2969 \cdot 10^{-07}$ & Isoenzyme (IDH) \\
\hline Wib5 & 3 & $5.4934 \cdot 10^{-13}$ & $1,1209 \cdot 10^{-08}$ & \\
\hline Wib6 & 8 & 0 & $7,9074 \cdot 10^{-06}$ & Isoenzyme (IDH, SKDH) \\
\hline Wib7 & 15 & $4.3299 \cdot 10^{-15}$ & $1,1990 \cdot 10^{-08}$ & \\
\hline Wib8 & 3 & $1.8541 \cdot 10^{-14}$ & $1,1904 \cdot 10^{-09}$ & \\
\hline Wib9 & 2 & $1.6718 \cdot 10^{-11}$ & $1,6718 \cdot 10^{-11}$ & \\
\hline Wib10 & 2 & $6.8013 \cdot 10^{-8}$ & $6,8013 \cdot 10^{-08}$ & \\
\hline Wib11 & 3 & 0 & $3,1075 \cdot 10^{-13}$ & \\
\hline Wib12 & 5 & 0 & $8,8324 \cdot 10^{-12}$ & \\
\hline Wib13 & 3 & $1.8541 \cdot 10^{-14}$ & $1,5363 \cdot 10^{-10}$ & \\
\hline Set1 & 2 & $2.8728 \cdot 10^{-10}$ & $2.8728 \cdot 10^{-10}$ & \\
\hline Set2 & 4 & 0 & $1.6375 \cdot 10^{-9}$ & \\
\hline Set3 & 3 & $7.3318 \cdot 10^{-11}$ & $2.9692 \cdot 10^{-7}$ & \\
\hline Set4 & 2 & $1.3239 \cdot 10^{-5}$ & $1.3239 \cdot 10^{-5}$ & \\
\hline Set5 & 2 & $1.1770 \cdot 10^{-7}$ & $1.1770 \cdot 10^{-7}$ & \\
\hline Set6 & 2 & $7.7284 \cdot 10^{-12}$ & $7.7284 \cdot 10^{-12}$ & \\
\hline Set7 & 2 & $2.8117 \cdot 10^{-10}$ & $2.8117 \cdot 10^{-10}$ & \\
\hline Set8 & 2 & $3.6917 \cdot 10^{-10}$ & $3.6917 \cdot 10^{-10}$ & \\
\hline Set9 & 2 & $1.5363 \cdot 10^{-10}$ & $1.5363 \cdot 10^{-10}$ & \\
\hline
\end{tabular}

Tab. 4.3: Multilocus-Genotypen (MLG), welche in den Beständen Roringen (Ror1 bis Ror4), Wibbecke (Wib1 bis Wib13) sowie Settmarshausen (Set1 bis Set9) bezüglich der sechs Mikrosatelliten (UDP96-005, UDP98-021, UDP98-410, UDP98412, BPPCT 034 und BPPCT 040) in wenigstens zwei Kopien vorliegen; die Anzahl Individuen mit beobachteten identischen MLG; die Testwerte $C_{n}{ }^{N}$ und $C_{2}{ }^{N}$ für die statistische Beurteilung asexueller vs. sexueller Reproduktion; der Markertyp, mit dessen Hilfe der statistische Fehler 1. Art entdeckt wurde

Wie aus Gleichung (1) der Box $4.2 \mathrm{zu}$ entnehmen ist, hängt die untere und die obere Grenze der Häufigkeiten eines MLG von den Häufigkeiten seiner Allele 
innerhalb des Kollektivs ab. Die untere Grenze $\alpha(g)$ ist immer dann gleich Null, wenn wenigstens ein Genlocus heterozygot ist. Dies ist für alle beobachteten MLG der Fall. Die obere Grenze $\omega(g)$ variiert über alle drei Bestände zwischen 0.038 und 0.308 .

Bei der Betrachtung der Ergebnisse in den beiden Kirschenvorkommen, in denen durch den Einsatz zusätzlicher Loci eine höhere Auflösung zu erzielen war (Tabelle 4.4), lagen die Werte für $\omega(g)$ zwischen 0.054 und 0.268 in Roringen und 0.038 und 0.282 in Wibbecke. Es zeigt sich, daß die höchsten $\omega(g)$-Werte bei denjenigen MLG zu beobachten sind, bei denen genau dieser statistische Fehler 1. Art begangen wurde $(\omega(g)$ zwischen 0.166 und 0.282$)$. Der größte Teil derjenigen MLG, bei denen ein solcher Fehler nicht zu verzeichnen war, wies die geringsten $\omega(g)$-Werte auf (mit nur drei Ausnahmen, den Genotypen Ror4, Wib7 und Wib10 mit $\omega(g)$ zwischen 0.224 und 0.282). Da ein geringer $\omega(g)$-Wert auch ein Indikator für das Vorhandensein seltener Allele an mindestens einem Genlocus eines betrachteten MLG ist, stimmt es daher auch mit der Erwartung überein, daß Kopien solcher MLG auch Ramets desselben Klons darstellen. Unterstrichen wird das auch durch die in Tabelle 4.4 dargestellten hypothetischen Genotyphäufigkeiten als Ergebnis zufallsmäBiger Genassoziation $\left(A_{r}(g)=0\right)$.

Im Bestand von Settmarshausen konnte nach der Untersuchung zweier weiterer Mikrosatelliten-Loci keine höhere Auflösung bezüglich klonaler Strukturen nachgewiesen werden. Auffallend dabei sind die recht hohen $\omega(g)$-Werte in diesem Bestand trotz der allgemein höheren genetischen Diversität (in fünf Fällen zwischen 0.180 und 0.308). Grund hierfür ist das Fehlen seltener Allele an zumindest einem Genlocus, wie es in den anderen beiden Beständen beobachtet werden konnte.

Die untere Grenze der relativen Genassoziation $A_{r}(g)$, durch den ein statistischer Fehler 1. Art an den o.g. fünf MLG hätte vermieden werden können, ist ebenfalls in Tabelle 4.4 dargestellt. Dieser untere Grenzwert resultiert aus demjenigen (minimalen) Wert $A_{r}(g)$, für den $C_{2}^{N}(H)$ gerade einmal das Signifikanzniveau $\varepsilon$ überschreitet. Die graphische Herleitung, in $\operatorname{der} C_{2}^{N}$ als Funktion von $A_{r}(g)$ dargestellt ist, kann Abbildung 4.4 entnommen werden.

Unter der Annahme, daß die Maximalwerte dieser so ermittelten unteren Grenzwerte der relativen Genassoziation (hier: $A_{r}(g)=0.0275$ ) auch von den anderen, in mindestens zweifacher Kopie vorliegenden MLG nicht überschritten werden, wurden für diese MLG neue Signifikanzwahrscheinlichkeiten $\left(C_{2}^{N}\right)$ ermittelt. Diese Neukalkulation basiert auf der Grundlage der MLG, welche durch die ursprünglich verwendeten sechs Mikrosatelliten-Loci charakterisiert sind. Die Ergebnisse zeigen, daß für drei der MLG (Ror4, Wib7 und Wib19) bei einem Signifikanzniveau von $\varepsilon=$ 0.05 die Hypothese nicht verworfen werden kann, daß sie eventuell aus mehr als nur einem Genet bestehen. Diese drei MLG gehören in den beiden Kollektiven zu denjenigen Gruppen, welche auch die die höchsten $\omega(g)$-Werte aufweisen (Tabelle 4.4). Für alle anderen MLG, die auch an den zusätzlich analysierten Marker-Loci Identität aufwiesen, lagen die Signifikanzwahrscheinlichkeiten $\left(C_{2}^{N}\right.$ für $A_{r}(g)=$ 0.0275 ) zwischen 0.0031 und 0.0453 , so daß für diese MLG auch für die anfänglich 
untersuchten sechs SSR-Loci angenommen werden kann, daß ihre Kopien Ramets desselben Klons darstellen.

\begin{tabular}{|c|c|c|c|c|}
\hline $\begin{array}{l}\text { Multilocus-Genotype } \\
\text { (MLG) } \\
\end{array}$ & $\tilde{P}(g)$ & $\omega(g)$ & $\begin{array}{c}A_{r}(g) \text { für } \\
C_{2}{ }^{N}=0.05 \\
\end{array}$ & $\begin{array}{c}C_{2}{ }^{N} \text { für } \\
A_{r}(g)=0.0275\end{array}$ \\
\hline Ror1 & $1.2196 \cdot 10^{-5}$ & 0.232 & 0.0275 & $x$ \\
\hline Ror2 & $1.2658 \cdot 10^{-7}$ & 0.054 & $x$ & 0.0032 \\
\hline Ror3 & $1.5866 \cdot 10^{-5}$ & 0.090 & $x$ & 0.0087 \\
\hline Ror4 & $3.4244 \cdot 10^{-5}$ & 0.268 & $x$ & 0.0649 \\
\hline Wib1 & $3.5754 \cdot 10^{-5}$ & 0.282 & 0.0162 & $x$ \\
\hline Wib2 & $1.6788 \cdot 10^{-7}$ & 0.071 & $x$ & 0.0140 \\
\hline Wib3 & $8.0274 \cdot 10^{-6}$ & 0.282 & 0.0162 & $x$ \\
\hline Wib4 & $1.0481 \cdot 10^{-5}$ & 0.166 & 0.0275 & $x$ \\
\hline Wib5 & $1.9321 \cdot 10^{-6}$ & 0.038 & $x$ & 0.0031 \\
\hline Wib6 & $5.1381 \cdot 10^{-5}$ & 0.282 & 0.0161 & $x$ \\
\hline Wib7 & $1.9983 \cdot 10^{-6}$ & 0.224 & $x$ & 0.0830 \\
\hline Wib8 & $6.2936 \cdot 10^{-7}$ & 0.052 & $x$ & 0.0057 \\
\hline Wib9 & $7.4621 \cdot 10^{-7}$ & 0.083 & $x$ & 0.0139 \\
\hline Wib10 & $4.7596 \cdot 10^{-6}$ & 0.282 & $x$ & 0.1231 \\
\hline Wib11 & $1.0203 \cdot 10^{-8}$ & 0.038 & $x$ & 0.0031 \\
\hline Wib12 & $5.4225 \cdot 10^{-8}$ & 0.064 & $x$ & 0.0085 \\
\hline Wib13 & $2.2618 \cdot 10^{-7}$ & 0.038 & $x$ & 0.0031 \\
\hline Set1 & $6.2261 \cdot 10^{-7}$ & 0.154 & $x$ & 0.0120 \\
\hline Set2 & $1.4857 \cdot 10^{-6}$ & 0.180 & $x$ & 0.0161 \\
\hline Set3 & $2.0023 \cdot 10^{-5}$ & 0.308 & $x$ & 0.0434 \\
\hline Set4 & $1.3366 \cdot 10^{-6}$ & 0.230 & $x$ & 0.0254 \\
\hline Set5 & $1.2605 \cdot 10^{-5}$ & 0.218 & $x$ & 0.0231 \\
\hline Set6 & $1.0212 \cdot 10^{-7}$ & 0.076 & $x$ & 0.0031 \\
\hline Set7 & $6.1600 \cdot 10^{-7}$ & 0.231 & $x$ & 0.0256 \\
\hline Set8 & $7.0584 \cdot 10^{-7}$ & 0.052 & $x$ & 0.0015 \\
\hline Set9 & $6.4044 \cdot 10^{-7}$ & 0.128 & $x$ & 0.0084 \\
\hline
\end{tabular}

Tab. 4.4: Die erwarteten Häufigkeiten der einzelnen Multilocus-Genotypen (MLG), welche in wenigstens zweifacher Kopie beobachtet wurden unter der Annahme zu fallsmäßiger Genassoziation; die obere Grenze der Häufigkeit der jeweiligen MLG $[\omega(g)]$, welche durch die jeweiligen Häufigkeiten seiner Allele innerhalb des Kollektivs bestimmt werden; die ermittelte untere Grenze der relativen Genassoziation, für die $C_{2}{ }^{N} \geq 0.05$; Rekalkulation der Werte des statistischen Parameters $C_{2}{ }^{N}$ für die ermittelte untere Grenze relativer Genassoziation $\left(A_{r}(g)\right.$ $=0.0275)$, bei der ein statistischer Fehler 1. Art vermieden worden wäre. 

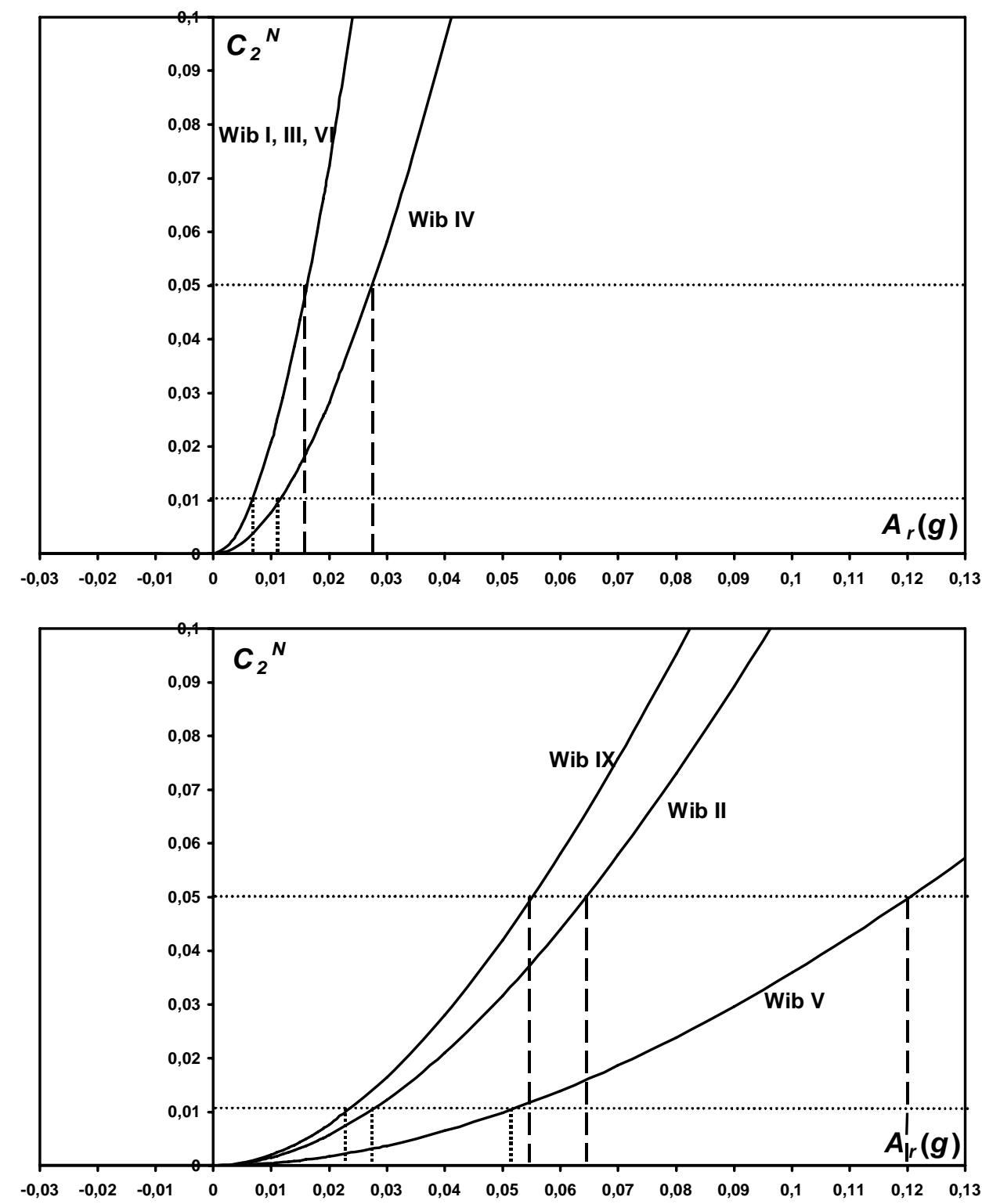

Abb. 4.4: $C_{2}{ }^{N}$ als eine Funktion der relativen Genassoziation $A_{r}(g)$ berechnet für verschiedene Multilocus-Genotypen (MLG) der Wildkirsche im Bestand Wibbecke; die signifikanten Werte von $A_{r}(g)$ für $C_{2}{ }^{N}=\varepsilon(=0.05$ und 0.01$)$ sind eingezeichnet: A: MLG in Wibbecke, für die ein statistischer Fehler 1. Art entdeckt wurde; B: Drei der 13 MLG in Wibbecke, die auch nach der Analyse zusätzlicher Genmarker Identität aufwiesen (kein statistischer Fehler 1. Art entdeckt)

\subsubsection{Anteile sexueller und asexueller Vermehrung innerhalb der Kirschen- vorkommen}

In Tab. 4.5 sind die Ergebnisse zu den in Kap. 4.2.4 aufgeführten Parametern zusammengestellt, welche die Anteile der asexuellen bzw. sexuellen Reproduktion in den einzelnen Beständen charakterisieren sollen. Die Grundlage bilden die sechs ursprünglich untersuchten Mikrosatelliten-Loci, die der populationsgenetischen Charakterisierung der in dieser Arbeit untersuchten Bestände dienen sollen, als 
auch die zusätzlich eingesetzten Marker-Genloci, welche noch eine geringfügig höhere Auflösung des Verhältnisses von vegetativen zu generativen Anteilen in den einzelnen Beständen erbrachten.

Es zeigt sich, daß der Bestand von Wib einen beträchtlich höheren Anteil an potentiell aus vegetativer Vermehrung stammender Individuen aufweist als Ror. So weist der Anteil vegetativ produzierter unter allen Individuen in Wib (77\%) nahezu den vierfachen Wert von dem in Ror (ca. 20\%) auf. In Set sind mindestens 54\% der Individuen aus vegetativer Reproduktion.

Bei Betrachtung der Anteile unterscheidbarer MLG (G/N) weist Ror den doppelten Wert von dem in Wib auf. Set liegt mit seinem Wert etwa im Mittel zwischen Ror und Wib (Tab. 4.5).

Die Klondiversität $v_{K l o n}$ beispielsweise bringt hier zum Ausdruck, ob der aus asexueller Reproduktion stammende Teil der Individuen zum größten Teil von einem Genotyp beherrscht wird oder ob viele Genotypen daran beteiligt sind. Dabei ist zu beachten, daß die Klondiversität hier einen minimalen Wert von $v_{K l o n}=1$ und einen maximalen Wert von $v_{K l o n}=G_{C}$ annehmen kann. So zeigen die Bestände Ror und Set bezüglich der Anzahl der asexuell reproduzierten Genotypen die höchsten Klondiversitäten, die nahe an $G_{C}$ heranreichen. In Wib hingegen ist die Klondiversität deutlich geringer. Hier wurden insgesamt 16 Genotypen gefunden, die gesichert aus asexueller Vermehrung stammen, die Klondiversität beträgt aber nur $v_{\text {Klon }}=9.47$. Das deutet darauf hin, daß in Wib einige MLG in der Anzahl ihrer Ramets deutlich überwiegen (siehe z.B. Wib7 mit 15 Ramets in Tab.4.3), andere hingegen sind nur mit zwei Ramets vertreten.

\begin{tabular}{cccc}
\hline Parameter & Ror & Wib & Set \\
\hline$N$ & 56 & 78 & 39 \\
$G$ & 49 & 33 & 27 \\
$N_{S}$ & 45 & 18 & 18 \\
$N_{C}$ & 11 & 60 & 21 \\
$G_{C}$ & 4 & 16 & 9 \\
$G / N$ & 0.875 & 0.432 & 0.692 \\
$N_{C} / N$ & 0.196 & 0.769 & 0.538 \\
$v_{K l o n}$ & 3.67 & 9.47 & 8.32 \\
\hline
\end{tabular}

Tab. 4.5: Parameter zur Charakterisierung der Anteile sexueller und asexueller Vermehrung in den Beständen Roringen (Ror), Wibbecke (Wib) und Settmarshausen (Set); $N=$ Anzahl Individuen, $G=$ Anzahl gefundener MLG, $N_{S}=$ Anzahl Individuen aus sexueller Vermehrung, $N_{C}=$ potentielle Anzahl asexuell entstandener Individuen, $G_{C}=$ Anzahl asexuell reproduzierter MLG, $G / N=$ Anteil unterscheidbarer Genotypen bezogen auf die Gesamtzahl an Individuen innerhalb der Kollektive, $N_{C} / N=$ Anteil asexuell produzierter unter allen Individuen; $v_{\text {Klon }}=$ effektive Anzahl von MLG unter den asexuellen Individuen 


\begin{tabular}{|c|c|c|c|c|c|c|c|c|c|}
\hline \multirow[b]{2}{*}{ SSR-Locus } & \multicolumn{3}{|c|}{ Ror } & \multicolumn{3}{|c|}{ Wib } & \multicolumn{3}{|c|}{ Set } \\
\hline & Gesamt & Sexuelle & Asexuelle & Gesamt & Sexuelle & Asexuelle & Gesamt & Sexuelle & Asexuelle \\
\hline UDP-005 & 3.47 & 3.48 & 3.41 & 2.49 & 1.58 & 2.78 & 3.67 & 3.60 & 3.60 \\
\hline UDP-021 & 2.01 & 2.01 & 1.91 & 1.51 & 1.25 & 1.60 & 2.60 & 2.77 & 2.37 \\
\hline UDP-410 & 2.56 & 2.60 & 2.00 & 3.85 & 3.38 & 3.89 & 3.54 & 3.56 & 2.95 \\
\hline UDP-412 & 3.90 & 3.85 & 3.51 & 4.88 & 4.66 & 4.26 & 2.80 & 3.31 & 2.39 \\
\hline ВРPCТ-034 & 4.02 & 3.67 & 3.14 & 4.57 & 3.12 & 4.93 & 6.81 & 7.28 & 5.04 \\
\hline ВРРСТ-040 & 2.48 & 2.61 & 1.60 & 3.89 & 3.62 & 3.95 & 4.49 & 4.77 & 3.92 \\
\hline Genpool & 2.88 & 2.88 & 2.36 & 3.00 & 2.37 & 3.10 & 3.60 & 3.82 & 3.14 \\
\hline
\end{tabular}

Tab. 4.6: Die genischen Diversitäten der Bestände von Roringen, Wibbecke und Settmarshausen für die einzelnen Loci sowie für den Genpool; die Werte sind jeweils für alle Individuen (gesamt), für die Sexuellen als auch für die Asexuellen der einzelnen Bestände getrennt aufgeführt

Der Parameter der genischen Diversität zeigt ebenfalls deutliche Unterschiede zwischen den Beständen. Dabei fallen folgende Ergebnisse besonders ins Auge:

(1) Die Genpool-Diversität im Bestand von Ror ist die geringste, obwohl dieser zu über $80 \%$ aus individuellen MLG zusammengesetzt ist und damit den vermutlich größten Anteil von aus generativer Vermehrung stammender Individuen aufweist.

(2) Der Bestand von Wib (maximal 23\% der Individuen aus sexueller Vermehrung) zeigt die höchste Genpool-Diversität bei den aus asexueller Reproduktion hervorgegangenen MLG. Insgesamt ist die Genpooldiversität trotz des hohen Anteils an aus asexueller Vermehrung entstandener Individuen größer als in Roringen.

(3) Die Diversität der Individuen sexueller Herkunft in Set ist hier erwartungsgemäß höher (3.82) als die der aus asexueller Vermehrung hervorgegangenen Individuen (3.14). Im Allgemeinen zeigt dieser Bestand die höchste Gesamtdiversität.

\subsection{Diskussion}

In diesem Kapitel wurden insbesondere die Auswirkungen verschiedener forstlicher Betriebsarten auf die Anteile sexueller und asexueller Reproduktion als auch auf die genetische Diversität in Vogelkirschenvorkommen untersucht werden. Dabei wurde unter anderem deutlich, daß die klassischen statistischen Testmethoden, sexuelle zugunsten von asexueller Vermehrung zu falsifizieren, auf fraglichen Annahmen beruhen. Diese Methoden berücksichtigen beispielsweise nicht, inwiefern sexuelle Reproduktion möglicherweise bestimmte Kombinationen von Genen in Genotypen häufiger oder seltener als unter panmiktischen Verhältnissen erzeugt (Genassoziationen). Bezüglich der Eigenschaften des Reproduktionssystems der Vogelkirsche (Insektenbestäubung und damit möglicherweise geringe effektive Pollenausbreitungsdistanzen im Wald, gametophytisches Inkompatibilitätssystem, etc.), 
erscheinen Annahmen über panmiktische Verhältnisse eher unrealistisch und führen möglicherweise im Hinblick auf die Beurteilung der Rolle vegetativer Vermehrung in verschiedenen Kirschenbeständen zu verfälschten Ergebnissen.

Das Problem wurde auch schon von WAITS et al. (2001) erkannt, wobei die Schätzung der Wahrscheinlichkeit $P_{(\mathrm{ID})}$ (=probability of identity), zwei Individuen mit identischem MLG innerhalb von Tierpopulationen vorzufinden, im Vordergrund stand. An Mikrosatelliten-Datensätzen aus Untersuchungen an verschiedenen Tierarten konnte gezeigt werden, daß der wahre (beobachtete) $P_{(\mathrm{ID})}$-Wert nicht der Annahme der Panmixie unterlag und damit auch nicht aus dem Produkt der jeweiligen Allelhäufigkeiten resultierte. Die beobachteten $P_{(\mathrm{ID})}$-Werte übertrafen die theoretisch erwarteten Werte in dieser Studie teilweise um ein Vielfaches, was auf Substrukturen (Genealogien) innerhalb dieser Tierpopulationen zurückgeführt wurde. Diese Arbeit stellt zwar verschiedene Wahrscheinlichkeitsmodelle zur Berechnung von Genotyphäufigkeiten dar, es fehlt hier aber die konzeptionelle Grundlage für eine statistische Prüfung, inwiefern das Auftreten identischer Multilocus-Genotypen (MLG) innerhalb von Pflanzenpopulationen das Ergebnis asexueller Vermehrung darstellt.

Um den Anteil asexueller Vermehrung innerhalb der drei Altbestände der Wildkirsche zu untersuchen, wurden zunächst sechs nukleare Mikrosatelliten verwendet. Dabei wurden zunächst zwei Methoden angewandt, welche auf den klassischen Annahmen basieren, daß die Kombination von Genen in sexuell reproduzierten Genotypen das Ergebnis einer stochastisch unabhängigen Weitergabe dieser Gene darstellt. Beide Testmethoden ergaben höchst signifikante Werte, so daß alle Genotypen, die in mindestens zwei Kopien vorgefunden wurden, mit hoher Sicherheit als das Resultat vegetativer Vermehrung betrachtet wurden.

Nachdem allerdings zusätzliche kodominante Genmarker (weitere Mikrosatelliten, Isoenzyme) eingesetzt wurden, konnte folgendes beobachtet werden: Bei einigen Individuengruppen, welche zuvor aufgrund der Identität ihrer MLG zu einem Genet gezählt wurden, stellten sich Unterschiede an einigen der hinzugekommenen Loci heraus. Damit war ein klassischer statistischer Fehlers 1. Art entdeckt worden. Dies traf für einen MLG in Roringen sowie vier MLG in Wibbecke zu, in Settmarshausen hingegen änderte sich an den bereits entdeckten klonalen Strukturen nichts. Die Analyse weiterer Markerloci führte dazu, daß die geschätzte Anzahl von Ramets pro Genet in den Beständen von Wibbecke und Roringen, wenn auch nur sehr geringfügig, abnahm.

Durch die Verwendung o.g. Verfahren konnte gezeigt werden, daß die Annahme geringer Assoziationen zwischen Genloci in unvermutet hohem Umfang nicht zutrifft. Deshalb wurden hier Maße für relative Genassoziation hergeleitet (auf der theoretischen Basis nach GREGORIUS 2005), die solche Fehler auf der Grundlage der ursprünglich analysierten sechs Mikrosatelliten vermieden bzw. auf die Möglichkeit einer Unterschätzung der Anzahl von MLG hingewiesen hätten. Das Ergebnis gibt Anlaß, unsere Vorstellungen über die tatsächlichen Ausmaße von Koadaptation und Koevolution in Genomen möglicherweise grundsätzlich zu überdenken. 
Insgesamt konnte gezeigt werden, daß die Umweltbedingungen, die hier stark durch anthropogene Einflüsse geprägt sind, jeweils unterschiedliche Anforderungen an das Anpassungssystem der Vogelkirsche stellen und möglicherweise auch modifizierend auf genetische Strukturen einwirken. Die unterschiedlichen forstlichen Betriebssysteme, welche in den untersuchten Beständen sichtbar sind, liefern ein Beispiel für derartige Herausforderungen. Historische Nutzungsformen, wie z.B. die Mittelwaldwirtschaft verschieben das Verhältnis der beiden Reproduktionsformen zugunsten der asexuellen Vermehrung. So beträgt die untere Grenze der Anzahl asexuell produzierter unter allen Individuen in Wibbecke mit $77 \%$ nahezu dem vierfachen vom Roringer Bestand mit knapp 20\%. Settmarshausen nimmt hier mit 54\% eine Mittelstellung ein.

Die unterschiedlichen Entwicklungsgeschichten der drei untersuchten Bestände als Folge unterschiedlicher forstlicher Bewirtschaftungsformen und damit auch unterschiedlicher ökologischer Umweltbedingungen spiegeln sich auch in typischen Artenzusammensetzungen wieder. Obwohl die Mittelwaldwirtschaft schon seit Anfang des letzten Jahrhunderts nicht mehr praktiziert wird, sind Arten wie z.B. Quercus petraea (Traubeneiche), Carpinus betulus (Hainbuche) als auch Tilia cordata (Winterlinde) immer noch die dominierenden Baumspezies im Bestand Wibbecke als auch im Bestand Settmarshausen. Nach FISCHER (2002) bringt die Fähigkeit, nach einer Beschädigung erneut auszutreiben, diesen Baumarten einen Vorteil gegenüber Fagus sylvatica (Rotbuche). Sie sind besser an Spätfrost und Trockenheit angepaßt, was sich unter den lichten Verhältnissen aufgrund der sehr unregelmäßigen Dichte des Kronendaches im Mittelwald vermutlich günstig ausgewirkt hat. Desweiteren sind diese Arten auch nach einer anthropogenen Schädigung (dem Hieb) klar im Vorteil. Hainbuche, Eiche und Linde vermögen erneut und rasch aus dem Stock auszutreiben. Heute stellt der Bestand Wibbecke einen 'durchgewachsenen Mittelwald' dar, der insbesondere an dem hohen Anteil von aus Stockausschlägen hervorgegangenen Bäumen deutlich zu erkennen ist. Die Wildkirsche, die ebenfalls toleranter gegenüber o.g. Beschädigungen ist, hat in diesem Falle zusätzliche Vorteile durch die Fähigkeit zur Wurzelbrutbildung, da Wurzelschößlinge nach Beschädigung meist eine bessere Überlebenschance aufweisen als Pflanzen aus generativer Verjüngung (siehe auch RÖHRIG \& BARTSCH 1992).

In diesem Zusammenhang soll aber auch darauf hingewiesen werden, daß bei der Schätzung der Anteile vegetativer Vermehrung es nicht vollständig auszuschließen ist, daß sich mit noch weiteren Genmarkern die einzelnen Klonkomplexe noch weiter auftrennen lassen. Andererseits ist es aber auch nicht bekannt, inwieweit individuell auftretende MLG nicht auch das Ergebnis vegetativer Vermehrung sind und es sich demnach um Ramets vormals größerer, vegetativ entstandener Individuengruppen handelt. Insbesondere auch der hohe Wilddruck im Bestand von Wibbecke sowie Settmarshausen läßt vermuten, daß der Anteil asexuell produzierter unter allen Individuen hier eher zu niedrig als zu hoch eingeschätzt wird.

Im Gegensatz dazu sind in hochwaldbewirtschafteten Beständen meist schattentolerantere Arten wie F. sylvatica dominant. Eine lichtbedürftige und wärmeliebende Baumart wie die Vogelkirsche besiedelt hier meist nur frühe sukzessionale Stadien, 
wenn sie nicht durch konsequente Pflege (Freistellung) gefördert wird. Im Bestand Roringen wurden in den 40er Jahren die übergebliebenen Strukturen ehemaliger Mittelwaldwirtschaft in Hochwald überführt. Dabei wurden femelartige Eingriffe vorgenommen, in dem durch die horstweise Entnahme starker Bäume, hauptsächlich Eiche, Esche und Hainbuche, neue Verjüngungsflächen geschaffen wurde. Bis zum heutigen Zeitpunkt sind diese drei Baumarten zwar noch immer recht häufig, werden aber immer stärker von der Buche, welche später auch teilweise durch Pflanzung eingebracht wurde, abgelöst. Die Vogelkirsche findet in den alten Forsteinrichtungsunterlagen keine Erwähnung, so daß angenommen werden kann, daß diese Art vor den waldbaulichen Eingriffen möglicherweise nur sehr vereinzelt in diesem Bestand vertreten war. Die Umweltbedingungen in Roringen zeigen aber nicht nur durch die Eingriffsmethode Unterschiede zu denen in Wibbecke, sondern auch durch die Tatsache, daß in diesem Bestand teilweise durch Gatterungen die Verjüngungsprozesse unterstützt wurden (siehe auch Kapitel 2).

Die Ergebnisse spiegeln diese Verhältnisse entsprechend wieder, da kaum Anzeichen für vegetative Vermehrung gefunden wurden. Allerdings ist in Roringen auch ein geringer Anteil an Individuen aus vegetativer Vermehrung zu verzeichnen. Hier könnte die Aussage von PeTERSON \& JONES (1997) zutreffen, daß durch klonales Wachstum produzierte Abkömmlinge aufgrund noch bestehender Wurzelverbindungen zum Altbaum bessere Chancen haben, über längere Zeiträume ungünstige Umweltbedingungen zu überdauern, bis Lücken im Kronendach die Möglichkeiten für eine selbständige Entwicklung gewährleisten. Vermutlich entstammen diese vegetativ produzierten Individuen aus Wurzelschößlingen, die schon vor den oben erwähnten Eingriffen aus Oberflächenwurzeln vereinzelt stehender Altbäume austrieben und von diesen mit Wasser, Nährstoffen und Assimilaten versorgt wurden. Insbesondere die Tatsache, daß die untersuchten Bäume altersmäßig alle in die Zeitspanne der femelartigen Eingriffe in den 40er Jahren passen, macht es sehr wahrscheinlich, daß die vorhandenen Bestandesstrukturen ihren Ursprung in dieser Zeit haben. Die Keimung der Samen wie auch die Entwicklung der asexuell entstandenen Abkömmlinge erfolgte vermutlich zur Zeit lichter Bestandesverhältnisse (in Femellöchern).

Es wäre aber insgesamt unzureichend, das Potential der Vogelkirsche zu vegetativer Vermehrung ausschließlich als eine Strategie zu bewerten, Etablierungschancen angepaßter Genotypen zu erhöhen. Klonale Vermehrung hat darüber hinaus auch Auswirkungen auf die sexuelle Reproduktion, insbesondere wenn die Möglichkeit gegeben ist, daß mehrere Ramets einer Klongruppe bis zum reproduktiven Stadium überleben können.

Deshalb ist die Klondiversität eingeführt worden, die aussagt, wie viele MLG der asexuell entstandene Anteil eines Bestandes auch effektiv tatsächlich beinhaltet. Dabei zeigte sich, daß die Anzahl der Individuen pro MLG in Wibbecke eine sehr breite Spanne (zwei bis 15 Individuen pro MLG) einnimmt. Bestimmte MLG dominieren also aufgrund der hohen Anzahl an Ramets. Auf diese Weise können beträchtliche Anteile der Bestände aufgrund des gametophytischen Inkompatibilitätssystems der Vogelkirsche vollständig von potentiellen Paarungsmöglichkeiten 
ausgeschlossen sein, was möglicherweise auch zu einer Reduktion der Fekundität führen kann. Im Gegensatz dazu bestehen die asexuell entstandenen MLG in Roringen und Settmarshausen nur aus zwei bis maximal vier Individuen.

Desweiteren stützen die Beobachtungen die Vermutung, daß die charakteristischen Eigenschaften des Reproduktionssystems der Vogelkirsche die Entwicklung von Genassoziationen über einen weiten Bereich des Genoms fördern. Insgesamt konnte beobachtet werden, daß die geschätzten Maße der Genassoziation beträchtlich zwischen Genotypen schwanken kann.

Eine weitere interessante Beobachtung betrifft die genetische Diversität in den drei Kirschenbeständen. Sowohl die genische Diversität als auch die hypothetische gametische Multilocus-Diversität sind in den Beständen mit den größten Verklonungsanteilen höher (Settmarshausen und Wibbecke) als in dem vorwiegend aus sexueller Reproduktion entstandenen (Roringen). Eigentlich wäre zu erwarten, daß der Austausch genetisch variabler Individuen durch Kopien weniger MLG eine Verringerung der genischen Variation zur Folge hätte.

In dem Zusammenhang wird von MCLELLAN et al. (1997) in einem Review-Artikel berichtet, daß Populationen klonal wachsender i.d.R. vergleichbare genetische Diversität enthalten, wie Populationen nicht-klonaler Pflanzen (vgl. auch ELLSTRAND \& RoOse 1987, HAMrICK \& GODT 1990). Insbesondere in Habitaten mit stabilen Umweltbedingungen sollte damit zu rechnen sein, daß jeglicher Unterschied im Verklonungserfolg vorliegender Genotypen sowie auch stochastische Prozesse wie Gendrift zu einer Verringerung der Anzahl an Genets, zur Dominanz weniger Klone und folglich auch zu einer Abnahme genetischer Variation führen müsste (MCLELLAN et al. 1997). Diese Situation wäre eigentlich auch für die Mittelwaldbestände Wibbecke und Settmarshausen zu erwarten. Vermutlich spielt hier aber die Entwicklung der Bestände eine entscheidende Rolle:

In Roringen beispielsweise finden wir nur vier MLG vor, die gesichert aus asexueller Vermehrung stammen. Da deren Ramets das gleiche Alter aufweisen wie die übrigen Bestandesmitglieder, liegt die Vermutung nahe, daß sie aus Wurzelbrut von Bäumen stammen, die schon vor den femelartigen Eingriffen die Fläche besiedelten. Ein zweiter wichtiger Hinweis sind die Genpool-Diversitäten in diesem Bestand. Sowohl die des Gesamtbestands als auch der (getrennt betrachteten) sexuell reproduzierten Individuen, die hier über 80\% der Individuen einnehmen, sind (im Vergleich zu den anderen Beständen) die niedrigsten. Darüber hinaus ist die Diversität der asexuell entstandenen MLG nur unwesentlich geringer. Es ist in diesem Bestand durchaus denkbar, daß die Kernwüchse dieses Bestandes Nachkommen derjenigen MLG sind, welche asexueller Herkunft sind.

In Wibbecke sieht die Situation völlig anders aus. Hier sind nicht nur die gesamten Diversitätswerte höher als in Roringen, die (gesichert) Asexuellen mit einer Genpool-Diversität von 3.10 übertreffen die Sexuellen mit 2.37. Erklärungen für dieses Phänomen sind äußerst schwierig, da über die Häufigkeiten und die Intensität der Eingriffe in diesem ehemaligen Mittelwaldbestand nichts bekannt ist. Es kann sein, daß waldbaulich aufgrund kurzer Nutzungsintervalle ständig günstige Besiedlungsbedingungen vorlagen, so daß einerseits von außen eingeschleppte Samen gute 
Keim- und Etablierungsmöglichkeiten hatten, andererseits die schon auf der Fläche stockenden MLG möglicherweise sexuell nicht effektiv reproduzieren konnten. In dieser Situation würde es unter den vorhandenen Bestandesmitgliedern im wesentlichen zu asexueller Reproduktion und keiner Neukombination der Gene (geringe Samenbildung) der Bestandesmitglieder führen, während neue genetische Information ausschließlich von außen eingetragen wurde. Dies würde die höhere GenpoolDiversität des Gesamtbestandes dann erklären, wenn dieses Verfahren über längere Zeiträume praktiziert wurde. Die geringere Diversität der (potentiell) sexuell entstandenen Individuen ist aufgrund der geringen Anzahl kaum interpretierbar, so daß hier auch zufällige Ereignisse mit eine Rolle spielen können. Andererseits kann es sein, daß diese Individuen auch nicht sexueller Herkunft, sondern Ramets vormals größerer, vegetativ entstandener Gruppen sind.

Wie unter anderem aus dem letzten Abschnitt zu entnehmen ist, ergeben sich aus der hier dargestellten analytischen Betrachtung des gemischten Reproduktionssystems der Vogelkirsche eine Reihe von weiteren Fragestellungen, deren Beantwortung in den folgenden Kapiteln angestrebt ist. Folgendes Problem ist bislang ungelöst: Einerseits führen Verklonung und Genassoziationen im Bestand von Wibbecke zu einer Verringerung genotypischer Diversität (bezüglich der sechs für populationsgenetische Zwecke verwendeten Mikrosatelliten-Loci), andererseits ist hier eine höhere allelische Diversität zu verzeichnen als in Roringen.

Inwiefern eine unterschiedliche Kolonisations-Extinktionsdynamik aufgrund unterschiedlicher Umweltbedingungen in diesem Zusammenhang von Bedeutung ist, kann möglicherweise mit Hilfe einer Analyse der räumlichen Verteilung genetischer Information innerhalb der Untersuchungsbestände geklärt werden. Dabei ist aber nicht nur die Verteilung sexuell und asexuell produzierter Individuen innerhalb der Bestände von Interesse. Die räumlich-genetischen Daten sollen vor allem auch Hinweise auf den Ver- und Ausbreitungstyp der Vogelkirsche unter Berücksichtigung möglicher Auswirkungen unterschiedlicher forstlicher Betriebsformen liefern. 


\section{Hinweise auf den Ver- und Ausbreitungstyp der Vogel- kirsche durch gezielte Analysen räumlich-genetischer Strukturen in adulten Vorkommen}

\subsection{Einleitung}

Im vorangegangenen Kapitel wurde eine konzeptionelle Vorgehensweise zur Identifikation sexueller und asexueller Vermehrung in drei adulten Vogelkirschenbeständen hergeleitet und damit die Möglichkeit geschaffen, genetische Strukturen in Pflanzenvorkommen mit gemischtem Reproduktionssystem ${ }^{5.1} \mathrm{zu}$ analysieren. In diesem Kapitel sollen an diesen Beständen nun erste Hinweise über den Ver- und Ausbreitungstyp dieser Baumart mit Hilfe populationsgenetischer Methoden hergeleitet werden. Wie im folgenden gezeigt wird, sind dabei Kenntnisse bezüglich der räumlichen Verbreitung von Individuen und ihrer genetischer Information von entscheidender Bedeutung.

\subsubsection{Die Einordnung der Vogelkirsche im Ökosystem Wald}

Wie in der Einführung (Kap. 1) schon näher erläutert wurde, weist die Vogelkirsche eine rezedente Lebensweise auf, was im wesentlichen in ihrer geringen Konkurrenzkraft begründet liegt. Dies äußert sich darin, daß sie auf natürlichem Wege niemals in Reinbeständen (als dominante Hauptbaumart), sondern stets in Mischung mit anderen vorkommt. Nach KLEINSCHMIT et al. (2000) spielt die Vogelkirsche im praktischen Waldbau bislang nur eine Nebenrolle und nimmt z.Zt. weit weniger als $1 \%$ der Waldfläche ein.

Die Vogelkirsche läßt sich nur sehr unpräzise in Waldgesellschaften einordnen. Ihr natürlicher Verbreitungsschwerpunkt wird nach der waldökologischen Literatur für Mitteleuropa auf den Bereich der Eichen-Hainbuchenwälder (Verband Carpinion betuli) beschränkt (vgl. FISCHER 2003, HÄRDTLE et al. 2004). Die Entwicklungsbedingungen für die typischen Baumartenkombinationen dieser Waldgesellschaft sind aber zum großen Teil anthropogener Natur, da Nutzungsformen wie z.B. die Nieder- und Mittelwaldwirtschaft viele Buchenwälder zu Eichen-Hainbuchenwäldern degradierten (РОтT 1981). Dies ist z.B. im Kirschenbestand Wibbecke (ehemaliger Mittelwaldbestand) eindeutig erkennbar. Der Bestand Settmarshausen zeigt ähnliche Eigenschaften (für nähere Informationen siehe Kap. 2 und 3).

Отто (1994) hingegen ordnet die Vogelkirsche anders ein. Er bezeichnet die Art als einen Ausweich- und Lückenstrategen. Aufgrund ihrer Lichtbedürftigkeit sowie ihrer engen Standorttoleranzen ist sie meist dazu gezwungen entweder an Waldränder oder in die freie Landschaft auszuweichen oder mit ihrem raschen Jugend-

\footnotetext{
${ }^{5.1}$ Mit dem Ausdruck des 'gemischen Reproduktionssystems' wird hier nicht etwa das Verhältnis von Selbst- zu Fremdbefruchtung angesprochen, sondern die Fähigkeit einer Art, sowohl sexuell als auch asexuell Nachkommen zu erzeugen.
} 
wuchs Waldlücken zu besetzen, wo sie allerdings der Konkurrenz anderer Baumarten meist rasch unterlegen ist. Letzteres kann beispielsweise im Bestand Roringen beobachtet werden. Dieser Vogelkirschenbestand ist im Zuge einer femelartigen Verjüngung Mitte der 40er Jahre entstanden. Heute wird dieser Bestand einzelstammweise genutzt, wodurch Lichtbaumarten wie die Vogelkirsche aufgrund der Konkurrenzkraft anderer Bäume, insbesondere der Buche, nur durch konsequente Freistellung erhalten werden kann (siehe auch Kap. 3).

Die gemachten Ausführungen machen deutlich, daß das Vorkommen von $P$. avium zum großen Teil störungsinduziert ist. Diese Störungen sind heute meist anthropogener Natur, da der Mensch durch waldbauliche Behandlungsformen temporäre Waldinnenränder oder durch die Fragmentierung ganzer Waldlandschaften sogar sehr dauerhafte Waldaußenränder schafft.

\subsubsection{Die Bedeutung von Kenntnissen über die Verbreitung von Individuen und genetischer Information im Raum}

Nach ZiEgenHAgEN \& SCHOlZ (2002) sind Erkenntnisse über die raum-zeitliche Dynamik der intraspezifischen Diversität in Abhängigkeit von der Bewirtschaftungsform eines Bestandes deshalb von Bedeutung, da hierdurch Entscheidungshilfen für ein genetisches Management auf Bestandesebene herleitbar sind.

Solche dynamischen Prozesse sind allerdings nicht direkt meßbar, sondern es müssen, wie z.B. bei einer Schätzung der Ausbreitung genetischer Information, spezifische Zustände früher ontogenetischer Stadien herangezogen werden. So kann die Entfernung der Pollen- bzw. Samenausbreitung nur durch eine Vater- oder Elternschaftsanalyse vorgenommen werden, wobei Väter bzw. Eltern nur potentiell bestimmt werden können. Darüber hinaus kann bei der Elternschaftsanalyse i.d.R. nicht zwischen Vater und Mutter differenziert werden, was ebenfalls die Schätzung von Samenverbreitungsdistanzen erschwert (Ausnahme: Endosperm bei Koniferen sowie Arten, deren Samenhüllen Bestandteile mütterlichen Gewebes enthalten, wie z.B auch das Endokarp bei der Gattung Prunus; siehe GODOY \& JORDANO 2001). Insgesamt sind diese Verfahren als sehr aufwendig zu bezeichnen, insbesondere wenn mehrere Waldbestände analysiert werden sollen. Ein weiteres Problem ist, daß durch diese Methoden die eigentliche „effektive“ Ausbreitung genetischer Information kaum wiedergegeben werden kann. Diese wird nämlich bestimmt durch lokale Unterschiede in der Vegetationsstruktur (siehe z.B. Habitatpräferenzen tierischer Ausbreiter in Kap. 2.2.5), durch das Auftreten von Samenprädatoren sowie Faktoren, welche die Keimung der Samen und die Etablierung der Jungpflanzen beeinflußt (siehe auch KOLLMANN 2000).

In Abb. 5.1 soll dargestellt werden, wie sich die unterschiedliche Effizienz in der Ausbreitung genetischer Information auf genetische Strukturen in Pflanzenvorkommen auswirken kann. Treten Individuen nicht nur räumlich sondern auch in ihren genetischen Merkmalen stark geklumpt auf, so läßt das auf sehr geringe Effizienz der Pollen- und Samenausbreitung und/oder eine starke Anpassung an die lokal vorgegebenen Umweltbedingungen schließen. Auch wenn nach SANTI (1988) 
die Biene bis zu über zwei Kilometer zum Sammeln von Nahrung zurücklegen kann, sagt das noch nichts über ihre tatsächliche Effektivität aus. Hält sie sich über längere Zeit innerhalb nur weniger, benachbarter Kronen auf, so kann es sein, daß die Vogelkirsche hauptsächlich von ihren nächsten Nachbarn bestäubt wird. Auch der größte Teil des „Samenregens“ kann meist in unmittelbarer Nähe des Mutterbaumes beobachtet werden. Vermag sich die Vogelkirsche auch in ihrer unmittelbaren Umgebung generativ zu vermehren, was lokale Umweltbedingungen zur Bildung mehrerer Generationen voraussetzt, so würde dies möglicherweise zu starken räumlich-genetischen Substrukturen führen. Insbesondere die Fähigkeit der Vogelkirsche zu asexueller Vermehrung durch Wurzelbrut kann sehr starke räumlich-genetische Gruppierung zur Folge haben (Fall 1 in Abb. 5.1).

Ein anderes Extrem wäre denkbar, wenn keine Zusammenhänge zwischen räumlicher und genetischer Gruppenbildung erkennbar sind (Fall 3 in Abb. 5.1). In diesem Fall wären diejenigen Individuen, die räumliche Nähe zueinander aufweisen, bezüglich ihrer genetischen Merkmale so unterschiedlich, daß die genetische der räumlichen Gruppenbildung nicht mehr folgt. Dies würde auf sehr effiziente Ausbreitungsmechanismen hindeuten. Bei der Vogelkirsche wären unter gegebenen Umweltbedingungen mehrere Generationen vor Ort nahezu ausgeschlossen und die generative Vermehrung diente in erster Linie der effektiven Besiedlung neuer Habitate dient.

Effizienz der Ausbreitung genetischer Information

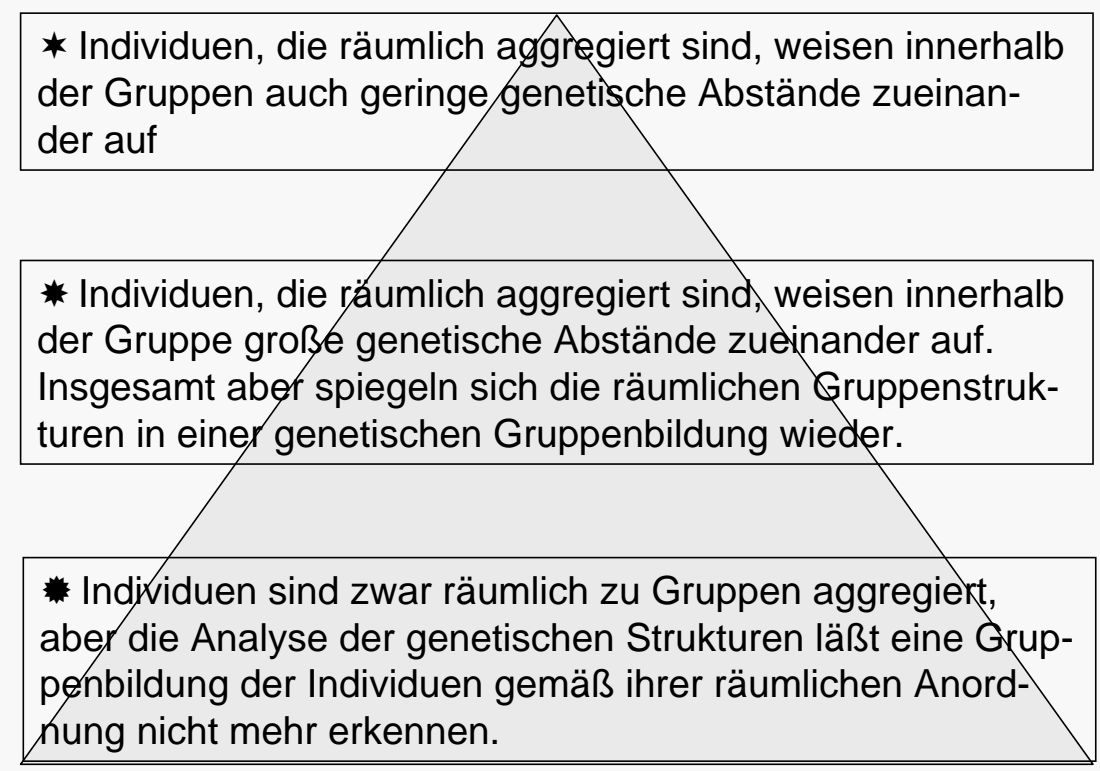

Abb. 5.1: Darstellung des Zusammenhangs verschiedener Zustände räumlich-genetischer Struktur und der Effizienz der Ausbreitung genetischer Information in Pflanzenvorkommen (Zunahme der Effizienz gemäß Dreieck von oben nach unten) 


\subsubsection{Zielsetzung}

In dieser Untersuchung werden Verfahren herangezogen, die eine Momentaufnahme aktuell bestehender Ergebnisse o.g. populationsdynamischer Prozesse darstellen (hier: die räumliche Verteilung der Individuen und ihrer genetischen Information in Altbeständen). Um Hinweise auf den Ver- und Ausbreitungstyp der Vogelkirsche zu erhalten, können wir auf natürliche Vorkommen dieser Art allerdings nicht mehr zurückgreifen. Deshalb sollen auch hier (wie in Kap. 4) verschiedene historische und gegenwärtige forstliche Betriebsarten mit ihren unterschiedlichen ökologischen Bedingungen zur Analyse herangezogen werden. Dazu werden die bestandesgeschichtliche Informationen (wie z.B. Störungen durch waldbauliche Eingriffe) in Zusammenhang mit einer umfassenden Analyse räumlich-genetischer Strukturen diskutiert.

In Kap. 4 wurden zwar die Auswirkungen verschiedener Betriebsformen auf die Anteile sexueller und asexueller Vermehrung quantifiziert, aber die Unterschiede in der genetischen Vielfalt konnten teilweise nur hypothetisch diskutiert werden. Die hohe genische Diversität in den Mittelwaldbeständen Wibbecke und Settmarshausen wurde beispielsweise dadurch erklärt, daß möglicherweise kurze Nutzungsintervalle das Erreichen des adulten Stadiums selten ermöglichte und damit eine effektive Fruktifikation innerhalb der Bestände stark verminderte. Dies führte zu fast ausschließlicher asexueller Reproduktion der Bestandesmitglieder (in Wibbecke mindestens $77 \%$ der Individuen gesichert aus asexueller Reproduktion), so daß die hohe genische Diversität innerhalb dieser Bestände eigentlich nur durch Migration (Sameneintrag von außen) in Verbindung mit einem langen Zeitraum der Ausübung dieser Bewirtschaftungsweise zu erklären ist. Im Gegensatz dazu wurde im Bestand Roringen eine geringere genische Diversität beobachtet, obwohl die untere geschätzte Grenze von Individuen asexueller Herkunft mit 20\% hier wesentlich geringer war. Hier wurde vermutet, daß die femelartigen Auflichtungen nur durch Nachkommen weniger Individuen besiedelt wurden.

Eine zentrale Fragestellung ist folglich die Art der Besiedlungsdynamik der untersuchten Bestände durch die Wildkirsche. Dieses soll durch eine gezielte Analyse der Verbreitung von Individuen und ihrer genetischen Information in den einzelnen Beständen näher durchleuchtet werden, woraus möglicherweise auch Schlüsse auf die Ausbreitungsmechanismen dieser Art gezogen werden können. Dabei sollen die anthropogen modifizierten ökologischen Bedingungen mit in die Diskussion einbezogen werden. Außerdem sollen folgende Hypothesen getestet werden:

(1) Im femelwaldartig bewirtschafteten Bestand (Roringen) liegen räumlich-genetische Strukturen nicht nur wegen der Fähigkeit der Vogelkirsche zu asexueller Vermehrung vor, sondern auch aufgrund der Kolonisation der Femellöcher durch nur wenige Samenbäume (Gründer-Effekt).

(2) In den ehemaligen Mittelwaldbeständen liegt räumlich-genetische Struktur ausschließlich aufgrund asexueller Vermehrung vor. Kurze Nutzungsintervalle in der Hauschicht führten dazu, daß die Bestandesmitglieder sich hauptsächlich asexuell vermehrten und nur selten effektiv fruktifizierten. Neue genetische Va- 
riation konnte ausschließlich von außen beigesteuert werden, so daß Familienstrukturen (oder ein Gründereffekt) hier nicht zu erwarten sind.

Außerdem ist eine Evaluierung verschiedener Verfahren der Analyse räumlich-genetischer Strukturen im Hinblick auf deren Informationsgehalt vorgesehen.

\subsection{Verfahren zur Interpretation räumlich-genetischer Bestan- desstrukturen}

Frühe theoretische Arbeiten (WRight 1943, MALÉCOT 1948) wie auch die meisten experimentellen Untersuchungen bis in die heutige Zeit basieren auf der Analyse räumlich-genetischer Kovariation. Dazu zählen unter anderem die Methoden der räumlichen Autokorrelationsanalyse, die den Zusammenhang zwischen räumlichen und genetischen Abständen beschreiben und testen (vgl. auch HEYWOOD 1991, LINHART \& GRANT 1996). Um aber den speziellen Aspekt der Verbreitungsmuster rezedenter Arten (wie etwa geringe Flächenrepräsentanz, starke Fragmentierung) zu berücksichtigen, wird hier zur Beschreibung und Erkennung räumlich-genetischer Bestandesstrukturen ein weiteres Verfahren, nämlich die Single-linkage (SL) Gruppierungsanalyse herangezogen. Dabei soll eine distanzbasierte, hierarchische Organisation der Individuen nicht nur räumlich oder genetisch, sondern auch in Kombination, also räumlich-genetisch, dargestellt werden.

\subsubsection{Die Clusteranalyse zur Untersuchung räumlich sowie räumlich-ge- netischer Fragmentiertheit in Pflanzenvorkommen}

Das vorrangige Ziel einer Gruppierungsanalyse liegt in der Erkennung und Erfassung von Strukturen innerhalb komplexer Datensätze, wobei dieses Verfahren zunächst rein explorativer Natur ist. Es soll dazu dienen, die erhobenen Daten durch die Abstraktion ihrer zugrundeliegenden Struktur in einer hierarchischen Ordnung zu organisieren und darzustellen (JAIN \& DuBES 1988). In dieser Arbeit soll die Strukturerkennung von Individuen und ihrer genetischen Information im Raum im Vordergrund stehen. Die Wahl der geeigneten Gruppierungsmethode setzt auch hier eine Formulierung der konzeptionellen Vorgehensweise voraus. Dabei sollen die gewünschten Gruppierungscharakteristika sowie die Richtlinien für die Interpretation der Ergebnisse dargestellt werden.

\subsubsection{Die Single-linkage Gruppierungsanalyse: Das Isolationsprinzip als Basis für eine bierarchische Ordnung von Elementen}

Die Bildung von hierarchischen Gruppen sollte in der Art und Weise erfolgen, daß zwischen den Elementen innerhalb einer bestimmten Gruppe höhere Ähnlichkeit besteht als zwischen Elementen verschiedener Gruppen (interne Kohärenz, externe Isolation). Diese Gruppierungseigenschaften werden durch das sogenannte Isolationsprinæip ermöglicht. Das Prinzip beruht darauf, daß für jede beliebige Gruppe (als Teil einer Gesamtmenge $\Omega$ ) bestehend aus mindestens zwei Elementen eine in- 
terne (I) und eine externe Differenzierung $(E)$ bestimmt werden kann. Gruppen mit größerer externer als interner Differenzierung werden dabei als isolierte Gruppen bezeichnet.

Um das Kriterium der Isolation zu realisieren, ist zunächst ein geeignetes $\mathrm{Ma}$ zu wählen, welches die paarweisen Differenzen $d$ der Objekte innerhalb der Gesamtmenge $\Omega$ mißt. Das Isolationsprinzip ist für beliebige Differenzenmaße geeignet, die symmetrische Unterschiede zwischen den Objekten quantifizieren $(d(x, y)=$ $d(y, x)$ und $d(x, y)=0$ nur wenn $x=y$ ) (GREgORIUS 2004). Dazu zählen der räumliche (euklidische) Abstand zwischen Individuen $d_{s}$ sowie das genetische Abstandsmaß $d_{0}$ (siehe auch Box 5.2). Bei der hierarchischen Darstellung soll der minimale Abstand zwischen zwei Gruppen als Gruppierungskriterium dienen (nearest-neighbour-Methode). Dadurch wird nicht nur der geringste Differenzierungsgrad bestimmt, sondern auch die Erfassung sehr feiner Gruppierungsstrukturen ermöglicht (GREGORIUS 2005a).

In einer so erzeugten hierarchischen (enkaptischen) Struktur kann jede beliebige Gruppe entweder vollständig von einer anderen getrennt oder innerhalb einer anderen (hierarchisch höheren Gruppe) eingeschlossen sein. Je höher die betrachteten hierarchischen Ebenen sind, desto größer sind auch die jeweiligen externen und internen Gruppendifferenzierungen. Dabei sind auf gleichen Hierarchieebenen die Werte für die externe Gruppendifferenzierung stets identisch, was aber nicht notwendigerweise für die interne Gruppendifferenzierung gilt. Dies wird in Box 5.1 veranschaulicht. Die Gruppen $G_{1}$ und $G_{2}$ zeigen die gleiche externe Differenzierung (Isolation), ihre internen Differenzierungen hingegen sind unterschiedlich.

Diese Methode der Organisation führt dazu, daß (a) alle Objekte in Gruppen mit geringerer interner als externer Differenzierung zusammengefaßt werden, daß (b) ein Teil als sogenannte „solitäre“ Objekte keiner Gruppierung angehören (siehe Element $z_{8}$ in Box 5.1) oder daß (c) eine Gruppierung der Objekte vollständig unterbleibt und keines der Objekte irgendeiner Gruppe zugeordnet werden kann (ausschließlich solitäre Objekte) (GREGORIUS 2004).

Bei der Prüfung schon vorhandener Algorithmen konnte nachgewiesen werden, daß nur die Single-linkage Gruppierungsmethode sowohl isolierte Gruppen als auch solitäre Objekte gemäß obiger Definition erzeugt. Damit können hierarchische Anordnungen von Gruppen und solitären Objekten mit Hilfe dieser Methode im Sinne des Isolationsprinzips interpretiert werden (siehe Box 5.1) (vgl. GrEGORIUS 2005a). Folgende vorteilhafte Eigenschaften der SL-Gruppierungsanalyse können zusammengefaßt werden:

(1) Ist $B$ die kleinste isolierte Gruppe innerhalb der Gesamtmenge $\Omega$, in der noch eine weitere Gruppe (nämlich $A$ ) isoliert ist, dann ist $I_{B}=E_{A}$. Da $I_{B}<E_{B}$ und $I_{A}<E_{A}$, impliziert dies streng monotone Verhältnisse innerhalb der hierarchischen Ordnung, und zwar $I_{A}<I_{B}$ sowie $E_{A}<E_{B}$ (GREGORIUS 2005a). Dies ist in anderen Gruppierungsmethoden wie z.B. UPGMA (Unweighted pair group method) oder WPGMA (weighted pair group method) nicht zu erwarten, so daß Interpretationen in o.g. Sinne erschwert sind. 


\section{Die Single-linkage Gruppierung: Strukturen der hierarchischen Ordnung}

Matrix der Differenzierung $d$ zwischen den Objekten $z_{1}$ bis $z_{8}$

\begin{tabular}{|l|c|c|c|c|c|c|c|}
\hline & $\mathbf{z}_{\mathbf{1}}$ & $\mathbf{z}_{\mathbf{2}}$ & $\mathbf{z}_{\mathbf{3}}$ & $\mathbf{z}_{\mathbf{4}}$ & $\mathbf{z}_{\mathbf{5}}$ & $\mathbf{z}_{\mathbf{6}}$ & $\mathbf{z}_{\mathbf{7}}$ \\
\hline $\mathbf{z}_{\mathbf{2}}$ & 1 & & & & & & \\
\hline $\mathbf{z}_{\mathbf{3}}$ & 3.5 & 3 & & & & & \\
\hline $\mathbf{z}_{\mathbf{4}}$ & 4.5 & 3.5 & 2 & & & & \\
\hline $\mathbf{z}_{\mathbf{5}}$ & 6 & 5 & 5.5 & 6 & & & \\
$\mathbf{z}_{\mathbf{6}}$ & 5.5 & 6 & 5 & 6.5 & 5 & & \\
\hline $\mathbf{z}_{\mathbf{7}}$ & 6 & 6 & 5.5 & 7 & 5.5 & 5 & \\
\hline $\mathbf{z}_{\mathbf{8}}$ & 7 & 6.5 & 6 & 6 & 6.5 & 8 & 6 \\
\hline
\end{tabular}

Single-linkage Dendrogramm

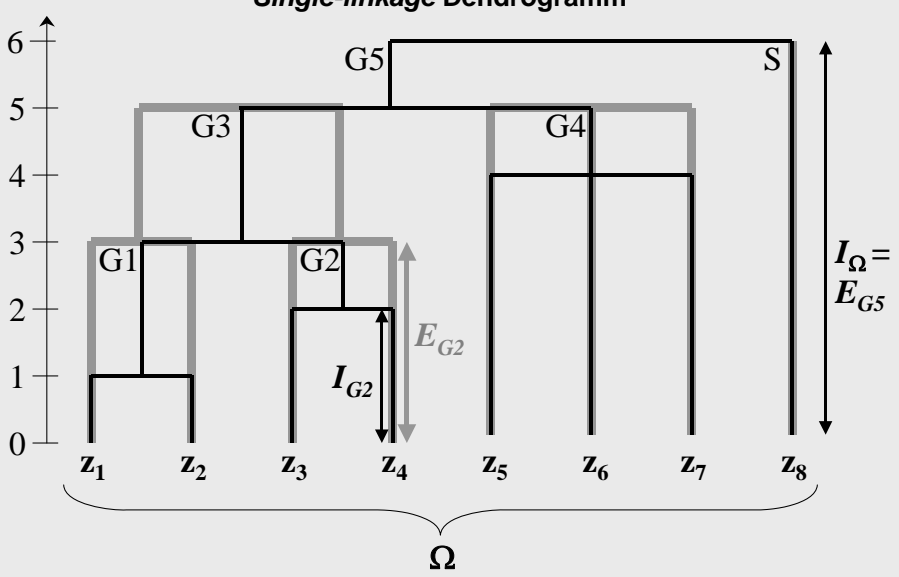

SL-Gruppierungskriterium: Als Differenz zweier verschiedener Gruppen $A$ und $B$ wird jeweils die minimale Distanz aller Objektpaare $\left(z_{x}\right.$ für $A$ und $z_{y}$ für $\left.B\right)$ zwischen den beiden Gruppen verwendet:

$$
d(A, B)=\min \left\{d\left(z_{X}, z_{Y}\right) \mid z_{X} \in A, z_{Y} \in B\right\}
$$

Im Beispiel wird die minimale Distanz zwischen den Gruppen G1 und G2 durch die Objekte $\mathbf{z}_{2}$ und $\mathbf{z}_{3}(d=3.0)$ bestimmt

Eigenschaften von Gruppen und solitären Objekten: Jede Gruppe innerhalb einer Gesamtmenge $\Omega$ besteht aus mindestens zwei Objekten und ist durch eine externe $(E)$ sowie eine interne (I) Differenzierung charakterisiert. $E_{A}$ mißt den kleinsten Abstand zwischen Objekten der Gruppe $A$ und den Objekten ihres Komplements. $I_{A}$ entspricht dem größten minimalen Abstand, der unter den Individuen innerhalb der Gruppe $A$ beobachtet wurde.

$$
E_{A}=d(A, \Omega \backslash A) \quad I_{A}=\max \min \left\{d\left(z_{X}, z_{W}\right) \mid z_{X} \in A, z_{W} \in A\right\}
$$

Für solitäre Objekte (Objekte, die keiner Gruppe zugeordnet werden konnten) ist eine interne Differenzierung, für $\Omega$ eine externe Differenzierung nicht definiert.

Im obigen Beispiel wird die externe Differenzierung der Gruppe $G 3\left(E_{G 3}\right)$ durch die Objekte $\mathbf{z}_{2}$ und $\mathbf{z}_{5}(d=5.0)$ bestimmt, die den minimalen Abstand zwischen den Gruppen $G 3$ und $G 4$ darstellen. Die interne Differenzierung der Gruppe $\mathrm{G} 3\left(I_{G 3}\right)$ wird durch die Objekte $z_{2}$ und $z_{3}(d=3.0)$ determiniert.

Maß für Gruppenisoliertheit: Die Gruppenisoliertheit läßt sich durch folgenden Parameter beschreiben:

$$
\text { Iso }{ }_{A}=\left(E_{A}-I_{A}\right) / E_{A}
$$

$I \mathrm{SO}_{A}$ beschreibt die Isoliertheit einer Gruppe $A$ von dem gesamten Komplement. Dieser Wert wird 1, wenn die Objekte einer Gruppe intern nicht differenziert, also bezüglich ihrer Merkmale gleich sind. Der Parameter nähert sich dem Wert 0, je weniger die Gruppe $A$ von ihrem Komplement isoliert ist. Der Wert 0 tritt nicht auf, da in diesem Fall keine Einordnung der Objekte in eine eigenständige Gruppe vorliegt.

Im obigen Beispiel beträgt die gesamte Struktur 0.833. Innerhalb der Gesamtmenge ist die Gruppe G3 mit einem Wert von 0.8 stärker strukturiert als beispielsweise Gruppe G4 mit einem Wert von 0.2. Gruppe G3 weist auch eine

Box 5.1 stärkere Gruppenisoliertheit (Wert: 0.333) als Gruppe G4 (Wert: 0.1667) auf.

(siehe GREGORIUS 2004, GREGORIUS 2005a)

(2) Alle solitären Objekte sowie Gruppen, welche die höchsten Hierarchieebenen einnehmen (=Top-level groups), weisen die gleiche externe Differenzierung auf (siehe Gruppe G5 sowie das solitäre Objekt S in Box 5.1). Diese Differenzierung ist gleich der maximalen externen Differenzierung unter allen isolierten 
Gruppen und solitären Objekten und entspricht der internen Differenzierung $I_{\Omega}$ der Gesamtmenge $\Omega$. (GREGORIUS 2005a).

(3) Von besonderem Interesse sind auch die Auswirkungen auf die hierarchischen Gruppenstrukturen, wenn Objekte aus der Gesamtmenge $\Omega$ entzogen oder zu dieser hinzugefügt werden. Nahezu alle Gruppierungsmethoden neigen zu drastischen Veränderungen in der hierarchischen Ordnung ihrer Elemente. Mit Ausnahme solitärer Objekte, wird durch das Isolationsprinzip nach GREGORIUS (2004) die interne Differenzierung einer Gruppe nicht beeinflußt, wenn der minimale Abstand eines jeden neuen, hinzugefügten Objektes zur ursprünglichen Gesamtmenge $\Omega$ dessen interne Differenzierung $I_{\Omega}$ überschreitet. Andernfalls verlieren einige aber nicht notwendigerweise alle Gruppen ihren charakteristischen Zustand der Isolation (GREGORIUS 2004). So wird die interne Differenzierung und die hierarchische Struktur der Gruppe G5 in dem Beispiel-Dendrogramm in Box 5.1 nicht verändert, wenn das Objekt $z_{8}$ entfernt würde. Diese Eigenschaft der SL-Methode war insbesondere auch bei der Abgrenzung der Untersuchungsbestände von Bedeutung. Die Kirschenvorkommen wurden hier so ausgewählt, daß einerseits eine vollständige Aufnahme der Individuen in den Waldbeständen ermöglicht wurde, andererseits die Hinzunahme weiterer Individuen die raumbezogene hierarchische Gruppenstruktur nicht beeinflußt hätte.

\subsubsection{Die bierarchische Gruppierung von Individuen im Raum}

Um die hierarchische Anordnung der Individuen im Raum zu veranschaulichen, wurden neben einer Kartenübersicht, in denen die Positionen der einzelnen Bäume verzeichnet sind, auch die Zugehörigkeit der einzelnen Individuen zu räumlichen Gruppen dargestellt. Für die Gruppenbildung wurden unterschiedliche Nachbarschaftsniveaus $(20 \mathrm{~m}, 30 \mathrm{~m}, 40 \mathrm{~m}$ und $50 \mathrm{~m})$ gewählt. Für ein gegebenes Nachbarschaftsniveau wurden um alle Individuen Kreise mit dem Durchmesser des Nachbarschaftsniveaus gezogen. Anschließend wurde die äußere, einhüllende Kurve um jede Gruppe sich überlappender Kreise eingezeichnet. Die Gruppenzugehörigkeit ist somit durch diese äußere 'einhüllende Kurve' (hier durch geglättete Linien dargestellt) bestimmt. Das gleiche Prinzip wurde auf verschiedene Nachbarschaftsniveaus angewandt. Da das Vorkommen der Vogelkirsche in der waldbaulichen Literatur oft als 'truppweise oder einzelstammweise beigemischt' beschrieben wird (siehe u.a. KLEINSCHMIT et al. 2000), wäre zu erwarten, daß niedrige Nachbarschaftsniveaus zunächst zur Ausbildung kleinerer Gruppen sowie 'relativ' solitärer Objekte $^{5.2}$ führen. Werden diese Niveaus schrittweise vergrößert, verschmelzen diese Strukturen, bis am Ende eine oder nur wenige Gruppen/solitäre Individuen übrigbleiben.

Diese auf einer Übersichtskarte graphisch erzeugte, hierarchische Gruppenbildung wird mit dem Verfahren der Single-linkage Methode exakt nachvollzogen. Werden gemäß dem Maßstab innerhalb der Dendrogramme die verschiedenen Nachbar-

${ }^{5.2}$ In der ursprünglichen Arbeit (GREGORIUS 2004) werden 'Solitäre' als solche Objekte bezeichnet, die über alle Nachbarschaftsniveaus keiner Gruppe zugeordnet werden können. Hier wird von 'relativ' solitären Objekten gesprochen, da hier der Bezug zu einem bestimmten Nachbarschaftsniveau hervorgehoben werden soll. 
schaftsniveaus abgetragen, so wird der Bestand in diejenigen Gruppen bzw. (relativen) solitären Objekte klassifiziert, die auch in den entsprechenden Übersichtskarten abgelesen werden können. Dabei sind die inneren Gruppendifferenzierungen dementsprechend kleiner oder gleich der definierten Nachbarschaftsniveaus. Zur Demonstration sind in den drei Altbeständen diejenigen Gruppen, die auf einem Nachbarschaftsniveau von $20 \mathrm{~m}$ gebildet werden, sowohl in den Übersichtskarten als auch in den entsprechenden Dendrogrammen mit blauen römischen Zahlen versehen.

Mit der Single-linkage Gruppierungsmethode gehen zwar Informationen wie beispielsweise die zweidimensionale Anordnung der Individuen bzw. der Gruppen verloren, jedoch können weitere verwertbare Maße gemäß dem Isolationsprinzips gewonnen werden, wie z.B. die interne und externe Gruppendifferenzierung (siehe Box 5.1). Außerdem soll diese Darstellungsweise als Grundlage für die räumlich-genetische Gruppierungsanalyse dienen. Gemäß den Zielsetzungen dieses Kapitels soll hier gezeigt werden, inwiefern diese Gruppenstrukturen erhalten bleiben, wenn die genetische Komponente mitberücksichtigt wird. Die Ausführungen in den folgenden Abschnitten sollen zunächst die Erzeugung eines Maßes für räumlichgenetische Gruppierung sowie Interpretationsmöglichkeiten für vorgefundene Strukturen liefen.

\subsubsection{Die Erzengung des räumlich-genetischen Abstandsmaßes $d_{s g}$}

Die kombinierte räumlich-genetische Gruppierungsanalyse bedarf eines Differenzenmaßes, welches eine Gruppierung von Elementen garantiert, die sich sowohl genetisch ähnlich sind als auch räumliche Nähe zueinander aufweisen (GREGORIUS 2005b). Der räumliche (euklidische) Abstand wird über die ermittelten Standortkoordinaten der einzelnen Individuen im Raum hergeleitet. Als Multilocus-Abstand zwischen zwei Genotypen wurde der Anteil von Genen eines Genotyps gewählt, die minimal ausgetauscht werden müssen, um den jeweils anderen Genotyp zu erzeugen $\left(d_{0}\right)$.

Um eine Vergleichbarkeit der räumlichen mit den genetischen Abstandmaßen zu erreichen, ist Kommensurabilität zwischen ihnen erzeugt werden. Hierbei sind nach GrEgorius (2005b) drei Möglichkeiten gegeben: Eine Normierung nach den entsprechenden Maximalwerten räumlicher und genetischer Distanz, die Transformation genetischer in räumliche oder die Transformation räumlicher in genetische Abstandsmaße (siehe Punkt 2 in Box 5.2)

Der Abstand zwischen zwei Individuen bzw. Gruppen kann damit sowohl nur räumlich oder nur genetisch aber auch räumlich-genetisch mit unterschiedlicher Gewichtung der beiden Komponenten gemessen werden (siehe Punkt 3 in Box 5.2). In dieser Arbeit wollen wir uns auf die Analyse von räumlichen und räumlichgenetischen Gruppierungen beschränken. Kommensurabilität wird durch eine Normierung der genetischen auf die räumlichen Abstände hergestellt.

Hierdurch können genetische Abstände in Dimensionen der räumlichen Entfernung ausgedrückt werden. Unter den vorgeschlagenen drei Möglichkeiten der Herstellung von Kommensurabilität zwischen räumlichen und genetischen Abständen ist die gewählte Normierung deshalb sinnvoll, da primär ein Vergleich zwischen der 
räumlichen Verteilung der Kirsche und ihren räumlich-genetischen Strukturen angestrebt ist. Dabei erhalten die beiden Komponenten die gleiche Gewichtung ( $a$ $=b=0.5)$ unter maximaler Berücksichtigung der Asymmetrie zwischen ihnen $(c=$ 0.5). Ist nämlich nur eine der Komponenten klein (mit großer Diskrepanz zur anderen Komponente $=$ Asymmetrie), würde dies keine ausreichende Ähnlichkeit implizieren, um eine Gruppierung zu rechtfertigen (vgl. auch GABRIEL \& SOKAL 1969).

\section{Arbeitsschritte der räumlich-genetischen Gruppierungsanalyse}

\section{Kalkulation symmetrischer Distanzmaße}

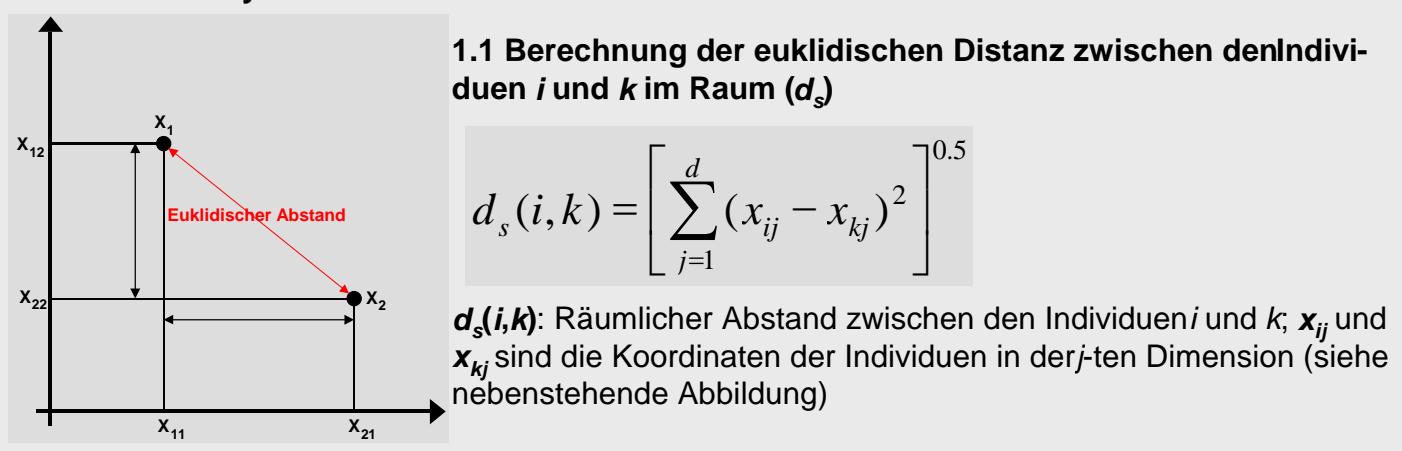

1.2 Der Parameter $\boldsymbol{d}_{0}$ zur Beschreibung der genetischen Distanz(GREGORIUS 1978)

$d_{0}(i, k)=\frac{1}{M} \cdot \sum_{i=1}^{M} D_{G}^{(l)}(i, k)$

$\boldsymbol{d}_{\boldsymbol{0}}(\boldsymbol{i}, \boldsymbol{k})$ quantifiziert den Multilocus-Abstand zwischen zweiGenotypen $i$ und $k$ und stellt den Anteil von Genen einesGenotyps dar, die minimal ausgetauscht werden müssen, um den jeweils anderer Genotyp zu erzeugen; analog dazu bestimmt $\boldsymbol{D}_{G}(\boldsymbol{i}, \boldsymbol{k})$ den genetischen Abstand für jeden einzelnen Locus $I$;

$\boldsymbol{D}_{\mathrm{G}}(\mathbf{i}, \mathbf{k})$ kann die Werte 0 (Identität der Genotypen), 0.5 (Genotypen besitzen jeweils ein gemeinsames Allel) oder 1 (Genotypen haben kein Allel gemeinsam) annehmen; $\boldsymbol{d}_{\boldsymbol{0}}(\boldsymbol{i}, \boldsymbol{k})$ nimmt Werte zwischen 0 und 1 an

$\boldsymbol{M}$ ist die Anzahl der untersuchten Genloci

\section{Erzeugung von Kommensurabilität zwischen räumlichen und genetischen Distanzmaßen} durch Transformation von genetischen Abständen in Einheiten des Raumes(GREGORIUS 2005b)

Wird die räumlich-genetische Gruppierung in Einheiten des Raumes erstellt, so ist die genetische Ein heit (d0) zunächst in die räumliche (in m oder $\mathrm{km}$ ) zu transformieren. Dabei wird deProportionalitätsfaktor x so gewählt, daß die Summe derAbweichungsquadrate minimiert wird. Analog gilt das auch für die Transformation räumlicher in genetische Einheiten.

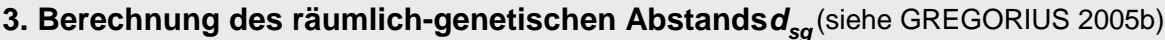

$$
d_{s g}=a \cdot d_{g}+b \cdot d_{s}+c \cdot\left|d_{g}-d_{s}\right|
$$

$\boldsymbol{d}_{s g}$ : Räumlich-genetischer Abstand zwischen zweilndividuen; $\boldsymbol{d}_{\boldsymbol{g}}, \boldsymbol{d}_{\boldsymbol{s}}$ : Kommensurables genetisches und räumliches Abstandsmaß; $\boldsymbol{a}, \boldsymbol{b}$ : Gewichtung des räumlichen undgenetischen Abstands zwischen zwei Individuen, wobeia $+b=1$ c: Parameter zur Berücksichtigung der Diskrepanz Asymmetrie) zwischen $d_{g}$ und $d_{s}$, wobei $|c| \leq \min \{a, b\}$

\section{Darstellung der Ergebnisse in einem Single-Linkage Dendrogramm}

Nach der Berechnung der räumlich-genetischen Distanzen zwischen allenlndividuenpaaren und der Zusammenstellung der Werte in einer Distanzmatrix, erfolgt nun die hierarchische Ordnung irGruppen. Nach der SL-Methode werden dabei im 1. Schritt zunächst die nächsten Nachbarn gruppiert. Im weiteren Verlauf der Gruppierung wird jeweils die minimale Distanz allerlndividuenpaare zwischen Gruppen verwendet (siehe Algorithmusgleichung in Box 5.1) Auf einer Distanzstufe sind demnach alle diejenigen Objekte zu einer Gruppe zusammengefaßt, die zu wenigstens einem der anderen Objekte einen Abstand kleiner oder gleich der Distanzstufe besitzen. 
Bei gleichem Mittelwert zwischen räumlichem und genetischem Abstand wird also gefordert, daß bei zunehmender Diskrepanz (Asymmetrie) zwischen den beiden Komponenten auch die räumlich-genetische Differenzierung zunimmt. Deshalb erhält der Asymmetrie-Parameter $c$ in diesem Falle einen positiven Wert (hier $c=$ $\min \{a, b\}=0.5)$, so daß der räumlich-genetische Abstand nicht mehr gleich dem gewichteten Mittelwert zwischen den kommensurablen Komponenten Raum und Genetik, sondern gleich dem Maximalwert der beiden Komponenten ist $\left(d_{s g}=\right.$ $\max \left\{d_{s}, d_{g}\right\}$ ) (siehe Box 5.2). Auf diese Weise bleiben räumlich-genetische Strukturen erkennbar, welche bei Anwendung herkömmlicher Analysemethoden aufgrund geringerer Korrelationen zwischen räumlichen und genetischen Abständen (Asymmetrie) möglicherweise unentdeckt blieben.

\subsubsection{Räumlich-genetische Gruppenbildung: Symmetrie/Asymmetrie, interne und externe Differenzierung sowie solitäre Objekte}

Werden räumlich-genetische Gruppen gemäß o.g. Definitionen erzeugt, so können folgende Beziehungen realisiert werden (vgl. GrEGORIUs 2005b):

(1) Eine Gruppe von Individuen weist räumlich-genetisch große Abstände zu allen anderen Gruppen auf (innerhalb einer räumlichen Gruppe sind auch die genetischen Abstände klein).

(2) Individuen weisen innerhalb räumlicher Aggregationen große genetische Abstände zueinander auf (genetische Abstände größer als räumliche).

(3) Individuen sind räumlich weit von denjenigen entfernt, zu denen sie geringe genetische Abstände aufweisen (räumliche Abstände größer als genetische).

Zustand (1) unterscheidet sich von den anderen beiden im wesentlichen dadurch, daß hier Symmetrie zwischen dem räumlichen und dem genetischen Abstandsmaß vorliegt (räumliche sowie genetische Nähe von Individuen). In einem Dendrogramm würde Fall (1) zu einer räumlich-genetischen Gruppierung mit einer geringen internen aber starken externen Differenzierung (starke Isoliertheit der Gruppen) führen. Im diesem Fall kann von geringer effektiver Ausbreitung genetischer Information (via Pollen und Samen) möglicherweise in Verbindung mit der Ausbildung mehrerer Generationen vor Ort ausgegangen werden (Familienstrukturen, Isolation-by-distance nach WRIGHT 1943). Auch klonale Vermehrung kann zu starker Gruppenisoliertheit führen. Im Vergleich zu den zuvor betrachteten rein räumlichen Gruppierungen kann erwartet werden, daß die Gruppenstrukturen erhalten bleiben, auch wenn interne Differenzierung und externe Isolation Veränderungen unterworfen sein kann.

In den Fällen (2) und (3) hingegen ist räumlich-genetische Asymmetrie (d.h. geringe räumliche in Kombination mit großen genetischen Abständen oder umgekehrt) zu verzeichnen. In diesen Fällen wäre im räumlich-genetischen Dendrogramm eine geringe externe Isolation der Gruppen zu erwarten, wobei die räumlichen Gruppenstrukturen durch die Hinzunahme des genetischen Abstandsparameters, also bei kombinierter räumlich-genetischer Betrachtungsweise, möglicherweise auch vollständig aufgelöst werden. Demnach würde eine die Einordnung der Individuen in Gruppen entweder erst auf höheren Hierarchieebenen stattfinden oder die Individuen werden im Extremfall als vollständig solitär eingestuft. Im Gegensatz zu Fall 
(1) können hier effiziente Ausbreitungsmechanismen angenommen werden, da Immigranten typischerweise entweder genetisch große Abstände zu denjenigen Gruppen aufweisen, denen sie räumlich nahe sind (d.h. in die sie immigriert sind) oder zu räumlich entfernteren Gruppen (aus denen sie emigriert sind) genetische Ähnlichkeit besitzen.

\subsubsection{Methoden der Erfassung räumlich-genetischer Kovariation}

Bei der Erfassung räumlich-genetischer Kovariation werden hier die räumliche Autokorrelationsanalyse sowie der Mantel-Test verwendet. Diese erlauben die Untersuchung von Zusammenhängen zwischen individuellen genetischen Merkmalen und ihren räumlichen Positionen. Dabei ist insbesondere die Fragestellung von Interesse, ob die vorgefundenen Strukturen der räumlichen Verbreitung genetischer Information möglicherweise signifikant von einer rein zufällig bedingten abweichen. Insbesondere im Zusammenhang mit der zuvor beschriebenen räumlich-genetischen Gruppierungsanalyse können dadurch möglicherweise wichtige Hinweise auf die beteiligten genetischen Mechanismen gewonnen werden, welche für die Entstehung bestimmter Strukturen verantwortlich sind. Auf dieser Grundlage können zumindest neue Hypothesen formuliert werden, welche zu einem späteren Zeitpunkt in gezielten experimentellen Untersuchungen näher analysiert werden können (siehe auch ESCUDERO et al. 2003). Für die im folgenden beschriebenen Verfahren wurde das Computerprogramm SGS (Spatial Genetic Software) verwendet ( DEGEN et al. 2001).

\subsubsection{Moran's Index}

Dieser Parameter quantifiziert die Korrelation bezüglich einer Gendosis zwischen zwei Individuen, welche sich innerhalb einer Distanzklasse befinden. Liegt eine systematische Struktur in der räumlichen Verteilung einer Variable (hier: genetische Information) vor, spricht man von räumlicher Autokorrelation. Positive Autokorrelation besagt, daß in der betrachteten Distanzklasse bestimmte Merkmalsausprägungen häufiger auftreten. In unserem Fall bedeutet dies, daß die Individuen bezüglich ihrer genetischen Information in dieser Distanzklasse untereinander größere Ähnlichkeit aufweisen (relative Häufigkeit eines Allels). Negative Autokorrelation hingegen $(I<0)$ weist darauf hin, daß in der jeweiligen Distanzklasse bevorzugt verschiedene Merkmalsausprägungen vorkommen. Zufällige Muster erhalten einen Wert, welcher nahe Null liegt (siehe auch SOKAL \& ODEN 1978 sowie SOKAL \& WARTENBERG 1983).

Der Index von MORAN $I_{q}(1950)$ berechnet sich wie folgt:

$$
I_{q}=\frac{n \sum_{i=1}^{n} \sum_{j \neq i}^{n} w_{i j}\left(a_{i}-\bar{a}\right)\left(a_{j}-\bar{a}\right)}{W \sum_{i=1}^{n}\left(a_{i}-\bar{a}\right)^{2}} \quad W=\sum_{i=1}^{n} \sum_{j \neq i}^{n} w_{i j}
$$


$\boldsymbol{n}$ : Anzahl Proben (hier jeweils die Vollaufnahme der auf Grundlage des hierarchischen Isolationsprinzips systematisch abgegrenzten Bestände);

$\boldsymbol{w}_{i j}$ : Parameter, der die Zugehörigkeit zweier Individuen zu einer bestimmten Distanzklasse erfaßt; der Parameter erhält den Wert 1, wenn die Individuen $i$ und $j$ in die bestimmte Distanzklasse fallen, andernfalls 0.

$\boldsymbol{a}_{i}, \boldsymbol{a}_{j}$ : Dosierung eines bestimmten Merkmals bei Individuen $i$ und $j$ (Wert 1: Individuum homozygot für ein bestimmtes Allel ist; 0.5: Individuum heterozygot für ein bestimmtes Allel; 0: Abwesenheit des bestimmten Allels)

$\overline{\boldsymbol{a}}$ : Arithmetischer Mittelwert von $\boldsymbol{a}_{\boldsymbol{i}}$ über alle $\boldsymbol{n}$ Individuen

Moran's I wurde einerseits für die Gesamtheit aller Individuen (also auch aller klongleichen Individuen) als auch für alle Genets kalkuliert. Letzteres wurde durch die Berechnung der geometrischen Mittelpunkte der gefundenen Klonkomplexe hergeleitet, d.h. durch die Ermittlung der arithmetischen Mittel der X- und Y-Koordinaten. Insgesamt wurden neun Distanzklassen (I bis IX) von jeweils $20 \mathrm{~m}$ (Spanne: 0 bis $180 \mathrm{~m}$ ) analysiert.

\subsubsection{Distanqklassenbasierte räumlich-genetische Kovariation unter Verwendung des gene- tischen Abstands $d_{0}$}

Hier wird der für eine bestimmte Distanzklasse ermittelte Wert für $d_{0}$ (GREGORIUS 1978, siehe symmetrisches genetisches Distanzmaß in Box 5.2) mit dem über alle Distanzklassen gemittelten Wert verglichen, wobei $0 \leq d_{0} \leq 1$ ist. Ist der Wert für eine bestimmte Distanzklasse kleiner als der Mittelwert, liegt positive räumlichgenetische Kovariation vor. Ist dieser Wert größer, liegt negative Kovariation vor. Als zufällig ist die räumliche Verbreitung der Genotypen dann zu bezeichnen, wenn die beobachteten Werte der Distanzklassen mit dem über alle Distanzklassen gemittelten Wert übereinstimmen (vgl. 5.2.2.1). Analog zu Moran's I wurden die Werte für $d_{0}$ hier ebenfalls sowohl für alle Individuen als auch ausschließlich für Genets innerhalb von neun Distanzklassen (I bis IX) von jeweils $20 \mathrm{~m}$ (Spanne 0 bis $180 \mathrm{~m}$ ) berechnet.

\subsubsection{Das statistische Testverfahren bęüglich distan₹klassenbasierter räumlich-genetischer Kovariation}

Um zu testen, ob signifikante Abweichungen von einer zufälligen räumlichen Verbreitung genetischer Information vorliegen, wird im o.g. Computerprogramm ein Permutationstest (Monte-Carlo Simulation) durchgeführt. Jede einzelne Permutation beinhaltet hier eine zufällige Neuverteilung der einzelnen Multilocus-Genotypen auf die jeweils ermittelten räumlichen Koordinaten der Altbäume innerhalb der untersuchten Bestände. Insgesamt wurden jeweils 1000 Permutationen pro Bestand ausgewertet, woraus ein Konfidenzbereich abgeleitet wurde, in dem sich jeweils 95\% aller ermittelten Werte für $I$ bzw. $d_{0}$ befanden. Lag der tatsächlich beobachtete Wert außerhalb dieses Intervalls, wurde das Ergebnis als signifikant abweichend (also positiv bzw. negativ autokorreliert) bewertet. 


\subsubsection{Der Mantel-Test}

Dieses Testverfahren (MANTEL 1967) benötigt ebenfalls eine genetische sowie eine räumliche (euklidische) Distanzmatrix. Dabei wird auf die Bildung von Distanzklassen verzichtet und über alle Individuenpaare ein Korrelationskoeffizient (Pearsons Korrelationskoeffizient) zwischen den beiden Distanzmaßen in der Stichprobe ermittelt. Der Korrelationskoeffizient $\left(r_{M}\right)$ variiert zwischen den Werten -1 und 1. Um eine statistische Beurteilung zu ermöglichen, wurden hier 10000 Permutationen durchgeführt, woraus der sogenannte $p$-Wert berechnet wurde. Dieser macht eine Aussage darüber, wie groß die Wahrscheinlichkeit ist, daß noch extremere (positive oder negative) Werte für $r_{M}$ bei zufälliger Besetzung der einzelnen räumlichen Positionen auftreten können.

\subsection{Ergebnisse}

\subsubsection{Die räumliche Verteilung der Altbäume: Erfassung von Gruppen- strukturen, Gruppenisoliertheit sowie solitäre Individuen}

Die Kartenübersichten der untersuchten Kirschenbestände (Abb. 5.2, 5.5, 5.8) zeigen die Positionen der Altbäume, die Einordnung der einzelnen Individuen in räumliche Gruppen sowie auch klonale Strukturen. Die einzelnen Klongruppen sind hier mit Buchstaben bezeichnet und basieren auf denjenigen Informationen, die schon in Kapitel 4.3.4 zur Berechnung der Anteile sexueller und asexueller Vermehrung innerhalb der Kirschenvorkommen dienten.

Die Zuordnung der Individuen in Gruppen wurde durch eine Zerlegung der Bestände auf unterschiedlichen Nachbarschaftsniveaus herausgearbeitet (Bildung von Gruppen auf der Basis unterschiedlicher Abstände zwischen nächsten Nachbarn). In einem zweiten Schritt wurden die paarweisen räumlichen Distanzmaße in ein Single-linkage-Dendrogramm überführt (Abb. 5.3, 5.6, 5.9). Zur Beschreibung der räumlichen Verteilung der Individuen innerhalb der Bestände werden Maße, wie z.B. die interne und externe Gruppendifferenzierung $\left(I_{A}\right.$ und $\left.E_{A}\right)$ sowie Gruppenisoliertheit $\left(I s o_{A}\right)$ aus Box 5.1 verwendet.

Der Bestand Roringen (=Ror) (siehe Abb. 5.2 und 5.3): Im Bestand von Ror (insg. 56 Individuen) kommt die Vogelkirsche auf einem Nachbarschaftsniveau von maximal $20 \mathrm{~m}$ zum Teil einzelstammweise, vorwiegend aber gruppiert mit unterschiedlichen Individuenzahlen pro Gruppe vor. Im nordwestlichen Bereich des Kirschenvorkommens, der eher den Innenbereich dieses Waldbestands von Ror charakterisiert, ist die Kirsche in drei größeren Gruppen vorzufinden (Gruppen I, III und IV mit bis zu 18 Individuen). Im südlichen und westlichen Bereich hingegen sind solitäre Einzelbäume und kleinere Gruppen (mit bis zu vier Individuen) zu beobachten. Insbesondere die Bäume Nr. 1 bis 5 sowie 10 sind in waldrandnahen Bereichen angesiedelt.

Insgesamt können acht Gruppen (mit zwei bis 18 Individuen pro Gruppe) sowie acht solitäre Objekte auf diesen Nachbarschaftsniveaus ausgeschieden werden. 
Bei der schrittweisen Erhöhung der Nachbarschaftsniveaus nimmt die Anzahl an Gruppen sowie an solitären Objekten stetig ab, während die Anzahl Bäume pro Gruppe stetig zunimmt. So können bei einem Nachbarschaftsniveau von 30 m nur noch sechs Gruppen sowie zwei Solitäre (Bäume Nr. 7 und 11) beobachtet werden. Wird dieses Nachbarschaftsniveau auf $40 \mathrm{~m}$ vergrößert, wird der gesamte nördliche sowie südwestliche Bereich einer einzigen Gruppe zugeordnet. Im südlichen und östlichen Bereich der Untersuchungsfläche werden auf letzterem Niveau weiterhin solitäre Objekte (Nr. 11) sowie isolierte Baumgruppen ausgeschieden (Gruppen V und VI sowie Bäume Nr. 1-2). Auf dem höchsten in den Übersichtkarten dargestellten Niveau $(50 \mathrm{~m})$ bleiben nur noch Gruppe V als isolierte Gruppe sowie Baum Nr. 11 als Solitär im östlichen Teil des Bestandes übrig, während alle anderen in einer Gruppe zusammengefaßt sind.

Die Darstellung der paarweisen Distanzen in einem Single-linkage-Dendrogramm spiegelt die oben beschriebenen Verhältnisse exakt wieder. Darüberhinaus erhalten wir hier zusätzliche Erkenntnisse bezüglich der Isoliertheit der einzelnen Gruppen (siehe Box 5.1). So zeigen die Gruppen V und VI die stärkste Isoliertheit (minimaler Abstand zur nächsten Gruppe von $58.5 \mathrm{~m}$ für Gruppe $\mathrm{V}$ und $44,5 \mathrm{~m}$ für Gruppe VI sowie einer Isolation von $\left.I s o_{V}=0.70, I s o_{V I}=0.64\right)$, während die Gruppen I bis IV sowie VII und VIII räumlich weniger stark isoliert sind (Iso = 0.17 bis 0.52). Dabei ist allerdings zu berücksichtigen, daß nicht nur der Abstand zwischen Gruppen zur Isoliertheit beiträgt, sondern auch die Stärke der Aggregation innerhalb der Gruppen (also die interne Differenzierung). Gruppe III beispielsweise weist einen minimalen Abstand von nur $25 \mathrm{~m}$ zu Gruppe IV auf, ist aber dennoch stark isoliert $\left(I s o_{I I I}=0.57\right)$ aufgrund einer sehr geringen internen Differenzierung (d.h. der größte minimaler Abstand zum nächsten Nachbarn innerhalb der Gruppe ist sehr gering).

Wie schon aus dem vorangegangenen Kapitel hervorgeht, ist der Verklonungsanteil in Ror der geringste. Die Ramets der verschiedenen Klonkomplexe liegen meist dicht beieinander (siehe Klongruppe RorA) oder weisen kettenartige Strukturen auf (RorB, RorD). So zeigen die Ramets des Klonkomplexes RorD einen maximalen Abstand zwischen nächsten Nachbarn von unter $11 \mathrm{~m}$, für RorA beträgt dieser Abstand nur knapp über $2 \mathrm{~m}$.

Der Bestand Wibbecke (=Wib) (siehe Abb. 5.5 und 5.6): Der Bestand Wib dehnt sich mit 78 Individuen über eine etwa doppelt so große Fläche aus wie der Bestand von Roringen. Hier konnten insgesamt 13 Gruppen auf einem Nachbarschaftsniveau von $20 \mathrm{~m}$ ausgeschieden werden. Bei der schrittweisen Erhöhung der Nachbarschaftsniveaus verschmelzen auch hier ein Großteil Gruppen, bis bei einem Niveau von $50 \mathrm{~m}$ noch drei isolierte Gruppen verbleiben.

Die Gruppen I bis V und XIII befinden sich im wesentlichen in waldrandnahen Bereichen, an die größere landwirtschaftliche Flächen anschließen. Die Gruppen VI bis XI besiedeln den Waldinnenraum dieses Bestands.

Insgesamt ist hier (im Gegensatz zum Bestand von Roringen) eine größere Spannbreite an Werten für die Isolation der einzelnen Gruppen zu verzeichnen. Sie reicht von $I s o_{X I I I}=0.03$ bis $I s o_{V I}=0.94$. Die Ursache für diese breit gefächerten Werte 
liegt zum einen in einer noch stärkeren Aggregation der Individuen innerhalb der einzelnen Gruppen und zum anderen auch in der Bildung von Kettenstrukturen durch die Single-linkage-Methode begründet. Die Gruppen I und VII beispielsweise weisen eine sehr starke Isolation auf $\left(I s o_{I}=0.72 ; I s o_{\text {III }}=0.80\right)$, was durch eine geringe innere Differenzierung von nur ca. $7 \mathrm{~m}$ zwischen nächsten Nachbarn und einer hohen externen Differenzierung von $E_{I}=27 \mathrm{~m}$ und $E_{V I I}$ von $35 \mathrm{~m}$ erklärt werden kann. Andererseits liegt für die Gruppe V im östlichen Teil des Bestandes eine wesentlich geringere Isolation vor $\left(I s o_{V}=0.17\right)$. So wird Baum Nr. 62 bei einem Nachbarschaftsniveau von $20 \mathrm{~m}$ gerade noch nicht in die Gruppe V eingegliedert, ist aber der Grund für die geringe externe Differenzierung sowie Isolation der Gruppe V.

Bei Betrachtung der klonalen Strukturen sind allerdings erhebliche Unterschiede zum Bestand von Ror festzustellen. Zum einen ist ein wesentlich höherer Anteil an potentiell aus vegetativer Vermehrung stammender Individuen zu verzeichnen, andererseits bestehen Klonkomplexe nicht ausschließlich aus Klumpungen (Aggregationen), sondern vermischen sich teilweise untereinander sowie auch mit individuellen (und somit vermutlich aus sexueller Reproduktion stammenden) Genotypen. Insbesondere die Ramets der Klongruppen Wib A, Wib C, Wib D, Wib F, Wib J und Wib K verteilen sich bei einem Nachbarschaftsniveau von $20 \mathrm{~m}$ auf verschiedene räumliche Gruppen (hier: Gruppen VIII und IX sowie XI und XII). Gruppe VII beispielsweise ist eine Mischung aus drei individuellen MLG sowie einem Genet bestehend aus sechs Ramets (Wib J). Gruppe V hingegen besteht (mit Ausnahme von Baum Nr. 46) aus einer großen Aggregation von Bäumen mit identischem MLG. Die Abstände einzelner Ramets desselben Klons können hier beträchtliche Werte annehmen. Die Bäume Nr. 62 und 64 (zu Klongruppe Wib K gehörend) liegen nahezu $70 \mathrm{~m}$ auseinander.

Der Bestand Settmarshausen (=Set) (siehe Abb. 5.8 und 5.9): Auf einem Nachbarschaftsniveau von $20 \mathrm{~m}$ können die insgesamt 39 Individuen in Set zu zehn Gruppen und drei Solitären zusammengefaßt werden. Bei der Erhöhung dieses Niveaus auf $30 \mathrm{~m}$ werden nur die Gruppen V bis VI zusammengefaßt, während die anderen Gruppen (I und II sowie VII bis X) auch hier noch als isolierte Gruppen bestehen bleiben. Erst auf einem Nachbarschaftsniveau von $40 \mathrm{~m}$ verschmelzen die meisten Gruppen zu größeren Komplexen.

Die Werte für die Isolation der einzelnen Gruppen innerhalb des Nachbarschaftsniveaus von $20 \mathrm{~m}$ sind im Vergleich zu den anderen Beständen geringfügig höher $\left(I s o_{I V}=0.42\right.$ bis $\left.I s o_{I I}=0.90\right)$.

Bezüglich des Anteils an aus potentiell vegetativer Vermehrung stammender Individuen nimmt dieser Bestand eine Mittelstellung ein. Ähnlich wie im Bestand von Ror sind die internen räumlichen Differenzierungen der einzelnen Genets meist nur sehr gering. Ausnahmen bilden die Klongruppen SetA und SetC $\left(I_{\text {SetA }}=22.85\right.$ $\mathrm{m}$ und $I_{\text {SetC }}=20.0 \mathrm{~m}$ ).

Dieser Bestand besiedelt im wesentlichen den Waldinnenbereich. Nur die Bäume Nr. 16 und 18 stocken am Waldrand. 
Vergleich der drei Bestände: Es zeigt sich, daß die Gesamthöhe der Dendrogramme im Falle von Ror und Set recht ähnlich ausfallen, nur in Wib wird ein höherer Wert erreicht. Diese Werte entsprechen der inneren räumlichen Differenzierung der Bestände, die gleich den höchsten der gemessenen Minimalabstände innerhalb der Vogelkirschenvorkommen sind. So beträgt der Minimalabstand der Baumgruppe XIII von seinem Komplement (also seine externe Differenzierung) in Wib ca. 90 $\mathrm{m}$. In Set bilden die Bäume $\{36,37\}$ die am stärksten isolierteste Gruppe mit einer externen Differenzierung von ca. $65 \mathrm{~m}$. In Roringen bildet ein Solitär (Baum Nr. 11) mit einem Abstand von ungefähr $60 \mathrm{~m}$ zu seinem nächsten Nachbarn die höchste Hierarchieebene im Dendrogramm.

Es bleibt anzumerken, daß die hier vorgefundenen internen hierarchischen Strukturen auch dann bestehen bleiben, wenn hypothetisch eine großräumigere Vernetzung mit weiteren Kirschenvorkommen in der Landschaft vorgenommen wird. Das liegt daran, daß der minimale Abstand zwischen einem Individuum der hier untersuchten Bestände zu weiteren Individuen der Vogelkirsche in der Umgebung in jedem Falle größer ist als die hier berechnete interne Differenzierung der vorliegenden Kollektive (siehe $I_{\Omega}$ in Box 4.3).

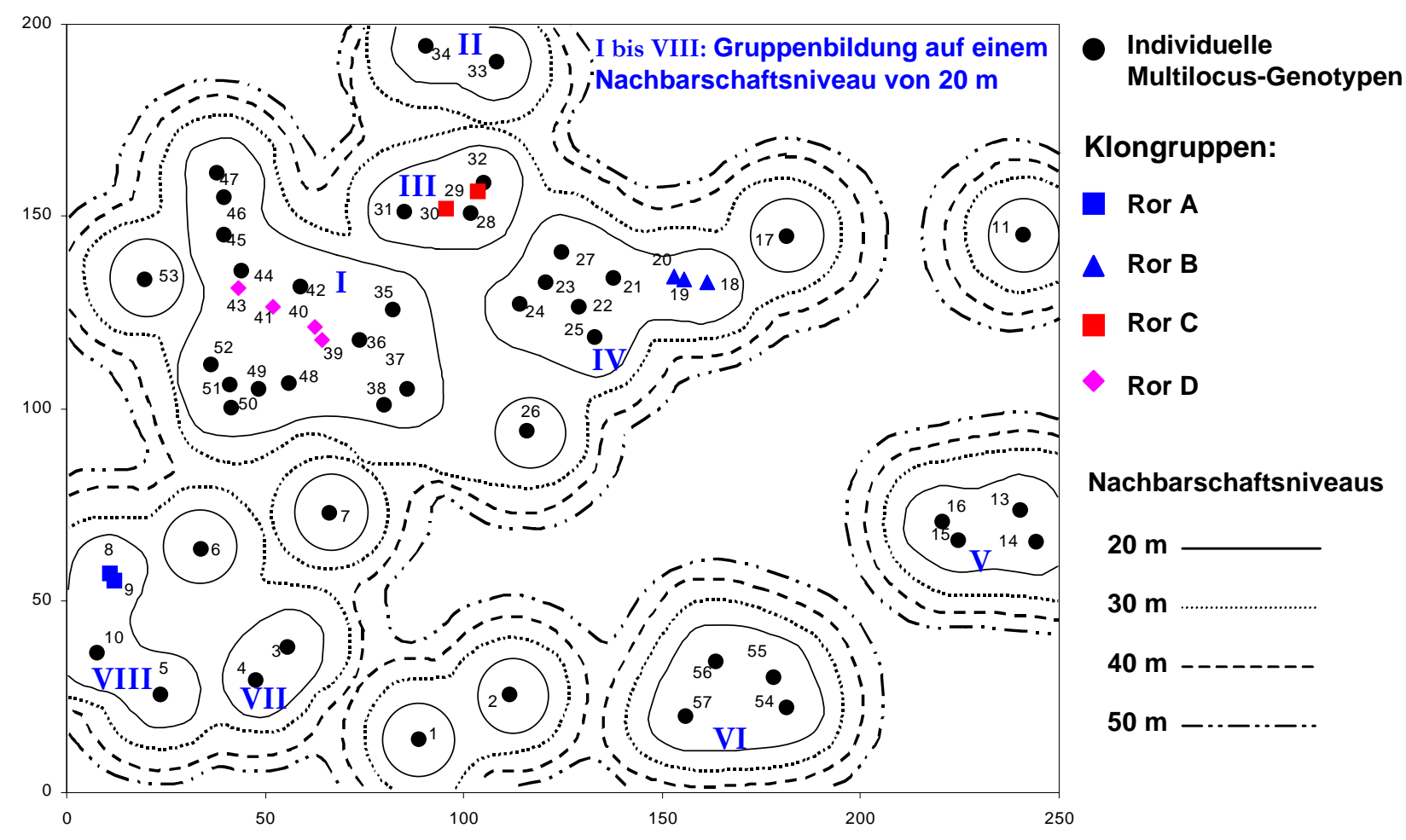

Abb. 5.2: Kartenübersicht mit der Verteilung der Altkirschen im Bestand von Roringen 


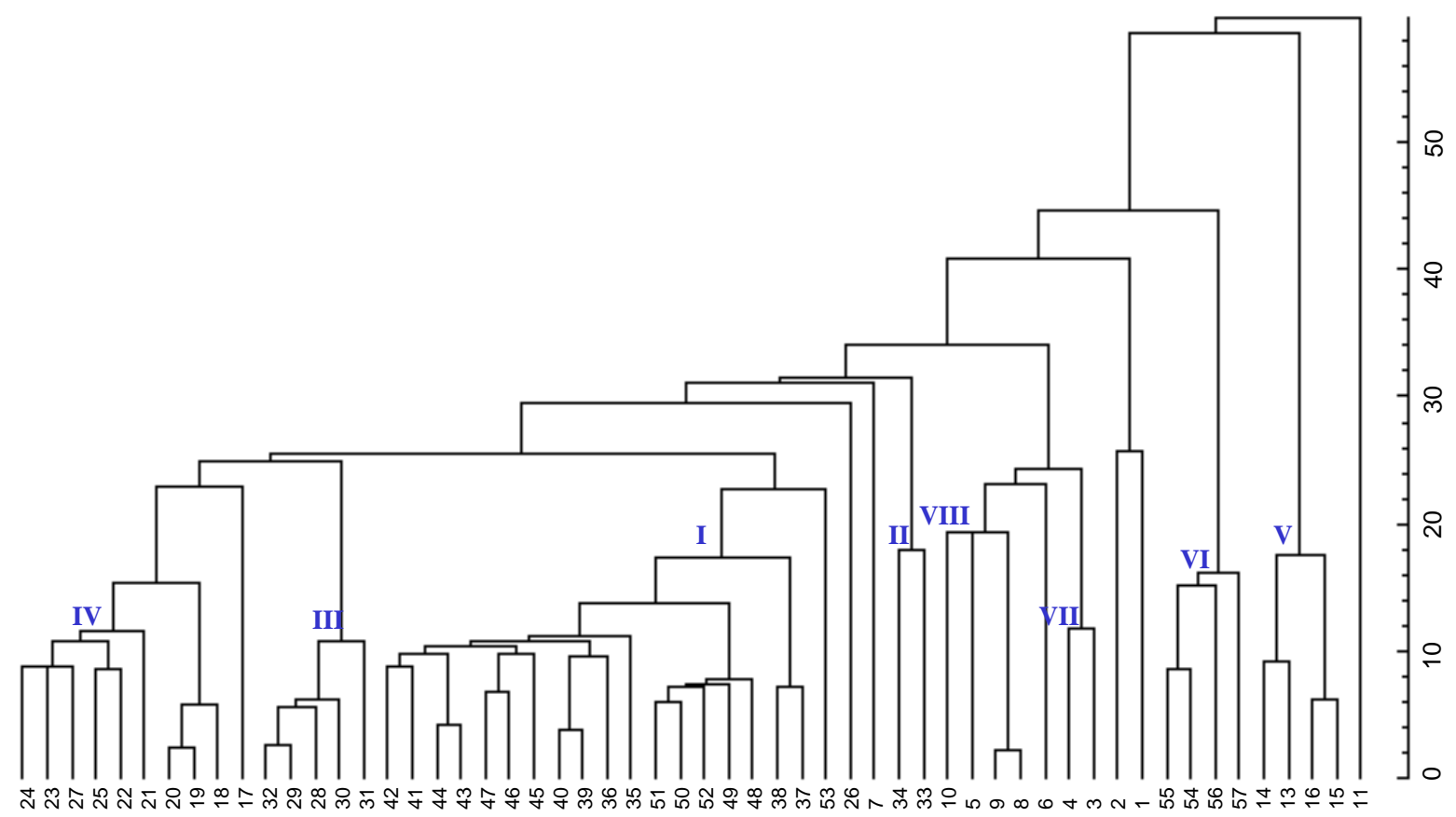

Abb. 5.3: Single-linkage-Dendrogramm der räumlichen Abstände zwischen Altbäumen im Bestand von Roringen

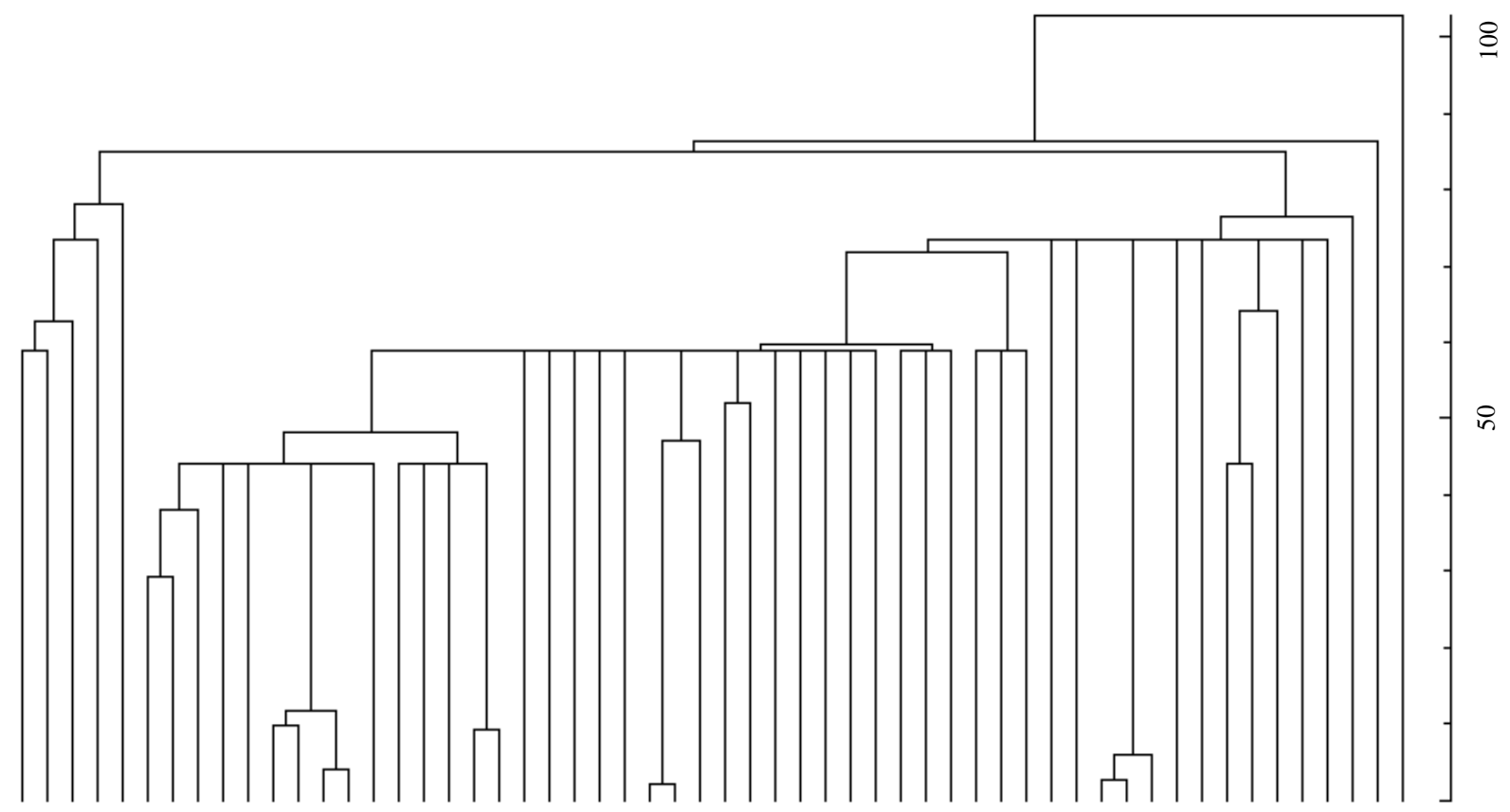

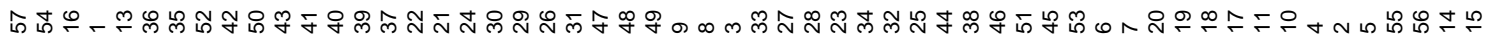

Abb. 5.4: Single-linkage-Dendrogramm der räumlichen-genetischen Abstände zwischen Altbäumen im Bestand von Roringen 


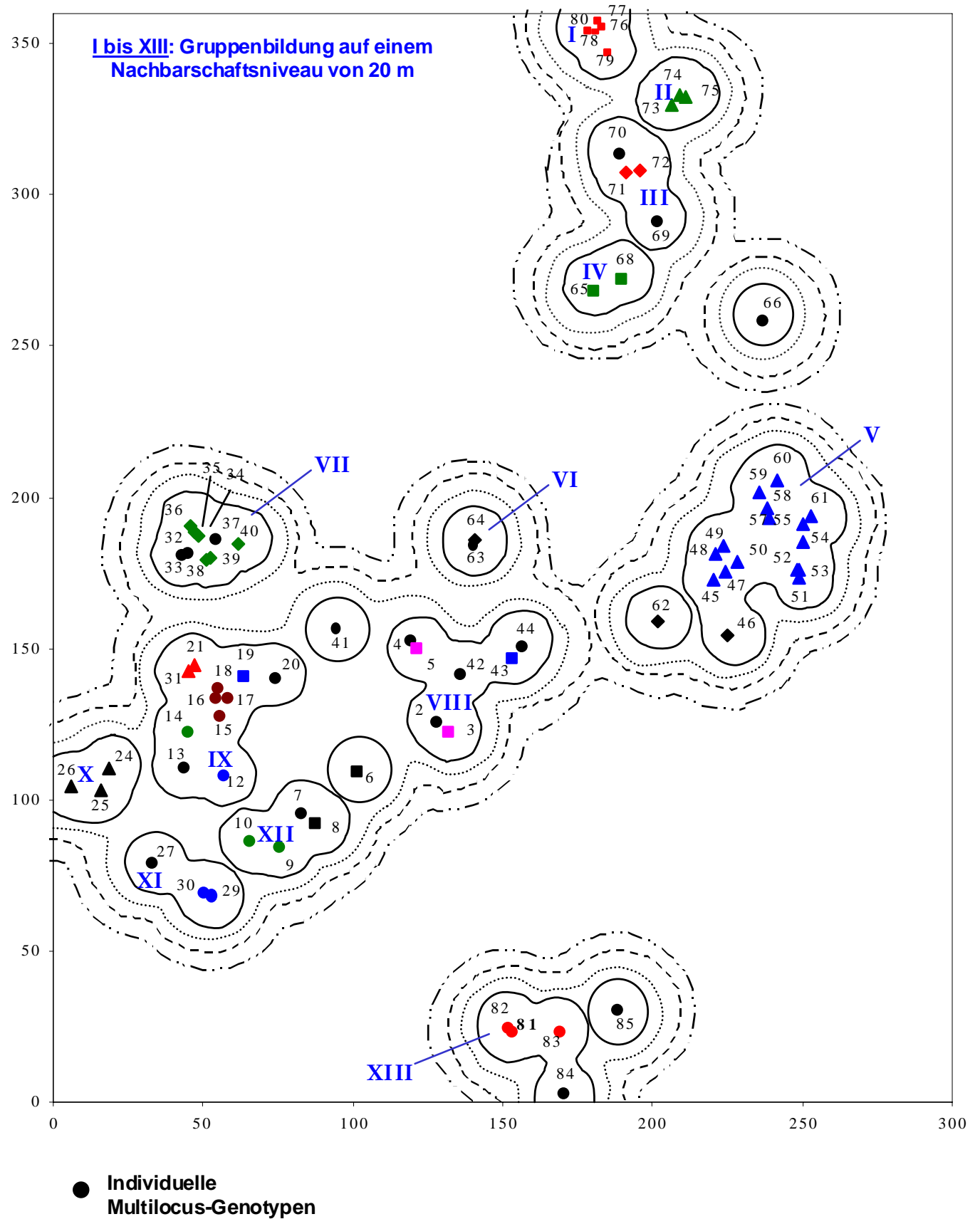

Klongruppen:

\begin{tabular}{|c|c|c|c|c|}
\hline Wib A & Wib E & $\Delta$ Wib I & Wib M & $20 \mathrm{~m}$ \\
\hline Wib B & Wib F & Wib J & $\Delta$ Wib $N$ & $30 \mathrm{~m}$ \\
\hline Wib C & $\Delta$ Wib G & $\diamond$ Wib K & Wib 0 & $40 \mathrm{~m}$ \\
\hline Wib D & $\Delta$ Wib H & Wib L & Wib P & $50 \mathrm{~m}$ - \\
\hline
\end{tabular}

Abb. 5.5: : Kartenübersicht mit der Verteilung der Altkirschen im Bestand von Wibbecke 


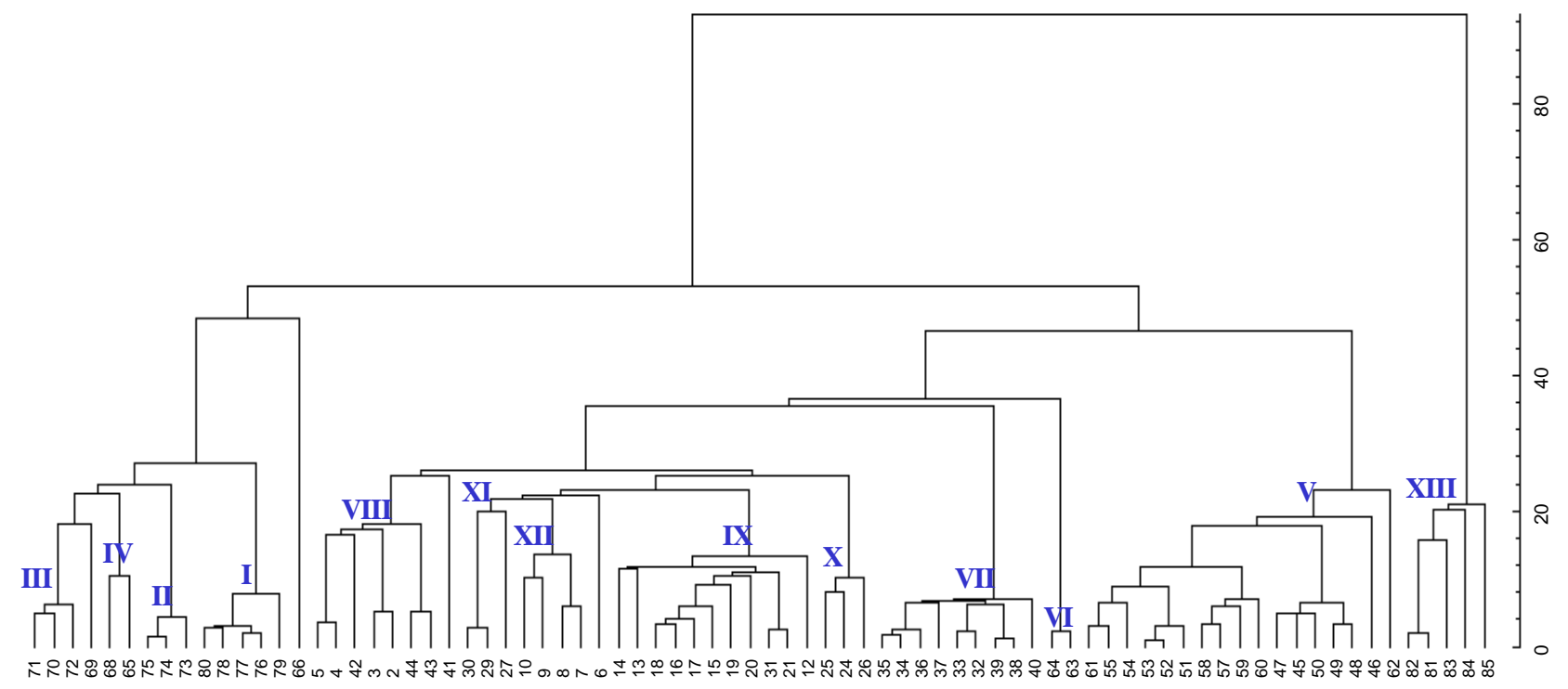

Abb. 5.6 : Single-linkage-Dendrogramm der räumlichen Abstände zwischen Altbäumen im Bestand von Wibbecke

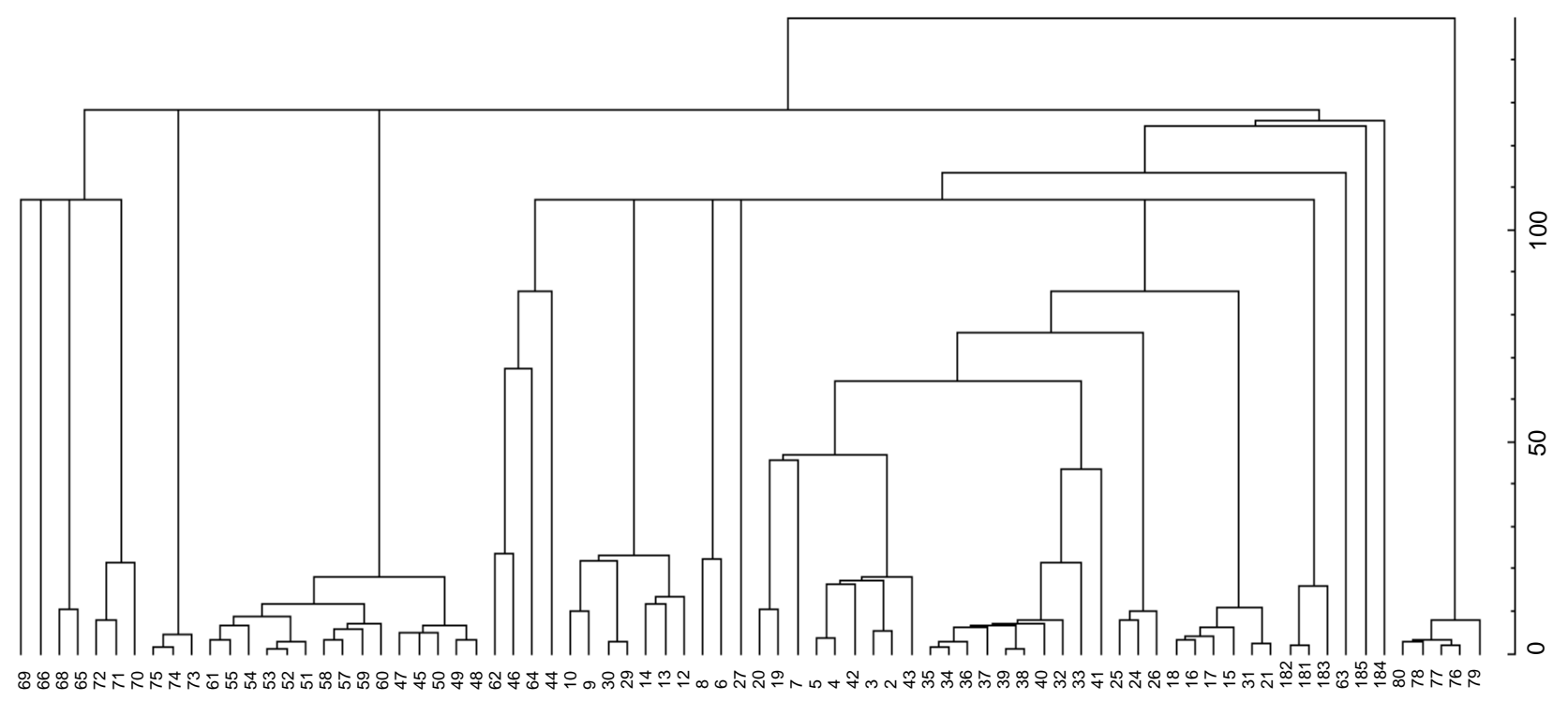

Abb. 5.7: Single-linkage-Dendrogramm der räumlichen-genetischen Abstände zwischen Altbäumen im Bestand von Wibbecke 


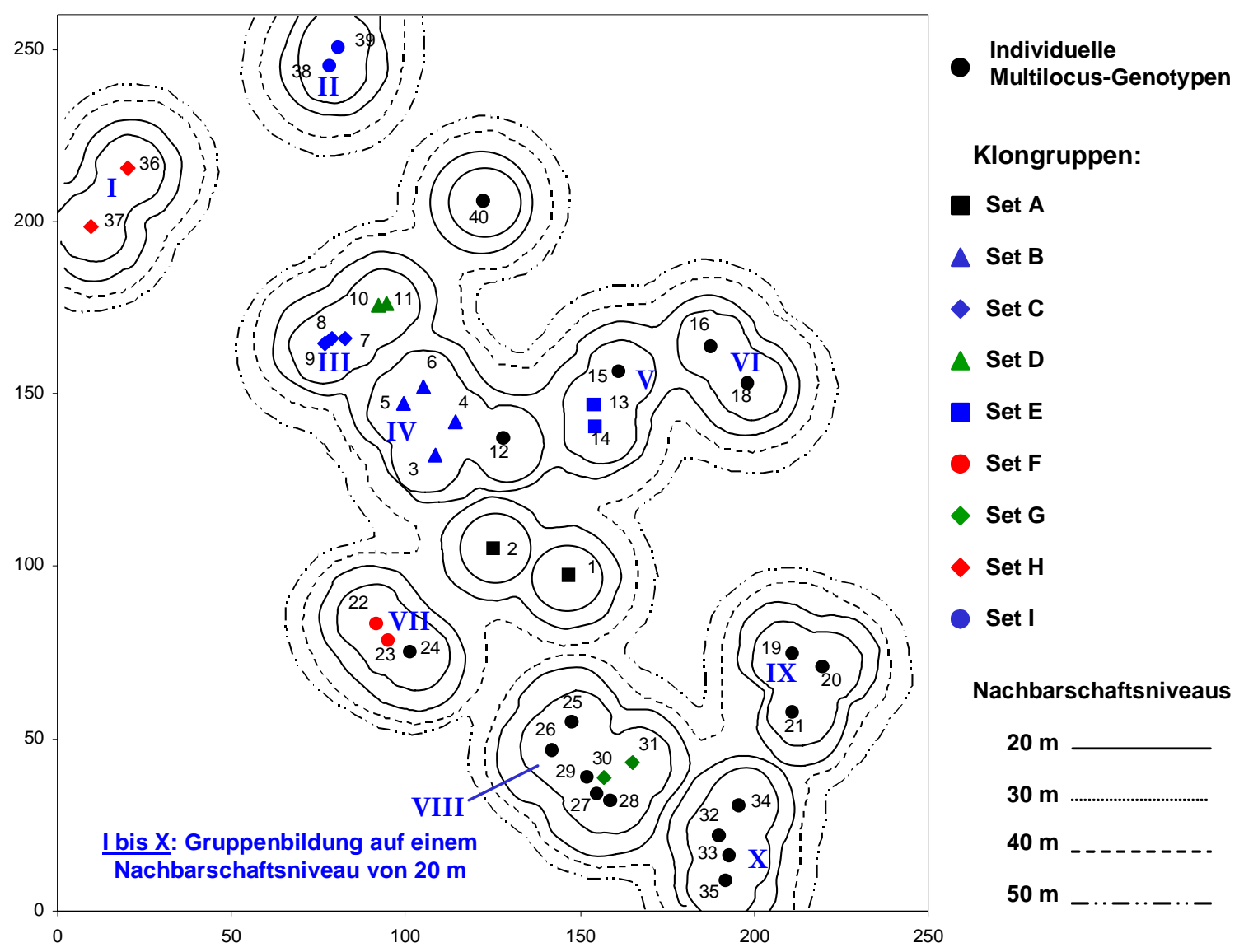

Abb. 5.8 : Kartenübersicht mit der Verteilung der Altkirschen im Bestand von Settmarshausen

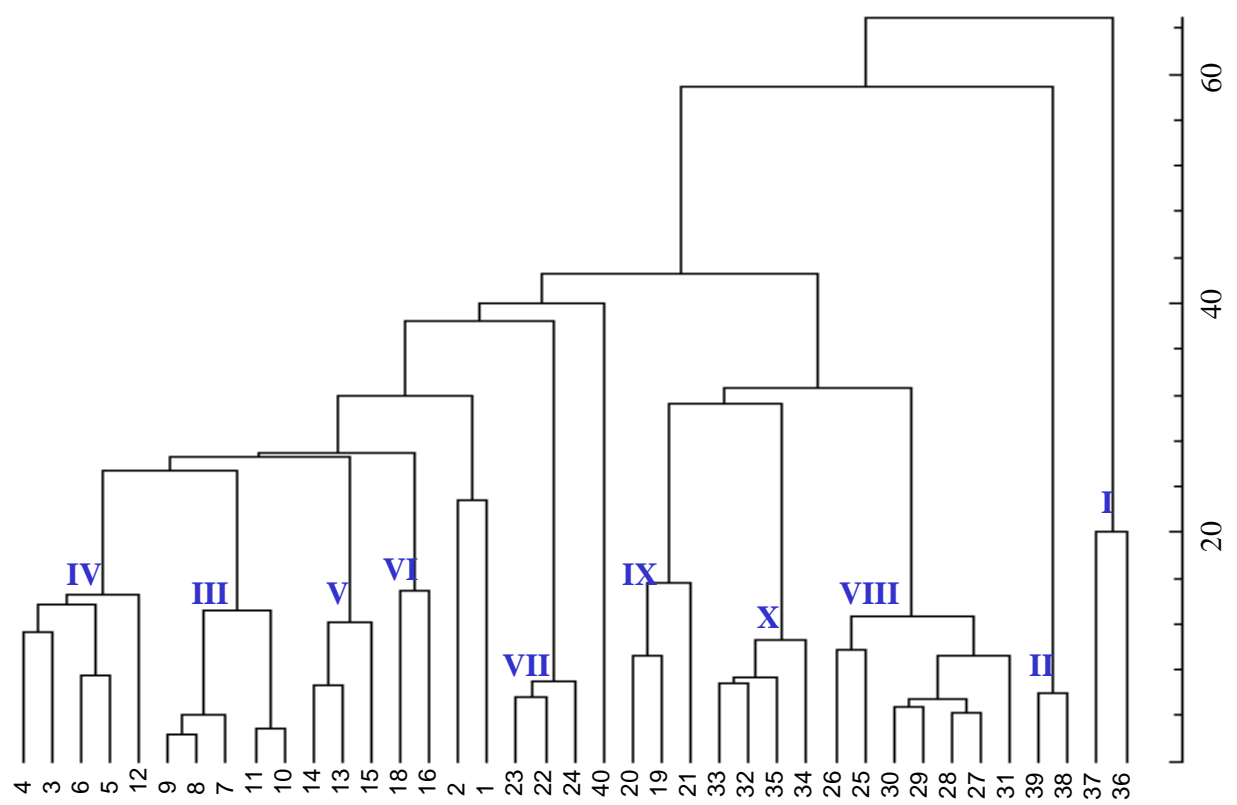

Abb. 5.9 : Single-linkage-Dendrogramm der räumlichen Abstände zwischen Altbäumen im Bestand von Settmarshausen 


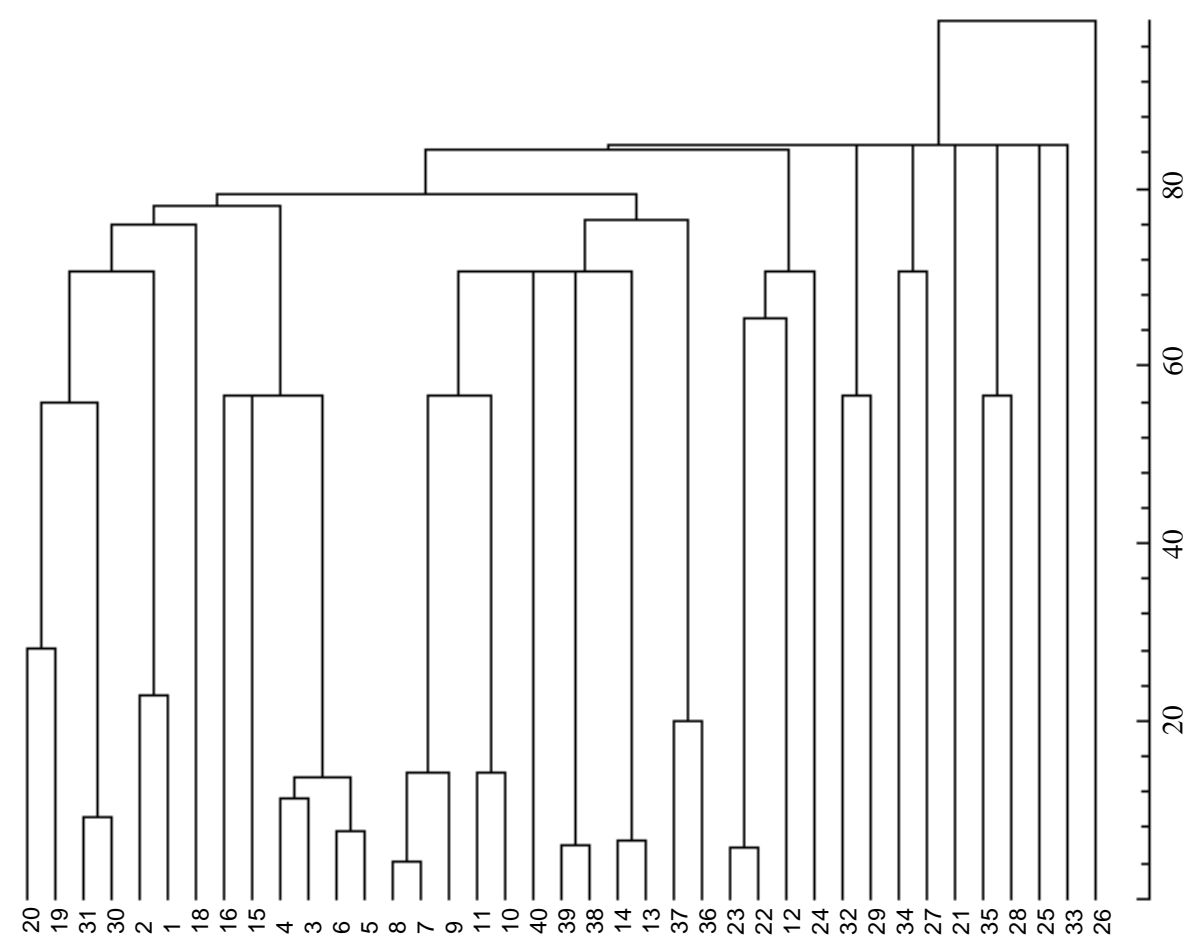

Abb. 5.10: Single-linkage-Dendrogramm der räumliche-genetischen Abstände zwischen Altbäumen im Bestand von Settmarshausen

\subsubsection{Die räumlich-genetische Gruppierung der Individuen ( $d_{0}$ als gene- tische Komponente)}

Bei Betrachtung der räumlich-genetischen Strukturen (Abb.5.4, 5.7, 5.10) fällt auf, daß die Maximalwerte in den Dendrogrammen in Bezug auf die rein räumlichen Abstände stark zugenommen haben. Das liegt an der Herleitung des räumlich-genetischen Abstandsmaßes $d_{s g}$ unter vollständiger Berücksichtigung der Asymmetrie zwischen den beiden Komponenten. Nur der größere von beiden Werten, also entweder der genetische oder der räumliche Abstand, fließt in die Kalkulation (räumlich-genetische Distanzmatrix) ein.

Werden Dendrogramme aus rein räumlichen Abstandsmaßen in natürlichen Pflanzenvorkommen erzeugt, ist meist eine viel größere Zahl an hierarchischen Ebenen erkennbar als in denjenigen, welche ausschließlich auf diskreten genetischen Abständen beruhen. In unserem Fall könnten durch die Verwendung von sechs kodominanten SSRs höchstens zwölf verschiedene Werte für $d_{0}$ in die genetische Distanzmatrix eingehen und damit auch maximal zwölf genetisch determinierte Hierarchieebenen im Dendrogramm erzeugt werden. Meistens ist die Anzahl an Hierarchieebenen aber deutlich geringer, da Single-linkage jeweils die Minimalabstände für die Gruppenbildung berücksichtigt. Alle potentiell möglichen Ebenen könnten nur dann erzeugt werden, wenn viele Individuen mit einer großen Zahl an privaten Allelen ausgestattet wären und mindestens ein Individuum vollständig durch private Allele charakterisiert ist. Dies ist selbst bei hochvariablen SSR-Markern kaum zu erwarten. Ein weiteres wichtiges Charakteristikum von auf rein genetischen Abstän- 
den basierten Dendrogrammen ist demzufolge die Entstehung von sogenannten Ties. Das sind hierarchische Ebenen, an denen mehr als zwei 'relativ' solitäre Objekte bzw. Gruppen hängen und deren externe Differenzierungen demnach identisch sind.

Bei Betrachtung der räumlich-genetischen Strukturen der drei Untersuchungsbestände können sowohl durch die Genetik (Ties) als auch durch den Raum beeinflußte Strukturen innerhalb der Dendrogramme beobachtet werden, wobei deren Anteile in den verschiedenen Beständen unterschiedlich ausfallen.

Der Bestand Roringen (Abb. 5.4): Für diesen Bestand kann festgestellt werden, daß intern schwache und extern starke räumlich-genetische Differenzierung (=starke Isoliertheit) nur für Klongruppen vorliegt (Bäume 18-20, 8-9, 39-40-41-43), da hier nur der geringe räumliche Abstand der Klonindividuen in dem räumlich-genetischen Parameter eingeht.

Insgesamt werden die räumlichen Strukturen durch die genetische Komponente stark verändert. So werden die meisten Individuen und Klongruppen der räumlichen Kirschengruppen I bis IV im nordwestlichen Bereich des Vorkommens (bis auf wenige Ausnahmen wie z.B. Bäume Nr. 45 und 51 sowie Klongruppe 18-19-20) räumlich-genetisch zwar in einem eigenen Cluster zusammengefaßt $\left(d_{s g}<60 \mathrm{~m}\right)$, allerdings mit intern starker und extern schwacher Differenzierung (=schwache Isoliertheit). Die Bildung dieser Gruppe wird im wesentlichen durch die genetische Komponente geprägt, da viele der Individuen bzw. der Untergruppen durch oben beschriebene Ties verknüpft sind. Allerdings sind hier auch noch zwei Untergruppen (mit Individuen aus den jeweiligen räumlichen Gruppen I sowie III und IV) zu erkennen mit einem räumlich-genetischen Abstand von $d_{s g}<40 \mathrm{~m}$.

Im südöstlichen Teil der Untersuchungsfläche werden die kleineren, räumlich existierenden Gruppen V und VI (Bäume Nr. 13-16, 54-57) aufgrund starker genetischer Differenzierung zwischen den Individuen teilweise vollständig aufgelöst. Auch die meisten Objekte, die bei einem Nachbarschaftsniveau von maximal $20 \mathrm{~m}$ als Einzelindividuen eingestuft wurden $(\mathrm{Nr} .1,2,6,7,11,17)$, werden auch räumlich-genetisch als solitäre Objekte eingeordnet $\left(d_{s g}\right.$ ca. 70 bis 100).

Insgesamt ist zu erkennen, daß die stärker isolierten Individuen im südlichen (waldrandnahen) Bereich der Untersuchungsfläche auch räumlich-genetisch meist erst auf höheren Ebenen einer Gruppe zugeordnet werden. Baum Nr. 15 beispielsweise bestimmt als solitäres Objekt die höchste räumlich-genetische Hierarchieebene und muß sich daher genetisch sehr stark von dem Rest der Individuen der räumlichen Gruppe V unterscheiden.

Der Bestand Wibbecke (Abb. 5.7): Im Gegensatz zu Ror ist in Wib eine viel stärkere Strukturierung erkennbar, wobei viele der dargestellten räumlichen Gruppen auch bei der räumlich-genetischen Betrachtungsweise erhalten bleiben (z.B. Gruppen I, II, III, IV, V, VII, X). Der wesentliche Unterschied zum Bestand in Roringen liegt in der Isoliertheit der räumlich-genetischen Gruppen. Ein wichtiger Grund ist der relativ hohe Anteil an Individuen, welcher aus vegetativer Vermehrung hervorgegangen ist. 
Allerdings finden sich innerhalb der räumlichen-genetischen Cluster auch Individuen, deren Multilocus-Genotyp nicht mit den übrigen Gruppenmitgliedern übereinstimmt. Im Bestand Wibbecke ist die starke räumlich-genetische Isoliertheit einiger Gruppen also nicht nur auf Verklonung zurückzuführen, sondern auch auf geringe genetische Abstände zwischen Individuen oder Genets innerhalb der räumlichen Cluster (z.B Gruppen III, VII, VIII). In anderen räumlichen Gruppen wiederum werden durch die Hinzunahme des genetischen Abstandsparameters, ähnlich wie in Roringen, die räumlichen Gruppierungen teilweise wieder aufgelöst (z.B. Gruppe XIII).

Allgemein ist zu beobachten, daß die genetischen den räumlichen Strukturen stärker folgen als in Roringen. Nahezu alle Individuen der räumlichen Gruppen VI bis XII, die den Waldinnenbereich besiedeln, sind im wesentlichen auch in einem eigenen Cluster zusammengefaßt $\left(d_{s g}=\right.$ ca. $100 \mathrm{~m}$ ). Das ist eine ähnliche Tendenz wie im Roringer Vorkommen, auch wenn die interne Differenzierung dieses Clusters $\left(d_{s g}>100 \mathrm{~m}\right)$ nahezu den doppelten Wert aufweist als der in Roringen $\left(d_{s g} \approx 60 \mathrm{~m}\right)$. Ein entscheidender Unterschied zum Bestand Roringen ist allerdings, daß dieses Cluster räumlich-genetisch aus Untergruppen mit z.T. starker externer aber geringer interner Differenzierung (starke Isoliertheit) besteht, deren Mitglieder sowohl aus asexueller als auch (wenn auch in geringerem Ausmaß) sexueller Herkunft sind. Die übrigen Gruppen hingegen, die sich nahe der Waldaußenränder befinden, sind räumlich-genetisch von denen des Innenbereichs differenziert (siehe Gruppen I, II, III, IV, V und XIII) und bestimmen meist auch die oberen Hierarchieebenen im Dendrogramm $\left(d_{s g}\right.$ ca. $\left.130-150 \mathrm{~m}\right)$.

Der Bestand Settmarshausen (Abb. 5.10): Die gebildeten räumlich-genetischen Gruppen im Bestand von Settmarshausen sind bis zu einem räumlich-genetischen Abstand von $d_{s g}<25 \mathrm{~m}$ nur durch die räumliche Komponente geprägt (es geht nur der räumliche Parameter in $d_{s g}$ ein, da es sich um Klongruppen handelt). Eine Ausnahme bildet die Gruppierung der Bäume 19 und 20. Dieser Abstand ist durch den geringen genetischen Abstand erklärt (räumlich-genetische Asymmetrie sexuell produzierter Individuen). Oberhalb dieses Niveaus bilden sich hierarchische Gruppenstrukturen erst auf einem relativ hohen Niveau (bei $d_{s g}$ knapp unter $60 \mathrm{~m}$ ) und sind meist durch die genetische Komponente geprägt. Die höchste Hierarchieebene wird von Baum Nr. 26 bestimmt $\left(d_{s g}=\right.$ ca. $\left.100 \mathrm{~m}\right)$.

\subsubsection{Räumlich-genetische Kovariation}

\subsubsection{Die räumliche Autokorrelation}

Moran's I: Bei Betrachtung der Korrelogramme (Abb. 5.11a und 5.11b), in denen alle Individuen, also auch alle klongleichen Ramets, berücksichtigt wurden, zeigt sich, daß dem in Kap. 4.3.4 geschätzten Anteil asexuell entstandener Individuen eine sehr starke Bedeutung zukommt (siehe Kap. 4.3.4): 

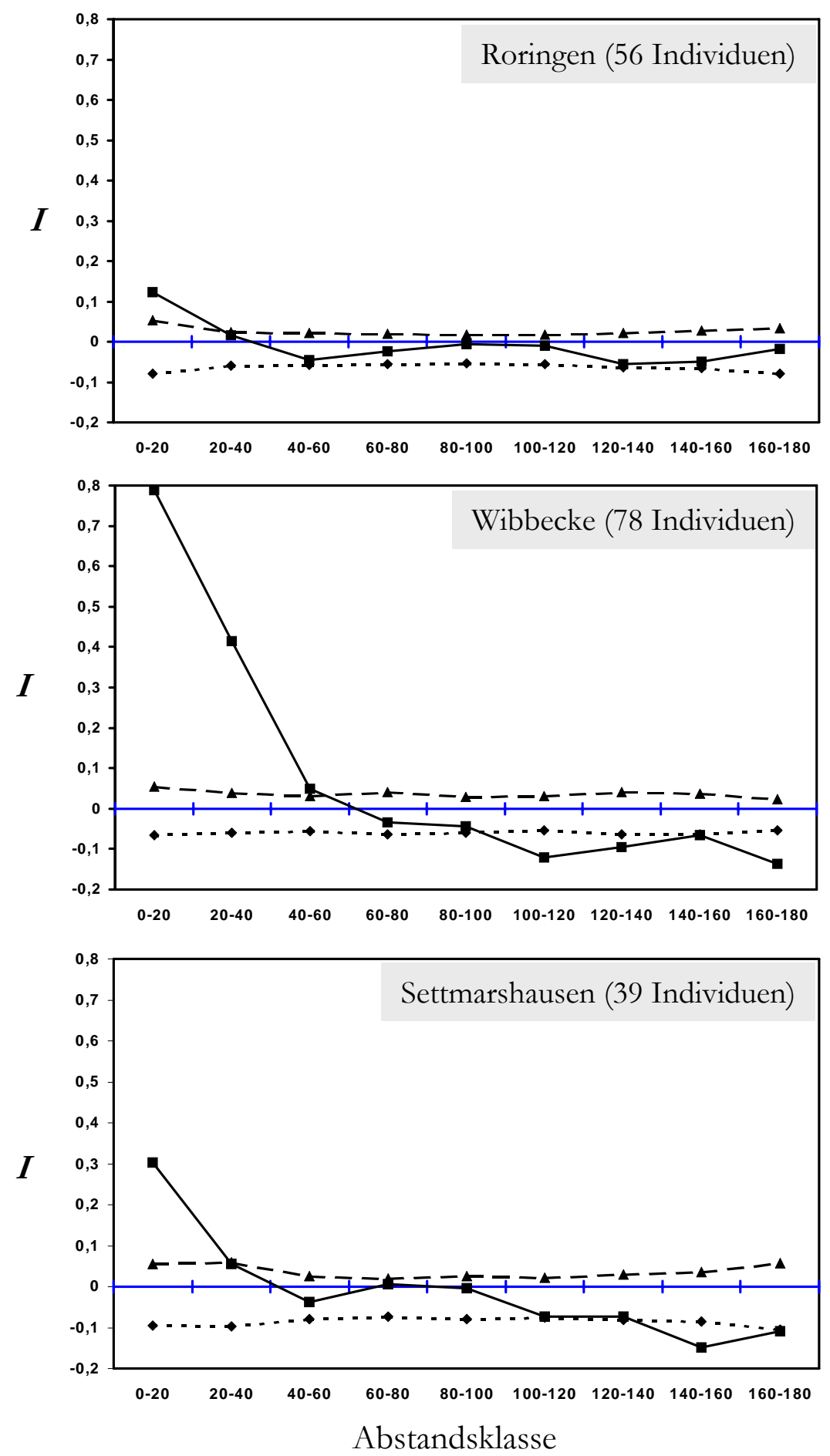

—— ermittelte Werte für Moran's I in der entsprechenden Distanzklasse

$\Delta-ー \rightarrow \quad$ obere Grenze des 95\%-Konfidenzintervall

$\bullet--\rightarrow \quad$ untere Grenze des 95\%-Konfidenzintervall

fehlende Autokorrelation

Abb. 5.11a: Korrelogramme (Moran’s I) für die Bestände Roringen, Wibbecke und Settmarshausen; hier Berücksichtigung aller, also auch der klongleichen Individuen 

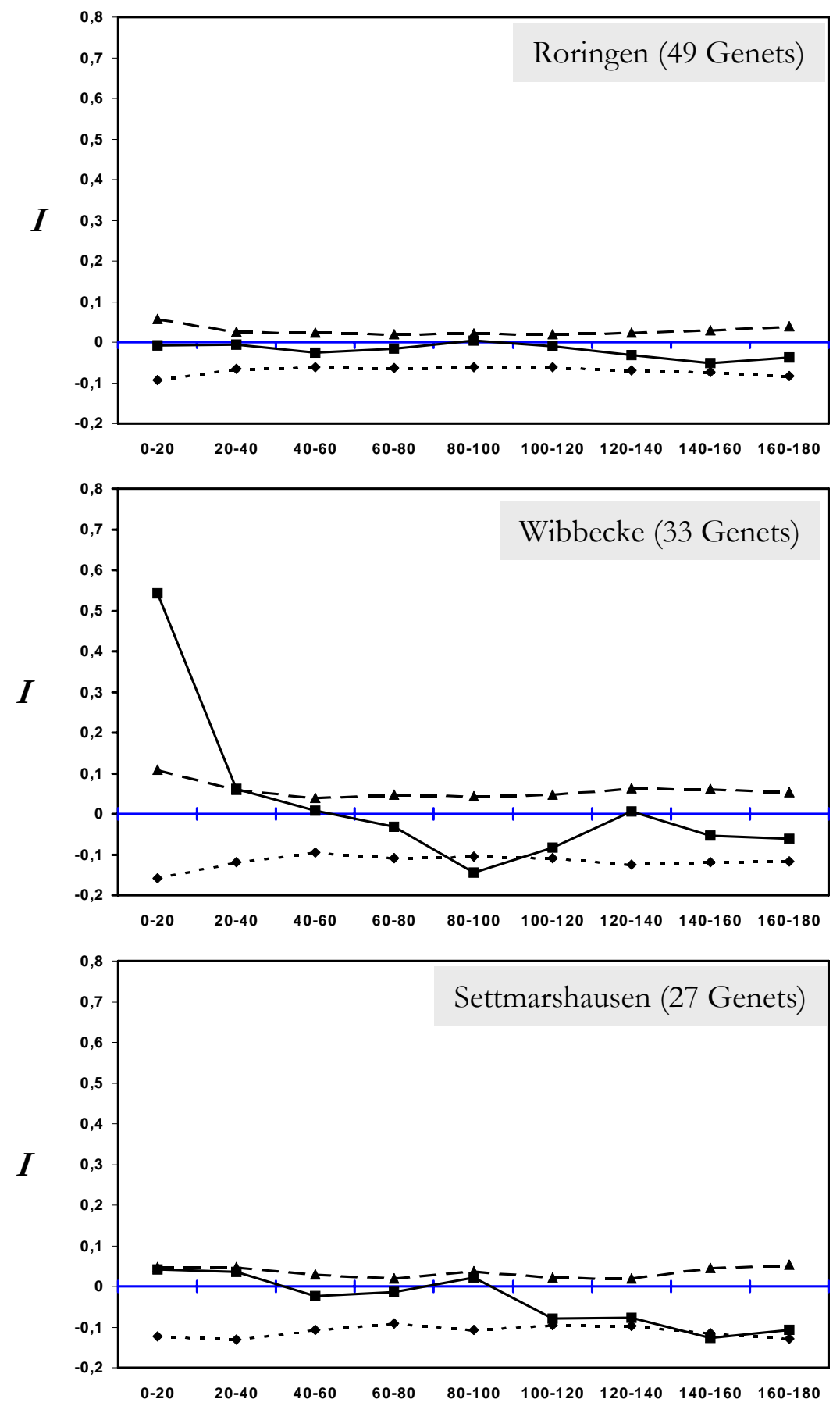

Abstandsklasse

- ermittelte Werte für Moran's I in der entsprechenden Distanzklasse

$\Delta--\rightarrow \quad$ obere Grenze des 95\%-Konfidenzintervall

$\bullet \quad$ untere Grenze des 95\%-Konfidenzintervall

fehlende Autokorrelation

Abb. 5.11b: Korrelogramme (Moran's I) für die Bestände Roringen, Wibbecke und Settmarshausen; hier Berücksichtigung nur der Genets 
Im Bestand von Wib (ca. 77\% der Individuen aus Wurzelbrut entstanden) sind die höchsten Autokorrelationswerte gefunden worden. Innerhalb der ersten drei Distanzklassen ist dieser Wert signifikant positiv. Ab der fünften Distanzklasse fällt der Wert in einen signifikant negativen Bereich ab. Nicht so extrem fallen die Werte für alle Individuen in Set aus (ca. 54\% aus asexueller Vermehrung). Signifikante, aber geringere positive Autokorrelation als in Wib erhält hier die erste Distanzklasse, während die höchsten zwei Distanzklassen (also 140 bis $180 \mathrm{~m}$ ) signifikant negative Werte erhalten.

Die geringste Autokorrelation ist im Bestand von Ror mit dem geringsten geschätzten Anteil Asexueller (untere Grenze der Schätzung: 20\%) zu verzeichnen. Hier ist ausschließlich der Wert in der ersten Distanzklasse signifikant. Die Werte der übrigen Distanzklassen deuten auf eine zufällige Verbreitung genetischer Information im Raum hin.

Werden nicht alle Individuen sondern nur die vorgefundenen Genets in die Kalkulation einbezogen, ergibt sich ein anderes Bild. Für den Bestand Ror beispielsweise kann keine signifikante Autokorrelation in den verschiedenen Distanzklassen festgestellt werden. Auch eine Tendenz von (nicht signifikanter) positiver zu negativer Autokorrelation ist hier nicht erkennbar. Der Bestand Set zeigt mit zunehmender Distanzklasse einen Trend von leicht positiven hin zu negativen Autokorrelationswerten, wobei auch nur ein Wert in der Distanzklasse zwischen 140 und $160 \mathrm{~m}$ signifikant negativ ausfällt. In Wib hingegen fallen die Werte anders aus. Hier weist dieser Parameter, insbesondere in der ersten Distanzklasse einen höchst signifikanten positiven Wert auf.

Distogramme mit dem genetischen Abstand $d_{0}$ als Basis: Analog zu Moran's I zeigen die Werte für $D_{G}$ (= die gemittelten Werte für $d_{0}$ in einer Abstandsklasse) sehr ähnliche Tendenzen (Abb. 5.12a und 5.12b). Die stärksten Abweichungen vom gemittelten genetischen Abstandswertwert $d_{0}$ finden sich wiederum in Wib und zwar sowohl unter Berücksichtigung aller Individuen als auch für die ausschließliche Betrachtung der Genets. Für Ror kann eine positive Autokorrelation nur unter Berücksichtigung aller Individuen ermittelt werden. Die Genets zeigen eine eher zufällige Verteilung ihrer genetischen Information im Raum.

Allerdings sind hier noch andere Details erkennbar. Die Schläuche, welche den 95\%-Konfidenzbereich abdecken, sind in den einzelnen Beständen jeweils leicht verschoben. Das liegt daran, daß das über die Gesamtheit aller Individuenpaare bzw. Genets gemittelte $d_{0}$ aufgrund der unterschiedlichen genischen Diversität in den einzelnen Beständen anders ausfällt. Die höchste genische Diversität wurde in Set gefunden. Hier liegt dieser Mittelwert für $d_{0}$ auch erwartungsgemäß am höchsten $\left(d_{0}=0.600\right.$ für alle Individuen, $d_{0}=0.614$ für alle gefundenen Genets). In Ror wurde die geringste genische Diversität berechnet, so daß auch die durchschnittlichen genetischen Abstände hier am geringsten ausfallen $\left(d_{0}=0.533\right.$ für alle Individuen, $d_{0}=0.530$ nur für Genets). In Wib ist $d_{0}$ allerdings unter Berücksichtigung aller Individuen mit dem Wert von Ror vergleichbar $\left(d_{0}=0.535\right)$. Bei ausschließlicher Betrachtung der unterschiedlichen MLG, also der Genets, ist der durchschnittliche genetische Abstand am geringsten $\left(d_{0}=0.507\right)$. 

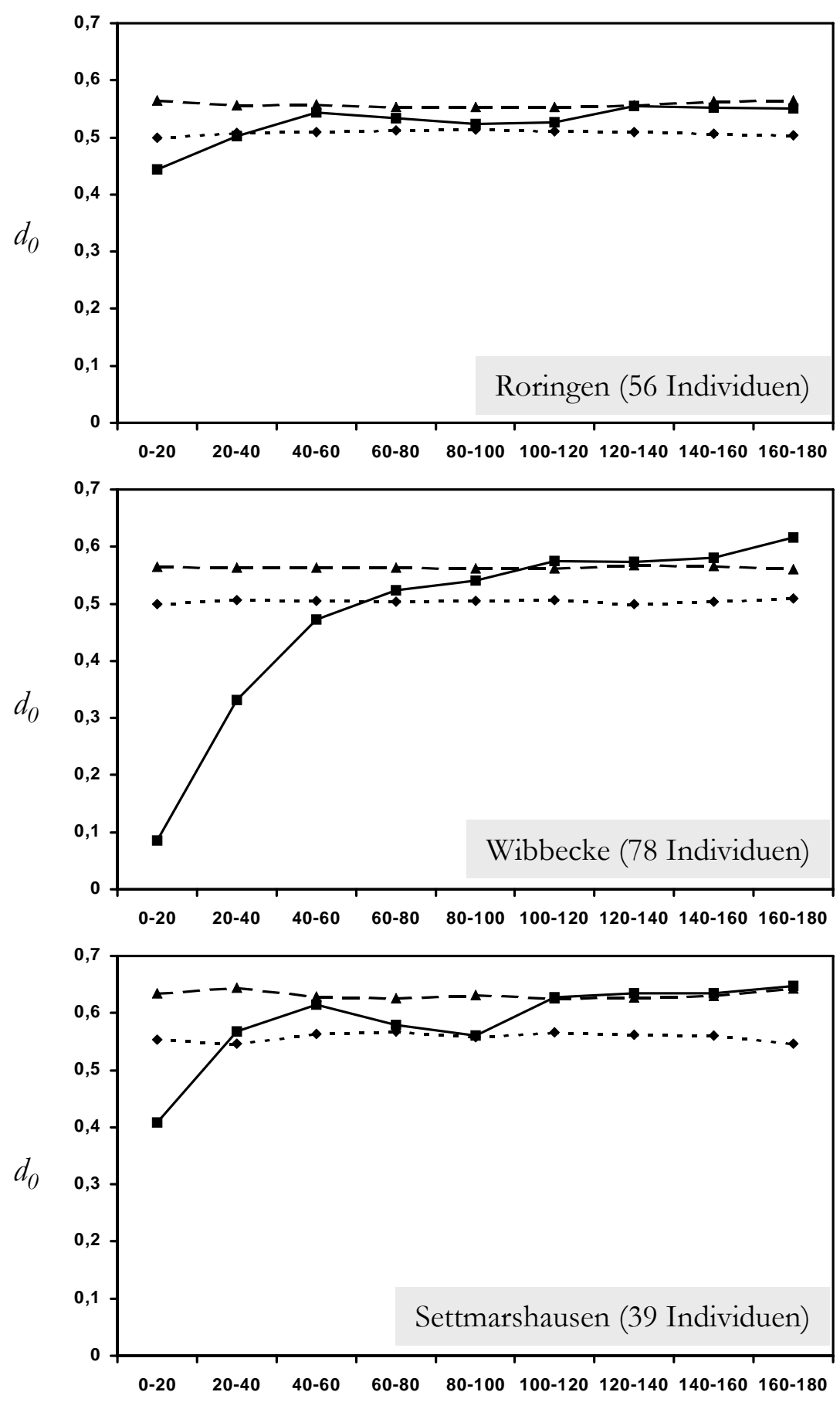

Abstandsklasse

ermittelte Werte für $d_{0}$ in der entsprechenden Distanzklasse

$\Delta-ー \rightarrow$ obere Grenze des 95\%-Konfidenzintervall

untere Grenze des 95\%-Konfidenzintervall

Abb. 5.12a: Distogramme (do) für die Bestände Roringen, Wibbecke und Settmarshausen; hier Berücksichtigung aller, also auch der klongleichen Individuen 

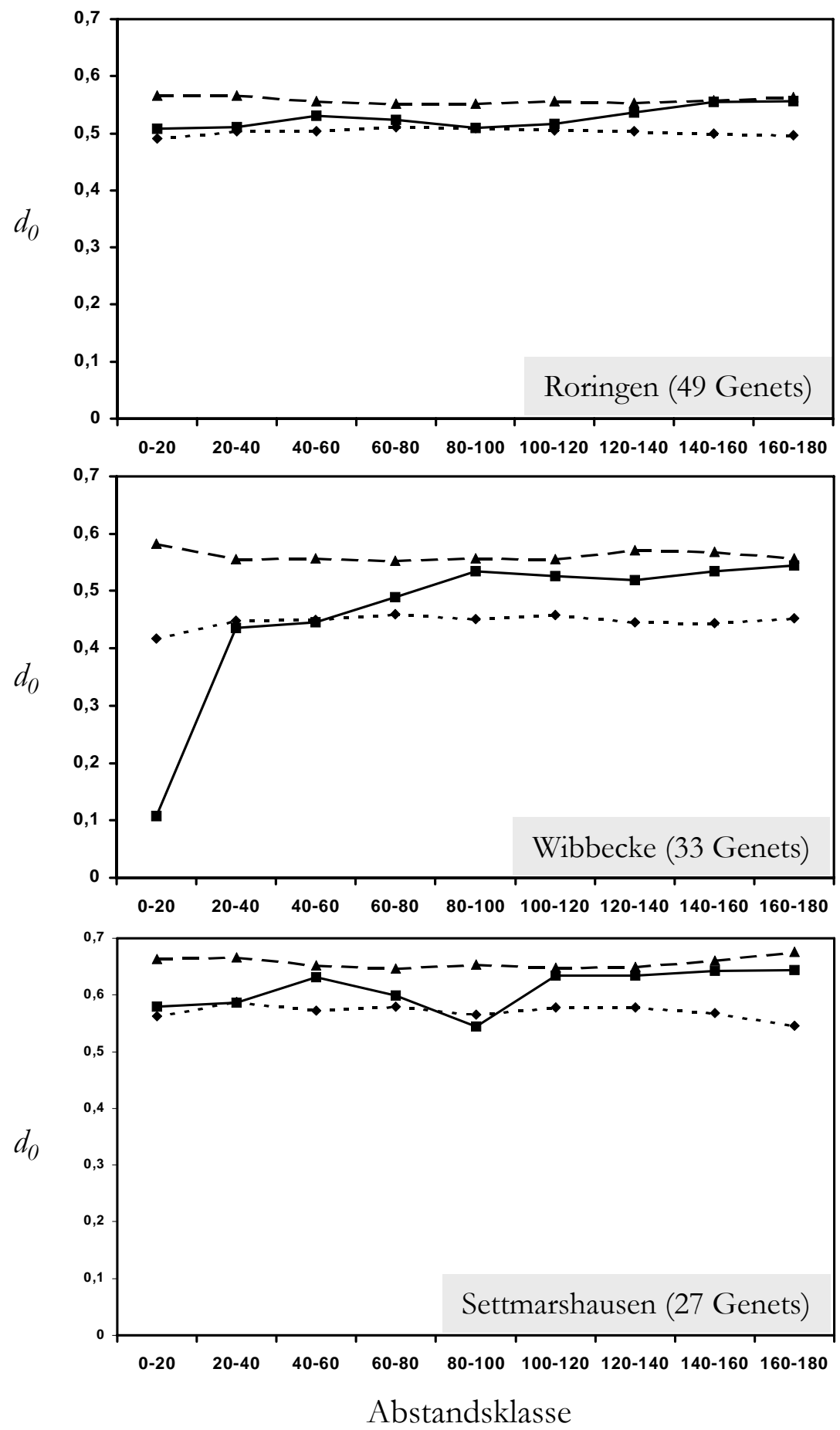

ermittelte Werte für $d_{0}$ in der entsprechenden Distanzklasse

$\Delta--\rightarrow$ obere Grenze des 95\%-Konfidenzintervall

untere Grenze des 95\%-Konfidenzintervall

Abb. 5.12b: Distogramme (do) für die Bestände Roringen, Wibbecke und Settmarshausen; hier Berücksichtigung nur der Genets 
Insgesamt kann also festgehalten werden, daß in allen drei Beständen zumindest in der ersten Distanzklasse (in Wib in den ersten drei Distanzklassen) die positive räumliche Autokorrelation auf Verklonung zurückzuführen ist. Werden die Positionen der einzelnen Genets ermittelt und auf dieser Basis Moran's $I$ bzw. $D_{G}$ kalkuliert, unterscheidet sich insbesondere Wib von den anderen beiden Beständen. Während die Genets in Ror und Set eine zufällige Verteilung ihrer genetischen Information im Raum aufweisen, sind in Wib diejenigen Genets, die sich genetisch ähnlich sind, verstärkt in den ersten beiden Distanzklassen (0 bis $40 \mathrm{~m}$ ) vorzufinden.

\subsubsection{Der Mantel-Test}

Wie aus Tab. 5.1 ersichtlich wird, ergibt der Mantel-Test unter Berücksichtigung aller Individuen in den einzelnen Beständen durchweg höchst signifikante Werte. Dies ist aufgrund des geklumpten Auftretens von aus asexueller Vermehrung stammender Individuen nicht sehr verwunderlich. Ror mit dem geringsten Anteil Asexueller weist die geringste, Wib mit dem höchsten Anteil die höchste Korrelation auf.

\begin{tabular}{|c|c|c|c|}
\hline & & Individuen & Genets \\
\hline Ror & $r_{M}$ & $\begin{array}{l}0.1627^{\star * \star} \\
(0.0005)\end{array}$ & $\begin{array}{l}0.1311^{\star *} \\
(0.0053)\end{array}$ \\
\hline Wib & $\boldsymbol{r}_{M}$ & $\begin{array}{l}0.4669 * * * \\
(0.000)\end{array}$ & $\begin{array}{l}0.3948^{\star \star \star} \\
(0.000)\end{array}$ \\
\hline Set & $r_{M}$ & $\begin{array}{l}0.2437^{\star \star \star *} \\
(0.000)\end{array}$ & $\begin{array}{l}0.1136 \\
\quad(0.0611)\end{array}$ \\
\hline
\end{tabular}

Tab. 5.1: Ermittelte Korrelationskoeffizienten $\left(r_{M}\right)$ der räumlichen (euklidischen) und genetischen Abstände in den Beständen Roringen (Ror), Wibbecke (Wib) sowie Settmarshausen (Set); $p$ gibt an, wie groß die Wahrscheinlichkeit ist, daß noch extremere Werte als der beobachtete gefunden werden (auf Basis von 10000 Permutationen); Werte wurden ermittelt unter Berücksichtigung der Gesamtheit der Individuen (also einschließlich aller klongleicher Individuen) sowie der mittleren Positionen der Genets

Interessant sind insbesondere die Werte, welche für die Genets ermittelt wurden. Hier stellte sich heraus, daß für Ror nur $0.5 \%$ der Korrelationskoeffizienten im Permutationstests extremere (positive) Werte erbrachten, so daß die hier gefundene beobachtete Korrelation als hoch signifikant zu bewerten ist. Man beachte, daß durch die räumlichen Autokorrelationsanalysen für diesen Bestand keine Signifikanzen erzeugt wurden.

Der Wert für Wib ist der höchste innerhalb der drei untersuchten Bestände, was auch in den Korrelogrammen und Distogrammen deutlich wird. In Set kann auch eine positive Korrelation beobachtet werden, welche aber (gerade eben) keine Sig- 
nifikanz aufweist. Es ist aber dennoch anzumerken, daß nur ca. 6\% der Werte des Permutationstests extremere Werte aufwiesen als die tatsächliche Beobachtung.

\subsection{Diskussion}

\subsubsection{Vergleich der Ergebnisse der verwendeten Verfahren im Hinblick auf ihren Informationsgehalt}

Zur Analyse räumlich-genetischer Strukturen in adulten Vorkommen von P. avium sind im wesentlichen drei Verfahren verwendet worden:

(1) Die Individuen wurden durch das Single-linkage Prinzip mittels ihrer rein räumlichen (euklidischen) sowie auch ihrer räumlich-genetischen Abstände hierarchisch gruppiert und in Form von Dendrogrammen dargestellt. Bei der Untersuchung der rein räumlichen Verteilung von Individuen konnte gezeigt werden, daß eine Gruppenbildung auf der Grundlage verschiedener Nachbarschaftsniveaus exakt dem Prinzip des Single-linkage Verfahrens entspricht.

Der Parameter $d_{s g}$ für räumlich-genetischen Abstand wurde durch die Erzeugung von Kommensurabilität zwischen räumlichen und genetischen Einheiten hergeleitet. In unserem Fall geschah dies durch die Transformation der genetischen Abstände in die Einheiten des Raumes, so daß genetische Abstände in Dimensionen der räumlichen Entfernung ausgedrückt werden konnten (siehe GREGORIUS 2005b). Dies wurde als sinnvoll betrachtet, da insbesondere ein Vergleich zwischen der räumlichen Verbreitung der Vogelkirsche und ihren räumlich-genetischen Strukturen von Interesse war.

(2) Methoden der räumlich-genetischen Autokorrelationsanalyse beschreiben Zusammenhänge zwischen individuellen genetischen Merkmalen und ihren räumlichen Positionen beschreiben. Die theoretischen Grundlagen derartiger Verfahren basieren meist auf dem Modell 'Isolation-by-Distance' (WRIGHT 1943). Demnach können, in effektiv unendlich großen Populationen mit uniformer Verteilung der Individuen, lokale Abweichungen von global erwarteten Genhäufigkeiten allein aufgrund verwandtschaftlicher Beziehungen benachbarter Individuen auftreten (bevorzugte Nachbarschaftspaarung, eingeschränkte Samenverbreitungsdistanzen) (HEYWOOD 1991).

(3) Schließlich wurde auch der Mantel-Test verwendet, der die Korrelation zwischen räumlichen und genetischen Abständen testet.

Insgesamt zeigt sich, daß die Kombination aus verschiedenen Verfahren der räumlich-genetischen Analyse aufschlußreiche Informationen über die Verbreitung von Individuen und ihrer genetischen Information im Raum liefern. Die Autokorrelationsanalyse und der Mantel-Test erbrachten bei Betrachtung aller Individuen in den jeweiligen Beständen durchweg signifikante Ergebnisse. Da hier alle Ramets eines Klons berücksichtigt wurden und diese, mit wenigen Ausnahmen in Wibbecke, auch räumlich meist geringe Abstände zueinander aufwiesen, zeigten diese Tests höchst signifikante Werte. Die Klongruppen sind auch in den Dendrogram- 
men meist eindeutig zu erkennen, da hier nur der räumliche Abstand in den räumlich-genetischen Parameter eingeht und die Klongruppen somit in beiden Dendrogramm die gleichen inneren Strukturen zeigen wie im auf rein räumlichen $\mathrm{Ab}-$ ständen basierten Dendrogramm.

Werden andererseits die Ergebnisse der Gruppierungs- sowie der (Auto-)Korrelationsanalysen nur in Bezug auf die Genets verglichen, so ist erkennbar, daß sie sich für den Bestand von Roringen in ihrem Informationsgehalt z.T. unterscheiden: Das Ergebnis der distanzklassenbasierten räumlich-genetischen Kovariation war beispielsweise nicht signifikant, so daß auf eine erratische Verteilung von MLG im Raum geschlossen werden könnte. Bei kombinierter Betrachtung der rein räumlichen sowie räumlich-genetischen Dendrogramme konnten jedoch noch weitere Details erkannt werden, auch wenn diese bislang ausschließlich explorativer Natur sind. Kleinere, in Waldrandnähe befindliche und im räumlichen Dendrogramm stark isolierte Gruppen lösten sich bei räumlich-genetischer Betrachtungsweise teilweise wieder auf. Andererseits wurden eine Reihe von generativ entstandenen Individuengruppen, die sich im Waldinnenbereich befinden und räumlich weniger stark isoliert sind, räumlich-genetisch in eine relativ individuenreiche aber schwach isolierte Untergruppe geordnet. Es zeigt sich also, daß es kleinere räumliche Individuengruppen gibt, die sich intern stärker genetisch unterscheiden, andere größere Gruppen hingegen zeigen geringere individuelle genetische Abstände. Dieser Sachverhalt wird durch die Single-linkage Gruppierung erfaßt, nicht aber durch die distanzklassenbasierte Kovariation. Letzteres liegt möglicherweise daran, daß hier nur die Mittelwerte der einzelnen Distanzklassen in die Kalkulation eingehen. Die Tatsache, daß diese Distanzklassen aber sehr starke Unterschiede bezüglich der Anzahl an Individuenpaaren aufweisen können, wird hier nicht berücksichtigt. Dieser Sachverhalt kann das Gesamtbild der Verteilung genetischer Information im Raum möglicherweise verzerren. Der Korrelationskoeffizient des Mantel-Tests hingegen ist positiv und hoch signifikant.

Die Ergebnisse bezüglich der verwendeten Verfahren fallen für Wibbecke wesentlich homogener aus. So zeigt der Mantel-Test einen höchst signifikanten, positiven Wert, und zwar sowohl unter Berücksichtigung aller Individuen als auch der einzelnen Genets. Dies wird auch durch die Korrelogramme sowie Distogramme bestätigt, welche signifikante räumlich-genetische Zusammenhänge für die ersten beiden Distanzklassen aufweisen. Allerdings ist auch hier zu betonen, daß die Dendrogramme noch zusätzliche Informationen liefern. So wird der größere Individuenkomplex aus dem Waldinnenbereich (Gruppen Nr. VI bis XII sowie Baum Nr. 62 und 46) in einem Cluster zusammengefaßt, dessen interne Differenzierung I in etwa mit der internen Differenzierung $I_{\Omega}$ des gesamten Bestandes von Roringen übereinstimmt $\left(d_{s g} \approx 100 \mathrm{~m}\right)$. Innerhalb dieses Clusters in Wibbecke ist aber noch weitere starke Strukturierung erkennbar. Es zeigt sich, daß die meisten Individuen, auch diejenigen, die nicht asexueller Herkunft sind, zu räumlich-genetischen Gruppen zusammengefaßt sind, die einen geringen internen, aber starken externen räumlich-genetischen Abstand zueinander aufweisen. 
Außerdem konnte durch das Single-linkage Prinzip gezeigt werden, daß diejenigen Baumgruppen in Wibbecke, die in der Nähe des Waldaußenrandes stocken (Baumgruppen I bis V sowie XIII an der Wald-Feld-Grenze), teilweise -ähnlich wie im Bestand von Roringen- auch räumlich-genetisch am stärksten vom Rest isoliert sind $\left(d_{s g} \approx 150 \mathrm{~m}\right)$.

\subsubsection{Hinweise auf den Ver- und Ausbreitungstyp der Vogelkirsche unter Berücksichtigung unterschiedlicher forstlicher Betriebsarten}

Die Ursachen heutiger Verbreitungsmuster der Wildkirsche einschließlich ihrer genetischen Information sind, wie einleitend in Kap. 5.1.1 dargestellt wurde, in unseren Wäldern vermutlich störungsinduziert. Obwohl waldökosystemare Störungen heute meist anthropogener Natur sind, können die Eigenschaften der Störung aber durchaus zur Klärung populationsbiologischer Eigenschaften dieser Baumart herangezogen werden.

Auch wenn die räumliche Verteilung der Individuen in den untersuchten Kirschenaltbeständen nur geringfügige Unterschiede zeigte (siehe Isolation einzelner Individuen und Individuengruppen sowie Unterschiede in der inneren räumlichen Gesamtdifferenzierung der Bestände), so konnten in den räumlich-genetischen Strukturen teilweise erhebliche Abweichungen festgestellt werden. Unter Berücksichtigung unterschiedlicher forstlicher Bewirtschaftungsformen sollen hier nun folgende Gesichtspunkte diskutiert werden, die möglicherweise populationsbiologische Prozesse beeinflußt haben und damit zur Ursachenanalyse der beobachteten räumlich-genetischen Muster beitragen:

(1) Unterschiede in der zeitlichen Komponente der Kolonisations- und Extinktionsdynamik geeigneter Habitate,

(2) Die zeitliche Variabilität effizienter bestandesinterner und-externer Pollen- und Samenquellen:

(3) Das gametophytische Selbstinkompatibilitätssystem in Verbindung mit der Fäbigkeit zu asexueller Fortpflanzung:

Nach AusterlitZ et al. (2000) sind Gründereffekte, die die genetische Differenzierung von Pflanzenvorkommen fördern und einen Rückgang genetischer Diversität bewirken, in den meisten Baumartenvorkommen aufgrund ihrer Lebensweise nur sehr selten zu beobachten. Neue Habitate werden von Baumarten aufgrund der ausgedehnten juvenilen Phase über möglicherweise mehrere Jahrzehnte nur über Migration (Samenverbreitung) aus umliegenden Vorkommen kolonisiert, was zu einer Akkumulation genetischer Diversität führt. Im Gegensatz dazu soll ein Gründereffekt bei krautigen Pflanzen häufiger auftreten, insbesondere wenn (a) die neuen Habitate von nur wenigen Immigranten besiedelt werden sowie (b) die Pflanzen meist schon im ersten Jahr fruktifizieren und ihre Samen in ihrer direkten Umgebung ausbreiten (vgl Arbeiten von MCCAULEY et al. 1995 und GILES \& GOUDET 1997). Auch MARIETTE et al. (1997) fanden an Vogelkirsche, daß nur geringe Unterschiede in der genetischen Diversität zwischen älteren, schon über längere Zeit etablierten, und jüngeren, erst vor kurzem besiedelten, Vogelkirschenvorkommen 
bestehen. Sie begründete es auch mit starker Immigration aus umliegenden Beständen, bevor die einzelnen Vogelkirschen im Bestand das Mannbarkeitsalter erreichen.

Letztere Begründung entspricht aber nicht ganz der Populationsbiologie der Vogelkirsche. Insgesamt kann nämlich davon ausgegangen werden, daß die Ausnutzung von Störungen (Lückenstrategie) besondere Anpassungsanforderungen impliziert. Die Unvorhersagbarkeit der auf diese Weise entstehenden günstigen Umweltbedingungen setzt insbesondere bei rezedenten Arten Möglichkeiten einer schnellen Besiedlung derartiger Habitate voraus, so daß eine Kolonisation und damit die Ansammlung genetischer Diversität über längere Zeiträume hier kaum vorstellbar ist. Untersuchungen von HERRERA (1985) und KOLLMANN (2000) ergaben, daß außer an Waldrändern überwiegend auch in Lichtungen und Bestandeslücken die höchsten ornithochoren Diasporenniederschläge festgestellt wurden. Der gerichtete Transport von Samen hin zu Bestandeslücken, der möglicherweise auch aus verschiedenen Richtungen erfolgt (Hypothese der gerichteten Ausbreitung nach JANZEN 1971), kann eine nur sehr schwache räumlich-genetische Strukturierung zur Folge haben. Man beachte, daß eine starke räumlich-genetische Differenzierung in Roringen nur für Klongruppen vorliegt. Die in Kap. 2.2.4 dargestellten Muster der durch Vögel ausgebreiteten fleischigen Früchte scheinen sich im Bestand von Roringen widerzuspiegeln.

Eine femelschlagweise Verjüngung, wie sie im Bestand von Roringen praktiziert wurde, die von zunächst trupp- bis horstweisen Auflichtungen über eine sukzessive Vergrößerung dieser unregelmäßigen Auflichtungen des Kronendaches bis hin zur vollständigen Endnutzung des Altbestands führt, erbringt meist eine raum-zeitliche Variation ökologischer Bedingungen, welche die Verjüngung von Mischbeständen, einschließlich Lichtbaumarten wie der Vogelkirsche, begünstigt (siehe SCHOPPA 2000). Da das Alter der Kirschen (ca. 55 Jahre) mit den ersten femelartigen Eingriffen in dieser Abteilung zeitlich übereinstimmt, ist zu vermuten, daß auch der Besiedlungsprozess zu diesem Zeitpunkt einsetzte.

Aufgrund der im Vergleich zu den anderen Beständen geringeren genetischen Diversität in Roringen wurde vermutet, daß die Individuen auf dieser Fläche möglicherweise Nachkommen weniger Individuen darstellen und somit räumlich-genetische Substrukturen (Familienstrukturen) erkennbar sind (Hypothese 1, Kap. 5.1.3). Einerseits wird dies vom Manteltest zwar bestätigt, andererseits wird nur ein Teil der räumlich aggregierten Individuen des Waldinnenbereichs durch das räumlich-genetische Gruppierungsverfahren einer Gruppe zugeordnet und dies auch nur mit intern starker und extern schwacher Differenzierung. Die distanzklassenbasierten Verfahren erbrachten für die Betrachtung der einzelnen Genets keine Signifikanz. Der Manteltest deutet zwar darauf hin, daß möglicherweise wenige, räumlich nahe, effiziente Samenquellen zur Kolonisierung dieses Bestandes und damit zu positiven Korrelationen räumlich-genetischer Abstände beigetragen haben, andererseits spricht die Auflösung anderer (kleinerer) räumlicher Gruppen durch die kombinierte räumlich-genetische Gruppierungsanalyse für sehr effiziente Ausbreitungssysteme. Ein weiterer wichtiger Grund für das Fehlen von räumlich-geneti- 
schen Strukturen ist der Pioniercharakter dieser Baumart, der eine Ausbildung mehrerer Generationen vor Ort, insbesondere auf hochwaldbewirtschafteten Flächen, nur selten erlaubt, da konkurrenzstärkere Arten die Vogelkirsche meist schnell verdrängen.

Ein anderes Bild zeigen die Ergebnisse in den Beständen von Wibbecke und Settmarshausen (durchgewachsene Mittelwaldbestände). Beide sind vermutlich wesentlich älter als der Roringer Bestand und die mittelwaldähnlichen Bewirtschaftungsformen erstreckten sich möglicherweise über mehrere Jahrhunderte. Durch die ständige niederwaldartige Nutzung der Unterschicht und aufgrund der Lichtdurchlässigkeit der Oberschicht (nach SIEDER 2003 aus nur 20-30 grupp- bis truppweise angeordneten Bäumen pro ha bestehend), ist davon auszugehen, daß die natürliche Sukzessionsdynamik in diesen Beständen über längere Zeiträume immer wieder unterbrochen wurde. Damit fand die Vogelkirsche in diesen Beständen dauerhafte Kolonisations- und Existenzmöglichkeiten vor.

Aufgrund der Verdrängung starker Konkurrenten (wie z.B. der Buche) und der ständigen Lichtzufuhr kann vermutet werden, daß die Kirsche in mittelwaldähnlich bewirtschafteten Wäldern nicht unbedingt auf effiziente Samenquellen und gerichtete Samenausbreitungsmechanismen zur Ausnutzung der Lückendynamik in diesen Wäldern angewiesen war. Dies ist insbesondere im Bestand von Wibbecke erkennbar. Hier liegen nicht nur die individuenreichsten Klone vor, sondern es kann auch die im Vergleich zu den anderen Beständen stärkste Ausprägung räumlich-genetischer Strukturen beobachtet werden, die nicht auf asexuelle Vermehrung zurückzuführen ist. Vermutlich fanden sich hier durch die spezielle Betriebsart auch bessere Verjüngungsmöglichkeiten in der Nähe von fruktifizierenden Altbäumen. Interessant ist auch die Tatsache, daß sich in diesem Bestand teilweise sehr starke Ähnlichkeiten räumlich aggregierter MLG fanden, die schon in Kapitel 4 zu Problemen bei der Unterscheidung sexueller und asexueller Vermehrung führten. Die Fähigkeit zu asexueller Vermehrung und damit zu einer Reduktion der reproduktionseffektiven Populationsgröße kann in Verbindung mit dem gametophytischen Selbstinkompatibilitätssystem möglicherweise der Schlüssel zur Klärung dieser Beobachtung sein. Auch die Art der Bewirtschaftung kann zeitweilig zu einer Reduktion bestandesinterner Samenquellen und damit zu räumlich-genetischen Strukturen führen. Dies ist im Mittelwaldbetrieb dann der Fall, wenn nur sehr wenige Stämme (gut geformte Lassreiser) in die Oberschicht einwachsen. Stehen keine effizienten externen Pollen- und Samenquellen zur Verfügung und sind intern nur wenige kompatible Genotypen im Bestand vorhanden, so kann das bei der Besiedlung eines Habitats zu einer starken Verminderung genetischer Diversität führen. Liegt darüber hinaus Semikompatibilität (aufgrund verwandtschaftlicher Beziehungen zwischen Individuen) vor und sind die untersuchten Genloci möglicherweise an den S-Locus gekoppelt, so können nur bestimmte Kombinationen von Genotypen erzeugt werden. In unserem Fall ist das nach SCHÜLER (persönliche Mitteilung) für zwei der hier untersuchten Mikrosatelliten-Loci der Fall (UDP98021 und UDP98-412). Höhere Homozygotiegrade bevorzugt paarender Individuen 
in Verbindung mit dem gametophytischen Inkompatibilitätssystem können demnach die Ursache für die in Kapitel 4 entdeckten genischen Assoziationen sein. 


\section{Erste explorative Untersuchungen zum reproduktiven Artzusammenhalt der Vogelkirsche}

\subsection{Einleitung}

\subsubsection{Die Bedeutung und die Determinanten des reproduktiven Artzu- sammenhalts}

Die Aufrechterhaltung des genetischen Artzusammenhalts impliziert die Fähigkeit einer Art zur effektiven Ausbreitung ihrer Gene im Raum. Sind andererseits Reproduktionsbarrieren vorhanden, besteht die Möglichkeit einer unabhängigen genetischen Differenzierung zwischen einzelnen Vorkommen. Diese stellen möglicherweise auch einen ersten Schritt in Richtung Speziation dar (vgl. auch STEINER \& GREGORIUS 1997). Reproduktionsbarrieren innerhalb von Vorkommen, wie z.B. Selbstinkompatibilitätssysteme, fördern eher den reproduktiven Artzusammenhalt, wobei aber auch gleichzeitig das Vorhandensein von Mechanismen zur Herstellung von Paarungskontakten und für den Transport genetischer Information (z.B. biotische Vektoren) eine größere Bedeutung erlangt.

Die Determinanten des reproduktiven Artzusammenhalts (Abbildung 6.1) können im wesentlichen durch das Paarungs- und Genflußsystem dargestellt werden. Nur das Zusammenspiel aller Determinanten bestimmt, wie stark sich die Vorkommen einer Art auch reproduktiv abgrenzen lassen.

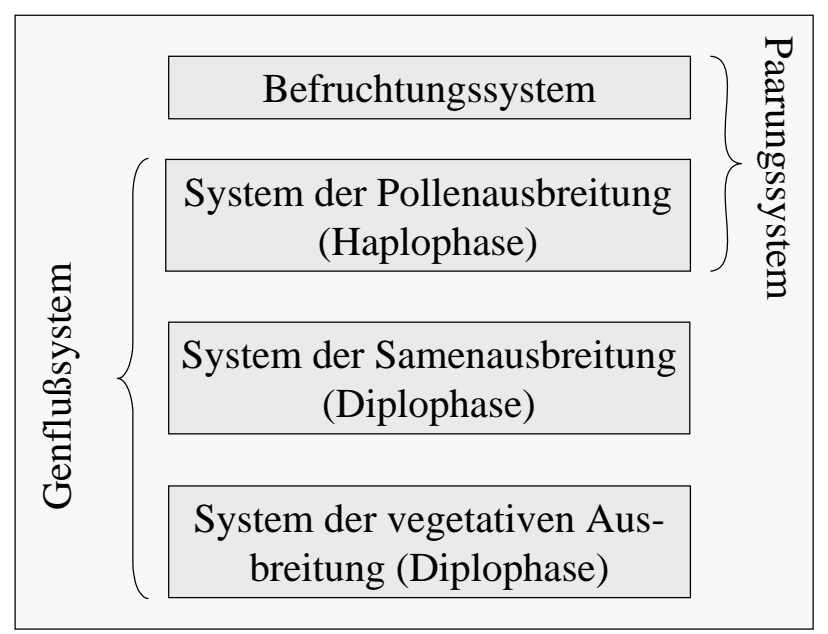

Abb. 6.1: Die Determinanten des reproduktiven Artzusammenhalts

Das Paarungssystem, dessen Analyse in diesem Kapitel im Vordergrund stehen soll, setzt sich aus dem Vorgang der Pollenausbreitung und dem Befruchtungssystem zusammen. Beide Faktoren bestimmen, ob eine Paarung zwischen zwei Individuen überhaupt stattfinden kann. Bei der Vogelkirsche sind dabei die räumlichen Entfernungen, welche Insekten effektiv als Pollenvektoren zurücklegen können, als auch das in Kap. 2.2.3.2 ausführlich dargestellte gametophytische Selbstinkompatibilitätssystem (GSI) von Bedeutung. Letzteres verhindert homotypische Paarungen 
(Selbstbefruchtung sowie Paarung zwischen Individuen mit identischen S-Allelen), was Inzuchteffekte reduziert und den Erfolg seltener gegenüber häufigen S-Allelen bei Paarungsvorgängen innerhalb der Kirschenvorkommen fördert (siehe STEINER \& GREGORIUS 1994). Über das Zusammenspiel zwischen dem GSI und der effektiven Pollenausbreitung ist allerdings nur sehr wenig bekannt. Auch wenn gezeigt werden konnte, daß innerhalb von Obstplantagen ein sehr effizienter Pollenaustausch zwischen einzelnen kompatiblen Kultursorten über den Vektor Biene stattfindet (Kap. 2.2.3.1), läßt dies kaum Rückschlüsse auf die Wildkirsche zu. In einem Review-Artikel von MURPHY \& LOVETT-DOUST (2004) wird nämlich ausführlich darauf hingewiesen, daß die effektive Ausbreitung von Pollen (und Samen) nicht nur von der Entfernung zu ihrer Quelle abhängig sein kann, sondern auch von den Strukturen der zur Zeit von einer Art nicht besiedelten Standorten. Dieser Zwischenraum wird hier als Matrix bezeichnet und kann geeignete, derzeit nicht besiedelte, oder aber auch nicht besiedelbare Standorte umfassen. Bezüglich der Vogelkirsche kann diese Matrix sehr unterschiedlicher Natur sein. Die Kirsche kann einerseits im adulten Zustand als Lückenstratege in Laubmischwäldern vorkommen (und diese können je nach Standort, Baumartenzusammensetzung und waldbaulichem Verfahren auch unterschiedliche Dichte aufweisen), andererseits ist sie als Ausweichstratege auch in Gebüschsäumen vorzufinden, welche landwirtschaftliche Flächen begrenzen (ОтTO 1994). Im ersten Fall ist Wald die Matrix zwischen zerstreuten Einzelbaumvorkommen bzw. Individuengruppen, im zweiten Fall ist es landwirtschaftlich genutzte Fläche (Offenland).

Es wird hier deutlich, daß dynamische Prozesse innerhalb von Pflanzengemeinschaften nicht ausschließlich durch die Umweltbedingungen innerhalb günstiger Habitate geprägt sein müssen, sondern auch durch landschaftliche Rahmenbedingungen, wie z.B. natürlich oder anthropogen bedingte Landschaftsfragmentierung (siehe auch Abb. 2.3, Kap. 2.3). Letzteres beeinflußt das Genflußsystem und damit die reproduktive Vernetzung (effektive Einfuhr/Ausfuhr von Genen) zwischen einzelnen Vorkommen.

\subsubsection{Zielsetzung}

In diesem Kapitel sollen erste Hinweise über die reproduktive Vernetzung von Vogelkirschenvorkommen innerhalb von Waldbeständen und in der freien Landschaft geliefert werden. Obwohl durch eine Vaterschaftsanalyse zwar Pollenausbreitungsdistanzen und der Anteil bestandesinterner zu -externer Pollenbeiträge in Saatgut mittels variabler Marker relativ genau geschätzt werden kann, ist aber noch keine Aussage darüber möglich, wie effektiv dadurch die genetische Diversität von Nachkommenschaften beeinflußt wird. Da dies aber ein wichtiger Mechanismus zur Erhaltung genetischer Variation innerhalb einer Art ist und damit genetischer Drift und einer Differenzierung von Pflanzenvorkommen entgegenwirkt, sollen auch die Diversitäten der Pollenbeiträge im Saatgut verschiedener Samenbäume geschätzt werden. 
$\mathrm{Da}$ in Bezug auf Genfluß via Pollenausbreitung innerhalb und zwischen Vogelkirschenvorkommen kaum etwas bekannt ist, sollen erste explorative Untersuchungen an Saatgut Hinweise auf folgende Fragestellungen liefern:

- Wird eine Pollenübertragung über Insekten als Vektoren nur innerhalb von Baumgruppen, also zwischen nächsten Nachbarn effektiv? Spielt möglicherweise der Grad der räumlichen Isolation eine Rolle? Wird externer Pollen (Polleneinfuhr aus anderen, umliegenden Beständen) überhaupt effektiv?

- Welche Rolle spielen solitäre Einzelbaumvorkommen in der freien Landschaft für die reproduktive Vernetzung von Vogelkirschenvorkommen? Gibt es Anzeichen für Unterschiede zwischen der Anzahl potentieller Paarungspartner in Offenland-Vorkommen zu denen in Waldbeständen?

- Ist die genetische Diversität der Pollenbeiträge möglicherweise positiv korreliert mit der effektiven Anzahl bestandesexterner Pollenbeiträge?

\subsection{Materielle und methodische Vorgehensweise}

\subsubsection{Das untersuchte Saatgut}

Saatgut wurde aufgrund sehr schlechter Jahre der Fruktifikation ausschließlich im Jahre 2003 in den Beständen von Roringen (siehe Kap. 3.1.1) und Settmarshausen (Kap. 3.1.3) als auch im Offenland bei Roringen geerntet.

Roringen: In diesem Bestand wurden jeweils 28 Samen zweier Bäume (Nr. 1 und 22) analysiert. Baum Nr. 1 liegt an der Peripherie (Waldrandbereich) des Bestandes und ist räumlich stärker isoliert als Baum Nr. 22, der im Waldinnenbereich des Bestandes zu finden ist. Möglicherweise sind zwischen dem Waldinnenbereich und einem in Waldrandnähe stockenden Baumes Unterschiede im Verhältnis bestandesinterner- und externer Pollenbeiträge sowie deren Diversität festzustellen.

Settmarshausen: In diesem Bestand wurden zwei Genets beerntet. Beide Genets bestehen aus jeweils zwei Ramets (Genet A aus den Bäumen Nr. 1 und 2; Genet E aus den Bäumen Nr. 13 und 14), von denen jeweils 24 Samen analysiert wurden (= 48 Samen pro Genet). In diesem Bestand besteht ein Anteil von mindestens 54\% aller Individuen aus asexueller Vermehrung (im Gegensatz zu Roringen mit knapp $20 \%$ ). Hier soll u.a. gezeigt werden, inwiefern ein höherer Verklonungsgrad Einfluß auf potentielle Vaterschaften hat.

Offenland: Um erste Hinweise über die Bedeutung von Kirschenvorkommen in der freien Landschaft zu erhalten, wurde ein Solitärbaum (S1) im Offenland von Roringen beernet (sowohl Saatgut (31 Samen) als auch Blattmaterial). Dieses Gebiet besteht vorwiegend aus landwirtschaftlich genutzter Fläche, deren Parzellen meist durch Weißdorn-Schlehenhecken begrenzt werden. Die Dornsträucher bieten der Vogelkirsche als Schutz vor Verbiß insbesondere in jüngeren Stadien teilweise günstige Anwuchsbedingungen. Um nun Pollenausbreitungsdistanzen und potentielle Vaterschaften zu bestimmen, wurde zusätzlich Blattmaterial seiner sechs nächsten Nachbarn (Umkreis bis über $300 \mathrm{~m}$ ) beerntet (Abb. 6.2). 


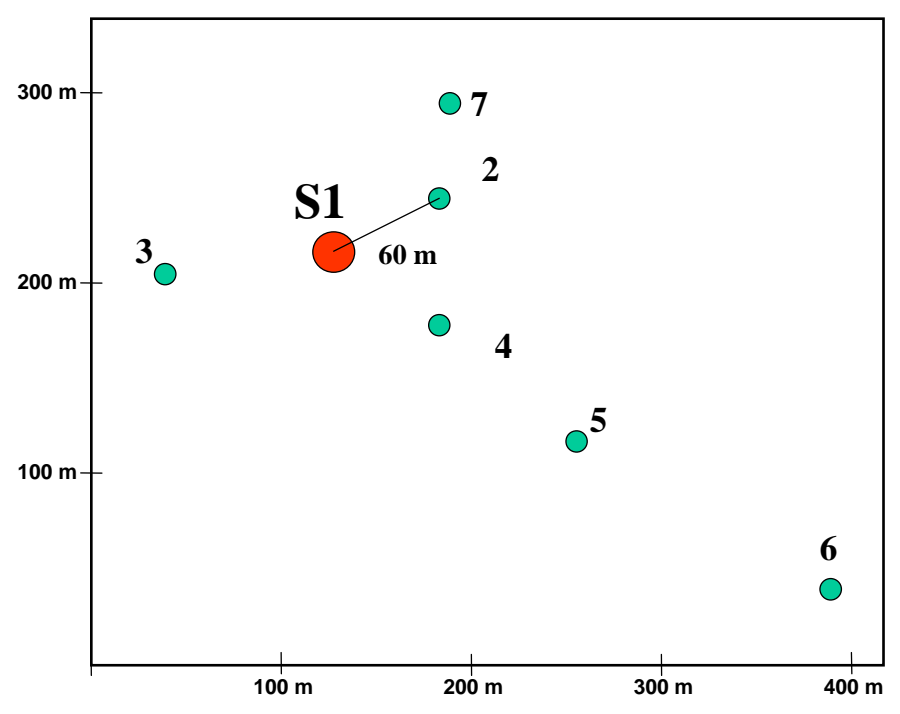

Abb. 6.2: Darstellung des Vogelkirschenvorkommens im Offenland von Roringen

\subsubsection{Vaterschaftsanalyse und Pollenausbreitungsdistanzen}

\subsubsection{Das Ausschlußprinzip}

Die Bestimmung der Vaterschaft wurde, basierend auf den gefundenen MultilocusGenotypen (MLG) in den analysierten Samen und Altbäumen, durch ein einfaches Ausschlußprinzip durchgeführt. Dabei wurde in den einzelnen Samen der genetische Beitrag des Pollens (Haplotyp) hergeleitet, in dem der mütterliche allelische Beitrag vom MLG des Embryos abgerechnet wurde. Dieser männliche Haplotyp wurde dann mit allen möglichen Haplotypen, die von den umliegenden, analysierten adulten Individuen erzeugt werden können, verglichen. Alle Individuen, deren potentielle Haplotypen nicht mit denjenigen der ermittelten männlichen Beiträge zu den Einzelbaum-Nachkommenschaften übereinstimmten, wurden als potentielle Väter ausgeschlossen. Im Idealfall blieb ein potentieller Vater nach dem Ausschlußverfahren übrig oder es konnten alle Individuen als potentielle Väter ausgeschlossen werden. In letzterem Fall konnte der Pollen nicht aus dem untersuchten Kollektiv, sondern mußte aus weiter entfernten Vorkommen der Vogelkirsche stammen.

Der männliche Beitrag an einem Genlocus war allerdings nur dann eindeutig festzustellen, wenn die Nachkommen bezüglich des betrachteten Genortes homozygot waren oder wenn, im Fall von Heterozygotie, eines der gefundenen Allele nicht im mütterlichen Genotyp enthalten war. Stellten sich sowohl Samenelter als auch Nachkomme als heterozygot bezüglich der gleichen Allele heraus, so gab es zwei Möglichkeiten der Zusammensetzung des männlichen Haplotypen (vgl. auch STREIFF et al. 1999, JONES \& ARDREN 2003). Dabei ist zu betonen, daß hier nur „potentielle“ Pollenspender ermittelt werden können. Kommt nämlich durch das Ausschlußprinzip innerhalb der Kollektive nur ein Baum als Spender in Frage, so kann es dennoch sein, dass tatsächlich externer Pollen zur Befruchtung dieses Samens beigetragen hat. 
Wie in Kapitel 3.2.3 schon erläutert, sind für diese Vaterschaftsanalyse zunächst sechs Mikrosatelliten-Marker verwendet worden. In Fällen, für die kein eindeutiger Ausschluß möglich war, wurden zwei weitere SSR-Marker eingesetzt.

\subsubsection{Darstellung der potentiellen Väter und die Berechnung der mittleren Pollenausbrei- tungsdistanzen}

Die Positionen einzelner Individuen in den Beständen Roringen und Settmarshausen wurden derart zusammengeführt, daß sie nur noch die verschiedenen Klonkomplexe (Genets) der einzelnen Bestände wiedergeben, da zwischen Pollenbeiträgen der einzelnen Ramets eines Klons nicht unterschieden werden kann (siehe Abb. 6.3 ( $a$ und b) und 6.4 (a bis d). Die Koordinaten der Klonkomplexe wurden durch die Berechnung ihrer geometrischen Mittelpunkte, d.h. der arithmetischen Mittel der X- und Y- Koordinaten ihrer Ramets, hergeleitet (analog zu Kap. 5.2.2, Methoden der Erfassung räumlich-genetischer Kovariation). Die Kennzeichnung durch geometrische Formen und Farben entspricht denjenigen der zugehörigen Ramets in den Abbildungen 5.2, 5.5 und 5.8. Damit ist die minimale Entfernung zwischen potentiellen Pollenspendern und den beernteten Samenbäumen als auch die mittlere Ausbreitungsdistanz bestandesinterner Pollen bestimmbar. War ein eindeutiger Auschluß zwischen mehreren potentiellen Vätern nicht möglich, so wurde von diesen der räumlich nächstliegende als potentieller Pollenspender in die Kalkulation einbezogen.

\subsubsection{Die genetische Diversität des männlichen gametophytischen Bei- trags in Nachkommenschaften einzelner Vogelkirschen}

Die Analyse von Paarungssystemen ist meist aufgrund der Verfügbarkeit von unvollständigen Informationen bezüglich der haplo-genetischen Zusammensetzung der gametophytischen Beiträge in den Nachkommenschaften stark eingeschränkt (siehe Kap. 6.2.1). Eine exakte Quantifizierung der genetischen Zusammensetzung effektiver Pollenwolken würde die Unterscheidbarkeit weiblicher und männlicher Beiträge und damit eine Ordnung der Genotypen voraussetzen. Eindeutig bestimmbar ist dies nur in Koniferensamen, da sich das Nährgewebe (primäres Endosperm) hier aus einem Makrogametophyten entwickelt und dessen haploides Gewebe somit auf ein Meioseprodukt zurückzuführen ist. Das Endosperm jeden Samens beinhaltet dasjenige Allel, welches der Samenelter auch zum zugehörigen Embryo beigesteuert hat.

Dieser Vorteil entfällt bei Angiospermensamen, die oft ein triploides sekundäres Endosperm aufweisen (siehe GILLET 1997, MÜLLER-STARCK 1976).

Ist es wie im Falle der Vogelkirsche nicht immer möglich, die Genotypen der Nachkommenschaften zu ordnen, so sind die männlichen gametischen Beiträge mit Hilfe von Wahrscheinlichkeitsmodellen zu schätzen. Hier soll das Maximum Likelihood Verfahren nach GILLET (1997) Verwendung finden (sie Box 6.1).

Die genische Diversität der Pollenbeiträge wurde anschließend (analog zu der Methode in Kapitel 4.2.4) durch die effektive Anzahl an Allelen pro Locus $\left(v_{2}\right)$ sowie 
durch das harmonische Mittel über alle Loci (=Genpool-Diversität, $\left.v_{\text {pool }}\right)$ berechnet (vgl. Gregorius 1978, Crow \& Kimura 1979).

\section{Das Maximum Likelihood Verfahren zur Schätzung genetischer Strukturen der männlichen Pollenbeiträge im Saatgut der Vogelkirsche (P. avium L.)}

Im Saatgut einer Population einer diploiden Baumart, wie z.B. der Vogelkirsche ( $P$. avium L.), kann eine Schätzung der männlichen Beiträge an einem betrachteten Genlocus $A$ mit $n$ Allelen $\left(A_{1}, A_{2}\right.$, $\left.\ldots, A_{n}\right)$ nur bei denjenigen Einzelbaum-Nachkommenschaften durch direktes Abzählen der hinzugekommenen Allele erfolgen, deren Sameneltern bezüglich des betrachteten Genlocus homozygot sind.

Für Einzelbaum-Nachkommenschaften heterozygoter Sameneltern ist eine direkte Schätzung der Pollenbeiträge allerdings nicht möglich, wenn der Pollen möglicherweise Träger der gleichen Allele ist wie der Samenelter.

Mit einem auf Wahrscheinlichkeitsmodellen basierenden Maximum Likelihood Verfahren ist eine Schätzung der Häufigkeiten allelischer Varianten möglich. In unserem Fall sollen dabei folgende Annahmen gelten: Es treten keine Nullallele auf und es herrscht reguläre Segregation unter den maternal vererbten Allelen.

Die Häufigkeiten der männlichen allelischen Beiträge $\left(p_{1}{ }^{*}, p_{2}{ }^{*}, \ldots, p_{k}{ }^{*}\right)$ in Saatgut des Samenelters mit dem Genotyp $A_{1} A_{2}$ können wie folgt geschätzt werden:

I. In der Saatgutprobe des Samenelters werden zunächst die absoluten Häufigkeiten der einzelnen Genotypen abgezählt. Ist $\boldsymbol{N}$ die Gesamtzahl an Stichproben, so können die Nachkommen homobzw. heterozygot bezüglich der mütterlichen Allelzusammensetzung sein $\left(A_{1} A_{1}, A_{2} A_{2}\right.$ oder $\left.A_{1} A_{2}\right)$ oder durch den väterlichen Pollenbeitrag neue allelische Varianten führen $\left(A_{1} A_{k}, A_{2} A_{k}\right)$. Folglich ist $\boldsymbol{N}=\left(N_{11}, N_{22}, N_{12}, N_{1 k}, N_{2 k}\right)_{k=3, \ldots, n}$.

II. Die Häufigkeiten der männlichen allelischen Beiträge $\left(p_{1}{ }^{*}, p_{2}{ }^{*}, \ldots, p_{k}{ }^{*}\right)$ werden anschließend wie folgt berechnet:

1. Schätzung der Häufigkeit $\left(p_{1}{ }^{*}, p_{2}{ }^{*}\right)$ derjenigen Allele, die heterozygot im Samenelter vorliegen: 1.1 Die Allele sind in der Pollenwolke nicht vertreten, wenn $N_{11}=N_{22}=N_{12}=0$.

Dieser Fall ist bei der Vogelkirsche aufgrund ihres Selbstinkompatibilitätssystems durchaus denkbar, insbesondere wenn der Samenelter heterozygoter Träger sehr seltener Allele ist.

1.2 Ist $N_{11}+N_{22}>0$, dann liegt die Maximum-Likelihood-Schätzung der Häufigkeiten bei

$$
\begin{gathered}
\left(p_{1}^{*}, p_{2}^{*}\right)=\left(\frac{N_{11} \cdot q}{N_{11}+N_{22}}, \frac{N_{22} \cdot q}{N_{11}+N_{22}}\right) \\
\text { wobei } q=\left(N_{11}+N_{22}+N_{12}\right) / N
\end{gathered}
$$

1.3 Ist $N_{11}=N_{22}=0$ und $N_{12}>0$, dann sind sämtliche Häufigkeiten für die beiden Allele gemäß Maximum Likelihood zulässig, wobei

$$
\left(p_{1}^{*}, p_{2}^{*}\right)=\{(a, q-a) \mid a \in[0, q]\} \text {. }
$$

Bei Auftreten derartiger Verhältnisse wurden bei der Kalkulation der Allelhäufigkeiten $p_{1}{ }^{*}=p_{2}{ }^{*}$ (also $a=0,5$ ) gesetzt.

2. Schätzung der Häufigkeit $\left(p_{k}\right)$ derjenigen Allele, die nicht im Samenelter vorliegen:

$$
p_{k}^{*}=\frac{N_{1 k}+N_{2 k}}{N} \quad(k=3, \ldots, n)
$$

Box 6.1

nach GILLET (1997) 


\subsection{Ergebnisse}

\subsubsection{Die Pollenverbreitung innerhalb von Waldbeständen und in der freien Landschaft}

In den Abbildungen 6.3 ( $\mathrm{a}$ und $\mathrm{b}$ ) und 6.4 (a bis d) sind alle Bäume dargestellt, welche innerhalb der untersuchten Vogelkirschenvorkommen als potentielle Pollenspender in den verschiedenen Saatgutproben identifiziert werden konnten. Durch die gewählten Mikrosatellitenmarker konnte insgesamt eine hohe Ausschlußwahrscheinlichkeit erzielt werden. Lediglich im Bestand Roringen tauchten einige Fälle auf, in denen ein eindeutiger Ausschluß nicht möglich war, was auf die geringere genetische Diversität des Bestandes zurückzuführen ist. Bezüglich der Vaterschaftsdistanzen können folgende Aussagen getroffen werden:

(1) Pollenausbreitung im geschlossenen W aldbestand: Innerhalb der untersuchten Bestände variieren die mittleren Ausbreitungsdistanzen bestandesinterner Pollen zwischen 30 und $67 \mathrm{~m}$.

Die kleinste mittlere Ausbreitungsdistanz $(30 \mathrm{~m})$ wurde im Bestand von Roringen für Baum Nr. 22 festgestellt. Dieser befindet sich in der Mitte einer Aggregation von Bäumen ausschließlich generativer Herkunft vorwiegend mit relativ geringen individuellen Abständen, welche im wesentlichen als Bestäuber fungiert haben (Abb. 6.3b). Damit findet auch diejenige Vermutung, daß eine räumlich-genetische Gruppierung der S-Allele nahezu ausschließlich aufgrund asexueller Vermehrung innerhalb dieser Waldbestände vorliegt, weitere Bestätigung.

Auch Baum Nr. 1 in Roringen wird zum größten Teil aus der nächsten Nachbarschaft bestäubt. Die mittlere Ausbreitungsdistanz ist allerdings nahezu doppelt so groß (Abb. 6.3a). Dies liegt zum einen an der stärkeren räumlichen Isolation dieses Baumes, impliziert aber gleichzeitig, daß eine effektive Bestäubung über Insekten als Vektoren auch über mittlere Distanzen innerhalb des Bestandes erfolgt. Außerdem ist es ein Hinweis darauf, daß es nicht zu einer starken Abnahme der Bestäubungseffektivität mit zunehmender Distanz zu Pollenspendern und damit zu einer Reduktion der Anzahl potentieller Vaterschaften kommt. Letzteres wird auch durch die Untersuchungen an den beiden Genets in Settmarshausen bestätigt. Hier liegen die mittleren Ausbreitungsdistanzen bei ca. 55 bis $60 \mathrm{~m}$, in Einzelfällen werden bis maximal $150 \mathrm{~m}$ erreicht (Abb. 6.4(a-d)).

Allerdings ist im Bestand von Settmarshausen zu berücksichtigen, daß auffallend oft Genets bestehend aus zwei oder mehr Ramets an den internen Vaterschaften beteiligt sind, da diese vermutlich überproportional in den Pollenwolken vertreten sind. Andere Individuen mit individuellem MLG sind oft unterrepräsentiert (siehe Anhang), bzw. leisten gar keinen Pollenbeitrag zu den Nachkommenschaften (siehe die zu Klon E benachbarten Bäume Nr. 15 und 16). 
Legende zu den Abbildungen $6.3(a, b)$ sowie $6.4(a, b, c, d)$ :

In den Abbildungen (Karten) sind folgende Informationen enthalten

z.B. A (8,9): A bezeichnet die Klongruppe, $(8,9)$ bezeichnet die dazugehörigen Individuen (Ramets)

Distanz zwischen dem bestandesinternen, potentiellen

Pollenspender und dem Samenelter (Ausschluß eindeutig)

Nicht eindeutiger Ausschluß: Hier wurde der räumlich

- n nächststehende potentielle männliche Paarungspartner in die Kalkulation aufgenommen

Kreisradius $=$ mittlere Transportweite bestandesinternen Pollens

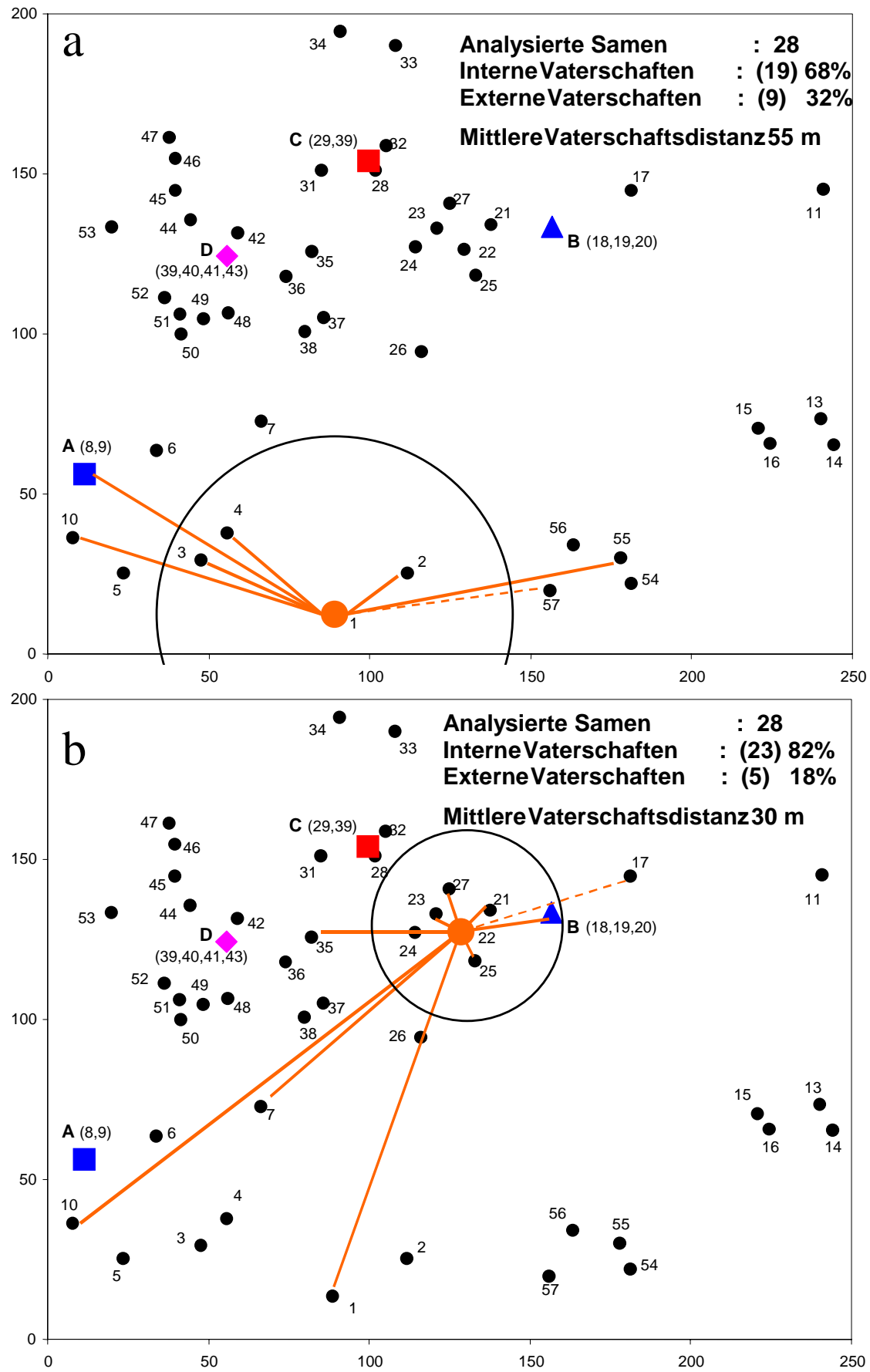

Abb. 6.3a und b: Pollenausbreitungsdistanzen im Bestand von Roringen (dargestellt für Saatgut von Baum Nr. 1 und Baum Nr. 22) 


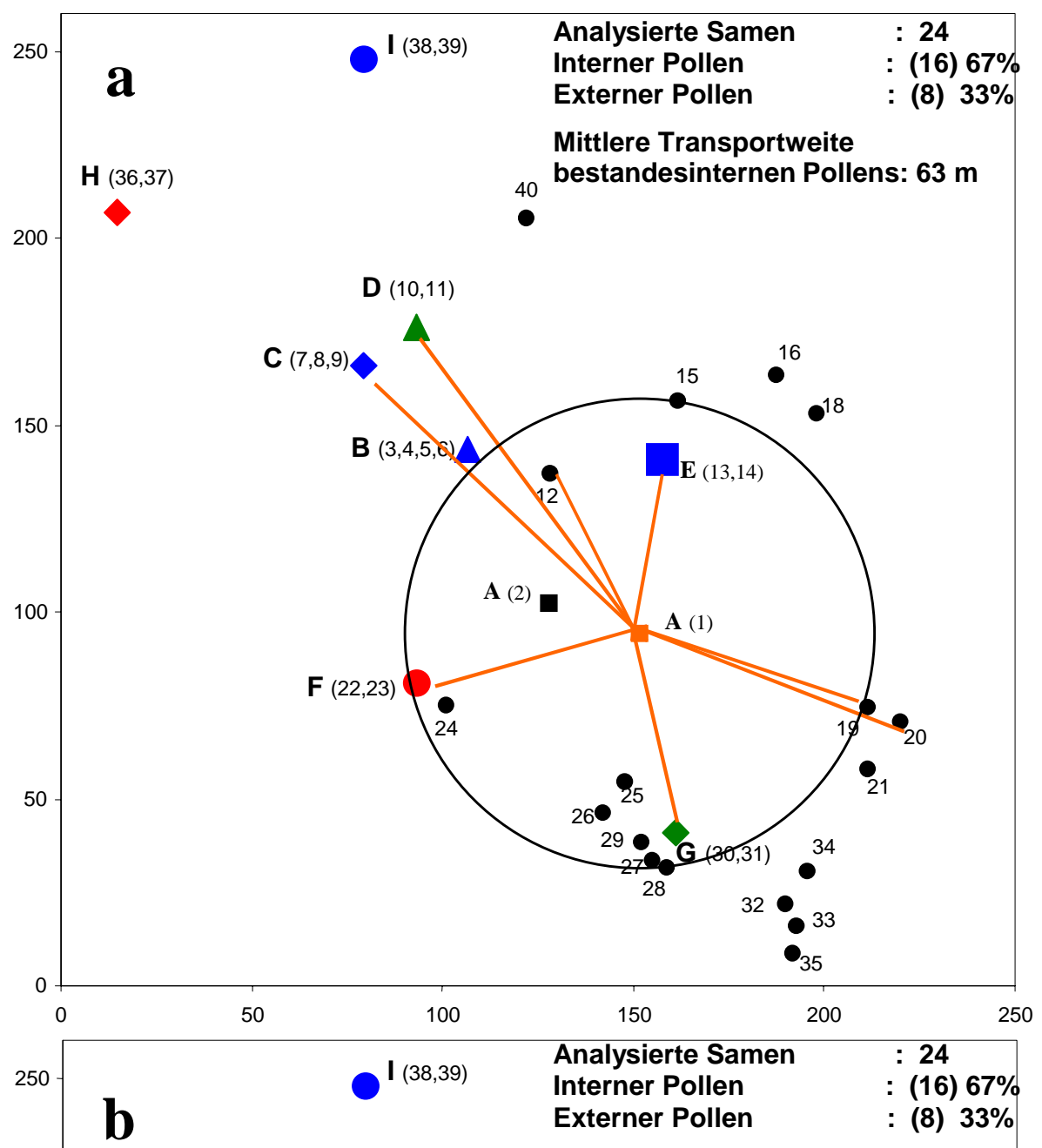

Mittlere Transportweite

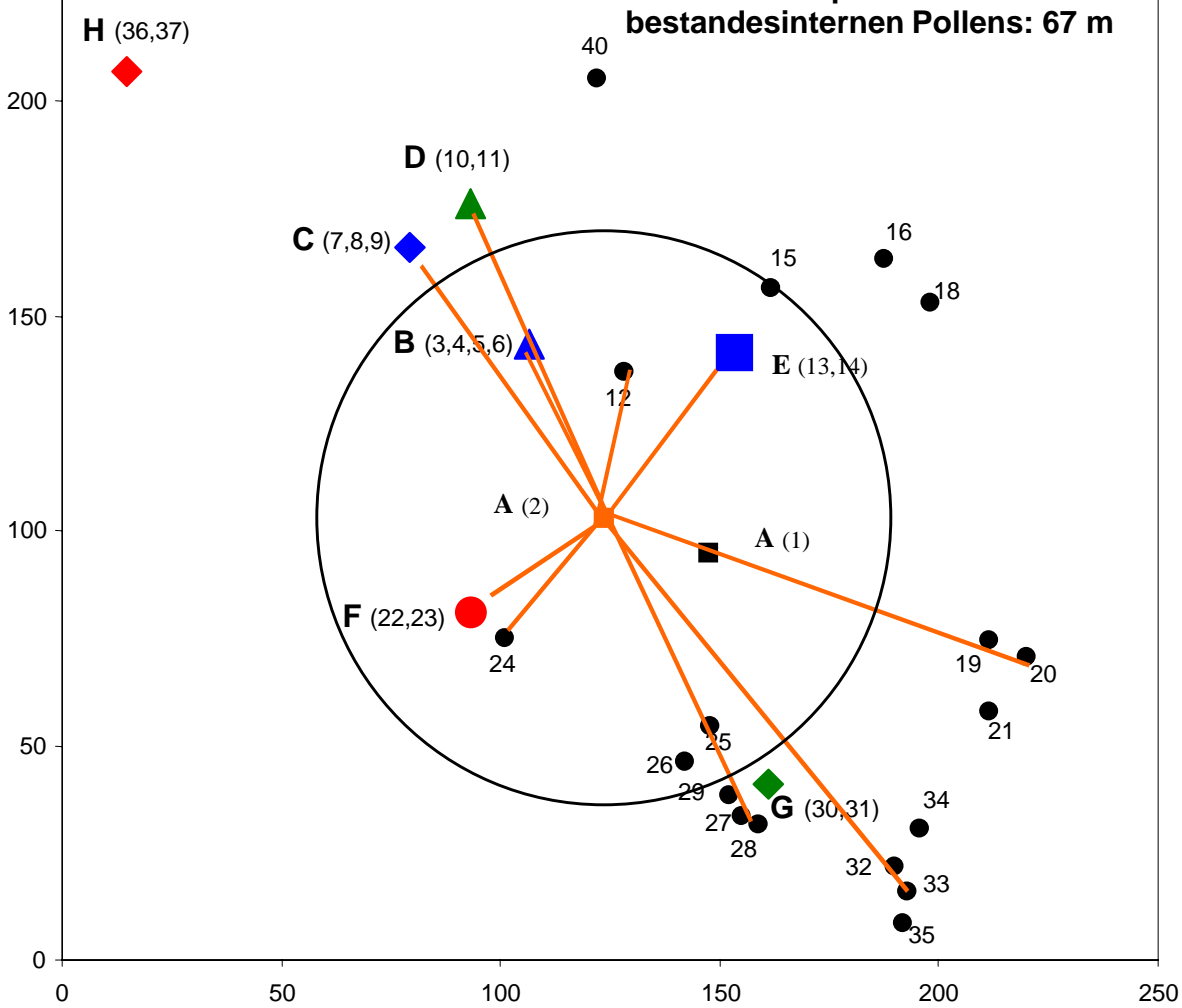

Abb. 6.4a und b : Pollenausbreitungsdistanzen im Bestand Settmarshausen (dargestellt für Saatgut von Baum Nr. 1 und 2) 

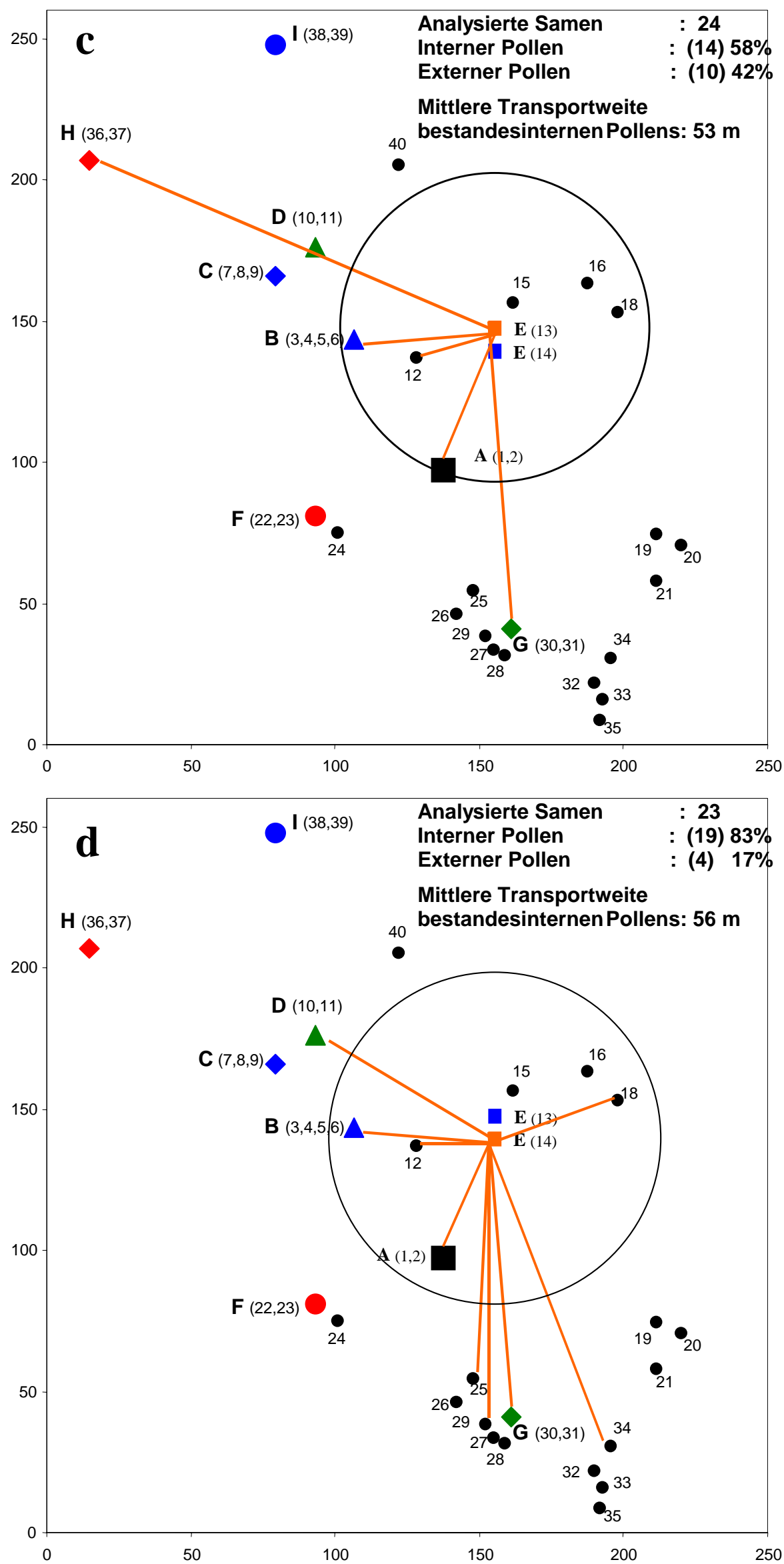

Abb. 6.4c und d : Pollenausbreitungsdistanzen im Bestand Settmarshausen (dargestellt für Saatgut von BaumNr. 13 und 14) 
(2) Bestandesexterne Polleneinträge im geschlossenen Waldbestand: Insgesamt konnten für alle Saatgutproben in den untersuchten Waldbeständen externe Vaterschaften mit Anteilen zwischen 18 bis $42 \%$ beobachtet werden. Interessant ist dabei die Tatsache, daß trotz nachgewiesener bevorzugter Paarung mit nächsten Nachbarn innerhalb der Bestände (kurze bis teilweise mittlere Vaterschaftsdistanzen) ein erheblicher Anteil bestandesexterner Polleneinträge (Ferntransport) für alle analysierten Samenbäume aufrecht erhalten bleibt.

(3) Pollenausbreitung in der freien Landschaft. Die Analyse des von Baum S1 geernteten Saatgutes (Offenland bei Roringen) ergab, daß keiner der umliegenden, blühfähigen Vogelkirschen als potentieller Vater in Frage kommt. Da demnach ausschließlich externer Pollen effektiv wurde, konnten Pollenausbreitungsdistanzen nicht eingeschätzt werden. Andererseits ist aber die Aussage möglich, daß der Pollen in jedem Fall hat über $300 \mathrm{~m}$ hat zurücklegen müssen, da der Entfernteste der sechs nächsten Nachbarn einen Abstand von ungefähr 300m zum untersuchten Samenbaum hatte. In diesem Fall scheinen sich die Pollenausbreitungsmechanismen anders zu gestalten als im Inneren von Waldbeständen. Nahe und mittlere Vaterschaftsdistanzen sind hier nicht nachweisbar. Ausschließlich Pollenferntransport kommt hier für die Befruchtung der analysierten Samen in Betracht.

\subsubsection{Die genetische Variation der Pollenbeiträge innerhalb der untersuch- ten Nachkommenschaften}

In Tabelle 6.1 sind die Werte für die Anzahl gefundener Allele sowie die genischen Diversitäten der Pollenbeiträge in den untersuchten Einzelbaumnachkommenschaften dargestellt. Letztere wurden aus den mit Hilfe des Maximum Likelihood Verfahrens geschätzten Allelhäufigkeiten berechnet.

\subsubsection{Anzahl gefundener Allele in den Pollenbeiträgen der analysierten Samen im Vergleich zu den Altbeständen}

Die Pollenbeiträge in den Nachkommenschaften der einzelnen Samenbäume in den Beständen Roringen und Settmarshausen (geschlossene Waldbestände) weisen generell eine geringere durchschnittliche Anzahl an Allelen pro Locus auf als der zugehörige Altbestand. Dies kann einerseits auf die geringe Anzahl an Samenstichproben zurückzuführen sein, andererseits konnte gezeigt werden, daß viele Bäume bevorzugt mit ihrer Nachbarschaft paaren (Pollen werden meist über kurze bis mittlere Distanzen ausgebreitet, vgl. Kap. 6.3.1) und somit die Pollenbeiträge des gesamten Bestandes nicht vollständig abgedeckt werden. Andererseits trägt auch der relativ hohe Anteil an bestandesexternen Pollen an den Befruchtungen mit durchschnittlich ca. 30\% nicht zu einer Erhöhung der genetischen Diversität bei.

Gegensätzlich verhält es sich bei Baum S1 auf der Freifläche Roringen (Offenland). Hier konnten in den männlichen Gametenbeiträgen im Saatgut mit Ausnahme von Locus UDP98-021 generell mehr Allele pro Locus beobachtet werden (im Mittel $A / L=5.83)$ als unter den nächsten sechs analysierten Nachbarbäumen. Diese Bäume fallen als Referenzwert allerdings aus, da keiner dieser Bäume als potentiel- 
ler Vater innerhalb des Saatgutes von S1 in Frage kommt. Auch der nahegelegene Roringer Altbestand zeigt mit 5.50 Allelen pro Locus einen geringeren Wert.

Besonders auffallend in dem Zusammenhang ist Mikrosatelliten-Locus BPPCT034. Hier konnten für den Solitär S1 im Roringer Offenland zehn Allele identifiziert werden, die höchste in allen Proben festgestellte Anzahl.

\subsubsection{Die genetische Diversität in den Pollenbeiträgen der analysierten Samen im Vergleich zu den Altbeständen}

Die Werte für diesen Parameter sind ebenfalls für die Pollenbeiträge der analysierten Nachkommen in den geschlossenen Waldbeständen Roringen und Settmarshausen niedriger als die entsprechenden Werte, die für die jeweiligen Altbestände ermittelt wurden. Eine Ausnahme bildet auch hier wieder der Baum S1 in der freien Landschaft von Roringen mit einem Wert von $v_{\text {pool }}=3.37$, der die umliegenden nächsten Nachbarn $\left(v_{\text {pool }}=3.21\right)$, insbesondere aber den Altbestand von Roringen $\left(v_{\text {pool }}=2.88\right)$ übertrifft.

\begin{tabular}{|c|c|c|c|c|c|c|c|}
\hline & UDP95-005 & UDP98-021 & UDP98-410 & UDP98-412 & ВРРСТ034 & ВРРСТ040 & $V_{\text {pool }}(A / L)$ \\
\hline Roringen Altbestand ( $\mathrm{N}=56)$ & $3.47(5)$ & $2.01(3)$ & $2.56(6)$ & $3.90(7)$ & $4.02(7)$ & $2.48(5)$ & $2.88(5.50)$ \\
\hline Pollenbeiträge (Samen Baum Nr. 1) & $2.42(4)$ & $1.99(2)$ & $2.91(5)$ & $3.26(6)$ & $4.71(7)$ & $2.13(3)$ & $2.67(4.50)$ \\
\hline Pollenbeiträge (Samen Baum Nr. 22) & $2.50(4)$ & $1.56(3)$ & $3.43(5)$ & $2.27(3)$ & $3.09(6)$ & $2.66(4)$ & $2.43(4.17)$ \\
\hline Roringen Offenland $(\mathrm{N}=7)$ & $3.38(4)$ & $2.00(3)$ & $2.80(3)$ & $3.63(5)$ & $7.54(9)$ & $3.27(4)$ & $3.21(4.67)$ \\
\hline Pollenbeiträge (Samen Baum S1) & $3.45(6)$ & $2.41(3)$ & $3.16(5)$ & $3.43(6)$ & $6.43(10)$ & $3.21(5)$ & $3.37(5.83)$ \\
\hline Settmarshausen Altbestand $(\mathrm{N}=39)$ & $3.67(5)$ & $2.60(5)$ & $3.54(6)$ & $2.78(6)$ & $6.81(9)$ & $4.49(9)$ & 3.60 (6.33) \\
\hline Pollenbeiträge (Samen Baum Nr. 1) & $2.23(4)$ & $3.14(4)$ & $3.30(5)$ & $4.11(6)$ & $3.51(6)$ & $4.12(5)$ & $3.26(5.00)$ \\
\hline Pollenbeiträge (Samen Baum Nr. 2) & $3.57(6)$ & $2.33(4)$ & $2.75(5)$ & $2.97(4)$ & $5.78(8)$ & $3.86(5)$ & $3.26(5.33)$ \\
\hline Pollenbeiträge (Samen Baum Nr. 13) & $3.39(4)$ & $1.94(3)$ & $3.41(4)$ & $2.61(5)$ & $5.29(6)$ & $2.93(5)$ & 2.97 (4.33) \\
\hline Pollenbeiträge (Samen Baum Nr. 14) & $3.79(5)$ & $2.00(4)$ & $3.77(5)$ & $1.74(4)$ & $5.88(8)$ & $3.77(5)$ & $2.94(5.17)$ \\
\hline
\end{tabular}

Tab. 6.1: Die genische Diversität $\left(v_{2}\right)$ sowie (in Klammern) die gefundene Anzahl an Allelen an den einzelnen Mikrosatelliten-Loci, das harmonische Mittel der Einzellocus-Diversitäten ( $\left.v_{\text {pool }}\right)$ sowie die mittlere Anzahl an Allelen pro Locus $(A / L)$ für die Pollenbeiträge im Saatgut der analysierten Samenbäume im Altbestand von Roringen, in der freien Landschaft von Roringen (=Roringen Offenland) als auch im Altbestand von Settmarshausen; Fettdruck: Die Daten der Altbäume in den einzelnen Vorkommen zum Vergleich

Innerhalb der Waldbestände ist zwischen dem Anteil externer Pollenbeiträge und der genetischen Diversität in den Pollenbeiträgen keine Korrelation zu verzeichnen. Vergleicht man allerdings die väterlichen Beiträge zum Saatgut von Baum S1 im Offenland (alles externer Pollen) mit denjenigen in den geschlossenen Waldbeständen (18 bis 42\% externer Pollen), so wird ein deutlicher Unterschied sichtbar.

Insgesamt kann dies als ein erster Hinweis daraufhin gedeutet werden, daß vermutlich gerade diejenigen Individuen, die in der freien Landschaft vorkommen, eine 
entscheidende Rolle bei der Aufrechterhaltung des reproduktiven Zusammenhalts dieser rezedenten Art spielen.

\subsection{Diskussion}

Im vorangegangenen Kapitel (Kap.5) wurde die Effizienz der Ausbreitung genetischer Information in verschiedenen Vorkommen der Vogelkirsche untersucht. Dabei wurde festgestellt, daß Vektoren (hier: Vögel, Säugetiere) für eine schnelle Besiedlung von Bestandeslücken, sogenannten 'recruitment foci’, sorgen können, indem sie die Samen aus möglicherweise verschiedenen Richtungen herantransportieren und damit zu einer Durchmischung der genetischen Information beitragen. Die nur geringen räumlich-genetischen Strukturen im femelartig bewirtschafteten Bestand von Roringen sind aber nicht nur das Ergebnis des Vorgangs des Samentransports, sondern auch einer Vielzahl weiterer, mit der Etablierung der einzelnen Pflanzen in Zusammenhang stehender Prozesse (siehe Kap. 5.1.2). Deshalb beschränkt sich diese Arbeit auf die einfacher zu analysierende Pollenausbreitung als eine Komponente des reproduktiven Artzusammenhalts der Vogelkirsche.

Die vorliegenden Ergebnisse bestätigen die Vorteile variabler DNA-Marker bei der Analyse der Pollenausbreitung innerhalb von Pflanzenvorkommen. Es konnte gezeigt werden, daß die eingesetzten (maximal acht) Mikrosatelliten-Loci ausreichen, um für nahezu alle untersuchten Samen in den jeweiligen Beständen eine bestandesinterne potentielle Vaterschaft zu ermitteln bzw. die Einfuhr des Pollens aus bestandesexternen Vogelkirschenvorkommen (Ferntransport) zu bestätigen.

Auf eine umfangreiche Analyse des Pollenferntransports wurde hier allerdings verzichtet, da dadurch vermutlich eine beträchtliche Vergrößerung des Untersuchungsgebietes notwendig gewesen wäre. Diese Untersuchung gibt deutliche Hinweise darauf, daß das symbiotische Verhältnis zwischen der Vogelkirsche als Nahrungsspender (Nektar, Pollen) und dem Insekt als Pollenvektor einen sehr effizienten Pollenausbreitungsmechanismus darstellt. Das machen die relativ hohen Anteile bestandesexterner Pollen innerhalb der Waldbestände (18 bis 42\%) und die ausschließlich durch Pollenferntransport übertragenen männlichen Beiträge im Saatgut des Baumes S1 im Roringer Offenland deutlich. In der Saatgutprobe von Baum S1 konnten die nächsten sechs Nachbarn (Abstände zwischen 60 und maximal $300 \mathrm{~m}$ ) als potentieller Väter vollständig ausgeschlossen werden. Für die exakte Bestimmung bestandesexterner potentieller Vaterschaften ist eine sehr hohe Anzahl an zu untersuchenden Individuen als auch der Einsatz einer höheren Zahl an variablen Genmarkern unumgänglich. Dieses war durch die limitierenden Ressourcen für labortechnische Analysen nicht möglich. Auf den Einsatz von Schätzverfahren, welche die Realität nur sehr unvollständig wiedergegeben hätten, wurde daher verzichtet.

Welche Faktoren bei der Pollenausbreitung eine möglicherweise entscheidende Rolle spielen, soll hier anhand der gefundenen Ergebnisse sowie an einigen Beispie- 
len der Bestäubungsbiologie insbesondere staatenbildender Insekten näher diskutiert werden.

(1) Wird beispielsweise der bei einem Blütenbesuch durch das Insekt aufgenommene Pollen auf der nächsten angeflogenen Blüte nicht vollständig deponiert, sondern kann dieser Pollen über mehrere angeflogene Blüten hinweg übertragen werden, so spricht man von einem Carry-over-Effekt. Dieser kann zu erheblich größeren Transportweiten führen, als es die direkten Flugwege der Insekten ermöglichen (vgl. auch FrOMM 2001). Dieser Effekt ist vermutlich auch innerhalb der untersuchten Vogelkirschenbestände im Waldinnenbereich von großer Bedeutung. Beladen sich Insekten bei dem Besuch mehrerer Blüten innerhalb der Krone eines Baumes mit dessen Pollen und wechseln dann auf einen kompatiblen Nachbarn, so kann es dort zu einer Vielzahl von Blütenbestäubungen und erfolgreichen Befruchtungen kommen.

(2) Einen weiteren Effekt bringt diejenige Tatsache mit sich, daß staatenbildende Insekten ohne zwischenzeitliche Energieaufnahme größere Entfernungen vom Stock möglicherweise nicht überbrücken können. Deshalb werden vermutlich einzelne Bäume/Baumgruppen, die sich auf der Flugroute zwischen dem Stock und dem eigentlichen Zielvorkommen befinden, regelmäßig auf Hin- und Rückflügen angeflogen (FROMM 2001). Dieser Sachverhalt dürfte mittlere und auch größere Pollentransportweiten verursachen. Bei der Vogelkirsche würde dies bedeuten, daß sich die Insekten auf dem Weg zum Zielbestand mit externem Pollen beladen und diesen gemäß dem oben beschriebenen Carry-over-Effekt solange auf die Blüten innerhalb der Bestände übertragen, bis dieser verbraucht ist und nur noch bestandesinterner Pollen effektiv werden kann.

Mit diesen beiden beschriebenen Mechanismen kann der überwiegende Teil der in dieser Untersuchung gefundenen geringen und mittleren Vaterschaftsdistanzen, aber möglicherweise auch der größte Teil der externen Pollenbeiträge innerhalb der Bestände erklärt werden.

Betrachtet man aber die gefundenen Ergebnisse von Baum S1 in der Roringer Feldmark, müssen hier noch weitere Erklärungsansätze gesucht werden. Auch wenn dieses Ergebnis nur durch gezieltere Untersuchungen zu erhärten ist, so geben die experimentellen Beobachtungen einen deutlichen Hinweis darauf, daß räumlich isoliert stehende Vogelkirschen sowohl Senke als auch Quelle für hohe genetische Variation und damit wichtige Trittsteine (Stepping-stones) für die Neubesiedlung von Habitaten darstellen.

(3) Interessant erscheint in dem Zusammenhang auch die Tatsache, daß nicht die Übertragung kompatiblen Pollens von 'Baum-zu-Baum' während der Insektenflüge, sondern von 'Insekt-zu-Insekt' innerhalb eines Stocks staatenbildender Insekten (wie z.B. der Honigbiene) enorme Pollentransportweiten verursachen kann, insbesondere wenn berücksichtigt wird, daß es in einer Kolonie verschiedene Flugrouten und -richtungen geben kann (DEGRANDI-HOFFMAN et al. 1984, FreE \& Williams 1972) (vgl. Kapitel 2.2.3.1). Dies würde zu einer umfangreichen Pollenmischung innerhalb eines Bienenstocks führen, welcher eine 
große Ansammlung verschiedener genetischer Varianten beinhalten kann. Dies ist an dem männlichen Beitrag im Saatgut des Baumes S1 zu beobachten, der sowohl die höchste durchschnittliche Anzahl an Allelen pro Locus $(A / L=$ 5.83) als auch die höchste genische Diversität $\left(v_{\text {pool }}=3.37\right)$ unter allen untersuchten Pollenbeiträgen aufwies. Es ist allerdings darauf hinzuweisen, daß dies aufgrund der geringen Datenmengen nur Hinweise explorativer Natur sind und daß für statistisch abgesicherte Ergebnisse noch weitere Untersuchungen notwendig sind.

(4) $\mathrm{Daß}$ in der Saatgutprobe von Baum S1 keine Pollenbeiträge von seinen nächsten Nachbarn und damit auschließlich externer Pollen nachgewiesen werden konnte, ist auch ein Hinweis darauf, daß eine gewisse Attraktivität für Insekten eine vermutlich sehr große Rolle spielen muß. Aufgrund des Freistands konnte dieser Baum eine der größten und blütenreichsten Kronen der Umgebung entwickeln. Nach HeINRICH (1975) kann das dazu führen, daß weiter entfernt gelegene, große Nahrungsquellen direkt angeflogen und kleinere dabei überflogen werden. Dieser Sachverhalt würde bedeuten, daß gerade solche Attraktionspunkte in der freien Landschaft, analog zu den 'recruitment-foci' für Samen in Bestandeslücken, eine Sammelstelle genetischer Variation darstellen.

Zusammenfassend kann gesagt werden, daß dem Befruchtungssystem (das betrifft hier insbesondere das gametophytische Inkompatibilitätssystem) als auch dem System der Pollenausbreitung als Determinanten des reproduktiven Artzusammenhalts vermutlich eine sehr große Bedeutung zukommt. KOWNATZKI (2002) stellte durch den Einsatz von Isoenzymen bereits fest, daß mindestens $44 \%$ der männlichen Beiträge in den Samen einer isolierten Freilandpopulation (bestehend aus zwei Genets) aus Importen von anderen Vorkommen stammen müssen. Vermutlich könnte diese Zahl noch deutlich höher ausfallen, wenn variablere Genmarker zur Verfügung gestanden hätten. Es zeigt sich also, daß insbesondere freistehenden Vorkommen vermutlich eine sehr große Bedeutung bei der reproduktiven Vernetzung der Vogelkirsche zukommt.

Es bliebe allerdings noch zu testen, welche der oben aufgeführten Vorgänge bei der Pollenausbreitung durch unterschiedliche landschaftliche Rahmenbedingungen, z.B. innerhalb des Waldes oder im Freiland, tendentiell von größerer Bedeutung ist. Möglicherweise hat der Carry-over-Effekt (Pollenübertragung von 'Baum-zu-Baum') innerhalb der Waldbestände insbesondere für kürzere Pollenausbreitungsdistanzen die größere Bedeutung, während die anderen Vorgänge (Pollenübertragung von 'Insekt-zu-Insekt' innerhalb des Stocks staatenbildender Insekten, Ansammlung hoher genetischer Vielfalt auf sehr attraktiven, solitären Einzelbaumvorkommen) in der freien Landschaft überwiegen. 


\section{Abschließende Bemerkungen und Ausblick}

Eine Vielzahl höherer Pflanzen besitzt die Fähigkeit, sich vegetativ auszubreiten. Bei den meisten Arten ist dieser Modus der Reproduktion fakultativer Natur, da sie gleichzeitig meist auch sexuell reproduzieren (SILANDER 1985). Dies impliziert, daß sich die beiden Reproduktionsformen möglicherweise stark beeinflussen und daß sich im Lebenszyklus klonal wachsender Pflanzen die beiden Strategien nicht unabhängig voneinander entwickelt haben. So kann es sein, daß das Resultat von starker Verklonung (z.B. Phalanx-Strategie) mit einer geringen Verfügbarkeit an Fremdpollen verbunden ist, was zu erhöhten Selbstbefruchtungsraten durch Geitonogamie (Bestäubung mit Pollen klongleicher Ramets) und damit zu Inzuchtdepressionen führen kann (siehe Review von FISCHER \& VAN KLEUNEN 2002).

Die Vogelkirsche hingegen, die ebenfalls zu asexueller Vermehrung durch Wurzelbrutbildung befähigt ist, besitzt einen gametophytischen (also präzygotalen) Selbstinkompatibilitätsmechanismus (GSI), der einerseits zwar eine Befruchtung durch Eigenpollen gänzlich verhindert, andererseits aber auf die Übertragung einer ausreichenden Menge an Fremdpollen angewiesen ist. Inwieweit dies bei rezedenter Lebensweise und Abhängigkeit von Insekten als Vektoren möglich ist, insbesondere in durch den Menschen stark modifizierten Umweltbedingungen, wurde schon zu Beginn dieser Arbeit in Frage gestellt.

In der waldbaulichen Literatur wird die Vogelkirsche im Wald mit einer nur sehr geringen Flächenrepräsentanz beschrieben und sie tritt meist in Trupps oder Gruppen auf. Dies wird als die Folge vegetativer Reproduktion (Wurzelbrutbildung) angesehen, da nur geringe Etablierungschancen generativer Abkömmlinge vermutet werden. Letzteres wird auf starken Wildverbiß und auf Samenprädation (Mäuse, Vögel, Insektenarten) zurückgeführt (RÖHRIG \& BARTSCH 1992, KOLLMANN 1994). Auch wenn vegetative Vermehrung als eine der Strategien dieser Baumart gewertet werden kann, sich erfolgreich im Wettbewerb mit konkurrenzstarken Arten behaupten zu können, so war es anfangs dennoch unklar, was die treibende Kraft zur Ausbildung vegetativer Abkömmlinge darstellt und wie das Verhältnis dieser beiden Reproduktionsformen in adulten Vorkommen unter verschiedenen Umweltbedingungen (hier: Waldbewirtschaftungsformen) aussieht (FERNANDEZ et al. 1996). So fanden FrasCARIA et al. (1993), DUCCI \& SANTI (1997) sowie KOWNATZKI (2002) bei genetischen Inventuren mit Hilfe von Isoenzymen, daß teilweise erhebliche Anteile der Vogelkirschen innerhalb von Beständen identische Multilocus-Genotypen aufwiesen. Allerdings wurde auch darauf hingewiesen, daß sich die teilweise hohen individuellen Homozygotiegrade möglicherweise verfälschend auf das Ergebnis auswirkten, da selbst im Falle sexueller Vermehrung dadurch kaum neue Rekombinanten hätte erzeugen werden können (FrASCARIA et al. 1993). Deshalb war die Problematik der sexuellen Erzeugung von Genotypkombinationen ein zentrales Problem dieser Arbeit, da ohne diesbezügliche Kenntnisse eine präzise Unterscheidung zwischen asexueller und sexueller Vermehrung nicht möglich ist.

Inwiefern frühere Mittelwaldwirtschaft das Verhältnis von asexueller zu sexueller Vermehrung beeinflussen konnte und wieviele Ramets eines Klons das reprodukti- 
ve Alter erreichen haben, war von Beginn an nicht zwingend erkennbar, da im Mittelwald möglicherweise auch Samen bessere Keimungs- und Etablierungsbedingungen aufgrund günstigerer Umweltverhältnisse (Licht, Wärme) vorfanden.

Andererseit war es auch nicht bekannt, wie das Verhältnis dieser beiden Reproduktionsmodi im Hochwald aussieht. In diesem Zusammenhang vermuteten DUCCI \& SANTI (1997), daß bei der Vogelkirsche selbst schon in frühen Entwicklungsstadien Wurzelbrutbildung möglich sein kann. Dies lassen auch die Ergebnisse eines Kirschenanbauversuches von OBAL \& BARTSCH (2000) vermuten, die eine starke Ausbildung horizontaler Wurzeln (unter Teischirm im Mittel 2,49 $\mathrm{m}$, maximal sogar 4,39 m) bei sechsjährigen Pflanzungen vorfanden.

Eine Analyse, ob und wie stark sich die Vogelkirsche unter verschiedenen historischen und gegenwärtigen Betriebsarten sexuell bzw. asexuell reproduziert, war auch für die weiteren populationsgenetischen und -biologischen Untersuchungen zwingend erforderlich (genetische Diversität, Pollenausbreitung etc.).

Wie in dieser Arbeit gezeigt werden konnte, ist die an einem Satz von Marker-Genloci ermittelte Identität zweier Individuen nicht zwingend auf deren gemeinsame vegetative Abstammung zurückzuführen, auch wenn die Wahrscheinlichkeit der Entstehung derartiger Genkombinationen zunächst als sehr unwahrscheinlich erscheint. Nach der Analyse von sechs Mikrosatelliten-Loci fiel zunächst auf, daß neben einer Vielzahl von identischen Multilocus-Genotypen (MLG), insbesondere in den ehemaligen Mittelwäldern, auch solche zu beobachten waren, die sich nur an einem Locus und teilweise nur durch ein Allel voneinander unterschieden. Es stellte sich zunächst die Frage, inwieweit Mutationen innerhalb der Mikrosatellitensequenzen dabei eine Rolle spielten. Dessen Bedeutung war zunächst nicht zu unterschätzen, da die meisten Kultursorten vieler Obstbäume aus spontanen somatischen Mutationen (z.B. an Knospen) hervorgegangen sind (SILANDER 1985, siehe auch HARTMANN \& KERSTER 1975) und das Alter der Klone innerhalb der Vogelkirschenbestände möglicherweise beträchtlich sein kann. Dieser Fall hätte bedeutet, daß der Anteil von Individuen asexueller Herkunft möglicherweise größer als die Menge der gefundenen identischen MLG hätte ausfallen können. Als eine weitere Erklärungsmöglichkeit für die häufige Erzeugung bestimmter Genotypkombinationen wurden Genassoziationen, d.h. eine stochastisch nicht unabhängige Weitergabe von Genen genannt. Hier hätte der Verklonungsgrad folglich nach unten korrigiert werden müssen.

Deswegen wurden noch weitere Marker-Loci untersucht. Deren Analyse bestätigte folgendes: Nicht nur diejenigen Individuen, die sich genetisch nur minimal von anderen unterschieden, sondern auch einige mit zunächst vollständig identischen MLG (an sechs Mikrosatelliten) konnten weiter aufgetrennt werden. Dies konnte nicht nur mit Hilfe weiterer Mikrosatelliten, sondern auch am Beispiel von Wibbecke mit Isoenzymen nachgewiesen werden, die eine hohe ontogenetische Stabilität aufweisen (KOWNATZKI 2002, HATTEMER et al. 1993). Die Ergebnisse dieser Arbeit sind damit aber nicht als Widerspruch zu denjenigen von KOWNATZKI (2002) aufzufassen. Schon er wies darauf hin, daß neuartige konzeptionell-theoretische Überlegungen zur Absicherung der genetischen Identität zweier Individuen 
und damit ihrer asexuellen Abstammung dringend erforderlich sind (KOWNATZKI 2002, S. 91). Dies wurde in der Arbeit von GREGorius (2005) durch die Entwicklung der statistischen Prüfgröße $C_{2}^{N}$ fortgesetzt (siehe Kapitel 4.2.2 und Box 4.2 auf S. 46). Beide Arbeiten an der Vogelkirsche stellen vielmehr eine entscheidende gegenseitige Ergänzung in der Problematik zur Unterscheidung von sexueller vs. asexueller Herkunft einzelner Individuen dar, da unter Verwendung beider Datensätze gezeigt werden konnte, daß die Annahme geringer Assoziationen zwischen Genloci in unvermutet hohem Umfang nicht zutrifft und damit herkömmliche Analysen zur Bestimmung sexueller und asexueller Anteile zu verzerrten Ergebnissen führen können. Die Ergebnissse geben außerdem Anlaß, unsere gegenwärtigen Vorstellungen über die Ausmaße von Koadaptation und Koevolution in Genomen möglicherweise grundsätzlich zu überdenken. Mögliche Ursachen für derartige Beobachtungen bei der Vogelkirsche werden hier zwar ansatzweise diskutiert (Kapitel 5.4.2), bedürfen aber noch eingehenderen Untersuchungen.

Die Entwicklung neuer Methoden zur Schätzung von Genassoziationen ermöglichte eine Präzisierung bei der Quantifikation von Anteilen asexueller und sexueller Vermehrung in Pflanzenpopulationen. So konnte in ehemaligen Mittelwaldbeständen für einen Anteil von 54 und 77\% aller Individuen eine asexuelle Herkunft nachgewiesen werden. Dabei zeigte sich, daß im Mittelwald räumliche Aggregationen von bis zu 15 Ramets pro Klon möglich waren. Im femelwaldartig bewirtschafteten Hochwald hingegen war ein wesentlich geringeres Ausmaß von nur 18\% festzustellen und die Anzahl der Ramets pro Klon lag hier nur zwischen zwei und vier. Insgesamt konnte also gezeigt werden, daß die Art der Bewirtschaftung einen deutlichen Einfluß auf das Verhältnis dieser beiden Reproduktionsmodi hat. Außerdem ergab diese Analyse einen deutlichen Hinweis darauf, daß die Bildung von Wurzelbrut in frühen Entwicklungsstadien der Vogelkirsche nur eine geringfügige Bedeutung hat (siehe Hochwald Roringen). Erst im höheren Alter, insbesondere wenn lichte Verhältnisse wie im Mittelwald geschaffen werden, vermag sich die Vogelkirsche verstärkt über Wurzelbrutbildung zu vermehren. Inwiefern das wiederholte 'auf den Stock setzen' der Kirsche im Mittelwald dabei eine Rolle gespielt hat, bleibt deshalb nachwievor offen.

Insgesamt spiegeln die hier gewonnenen Ergebnisse nicht nur den Wandel forstlicher Nutzungsformen wieder, sondern auch die sich ändernden Anpassungsanforderungen, die an das Reproduktionssystem der Vogelkirsche gestellt werden. Die Anteile der beiden Reproduktionsmodi und die ermittelten genetischen Diversitäten lassen allerdings noch kaum Aussagen über die Vorgänge der Ausbreitung genetischer Information bei der Vogelkirsche zu (z.B. Pollen- und Samentransport). Aus diesem Grunde wurden mehrere indirekte und eine direkte Methode angewandt.

Zu den indirekten Verfahren zählt die Beschreibung des statischen Zustands der Verbreitung von Individuen und genetischer Information im Raum. Viele Untersuchungen an Baumarten beschränkten sich bis dato auf eine einfache, kartographische Darstellung von genetischen Merkmalen (siehe frühe räumlich-genetische Analysen von TIGERSTEDT 1973) bis hin zur Berechnung räumlich-genetischer Ko- 
variation (siehe u.a. distanzklassenbasierte Verfahren, SOKAL \& ODEN 1978). Bei den meisten experimentellen Arbeiten an Baumarten war dabei, neben einer Reihe von anderen Faktoren, insbesondere die Effizienz der Pollen- und Samenausbreitung von Interesse, welche maßgeblich die räumlich-genetische Strukturen einer Art beeinflussen können.

So fanden Dounavi (2000) und DeCarli (2003) an der Buche (Fagus sylvatica L.), daß eine positive Korrelation zwischen dem räumlichen und genetischen Abstand in Distanzklassen von bis zu $30 \mathrm{~m}$ zu verzeichnen war (vgl. auch MERZEAU et al. 1994, LeOnARDi \& MenOZZI 1996). Ein ähnlicher Trend wurde auch bei Quercus petraea (MATT.) LIEBL. und Q. robur L. (BACILIERI et al. 1994) gefunden. Dies wurde mit einer relativ geringen effektiven Verbreitungsentfernung der Pollen, insbesondere aber mit Barochorie erklärt. Aber auch am Zuckerahorn (Acer saccharum Marsh.), dessen Früchte aufgrund ihrer Flugeigenschaften (Schraubenflieger) auch größere Distanzen zurücklegen können, konnten kaum Abweichungen von diesem Bild festgestellt werden (siehe PERRY \& KNOWLES 1991).

Unberücksichtigt bei den Verfahren der Autokorrelationsanalyse bleibt allerdings der Einfluß der räumlichen Anordnung der Individuen auf genetische Strukturen. Inwiefern das Vorkommen der Vogelkirsche in räumlichen Aggreationen auch eine genetische Gruppenbildung fördert, wurde mit Hilfe eines single-linkage Gruppierungsverfahrens geprüft.

In diesem Zusammenhang ist auch die Analyse der Verbreitung klongleicher Ramets von Interesse. Treten Klone nur in räumlich aggregierten Gruppen auf, so führt das im räumlich-genetischen Dendrogramm zu einer starken externen Gruppenisolation, während die interne Differenzierung nur schwach ausgeprägt ist. In dem Fall geht auch nur der räumliche Abstand in das Dendrogramm ein. Dies ist in den einzelnen Beständen auch überwiegend der Fall. Es gibt aber auch Ausnahmen wie z.B. im Bestand Wibbecke, in dem einzelne klongleiche Ramets auch Abstände von bis zu 75 m zueinander aufweisen (siehe Bäume Nr. 46, 62 und 64). Die Größe der Abstände innerhalb der Bestände kann auch als ein Hinweis auf das Alter der Klone und auf die Intensität der Bewirtschaftung gewertet werden. Insbesondere lange mittelwaldartige Bewirtschaftungszeiträume können zu einem starken räumlichen Auseinanderdriften einzelner Klonmitglieder geführt haben.

Im Gegensatz zu den oben zitierten Arbeiten an meist dominanten Baumarten, die ein jeweils sehr homogenes Ergebnis aufwiesen, zeigten die Untersuchungen an der rezedenten Vogelkirsche, daß in Bezug auf verschiedene Bewirtschaftungsformen vielschichtige Ursachen zu einem sehr differenziertem Bild führen können.

Eine Erklärung für derartige Strukturen kann darin gesucht werden, daß die Früchte der Vogelkirsche sowohl in der Nähe des Mutterbaumes herunterfallen als auch durch Tiere als Vektoren ausgebreitet werden und daß das Verhältnis von Nahund Ferntransport entscheidend von den jeweiligen Umweltbedingungen (Bestandesstrukturen) abhängen kann.

Dabei unterscheidet sich der Hochwald Roringen im Vergleich zum Mittelwald (Wibbecke) durch eine sehr starke Ausprägung räumlich-genetischer Strukturen. Während im Mittelwald aufgrund ständig günstiger Umweltbedingungen mehrere Generationen vor Ort möglich sind und dadurch der Nahtransport größere Bedeu- 
tung erlangen kann, ist die Vogelkirsche im Hochwald stets auf die schnelle Besiedlung von Bestandeslücken (recruitment-foci), also eher auf Ferntransport angewiesen. Mit den unterschiedlichen Bestandesstrukturen ist möglicherweise auch eine Veränderung der durch tierische Vektoren erzeugten Ver- und Ausbreitungsmuster verbunden. Wie in Kapitel 2.2.4.1 schon erwähnt, ist der höchste ornithochore Diasporenniederschlag in Bestandeslücken festzustellen, die beispielsweise Rast- und Nistmöglichkeiten für Vögel darstellen (HERRERA 1985, KOLLMANN 2000). Im Hochwald sind derartige Störungen (z.B. femelartige Auflichtungen) aber eher sehr unregelmäßig und oft über größeren Distanze verteilt, so daß hier meist nur Arten für die Ausbreitung in Frage kommen, die auch effektiv diese Distanzen zurücklegen. Im Mittelwald hingegen wurden ständig Bestandeslücken geschaffen, die vermutlich auch die Ausbreitungsmuster stark beeinflußten. So können hier auch diejenigen Vektoren zur generativen Vermehrung der Vogelkirsche beigetragen haben, die nur sehr kurze Distanzen zurücklegen. Dabei kam der Barochorie vermutlich eine bedeutendere Rolle zu als bisher vermutet wird.

Eine direkte Messung der Ausbreitung genetischer Informartion (hier: Pollenausbreitungsdistanzen) erfolgte in dieser Arbeit über die Vaterschaftsanalyse an Embryonalgewebe in Saatgut.

Im allgemeinen kann davon ausgegangen werden, daß eine effektive Besiedlung störungsinduzierter, meist räumlich isolierter Habitate die Existenz ausreichender genetischer Variation voraussetzt. Die Konsequenz einer rezedenten Lebensweise ist demnach die Aufrechterhaltung des reproduktiven Artzusammenhalts. Letzteres findet Bestätigung in geringer genetischer Differenzierung, die zwischen Vorkommen rezedenter Arten ermittelt wurde (siehe Übersicht in DEMESURE 2000). Allerdings wird betont, daß die genetische Inventur Probleme bereitet, da eine Populationsabgrenzung bei rezedenten Arten nur schwer vorzunehmen ist. Deshalb scheint die Beschreibung der Mechanismen des reproduktiven Artzusammenhalts hier sinnvoller.

Im Gegensatz zu Windblütern setzen viele rezedente Arten wie die Vogelkirsche auf eine Ausbreitung ihrer Pollen durch Vektoren. STREIFF et al. (1999) fanden, daß eine effektive Pollenausbreitung bei Quercus petraea (MATT.) LIEBL. und Q. robur L. aus einer Kombination von zwei Prozessen besteht, nämlich einer lokalen, also bestandesinternen Komponente als auch dem Ferntransport. So konnte in einem Bestand dieser beiden Eichenarten ein effektiver, externer Pollenanteil von über $60 \%$ ermittelt werden.

Im Gegesatz zu Windlütern, die eine immens große Pollenmenge produzieren (PoHL 1936), setzt die Vogelkirsche als rezedente Baumart auf Vektoren (hier hauptsächlich die Honigbiene), die eine hohe Direktionalität beim Aufsuchen ihrer Nahrungsquellen und eine hohe Blütenkonstanz und damit Artreinheit des Pollens gewährleistet (FrOMM 2001). Auch wenn innerhalb der Bestände Roringen und Settmarshausen 30\% des effektiven Pollens von externen Vorkommen stammt, so kommt insbesondere Einzelbaumvorkommen in der freien Landschaft oder an Waldrändern eine große Bedeutung zu. Sie stellen durch ihre große Krone, die reichliche Blüte und ein großes Nektar- und Pollenangebot (hohe Attraktivität) 
gleichzeitig eine Sammelstelle (Senke) als auch eine Quelle genetischer Variation für die Neubesiedlung von Habitaten dar (Trittsteineffekt, stepping-stones). Damit sind diese 'Trittsteine' möglicherweise aber auch Eintrittspforten für Erbgut aus Kulturkirschenvorkommen, deren Auswirkungen auf die Wildkirsche bislang allerdings nur wenig untersucht sind.

Bei der Saatguternte fiel auf, daß im Bestand Wibbecke mit dem höchsten Verklonungsgrad eine Datenerhebung aufgrund zu geringer Fruktifikation nicht möglich war. Dies befindet sich in auffälliger Übereinstimmung mit der in einigen Fällen vergleichsweise starken Aggregation klongleicher Ramets. In anderen Baumgruppen war ein teilweise nur sehr geringer genetischer Abstand zwischen Individuen vorzufinden, was möglicherweise auf einen erhöhten Verwandtschaftsgrad hindeutet und ebenfalls auf erhöhte Semikompatibilität oder sogar vollständige Inkompatibilität schließen läßt. Dies wäre allerdings erst durch eine Identifikation der vorliegenden S-Allele und deren räumlicher Verteilung zu verifizieren. Die aus diesen Bestandesstrukturen resultierende erhöhte Reduktion kompatibler Paarungen stellt möglicherweise ein Beispiel für das eingangs dargestellte Dilemma eines gemischten Reproduktionssystems mit GSI bei rezedenten Baumarten dar. Dies wird noch dadurch verstärkt, wenn durch Landschaftsfragmentierung effektive externe Pollenquellen erst in größerer Entfernung zu finden sind und die meisten Bäume innerhalb der Bestände bevorzugt mit ihren nächsten Nachbarn paaren. Ein weiterer Grund kann auch durch eine Art Seneszenz der einzelnen Klone begründet sein, denn die möglicherweise über Jahrhunderte geführte Mittelwaldwirtschaft kann ein unerwartet hohes Alter einzelner Genets zur Folge haben (siehe auch SILANDER 1985). Diese für drei Jahre zutreffende Beobachtung der Fruktifikationsausfälle im Bestand Wibbecke läßt die Weiterführung dieses Bestandes als zugelassener Saatgutbestand als problematisch erscheinen.

Die Vermutung, daß besonders rezedente Baumarten von den Veränderungen der Waldwirtschaft betroffen gewesen sind (SCHOPPA 2000), findet in den Analyseergebnissen dieser Arbeit weitere Bestätigung, insbesondere wenn die extremen Abweichungen sowohl in den verschiedenen Verklonungsanteilen, die sehr unterschiedlichen räumlich-genetischen Strukturen sowie die stark unterschiedliche Fruktifikation der einzelnen Bestände betrachtet wird. Desweiteren wurden erste deutliche Hinweise auf die Ausbreitung genetischer Information als auch deren Bedeutung für rezedente Arten diskutiert.

Um zukünftig konkrete Erkenntnisse über die Besiedlungsdynamik der Vogelkirsche unter heutigen Verhältnissen (also im Hochwald) zu erhalten und damit auch waldbaulich eine gewünschte Mischungsregulierung ansteuern zu können, ist allerdings eine direkte Messung der effektiven Samenausbreitung notwendig. Dabei können die hier verwendeten Mikrosatelliten sehr hilfreich sein, zumal DNA-Extraktionsmethoden aus der Samenschale (Endokarp) der Gattung Prunus schon beschrieben sind (GODOY \& JORDANO 2001). Damit kann nicht nur direkt auf den potentiellen Samenelter, sondern mit Hilfe der genetischen Information im Embryonalgewebe auch auf erfolgte Pollenausbreitungsdistanzen geschlossen werden. 
Auch eine Analyse weiterer Faktoren ist vorzunehmen, die die Verjüngungsprozesse (Keimungs- und Etablierungsmöglichkeiten) im Wald beeinflussen können. Dazu zählen die Effizienz, mit der die Vogelkirsche Bestandeslücken zu besiedeln vermag als auch die Distanzen, die durch vegetative Vermehrung über Wurzelbrut in heutigen Waldbeständen überbrückt werden können. 


\section{Zusammenfassung/Summary}

\section{Zusammenfassung}

Die Vogelkirsche (Prunus avium L.) kommt in kleinen Gruppen oder auch vereinzelt in nährstoffreichen Buchen- und Eichenwäldern wärmerer Standorte vor. Sie besiedelt meist frühe forstliche Sukzessionsstadien, wo sie aber im Laufe der Bestandesentwicklung rasch konkurrenzstärkeren Baumarten unterlegen ist. Es müssen demnach Voraussetzungen vorliegen, die eine Existenz dieser Art unter den Bedingungen ständiger Kolonisation und Extinktion gewährleisten.

Die Besiedlung geeigneter, meist räumlich isolierter Habitate wird durch ein gemischtes (sexuelles und asexuelles) Reproduktionssystem erreicht, wobei die asexuelle Vermehrung über die Bildung von Wurzelbrut erfolgt. In der waldbaulichen Literatur wird der Vogelkirsche eine nur wenig effektive Vermehrung über Samen nachgesagt. Die Fähigkeit zu asexueller Vermehrung, die Verhinderung von Selbstbefruchtung und damit auch von Paarungsmöglichkeiten zwischen Klonmitgliedern aufgrund gametophytischer Selbstinkompatibilität (GSI) und vermutete eingeschränkte effektive Pollenausbreitungsdistanzen (Insektenbestäubung) scheinen demzufolge eine eher ungünstige Kombination zur schnellen Besiedlung geeigneter Habitate darzustellen.

Zur Klärung dieses scheinbaren Widerspruchs wurden verschiedene Vorkommen der Vogelkirsche mit Hilfe molekulargenetischer Methoden (Mikrosatelliten) untersucht. Da die Entwicklung des Waldbestands ohne menschliche Einflüsse historisch und gegenwärtig nahezu unbekannt ist, erschien eine Untersuchung der lokalen Verbreitung von Individuen und ihrer genetischen Information unter verschiedenen Waldbewirtschaftungsformen (also unterschiedlichen Umweltbedingungen) als ein sinnvoller Lösungsansatz, Erkenntnisse über das populationsbiologische Verhalten dieser Art zu erhalten. Untersucht wurde ein femelartig bewirtschafteter Hochwaldbestand sowie zwei ehemalige Mittelwaldbestände. Alle drei Bestände sind als mesophile Kalkbuchenwälder eingestuft. Der Hochwaldbestand ist ein buchendominierter Laubmischwald, während in den anderen beiden Beständen aufgrund der vermutlich über längere Zeit anhaltenden Mittelwaldwirtschaft im wesentlichen Eiche (Quercus petraea und Q. robur) und Hainbuche (Carpinus betulus) vorherrschen.

Ergebnisse, die Interpretationen zur Populationsdynamik der Vogelkirsche zulassen, wurden zu folgenden Themenkreisen erzielt: (1) Analyse und Folgen des gemischten Reproduktionssystems und (2) räumlich-genetische Strukturen der Vogelkirsche unter verschiedenen Aspekten der Bestandesgeschichte als auch (3) die Bedeutung der Pollenausbreitung als eine Komponente des reproduktiven Artzusammenhalts.

(1) Aufgrund unterschiedlicher Überlebenswahrscheinlichkeiten durch inter- und intraspezifische Konkurrenz war es zunächst unklar, wie viele Ramets desselben Klons unter jeweils gegebenen Umweltbedingungen das reproduktive Alter erreichen und inwieweit klonale Reproduktion damit zur Bildung der nächsten Generation beiträgt. Insgesamt stellte sich heraus, daß vegetative Vermehrung sowohl im 
Hochwald als auch in ehemaligen Mittelwäldern als eine Strategie gewertet werden kann, sich erfolgreich im Wettbewerb mit konkurrenzstarken Arten behaupten zu können. Die in dieser Arbeit erzielten Ergebnisse sind mit den bislang gängigen waldbaulichen Einschätzungen zu vergleichen, die davon ausgehen, daß die Mehrzahl des Vogelkirschennachwuchses im Walde aus Wurzelbrut stammt. Allerdings war eine Quantifizierung dieser Aussage insbesondere unter adulten Individuen bisher nicht möglich. Die Entwicklung neuer Methoden zur Quantifizierung der Anteile asexueller Vermehrung ermöglichte eine Präzisierung dieser Aussage mit teilweise unerwarteten Erkenntnissen. So konnte in den Mittelwaldbeständen für einen Anteil von 54 bzw. 77\% aller Individuen eine asexuelle Herkunft nachgewiesen werden. Im Hochwald war ein deutlich geringeres Ausmaß von 18\% zu verzeichnen. Dabei zeigte sich, daß im Mittelwald einige Multilocus-Genotypen in der Anzahl ihrer Ramets anderen deutlich überlegen sein können (zwei bis maximal 15 Ramets pro Klon). Deshalb wäre es unzureichend, das Potential der Vogelkirsche zu vegetativer Vermehrung ausschließlich als eine Strategie zu bewerten, Etablierungschancen angepaßter Genotypen zu erhöhen. Damit sind auch Auswirkungen auf die sexuelle Reproduktion in Form einer Reduktion der reproduktionseffektiven Populationsgröße (siehe GSI) verbunden.

Für den Nachweis vegetativer Vermehrung war eine genetische Inventur der Individuen unumgänglich. Die am häufigsten eingesetzten Verfahren bedienen sich der Annahme, sexuelle Rekombination sei durch stochastische Unabhängigkeit zwischen den einzelnen Loci hinreichend zu kennzeichnen. Die Verwendung o.g. Verfahren ließ allerdings erkennen, daß die Annahme geringer Assoziationen zwischen Genloci in unvermutet hohem Umfang nicht zutrifft. Zur Quantifizierung dieses Umfangs wurde ein neu entwickeltes Verfahren eingesetzt. Das Ergebnis gibt Anlaß, unsere Vorstellungen über die tatsächlichen Ausmaße von Koadaptation und Koevolution in Genomen möglicherweise grundsätzlich zu überdenken.

Eine weitere Beobachtung war, daß trotz der drastischen Verringerung genotypischer Diversität aufgrund von Verklonung und Genassoziationen im Mittelwald eine höhere allelische Diversität möglich ist als im Hochwald. Dazu wurden mehrere Gründe aufgeführt: Einerseits kann es im Mittelwald im Laufe der Zeit zu einer Akkumulation genetischer Variation gekommen sein, insbesondere wenn dieses Verfahren über längere Zeiträume praktiziert wurde und ständig günstige Besiedlungsmöglichkeiten für die Vogelkirsche geschaffen wurden. Dies wäre hier durchaus denkbar aufgrund der Verdrängung starker Konkurrenten wie der Buche und der ständigen Lichtdurchlässigkeit der Oberschicht. Im femelartig bewirtschafteten Hochwald ist die Vogelkirsche auf ein nur sehr begrenztes Zeitfenster für die Besiedlung angewiesen, so daß nur die derzeit verfügbare genetische Variation effektiver, externer Samenquellen für die Kolonisation genutzt werden kann.

Werden andererseits im Mittelwaldbetrieb nur wenige, qualitativ hochwertige Stämme (hier: Laßreiser) gefördert, führt das in Verbindung mit einem hohen Anteil klongleicher Individuen auch zu einer starken Reduktion kompatibler Paarungsmöglichkeiten (Flaschenhalseffekt). Liegt zusätzlich Semikompatibilität vor, so können diejenigen untersuchten Genloci, die an den S-Locus gekoppelt sind, nur be- 
stimmte Kombinationen von Genotypen erzeugen. Da dies für zwei der SSR-Loci der Fall ist, kann das in Verbindung mit erhöhter Homozygotie an anderen Genloci der Schlüssel zur Erklärung starker Genassoziationen darstellen.

(2) Die Form der Verbreitung der einzelnen Ramets verschiedener Klone innerhalb eines Bestandes kann aufgrund des besonderen Paarungssystems der Vogelkirsche erheblich die Anzahl kompatibler Paarungen und damit die Fekundität eines Bestandes beeinflussen. Die räumliche Verteilung genetischer Information zeigte, daß die meisten Ramets der einzelnen Klone geklumpt auftraten. Im Mittelwald konnten bis zu 15 räumlich aggregierte Ramets pro Klon beobachtet werden. In mehreren Fällen wurden allerdings auch Durchmischungen der Ramets verschiedener Klone festgestellt. In seltenen Fällen vermischten sich die Ramets mit anderen Genets und wiesen Abstände von bis zu $75 \mathrm{~m}$ zueinander auf.

Die Verwendung verschiedener Verfahren der räumlich-genetischen Analyse (singlelinkage-Gruppierungsverfahren, räumlich-genetische Autokorrelation, Mantel-Test) sollte darüberhinaus klären, ob die unter (1) vermutete unterschiedliche Kolonisations-Extinktionsdynamik in den verschiedenen Beständen vorlag. Es konnte gezeigt werden, daß die Präsenz der Vogelkirsche im wesentlichen störungsinduziert ist und daß die Art der Störung unterschiedliche Anforderungen an das Reproduktionssystem stellt. Die im femelartig verjüngten Hochwald vorgefundenen nur geringen und nahezu ausschließlich auf vegetative Vermehrung zurückzuführenden räumlich-genetischen Strukturen deuten auf eine effiziente Ausnutzung der auf diese Weise kurzfristig entstandenen, günstigen Umweltbedingungen (Lückendynamik) hin. Tiere als Ausbreiter (hier: Ornithochorie, Mammaliochorie) scheinen einen gezielten Transportvektor von Samen hin zu Bestandeslücken (sog. ‘recruitment-foci') darzustellen.

In einem der Mittelwaldbestände zeigte sich ein ganz anderes Bild. Hier hatte sich eine stark ausgeprägte räumlich-genetische Struktur entwickelt, die nicht ausschließlich auf vegetative Vermehrung zurückzuführen ist, so daß entgegen den allgemeinen Vorstellungen von einer Ausbildung mehrerer Generationen vor Ort ausgegangen werden kann. Samen fanden günstige Keimungs- und Etablierungsmöglichkeiten auch in der Nähe des Mutterbaumes vor, so daß die Vogelkirsche demzufolge nicht auf effiziente Samenausbreitungsmechanismen angewiesen war. In dem anderen Mittelwald waren derartige Strukturen zwar auch vorhanden, zeigten aber eine schwächere Ausprägung.

(3) Neben der Möglichkeit der effizienten Ausbreitung von Samen, stellt das Paarungssystem eine wichtige Determinante des reproduktiven Artzusammenhalts dar. Erste explorative Ergebnisse zeigen, daß die Ausbreitung von Pollen nicht nur von der Entfernung zu ihrer Quelle abhängig sein kann, sondern auch von den Strukturen der von einer Art derzeit nicht besiedelten Standorten.

Es stellte sich heraus, daß Vogelkirschen innerhalb der Waldbestände einerseits zwar bevorzugt mit ihren nächsten Nachbarn paaren, daß andererseits aber auch ein relativ hoher Anteil an bestandesexternen Pollenbeiträgen aufrecht erhalten bleibt (Ferntransport). Insgesamt konnten in zwei der untersuchten Waldbestände ein Anteil von 18 bis $42 \%$ an bestandesexternen Vaterschaften ermittelt werden. In 
dem Mittelwaldbestand mit dem höchsten Verklonungsgrad war eine Datenerhebung aufgrund zu geringer Fruktifikation nicht durchführbar. Dies befindet sich in auffälliger Übereinstimmung mit der vergleichsweise starken Aggregation klongleicher Ramets und der daraus folgenden erhöhten Reduktion kompatibler Paarungen. Damit stellt diese Bestandesstruktur möglicherweise ein Beispiel für das eingangs dargestellte Dilemma eines gemischten Reproduktionssystems mit GSI bei rezedenten Baumarten dar. Ein weiterer Grund kann auch in einer Art Seneszenz der einzelnen Klone begründet sein, denn die möglicherweise über Jahrhunderte geführte Mittelwaldwirtschaft kann ein unerwartet hohes Alter einzelner Genets zur Folge haben. Diese für drei Jahre zutreffende Beobachtung läßt die Weiterführung dieses Bestandes als zugelassener Saatgutbestand als problematisch erscheinen.

Saatgutuntersuchungen eines in der freien Landschaft relativ isoliert stehenden Baumes ergaben, daß benachbarte Vogelkirschen als potentielle Väter ausgeschlossen werden können. Darüberhinaus stellten sich die durchschnittliche Anzahl an Allelen pro Locus und die genische Diversität der männlichen Pollenbeiträge als die höchsten unter allen Saatgutstichproben heraus.

Da eine möglichst effiziente Besiedlung geeigneter Habitate die Existenz ausreichender genetischer Variation voraussetzt, sind rezedente Arten auf gut abgestimmte Mechanismen des genetischen Systems (hier insbesondere die Ausbreitung genetischer Information) angewiesen. Die Konsequenz einer rezedenten Lebensweise liegt also in der Erhaltung des reproduktiven Artzusammenhalts. Die experimentellen Beobachtungen geben einen deutlichen Hinweis darauf, daß räumlich isoliert stehende Vogelkirschen einerseits eine Quelle für hohe genetische Variation, andererseits für die Neubesiedlung von Habitaten wichtige Trittsteine darstellen. Dieses exploratorische Ergebnis ist allerdings noch durch gezieltere Untersuchungen zu erhärten.

Erklärungen für diese Ergebnisse fanden sich in folgenden Ansätzen: Möglicherweise hat ein Carry-over-Effekt (Pollenübertragung von Baum-zu-Baum) innerhalb der Waldbestände insbesondere für kürzere Pollenausbreitungsdistanzen die grössere Bedeutung. Andere Vorgänge wie die Pollenübertragung von Insekt-zu-Insekt innerhalb des Stocks staatenbildender Insekten und auch der direkte Anflug weiter entfernt gelegener, großer Nahrungsquellen lassen räumlich isoliertere Einzelbäume in der freien Landschaft (reichliche Blüte, große Krone, großes Nektar- und Pollenangebot) zu einer Sammelstelle genetischer Variation werden. Derartige Sammelstellen sind möglicherweise auch Eintrittspforten für Erbmaterial aus Kulturkirschenvorkommen, deren Auswirkungen auf die Wildkirsche bislang allerdings nur wenig bekannt sind.

Insgesamt sind die hier entwickelten Methoden und gewonnenen Einsichten in das Reproduktionssystem der Kirsche von Interesse für eine Vielzahl rezedenter Baumarten. 


\section{Summary}

Wild cherry (Prunus avium L.) occurs in small or scattered groups in nutrient-rich beech and oak forests. Due to its low competitive ability it mostly colonizes early stages of forest succession. Accordingly, requirements must thereby exist that guarantee the existence of this species under conditions of constant colonization and extinction.

The colonization of suitable, usually spatially isolated habitats is achieved by a mixed sexual and asexual reproduction system, where asexual reproduction occurs by root succering. In the silvicultural literature, wild cherry is considered less effective in seed propagation. This may be the result of a combination of several contradicting characteristics: asexual propagation, the prevention of self-fertilisation as well as matings among clonal groups due to a gametophytic self-incompatibility system (GSI) and presumably limited pollen dispersal distances to be expected by insect pollination.

To elucidate this apparent contradiction, various stands of wild cherry were investigated using molecular markers (microsatellites). Since, historically and presently, the development of forest stands without human influence is virtually unknown, a study of the local distribution of individuals and their genetic information among different forest management systems appeared to be a logical approach to gaining knowledge about the population biology of this species. A high forest system managed by a group selection method (shelterwood) and two formerly coppice-withstandards forests were studied.

Results were achieved that allow interpretation of the population dynamics of wild cherry in the following subject areas: (1) analysis and consequences of its mixed reproduction system, (2) spatio-genetic structures of wild cherry reflected by various aspects of forest history and (3) the importance of pollen dispersal as a component of reproductive (or genetic) coherence.

(1) Given the different survival probabilities due to inter- and intraspecific competition, the degree to which root suckers survive to adulthood as multiple ramets of a single clone is largely unknown. To date, it has not been possible to quantify the assumption that the majority of wild cherry progeny in forests derived from root succers, particularly among adult individuals. New methods have been developed for quantifying the proportions of asexual propagation, enabling us to clarify this assumption more precisely with sometimes unexpected results.

In the coppice-with-standards forests, 54 to $77 \%$ of all individuals proved to be of asexual origin. In the high-forest system, a markedly lower percentage of $18 \%$ was recorded. In the coppice-with-standards forest, it was shown that several multilocus genotypes can have much higher numbers of ramets than others (two to a maximum of 15 ramets per clone). Hence, the capability of wild cherry for vegetative reproduction should not only be regarded a strategy for increasing its chances for establishing adapted genotypes, but also affects sexual reproduction by reducing effective population sizes (see GSI). 
For this purpose, a genetic inventory of the individuals was necessary. The most commonly applied methods rely on the assumption that sexual recombination is sufficiently characterized by stochastically independent association between gene loci. However, the use of conventional methods showed that low associations between gene loci cannot be assumed to an unexpectedly high extent. A newly developed method was applied to quantify this scope. The results demand a fundamental rethinking of our beliefs about the true extent of coadaptation and coevolution in genomes.

One further observation was that a higher allelic diversity is possible in the coppice-with-standards forest than in the high-forest system despite a dramatic reduction in genotypic diversity due to clonal propagation and gene associations. This was attributable to the following:

On one hand, an accumulation of genetic variation in coppice-with-standards forests can occur over time, particularly when this method is applied for extended periods and favourable colonization conditions are maintained for wild cherry. The displacement of strong competitors like beech might be a conceivable explanation for this. In the high-forest system, wild cherry was given very little time for colonization, which only allowed the currently available genetic variation of surrounding external seed sources to become established.

On the other hand, the number of compatible mating probabilities is greatly reduced if coppice-with-standards forest management supports just a few, high-quality trees and assuming that a higher proportion of individuals have identical multilocus genotypes (MLG) [bottleneck effect]. And, if semi-compatibility exists and, in addition, the investigated gene loci are linked to the S-locus, then sexual reproduction can only produce certain combinations of genotypes. The fact that this was the case for two of the simple sequence repeat (SSR) loci - in conjunction with increased individual homozygosity at other gene loci - might be the key to explaining the higher gene associations.

(2) Considering the unique mating system characteristics of wild cherry, the distribution pattern of the single ramets of the various clones within one stand can significantly influence the number of compatible crosses and thus the fecundity of a stand. The spatial distribution of genetic information shows that most ramets of the single clones occurred in clusters. In the coppice-with-standards forest, up to 15 spatially aggregated ramets were observed per clone. In many cases, however, mixtures of the ramets of different clones were determined. In rare cases, the ramets were mixed with other genets, existing at distances of up to $75 \mathrm{~m}$ from each other.

Spatio-genetic analysis methods (single-linkage method, autocorrelation, Mantel test) were applied to identify whether the different colonization-extinction dynamics as presumed under (1) actually exist. It was demonstrated that the presence of wild cherry is primarily induced by local disturbances and that the type of disturbance represents different challenges to the reproduction system. The fact that only few spatio-genetic structures were found in the high-forest system and that these were exclusively attributed to vegetative reproduction suggests a high utilization ef- 
ficiency of favorable environmental conditions (gap dynamics). Animals as dispersers seem to effectively transport wild cherry seeds to forest gaps, acting as socalled 'recruitment foci'.

On the other hand, a markedly pronounced spatio-genetic structure was found in one of the coppice-with-standards forests which could not exclusively be attributed to vegetative reproduction. Thus, contrary to general belief, the local development of several generations can be assumed. Given the favourable germination and establishment conditions that also existed in the proximity of the mother tree, wild cherry was not dependent on effective seed dispersal mechanisms.

(3) In addition to efficient seed dispersal, the mating system represents an important determinant of reproductive (genetic) coherence. Initial explorative results reveal that pollen dispersal is not only dependent on its distance from its source, but also on the structures of the locations currently not colonized by a species (matrix). It emerged that Wild Cherry most preferably mates with its closest neighbours within the forest stands, but a relative high percentage of external pollen contributors is maintained (long distance dispersal). In total, 18 to $42 \%$ external pollen was determined in two of the forest stands investigated. In the coppice-with-standards forest with the highest degree of clonal propagation, it was not possible to collect data because the seed set was too low. This observation is remarkably consistent with the more pronounced clustering of ramets of the same clone and relatives and the resultantly strong decrease of compatible crosses. Thus, this stand structure is likely to be an example for the dilemma of a mixed reproduction system with GSI in recedent tree species. Another reason could be seen in senescence of clones, which may be the result of the coppice system over longer periods.

Seed analysis of a wild cherry tree isolated in an open, non-forested landscape showed that neighbour trees could be excluded as pollen donors. Furthermore, the average number of alleles per locus and the genetic diversity of the male gametic contribution proved to be the highest among all seed samples.

Since the existence of sufficient genetic variation is prerequisite for efficient colonization of suitable habitats, recedent species are dependent on well-adapted genetic mechanisms, and, particularly, on the dispersal of genetic information. The consequence of recedent life is thus the preservation of reproductive coherence. The experimental observations provide clear evidence that spatially isolated cherry trees represent a source of high genetic variation, whilst at the same time providing important stepping stones for the formation of new colonies.

These results might be explained by the following suppositions:

- Tree-to-tree pollen transfer plays a more important role within the forest stands by causing effectively short pollen dispersal distances ("carry-over effect").

- Large pollen dispersal distances are created by other processes, such as insect-toinsect pollen transfer within a colony of state-forming insects, and by direct insect flight to large, nutrient sources in open, non-forested areas. Spatially singular trees therein supply a sink of genetic variation with their abundance of flowers, and large supply of nectar and pollen. 
Nonetheless, these explorative results should be substantiated by more targeted studies.

These provide potential entry portals for new genetic information from cultivated cherries, whose effects on Wild Cherry trees have been rather little known to date. In conclusion, the methods developed here and the insights gained into the reproduction system of Wild Cherry trees are applicable to a large number of recedent tree species. 


\section{Literaturübersicht}

Austerlitz F., MARiette S., MACHON N., Gouyon P.H. und Godelle B. (2000) Effects of colonizing processes on genetic diversity: Differences between annual plants and tree species. Genetics 154, 1309-1321.

BACILIERI R., LABBE T. und KREMER A. (1994) Intraspecific genetic structure in a mixed population of Quercus petraea (MATT.) LEIBL. und Q. robur L. Heredity 73, 130-141.

BEск O. (1977) Die Vogelkirsche (Prunus avium L.) Ein Beitrag zur Ökologie. Forstarchiv 48, 154158.

BENET J.H. and BINET F.E. (1956) Association between Mendelian factors with mixed selfing and random mating. Heredity 10, 51-56.

Berger K. (1963) Fertilitätsuntersuchungen an der Wildkirsche Prunus avium L. In: Die Kulturpflanze, Band XI, Akademie-Verlag, Berlin, S. 358-375.

BERGMANN F. (1991) Causes and consequences of species-specific genetic variation patterns in European tree species: Examples with Norway spruce and silver fir. In: Genetic V ariation in European Populations of Forest Trees, pp 192-204 (Hrsg. G. Müller-Starck und M. Ziehe). J.D. Sauerländers Verlag, Frankfurt am Main.

BONN UND Poschlod (1998) Ausbreitungsbiologie der Pflanzen Mitteleuropas. Grundlagen und kulturhistorische Aspekte. Quelle und Meyer, Wiesbaden, 404 S.

BošKović R., Russell K. und TobUTT K.R. (1997) Inheritance of stylar ribonucleases in cherry progenies and reassignment of incompatibility alleles to two incompatibility groups. Euphytica 95, 221-228.

BošKović R. und ToBUTT K.R. (1996) Correlation of stylar ribonuclease zymograms with incompatibility alleles in sweet cherry. Euphytica $\mathbf{9 0}, 245-250$.

BošKović R. und ToBUTT K.R. (1998) Inheritance and linkage relationships of isoenzymes in two interspecific cherry progenies. Eupbytica 103, 273-286.

BREDEMEIJER G.M. und BLASS J. (1981) S-specific proteins in styles of self-incompatible Nicotiana alata. Theor. Appl. Genet. 59, 185-190.

CAIN M.L. (1994) Consequences of foraging in clonal plants. Ecology 75, 933-944.

CASTRIC V. und VeKemans X. (2004) Plant self-incompatibility in natural populations: a critical assessment of recent theoretical and empirical advances. Molecular ecology 13, 2873-2889.

ChINERY (1984) Insekten Mitteleuropas. Ein Taschenbuch für Zoologen und Naturfreunde. Verlag Paul Parey, Hamburg und Berlin.

Chung M.G., Chung J.M., Chung M.Y. Und EpPerson B.K. (2000) Spatial distribution of allozyme polymorphisms following clonal and sexual reproduction in populations of Rhus javanica (Anacardiaceae). Heredity 84, 178-185.

Cipriani G., lot G., Huang W.G., Marrazzo M.T., Peterlunger E. And Testolin R. (1999) AC/GT and AG/CT microsatellite repeats in peach [Prunus persica (L) Batsch]: Isolation, characterization and cross-species amplification in Prunus. Theoretical and Applied Genetics 99, 65-72.

Crane M.B. und LawrenCE W.J.C. (1929) Genetical and cytological aspects of incompatibility and sterility in cultivated fruits. Journal of Pomology and Horticultural Science 7, 276-301.

Crane M.B. und LAWRENCE W.J.C. (1931) Sterility and incompatibility in diploid and polyploid fruits. Journal of Genetics 24, 97-107. 
Crow J.F. and Kimura M. (1979) Introduction to Population Genetics Theory. New York, Evanston and London. Harper and Row, p. 324.

DALE M.R.T. (200) Spatial Pattern Analysis in Plant Ecology. Cambridge University Press.

Darwin C. (1876) The Effect of Cross and Self Fertilization in the Plant Kingdom. John Murray, London.

DECARLI N. (2003) Räumliche Verteilung der genetischen Ausstattung von Eckern und Jungwuchs der Buche (Fagus sylvatica L.) in Abhängigkeit von Bestandesstrukturen. Dissertation, Fakultät für Forstwissenschaften und Waldökologie, Georg-August-Universität Göttingen.

Degen B., Petit R. und Kremer A. (2001) SGS - Spatial genetic software: A computer program for analysis of spatial genetic structures of individuals and populations. The Journal of Heredity 92, 447-448.

Demesure B., Le Guerroué B., Lucchi G., Prat D. und Petit R.-J. (2000) Genetic variability of a scattered temperate forest tree: Sorbus torminalis L. (Crantz). Ann. For. Sci 57, 63-71.

Dirlewanger E., Cosson P., Tavaud M., Aranzana M.J., Poizat C., Zanetto A., ARÚS P. AND LAIGRET F. (2002) Development of microsatellite markers in peach [Prunus persica (L.) Batsch] and their use in genetic diversity analysis in peach and sweet cherry (Prunus avium L.). Theoretical and Applied Genetics 105, 127-138.

DoNNELLY P. (1995) Nonindependence of matches at different loci in DNA profiles: quantifying the effect of close relatives on the match probability. Heredity 75, 26-34.

Dounavi A. (2000) Familienstrukturen in Buchenbeständen (Fagus sylvatica). Dissertation, Fakultät für Forstwissenschaften und Waldökologie, Georg-August-Universität Göttingen.

DUCCI F. UND SANTI F (1997) The distribution of clones in managed and unmanaged populations of wild cherry (Prunus avium). Can. J. For. Res. 27: 1998-2004.

Dounavi A. (2000) Familienstrukturen in Buchenbeständen. Dissertation, Fakultät für Forstwissenschaften und Waldökologie, Georg-August-Universität Göttingen.

EAST E.M. und PARK J.B. (1918) Studies on self-sterility II. Pollen tube growth. Genetics 3, 353366.

Ellenberg H. (1986) Vegetation Mitteleuropas mit den Alpen. Eugen Ulmer Verlag, Stuttgart, 4. Auflage.

Ellstrand N.C. and Roose M.L. (1987) Patterns of genotype diversity in clonal plant species. American Journal of Botany 74, 123-131.

Entani T., Iwano M., Shiba H., Che F.-S., Isogai A. und Takayama S. (2003) Comparative analysis of the self-incompatibility (S-) locus region of Prunus mume: identification of a pollen-expressed F-box gene with allelic diversity. Genes to Cells 8, 203-213.

EsCUDERO A., IRIONDO J.M. und TORRES M.E. (2003) Spatial analysis of genetic diversity as a tool for plant conservation. Biological Conservation 113, 351-365.

FERNANDEZ R., SANTi F. und Dufour J. (1996) Ausgewähltes Vermehrungsgut der Vogelkirsche in Frankreich. AFZ/Der Wald 6, 290-294.

Fischer A. (2002) Forstliche Vegetationskunde. Paul Parey Verlag. Berlin

FISCHER M. und VAN KLEUNEN M. (2002) On the evolution of clonal plant life histories. Evolutionary Ecology 15, 565-582.

Frascaria N., SaNTi F. und GouYON P.H. (1993) Genetic differentiation within and among populations of chestnut (Castanea sativa Mill.) and wild cherry (Prunus avium L.). Heredity 70, 634641. 
FrEe J.B. (1993) Insect Pollination of Crops. 2. Auflage, Academic Press, New York.

FreE J.B. und BUTLER C.G. (1959) Bumblebees. London, Collins.

FrEE J.B. und WiLliams I.H. (1972) The transport of pollen on the body hair of honeybees (Apis melifera L.) and bumblebees (Bombus ssp. L.). Journal of Applied Ecology 9, 609-615.

Fromm M. (2001) Reproduktion einer entomophilen Baumart in geringer Populationsdichte Das Beispiel der Winterlinde. Dissertation, Fakultät für Forstwissenschaften und Waldökologie, Göttingen.

GABRIEL K.R. und SOKAL R.R. (1969) A new statistical approach to geographic variation analysis. Systematic Zoology 18, 259-278.

GILES B. und GoudET J. (1997) Genetic differentiation in Silene dioica metapopulations: Estimation of spatio-temporal effects in a successional plant species. The American Naturalist 149, 507526.

GILLET E. (1997) Maximum Likelihood Estimators of the Gametic Contributions to single Plant Progenies. Biometrics 53, 504-523.

DeGrandi-Hoffman G., Hoopingarner R. und BaKer K. (1984) Pollen Transfer in Apple Orchards: Tree-to-Tree or Bee-to-Bee? Bee World 65, 126-133.

Godoy J.A. und JoRDANO P. (2001) Seed dispersal by animals: exact identification of source trees with endocarp DNA microsatellites. Molecular Ecology 10, 2275-2283.

GREGORIUS H.R. (1978) The concept of genetic diversity and ist formal relationship to heterozygosity and genetic distance. Math. Biosci. 41, 253-271.

GREgORIUS H.R. (1987) The relationship between the concepts of genetic diversity and differentiation. Theor. Appl. Genet. 74, 397-401.

GREGORIUS H.R. (1996) The contribution of the genetics of populations to ecosystem stability. Silvae Geneticae $\mathbf{4 5}$.

GREGORIUS H.R. (2001) Sustainaible treatment of resources: The genetic basis. In: Genetic Response of Forest Systems to Changing Environmental Conditions (Hrsg. G. Müller-Starck und R. Schubert) Kluwer Academic Publishers, Dordrecht, Boston, London.

Gregorius H.R. (2004) The Isolation Approach to Hierarchical Clustering. Journal of classification 21, 51-69.

GREGORIUS H.R. (2005) Testing for clonal propagation. Heredity 94, 173-179.

GREGORIUS H.R. (2005a) Single-linkage clustering obeys the isolation principle. Journal of classification (zur Veröffentlichung eingereicht).

GREGORIUS H.R. (2005b) Revealing spatial genetic structure through cluster analyses. Ecological modelling (zur Veröffentlichung eingereicht).

HÄRDTle W., Ewald J. und Hölzel N. (2004) Wälder des Tieflandes und der Mittelgebirge. Verlag Eugen Ulmer, Stuttgart.

HAMRICK J.L. and GodT M.J.W. (1990) Allozyme diversity in plant species. In: Plant population genetics, breeding and genetic variation in plants (Hrsg. A.H.D. Brown, M.T. Clegg, A.L. Kahler and B.S. Weir), S. 43-63, Sinauer, Sunderland.

HARPER J.L. (1985) Modules, Branches, and the Capture of Resources. In: Population Biology and Evolution of Clonal Organisms (Hrsg. J.B.C. Jackson, L.W. Buss, R.E. Cook), S. 1-33, Yale University Press, New Haven und London.

Hartmann H.T. UND Kerster D.E. (1975) Plant propagation. Englewood Cliffs, NJ, Prentice-Hall. 
HATTEMER H.H., BERgmanN F. und ZiEHE M. (1993) Einführung in die Forstgenetik. J.D. Sauerländer's Verlag, Frankfurt am Main.

HATTEMER H.H. und Gregorius H.R. (1996) Bedeutung der biologischen Vielfalt für die Stabilität von Waldökosystemen. In: Biodiversität und nachhaltige Forstwirtschaft (Hrsg. G. MüllerStarck). Ecomed-Verlag, Landsberg.

HeINRICH B. (1975) Energetics of pollination. Ann. Rev. Ecol. Syst. 6, 139-170.

Herben T. und Hara T. (2003) Spatial Pattern Formation in Plant Communities. In: Morphogenesis and Pattern Formation in Biological Systems - Experiments and Models. (Hrsg. T. Sekimara, S. Noji, N. Ueno und P.K. Maini), Springer Verlag, S. 223-235.

HerRera C.M. (1985) Habitat-consumer interactions in frugivorous birds. In: Habitat selection in Birds (Hrsg. A. Estrada \& T.H. Flemming). Junk, Dordrecht. S. 341-365.

HeYwood J.S.(1991) Spatial analysis of genetic variation in plant populations. Annu. Rev. Ecol. Syst. 22, 335-355.

Howe H.F. UND SMALLWOOd J. (1982) Ecology of Seed Dispersal. Ann. Rev. Ecol. Syst. 13, 201 228.

Huang S., LeE H.-S., KarunanandaA B. und KaO T.-H. (1994) Ribonuclease activity of Petunia inflata $\mathrm{S}$ proteins is essential for rejection of self pollen. Plant Cell 6, 1021-1028.

HutChings M.J. (1999) Clonal plants as cooperative systems: Benefits in heterogeneous environments. Plant Species Biology 14, 1-10.

Hutchings M.J. und WiJesinghe D.K. (1997) Patchy habitats, division of labour and growth dividends in clonal plants. Trends in Ecology and Evolution 12, 390-394.

IVEY C.T. and RICHARDS J.H. (2001) Genotypic diversity and clonal structure of everglades sawgrass Cladium jamaicense (Cyperaceae). Int. J. Plant. Sci. 162, 1327-1335.

JAIN A.K. UND DubEs R.C. (1988) Algorithms for Clustering Data. Prentice Hall.

JANZEN D.H. (1971) Seed predation by animals. Ann. Rev. Ecol. Syst. 2, 465-492.

JENík J. (1994) Clonal growth in woody plants: A review. Folia Geobotanica et Phytotaxonomica 29, 291-306.

JONES A.G. und ARDREN W.R. (2003) Methods of parentage analysis in natural populations. Molecular Ecology 12, 2511-2523.

JORDANO P. (1995) Spatial and temporal variation in the avian-frugivore assemblage of Prunus mahaleb: patterns and consequences. Oikos 71, 479-491.

KAO T.-H. (2004) Identification of the pollen determinant of S-RNase-mediated self-incompatibility. Nature 429, 302-305.

KaO T.-H. und MCCubBIN A.G. (1996) How flowering plants discriminate between self and non-self pollen to prevent inbreeding. Proc. Natl. Acad. Sci. USA 93, 12059-12065.

KaO T.-H. und Tsukamoto T. (2004) The Molecular and Genetic Bases of S-RNase-Based Self-Incompatibility. The plant Cell 16, 72-83.

Kato S. und MuKaI Y. (2004) Allelic diversity of S-RNase at the self-incompatibility locus in a natural flowering cherry population (Prunus lannesiana var. Speciosa). Heredity 92, 249-256.

KLEINSCHMit J., SPEllmaNN H. und RuMPF H. (2000) Entscheidungshilfen zur Bewirtschaftung der Vogelkirsche in Nordwestdeutschland. Forst und Holz 55, 611-616.

Knowles P., Perry D.J. und Foster H.A. (1992) Spatial genetic structure in two tamarack (Larix laricina) populations with differing establishment histories. Evolurion 46, 572-576. 
KollmanN J. (1994) Ausbreitungsökologie endozoochorer Gehölzarten. In: Veröffentlichungen Projekt „Angewandte Ökologie“, Band 9 (Hrsg. Landesanstalt für Umweltschutz Baden-Württemberg)

KollmanN J. (2000) Dispersal of fleshy-fruited species: a matter of spatial scale? Perspectives in Plant Ecology, Evolution and Systematics 3, 29-51.

KownATZKI D. (2002) Asexuelle und sexuelle Reproduktion bei der Vogelkirsche. Dissertation, Fakultät für Forstwissenschaften und Waldökologie, Göttingen.

KüSTER H. (1988) Geschichte des Waldes. Verlag C.H. Beck, München.

DE Kroon und van Groenendal (1997) The ecology and evolution of clonal plants. Backhuys Publishers, Leiden, The Netherlands.

LEONARDi S. und MENOZZI P. (1996) Spatial structure of genetic variability in natural stands of Fagus sylvatica L. (beech) in Italy. Heredity 77, 359-368.

LINHART Y.B. und GRANT M.C. (1996) Evolutionary significance of local genetic differentiation in plants. Annu. Rev. Ecol. Syst. 27, 237-277.

LuU D.-T., QIN X., Morse D. und Cappadocia M. (2000) S-RNase uptake by compatible pollen tubes in gametophytic self-incompatibility. Nature 407, 649-651.

MALÉCOT G. (1948) Le Mathematiques de L’heredite. Masson, Paris.

MANTEL N. (1967) The detection of desease clustering and a generalizated regression approach. Cancer Research 27, 209-220.

Mariette S., Lefranc M., Legrand P., Tanneyhill D., Frascaria-Lacoste N. und MACHON N. (1997) Genetic variability in wild cherry populations in France. Effects of colonizing processes. Theoretical and Applied Genetics 94, 904-908.

MATEJKa H., RöBEN P. und SchröDER E. (1997) Zur Ernährung des Rotfuchses V ulpes vulpes (Linné, 1758) im offenen Kulturland. Zeitschrift Säugetierkunde 42, 347-357.

McCauley D.E., Raveill J. und ANTonovics J. (1995) Local founding events as determinants of genetic structure in a plant metapopulation. Heredity 75, 630-636.

McClure B.A., Haring V. und Ebert P.R. (1989) Style self-incompatibility gene products of Nicotia alata are ribonucleases. Nature 342, 955-957.

McClure B.A., Gray J.E., Anderson M.A. und Clarke A.E. (1990) Self-incompatibility in Nicotiana alata involves degradation of pollen rRNA. Nature 347, 757-760.

Mclellan A.J., Pratt D., Kaltz O. und Schmid B. (1997) Structure and analysis of phenotypic and genetic variation in clonal plants. . In: The ecology and evolution of clonal plants, pp 185-210 (Hrsg. H. de Kroon and J. van Groenendael), Backhuys Publishers, Leiden, The Netherlands

Meusel H., JäGer E. und Weinert E. (1965) Vergleichende Chorologie der zentraleuropäischen Flora. G. Fischer Verlag, Jena.

Merzeau D., Comps P., Thiébaut, B., Cuguen J. und Letouzey J. (1994) Genetic structure of natural stands of Fagus sylvatica L. (beech). Heredity 72, 269-277.

Mitchell A. (1979) Wald und Parkbäume Europas. Verlag Paul Parey, Hamburg, Berlin.

Mogie M. und Hutchings M.J. (1990) Phylogeny, ontogeny, and clonal growth in vascular plants. In: Clonal growth in plants: regulation and function, S. 3-22 (Hrsg. J. van Groenendael \& H. de Kroon). SPB Academic Publishing, The Hague.

MORAN P.A.P. (1950) Notes on continuous stochastic phenomena. Biometrica 37, 17-23.

MURPHY H.T. UND LOVETT-DousT J. (2004) Context and connectivity in plant metapopulations and landscape mosaics: does the matrix matter? Oikos 105: 3-14. 
DeNetTancourt (1977) Incompatibility in Angiosperms. In: Monographs on Theoretical and Applied Genetics (Hrsg. R. Frankel, G.A.E. Gall, M. Grossman, H.F. Linskens und D. Zeeuw). Springer-Verlag, Berlin, Heidelberg, New York.

DeNetTanCourT D. (2001) Incompatibility and Incongruity in Wild and Cultivated Plants. Springer-Verlag, Berlin.

OBAL K.-H. und BARTSCH N. (2000) Anwuchs und Jugendwachstum von Vogelkirsche unter Schirm. Forst und Holz 19, 616-621.

Oddou-Muratorio S., Petit R.J., Le Guerroue B., Guesnet D. und Demesure B. (2001) Pollen- versus seed mediated gene flow in a scattered forest tree species. Evolution 55, 1123-1135.

Отто H.-J. (1994) Waldökologie. Verlag Eugen Ulmer, Stuttgart.

PARKs J.C. and WerTh C.R. (1993) A study of spatial features of clones in a population of bracken fern, Pteridium aquilinum (Dennstaedtiaceae). American Journal of Botany 80, 537-544.

Perry D.J. und KNowles P (1991) Spatial genetic structure within three sugar maple (Acer saccharum Marsh.) stands. Heredity 66, 137-142.

Peterson C.J. and Jones R.H. (1997) Clonality in woody plants: A review and comparison with clonal herbs. In: The ecology and evolution of clonal plants, pp 263-289 (eds. H. de Kroon and J. van Groenendael), Backhuys Publishers, The Netherlands.

PIRL M. (2000) Reproduktionsökologische Untersuchungen an Sträuchern und Bäumen Zentraleuropäischer Gehölzfluren. Dissertation, Gießen.

PitelKa L.F. (1984) Application of the $-3 / 2$ power law to clonal herbs. American Naturalist 123, 442-449.

PoHl F. (1936) Die Pollenerzeugung der Windblütler. Beih. Bot. Cbl. 46 I, 286-305.

PoтT R. (1981) Der Einfluß der Niederwaldwirtschaft auf die Physiognomie und floristischsoziologische Struktur von Kalkbuchenwäldern. Tuexenia 1: 233-242.

Praeger R.L. (1923) Dispersal and distribution. Journal of Ecology 11, 114-123.

RöHrig E. und BARTSCH N. (1992)Waldbau auf ökologischer Grundlage. Band 1, 6. Auflage. Parey Verlag, Hamburg, Berlin.

Röös M. (1990) Zum Wachstum der Vogelkirsche (Prunus avium L.) in Nordrhein-Westfalen und angrenzenden Gebieten. Dissertation, Fakultät für Forstwissenschaften und Waldökologie, Göttingen.

RoTACH P. (1999) In situ conservation and promotion of noble hardwoods in Europe throughout improved silvicultural management strategies. Forest Genetic Resources 27, 43-48.

SANTI F. (1988) Variabilité génétique inter et intrapopulations chez le merisier (Prunus avium L.). Thèse de Doctorat, INRA, Paris-Grignon.

SCHÄFER M. (2003) Wörterbuch der Ökologie. Gustav Fischer. Spektrum Akademischer Verlag. Heidelberg. Berlin. 4. Auflage

ScHoppa F.N. (2000) Konsequenzen wald- und forstgeschichtlicher Entwicklungen für die aktuelle genetische Zusammensetzung von Waldbaumpopulationen in Mitteleuropa. Dissertation, Fakultät für Forstwissenschaften und Waldökologie, Georg-August-Universität Göttingen.

Schüler S., Tusch A., Schuster M. und Ziegenhagen B. (2003) Characterization of microsatellites in wild and sweet cherry (Prunus avium L.) - markers for individual identification and reproductive processes. Genome 46, 95-102. 
SchütT P., Schuck H.J. und Stimm B. (1992) Lexikon der Forstbotanik - Morphologie, Pathologie, Ökologie und Systematik wichtiger Baum- und Straucharten. ecomed-Verlag, Landsberg.

SIEDER P. (2003) Angewandter Waldbau, Waldbausysteme und -strategien. Waldbau zur Jahrtausendwende, Band 4. Shaker Verlag. Aachen.

Sijacic P., Wang X., Skirpan A.L., Wang Y., Dowd P.E., MCCubbin A.G., Huang S. und KAO T.-H. (2004) Identification of the pollen determinant of S-RNase-mediated selfincompatibility. Nature 429, 301-305.

Silander J. A. (1985) Microevolution in Clonal Plants. In: Population Biology and Evolution of Clonal Organisms (Hrsg. J.B.C. Jackson, L.W. Buss, R.E. Cook), Yale University Press, New Haven und London, S. 107-152.

Silvertown J. und Charlesworth D. (2001) Introduction to Plant Population Biology. Blackwell Science. Iowa State University Press.

SPIEKER M. (1994) Wachstum und Erziehung wertvoller Waldkirschen. In: Mitteilungen der Forstlichen Versuchs- und Forschungsanstalt Baden-Württemberg 181, Freiburg i. Breisgau.

SPIEKER M. und SPIEKER H. (1988) Erziehung von Kirschenwertholz. Allg. Forstz: 43, 562-565.

SOKAL R.R. und ODEN N.L. (1978) Spatial autocorrelation in biology. 1. Methodology. Biological Journal of Linnean Society 10, 199-228.

SOKAL R.R. und WARTENBERg D.E. (1983) A test of spatial autocorrelation analysis using an isolation-by-distance model. Genetics 105, 219-237.

Starke R., Hattemer H.H, Ziehe M., Vornam B., Turok J., Herzog S., Maurer W. UND TABEL U. (1995) Genetische Variation an Enzym-Genloci der Buche. Allgemeine Forst- und Jagdzeitung 166, 161-167.

STEINER W. und Gregorius H.R. (1994) Single-locus gametophytic incompatibility: the symmetric equilibrium is globally asymptotically stable. J. Math. Biol 32, 515-520.

STEINER W. und GREgORIUS H.R. (1997) Reinforcement of genetic coherence: a single-locus model. BioSystems 43, 137-144.

STEPHEN J.R., Dent K.C. und FinCH-SAVAgE W.E. (2003) Molecular responses of Prunus avium (wild cherry) embryonic axes to temperatures affecting dormancy. New phytologist 161, 401403.

STIMm B. und Böswald K. (1994) Die Häher im Visier: Zur Ökologie und waldbaulichen Bedeutung der Samenausbreitung durch Vögel. Forstwissenschaftliches Centralblatt 113, 204-223.

Streiff R., Ducousso A., LeXer C., Steinkellner H., Gloessl J. und Kremer A. (1999) Pollen dispersal inferred from paternity analysis in a mixed oak stand of Quercus robur L. and Q. petraea (Matt.) Liebl. Molecular Ecology 8, 831-841.

STUEFER J.F., DURING H.J. UND DE KROON H. (1994) High benefits of clonal integration in two stoloniferous species, in response to heterogeneous light environments. Journal of Ecology 82, 511-518.

Suszka B., Muller C. und Bonnet-Massimbert M. (1996) Seeds of forest broad-leaves. From harvest to sowing. 1. Auflage, INRA, Paris.

Testolin R., Marazzo T. Cipriani G., Quarta R., Verde I., DetTori M.T., Pancaldi M. und SANSAVINi S. (2000) Microsatellite DNA in peach (Prunus persica L. Batsch) and ist use in fingerprinting and testing the genetic origin of cultivars. Genome 43, 512-520.

TigerstedT P.M.A. (1973) Studies on isozyme variation in marginal and central populations of Picea abies. Hereditas 75, 47-60. 
TURĈEK F.J. (1961) Ökologische Beziehungen der Vögel und Gehölze. Verlag der Slowakischen Akademie der Wissenschaften, Bratislava.

TURĈEK F.J. (1967) Ökologische Beziehungen der Säugetiere und Gehölze. Verlag der Slowakischen Akademie der Wissenschaften, Bratislava.

TuRĈEK F.J. (1968) Die Verbreitung der Vogelkirsche in den Wäldern durch Vögel. Waldhygiene 7(5), 129-132.

Turok J. (1995) Genetische Untersuchungen bei der Buche. Genetische Anpassungsprozesse und die Erhaltung von Genressourcen in Buchenwäldern (Fagus sylvatica L.). Schriftenreihe der Landesanstalt für Ökologie, Bodenordnung und Forsten. Landesamt für Agrarordnung Nordrhein-Westfalen. Band 8, 1-136.

UrbansKa K.M. (1992) Populationsbiologie der Pflanzen. Grundlagen, Probleme, Perspektiven. Gustav Fischer Verlag, Stuttgart, Jena.

WAGENITZ G. (2003) Wörterbuch der Botanik. Gustav Fischer. Spektrum Akademischer Verlag. Heidelberg. Berlin. 2. Auflage

Waits L.P., Kuikart G. und Taberlet P. (2001) Estimating the propability of identity among genotypes in natural populations: cautions and guidelines. Molecular Ecology 10, 249-256.

Wiens J.A., AdDicotT, J.F., CASE T.J. und Diamond J. (1986) Overview: The importance of spatial and temporal scale in ecology investigations. In: Community Ecology (Hrsg. J. Diamond \& T.J. Case), S. 145-153. Harper \& Row, New York.

WRIGHT S. (1939) The distribution of self-sterility alleles in populations. Genetics 24, 538-552.

WRIGHT S. (1943) Isolation by distance. Genetics 28, 114-138.

ZIEGENHAGEN B. UND SCHOlZ B. (2002) Der Beitrag der Genetik zur Biodiversitätsforschung in Wäldern. Schriftenreihe des BMVEL „Angewandte Wissenschaft“, Heft 494, „Biologische Vielfalt mit der Land- und Forstwirtschaft?“, S. 51-58.

ZIEHE M. (2003) Genomische Assoziationen durch Selbst- und Fremdbefruchtung und ihre Bedeutung für die Interpretation genetischer Strukturen am Beispiel der Buche (Fagus sylvatica L.). Schriften aus der Forstlichen Fakultät der Universität Göttingen und der Niedersächsischen Forstlichen Versuchsanstalt. 


\section{Anhang}

Tabelle 1: Polarkoordinaten und Mikrosatelliten-Genotypen der Vogelkirschen im Bestand von Roringen

\begin{tabular}{|c|c|c|c|c|c|c|c|c|c|c|}
\hline \multirow[t]{2}{*}{$\mathrm{Nr}$} & \multicolumn{2}{|c|}{ Polarkoordinaten } & \multirow[b]{2}{*}{ UDP96-005 } & \multicolumn{6}{|c|}{ Mikrosatelliten-Loci } & \multirow[b]{2}{*}{ UDP98-411 } \\
\hline & $\mathrm{x}$ & $y$ & & UDP98-021 & UDP98-410 & UDP98-412 & ВРРСТ034 & ВРРСТ040 & UDP96-001 & \\
\hline 1 & 88,6 & 13,8 & 26 & 13 & 44 & 38 & 26 & 34 & 34 & 56 \\
\hline 2 & 111,7 & 25,3 & 26 & 11 & 47 & 58 & 37 & 33 & 34 & 15 \\
\hline 3 & 55,7 & 37,9 & 36 & 13 & 27 & 55 & 27 & 33 & 34 & 12 \\
\hline 4 & 47,6 & 29,4 & 36 & 11 & 24 & 58 & 28 & 23 & 33 & 35 \\
\hline 5 & 23,6 & 25,4 & 26 & 13 & 24 & 66 & 38 & 33 & 13 & 56 \\
\hline 6 & 33,6 & 63,4 & 22 & 11 & 24 & 15 & 28 & 34 & 34 & 35 \\
\hline 7 & 66,3 & 72,9 & 22 & 13 & 25 & 36 & 28 & 24 & 14 & 35 \\
\hline 8 & 10,8 & 57,1 & 23 & 13 & 27 & 56 & 78 & 33 & 34 & 15 \\
\hline 9 & 11,9 & 55,2 & 23 & 13 & 27 & 56 & 78 & 33 & 34 & 15 \\
\hline 10 & 7,7 & 36,3 & 66 & 11 & 24 & 56 & 38 & 23 & 33 & 36 \\
\hline 11 & 240,8 & 145,2 & 13 & 13 & 44 & 68 & 22 & 34 & 34 & 35 \\
\hline 13 & 240,0 & 73,6 & 23 & 11 & 57 & 56 & 48 & 33 & 34 & 15 \\
\hline 14 & 244,0 & 65,3 & 22 & 11 & 22 & 16 & 22 & 24 & 13 & 15 \\
\hline 15 & 224,4 & 65,7 & 16 & 11 & 22 & 66 & 16 & 13 & 34 & 35 \\
\hline 16 & 220,6 & 70,7 & 36 & 11 & 44 & 56 & 28 & 12 & 13 & 35 \\
\hline 17 & 181,2 & 144,9 & 12 & 55 & 44 & 16 & 22 & 44 & 34 & 35 \\
\hline 18 & 161,5 & 133,0 & 25 & 13 & 48 & 68 & 68 & 13 & 13 & 56 \\
\hline 19 & 155,6 & 133,6 & 25 & 13 & 48 & 68 & 68 & 13 & 13 & 56 \\
\hline 20 & 153,1 & 134,2 & 25 & 13 & 48 & 68 & 68 & 13 & 13 & 56 \\
\hline 21 & 137,8 & 134,1 & 26 & 11 & 24 & 56 & 28 & 34 & 14 & 35 \\
\hline 22 & 129,1 & 126,3 & 23 & 11 & 44 & 16 & 28 & 34 & 13 & 35 \\
\hline 23 & 120,7 & 133,0 & 22 & 13 & 47 & 66 & 27 & 34 & 14 & 13 \\
\hline 24 & 114,1 & 127,1 & 25 & 11 & 24 & 66 & 22 & 34 & 13 & 35 \\
\hline 25 & 133,0 & 118,5 & 23 & 15 & 46 & 15 & 27 & 24 & 34 & 23 \\
\hline 26 & 116,0 & 94,3 & 26 & 13 & 25 & 58 & 22 & 34 & 14 & 23 \\
\hline 27 & 124,7 & 140,9 & 35 & 13 & 44 & 56 & 28 & 23 & 13 & 55 \\
\hline 28 & 101,8 & 151,0 & 23 & 35 & 27 & 16 & 27 & 34 & 13 & 13 \\
\hline 29 & 103,7 & 156,3 & 22 & 15 & 44 & 36 & 28 & 34 & 13 & 36 \\
\hline 30 & 95,7 & 151,9 & 22 & 15 & 44 & 36 & 28 & 34 & 13 & 36 \\
\hline 31 & 84,9 & 151,1 & 12 & 11 & 44 & 68 & 13 & 24 & 34 & 36 \\
\hline 32 & 104,9 & 158,7 & 23 & 15 & 44 & 13 & 26 & 22 & 34 & 35 \\
\hline 33 & 108,1 & 190,1 & 25 & 13 & 44 & 67 & 23 & 23 & 34 & 45 \\
\hline 34 & 90,6 & 194,4 & 23 & 15 & 24 & 16 & 22 & 24 & 14 & 44 \\
\hline 35 & 82,0 & 125,8 & 36 & 13 & 44 & 68 & 37 & 33 & 34 & 15 \\
\hline 36 & 73,9 & 118,0 & 36 & 13 & 47 & 68 & 78 & 33 & 44 & 15 \\
\hline 37 & 85,7 & 105,2 & 36 & 11 & 44 & 68 & 23 & 34 & 44 & 35 \\
\hline 38 & 79,9 & 100,8 & 35 & 15 & 24 & 18 & 22 & 47 & 13 & 36 \\
\hline 39 & 64,3 & 117,8 & 36 & 11 & 44 & 58 & 38 & 33 & 34 & 55 \\
\hline 40 & 62,5 & 121,3 & 36 & 11 & 44 & 58 & 38 & 33 & 34 & 55 \\
\hline 41 & 51,9 & 126,4 & 36 & 11 & 44 & 58 & 38 & 33 & 34 & 55 \\
\hline 42 & 59,0 & 131,6 & 23 & 13 & 44 & 68 & 88 & 33 & 33 & 55 \\
\hline 43 & 43,4 & 131,4 & 36 & 11 & 44 & 58 & 38 & 33 & 34 & 55 \\
\hline 44 & 44,1 & 135,7 & 23 & 15 & 25 & 16 & 22 & 34 & 14 & 33 \\
\hline 45 & 39,5 & 145,0 & 22 & 15 & 27 & 15 & 28 & 23 & 34 & 35 \\
\hline 46 & 39,6 & 154,8 & 23 & 15 & 45 & 66 & 26 & 44 & 13 & 35 \\
\hline 47 & 37,7 & 161,3 & 26 & 11 & 47 & 58 & 67 & 33 & 34 & 16 \\
\hline 48 & 56,0 & 106,7 & 26 & 13 & 27 & 66 & 78 & 34 & 33 & 12 \\
\hline 49 & 48,3 & 104,9 & 26 & 13 & 45 & 56 & 23 & 33 & 33 & 55 \\
\hline 50 & 41,5 & 100,1 & 23 & 11 & 47 & 58 & 77 & 33 & 34 & 16 \\
\hline 51 & 41,0 & 106,1 & 33 & 15 & 24 & 15 & 23 & 23 & 14 & 35 \\
\hline 52 & 36,3 & 111,5 & 23 & 13 & 27 & 56 & 78 & 33 & 14 & 35 \\
\hline 53 & 19,8 & 133,6 & 36 & 15 & 44 & 16 & 23 & 23 & 14 & 55 \\
\hline 54 & 181,2 & 22,0 & 33 & 11 & 44 & 56 & 28 & 23 & 14 & 35 \\
\hline 55 & 155,9 & 19,9 & 66 & 13 & 44 & 18 & 37 & 34 & 34 & 55 \\
\hline 56 & 163,4 & 34,2 & 25 & 11 & 25 & 12 & 22 & 33 & 13 & 36 \\
\hline 57 & 178,0 & 30,1 & 23 & 35 & 44 & 56 & 28 & 34 & 13 & 35 \\
\hline
\end{tabular}


Tabelle 2: Polarkoordinaten und Mikrosatelliten-Genotypen der Vogelkirschen im Bestand von Settmarshausen

\begin{tabular}{|c|c|c|c|c|c|c|c|c|c|c|}
\hline \multirow[t]{2}{*}{ Nr. } & \multicolumn{2}{|c|}{ Polarkoordinaten } & \multirow[b]{2}{*}{ UDP96-005 } & \multicolumn{4}{|c|}{ Mikrosatelliten-Loci } & \multirow[b]{2}{*}{ ВРРСТ040 } & \multirow[b]{2}{*}{ UDP96-001 } & \multirow[b]{2}{*}{ UDP98-411 } \\
\hline & $x$ & $\mathrm{y}$ & & UDP98-021 & UDP98-410 & UDP98-412 & ВРРСТ034 & & & \\
\hline 1 & 146,6 & 97,1 & 26 & 23 & 25 & 66 & 23 & 26 & 34 & 23 \\
\hline 2 & 125,2 & 105,1 & 26 & 23 & 25 & 66 & 23 & 26 & 34 & 23 \\
\hline 3 & 108,4 & 132,3 & 35 & 11 & 27 & 56 & 46 & 33 & 23 & 15 \\
\hline 4 & 114,3 & 141,9 & 35 & 11 & 27 & 56 & 46 & 33 & 23 & 15 \\
\hline 5 & 99,4 & 147,0 & 35 & 11 & 27 & 56 & 46 & 33 & 23 & 15 \\
\hline 6 & 105,1 & 152,0 & 35 & 11 & 27 & 56 & 46 & 33 & 23 & 15 \\
\hline 7 & 82,7 & 166,2 & 56 & 15 & 25 & 56 & 78 & 36 & 14 & 35 \\
\hline 8 & 78,6 & 166,1 & 56 & 15 & 25 & 56 & 78 & 36 & 14 & 35 \\
\hline 9 & 76,8 & 164,6 & 56 & 15 & 25 & 56 & 78 & 36 & 14 & 35 \\
\hline 10 & 92,0 & 175,6 & 56 & 15 & 24 & 55 & 48 & 27 & 33 & 55 \\
\hline 11 & 94,7 & 176,4 & 56 & 15 & 24 & 55 & 48 & 27 & 33 & 55 \\
\hline 12 & 128,2 & 137,3 & 66 & 11 & 55 & 68 & 77 & 24 & 34 & 35 \\
\hline 13 & 154,1 & 146,8 & 66 & 15 & 25 & 56 & 88 & 37 & 33 & 11 \\
\hline 14 & 154,7 & 140,2 & 66 & 15 & 25 & 56 & 88 & 37 & 33 & 11 \\
\hline 15 & 161,4 & 156,6 & 35 & 13 & 25 & 56 & 37 & 33 & 13 & 36 \\
\hline 16 & 187,5 & 163,5 & 56 & 23 & 25 & 56 & 33 & 36 & 33 & 36 \\
\hline 18 & 198,1 & 152,9 & 56 & 13 & 57 & 66 & 26 & 23 & 33 & 12 \\
\hline 19 & 219,8 & 70,9 & 56 & 13 & 24 & 56 & 36 & 36 & 36 & 56 \\
\hline 20 & 211,2 & 74,5 & 22 & 13 & 24 & 56 & 36 & 36 & 36 & 56 \\
\hline 21 & 211,2 & 57,8 & 26 & 35 & 57 & 58 & 13 & 57 & 24 & 56 \\
\hline 22 & 91,6 & 83,1 & 66 & 11 & 59 & 68 & 27 & 46 & 44 & 55 \\
\hline 23 & 94,9 & 78,5 & 66 & 11 & 59 & 68 & 27 & 46 & 44 & 55 \\
\hline 24 & 101,0 & 75,2 & 66 & 33 & 55 & 68 & 78 & 37 & 44 & 33 \\
\hline 25 & 147,6 & 54,5 & 25 & 11 & 45 & 55 & 24 & 27 & 34 & 27 \\
\hline 26 & 142,0 & 46,5 & 33 & 12 & 55 & 36 & 26 & 27 & 34 & 33 \\
\hline 27 & 154,9 & 33,8 & 23 & 11 & 25 & 67 & 25 & 45 & 23 & 27 \\
\hline 28 & 158,6 & 31,8 & 36 & 11 & 45 & 56 & 78 & 77 & 24 & 55 \\
\hline 29 & 152,1 & 38,7 & 26 & 11 & 24 & 38 & 67 & 23 & 44 & 55 \\
\hline 30 & 156,9 & 38,9 & 22 & 13 & 45 & 66 & 36 & 67 & 34 & 26 \\
\hline 31 & 165,1 & 43,1 & 22 & 13 & 45 & 66 & 36 & 67 & 34 & 26 \\
\hline 32 & 189,8 & 21,9 & 26 & 15 & 49 & 36 & 17 & 23 & 34 & 36 \\
\hline 33 & 192,9 & 15,9 & 36 & 26 & 46 & 56 & 15 & 27 & 35 & 56 \\
\hline 34 & 195,7 & 30,7 & 23 & 13 & 57 & 68 & 15 & 14 & 33 & 78 \\
\hline 35 & 191,8 & 8,6 & 36 & 11 & 22 & 56 & 89 & 37 & 33 & 13 \\
\hline 36 & 20,3 & 215,4 & 12 & 13 & 22 & 56 & 48 & 36 & 34 & 26 \\
\hline 37 & 9,4 & 198,6 & 12 & 13 & 22 & 56 & 48 & 36 & 34 & 26 \\
\hline 38 & 78,2 & 244,9 & 26 & 15 & 22 & 36 & 78 & 22 & 44 & 35 \\
\hline 39 & 80,7 & 250,4 & 26 & 15 & 22 & 36 & 78 & 22 & 44 & 35 \\
\hline 40 & 122,1 & 205,6 & 56 & 25 & 45 & 16 & 28 & 23 & 34 & 36 \\
\hline
\end{tabular}


Tabelle 3: Polarkoordinaten sowie Mikrosatelliten- und Isoenzym-Genotypen der Vogelkirschen im Bestand von Wibbecke

\begin{tabular}{|c|c|c|c|c|c|c|c|c|c|c|c|c|c|c|}
\hline \multirow[t]{2}{*}{$\mathrm{Nr}$} & \multicolumn{2}{|c|}{ Polarkoordinaten } & \multicolumn{6}{|c|}{ Mikrosatelliten-Loci } & \multicolumn{6}{|c|}{ Isoenzyme } \\
\hline & $x$ & $y$ & UDP96-005 & UDP98-021 & UDP98-410 & UDP98-412 & ВРРСТ034 & ВРРСТ 040 & PGM & IDH & 6PGDH & SKDH & GOT & ACO \\
\hline 2 & 128,2 & 125,6 & 66 & 11 & 25 & 38 & 24 & 47 & 12 & 12 & 11 & 12 & 11 & 22 \\
\hline 3 & 132,2 & 122,2 & 66 & 11 & 25 & 38 & 24 & 47 & 12 & 22 & 12 & 22 & 11 & 22 \\
\hline 4 & 119,7 & 152,6 & 66 & 11 & 25 & 38 & 24 & 47 & 12 & 22 & 11 & 22 & 11 & 22 \\
\hline 5 & 121,7 & 149,5 & 66 & 11 & 25 & 38 & 24 & 47 & 12 & 22 & 12 & 22 & 11 & 22 \\
\hline 6 & 101,7 & 109,1 & 26 & 11 & 58 & 11 & 23 & 34 & 12 & 12 & 12 & 22 & 11 & 12 \\
\hline 7 & 83 & 95,5 & 66 & 11 & 28 & 37 & 24 & 47 & 12 & 12 & 12 & 22 & 11 & 22 \\
\hline 8 & 87,7 & 91,7 & 26 & 11 & 58 & 11 & 23 & 34 & 12 & 12 & 12 & 22 & 11 & 12 \\
\hline 9 & 75,5 & 84,3 & 16 & 13 & 55 & 66 & 47 & 27 & 22 & 11 & 12 & 12 & 11 & 12 \\
\hline 10 & 65,5 & 86,1 & 16 & 13 & 55 & 66 & 47 & 27 & 22 & 11 & 12 & 12 & 11 & 12 \\
\hline 12 & 57,00 & 107,6 & 16 & 13 & 55 & 66 & 47 & 27 & 22 & 11 & 11 & 12 & 11 & 12 \\
\hline 13 & 44 & 110,6 & 16 & 13 & 55 & 66 & 47 & 27 & 12 & 11 & 12 & 22 & 11 & 12 \\
\hline 14 & 45,3 & 122,1 & 16 & 13 & 55 & 66 & 47 & 27 & 22 & 11 & 12 & 12 & 11 & 12 \\
\hline 15 & 55,7 & 127,4 & 16 & 11 & 24 & 67 & 24 & 12 & 22 & 12 & 11 & 12 & 12 & 22 \\
\hline 16 & 54,10 & 133,2 & 16 & 11 & 24 & 67 & 24 & 12 & 22 & 12 & 11 & 12 & 12 & 22 \\
\hline 17 & 58,2 & 133,2 & 16 & 11 & 24 & 67 & 24 & 12 & 22 & 12 & 11 & 12 & 12 & 22 \\
\hline 18 & 54,8 & 136,4 & 16 & 11 & 24 & 67 & 24 & 12 & 22 & 12 & 11 & 12 & 12 & 22 \\
\hline 19 & 63,9 & 140,3 & 66 & 11 & 25 & 38 & 24 & 47 & 22 & 11 & 12 & 22 & 11 & 22 \\
\hline 20 & 74,4 & 140,1 & 66 & 11 & 25 & 38 & 24 & 47 & 22 & 11 & 11 & 12 & 11 & 22 \\
\hline 21 & 45,2 & 142,7 & 16 & 11 & 24 & 67 & 24 & 12 & 22 & 11 & 11 & 12 & 12 & 22 \\
\hline 24 & 18,80 & 110,5 & 66 & 11 & 45 & 28 & 22 & 24 & 22 & 11 & 22 & 12 & 11 & 22 \\
\hline 25 & 16,1 & 103 & 66 & 11 & 45 & 28 & 22 & 24 & 22 & 11 & 22 & 12 & 11 & 22 \\
\hline 26 & 6,00 & 104,5 & 66 & 11 & 45 & 28 & 22 & 24 & 22 & 11 & 22 & 12 & 11 & 22 \\
\hline 27 & 33,5 & 79 & 16 & 11 & 22 & 15 & 23 & 23 & 22 & 11 & 11 & 22 & 12 & 22 \\
\hline 29 & 53,2 & 68,1 & 16 & 13 & 55 & 66 & 47 & 27 & 22 & 11 & 11 & 12 & 11 & 12 \\
\hline 30 & 50,7 & 69,1 & 16 & 13 & 55 & 66 & 47 & 27 & 22 & 11 & 11 & 12 & 11 & 12 \\
\hline 31 & 47,10 & 144,3 & 16 & 11 & 24 & 67 & 24 & 12 & 22 & 11 & 11 & 12 & 12 & 22 \\
\hline 32 & 43,4 & 180,4 & 66 & 11 & 24 & 36 & 22 & 27 & 22 & 12 & 11 & 12 & 12 & 22 \\
\hline 33 & 45,4 & 181,2 & 66 & 11 & 24 & 38 & 22 & 27 & 22 & 22 & 11 & 12 & 12 & 22 \\
\hline 34 & 48,4 & 187,2 & 66 & 11 & 24 & 36 & 22 & 27 & 22 & 22 & 11 & 12 & 11 & 22 \\
\hline 35 & 47,4 & 188,6 & 66 & 11 & 24 & 36 & 22 & 27 & 22 & 22 & 11 & 12 & 11 & 22 \\
\hline 36 & 45,7 & 190,6 & 66 & 11 & 24 & 36 & 22 & 27 & 22 & 22 & 11 & 12 & 11 & 22 \\
\hline 37 & 54,7 & 186,1 & 66 & 11 & 24 & 36 & 22 & 27 & 22 & 22 & 11 & 22 & 11 & 22 \\
\hline 38 & 51,3 & 179,6 & 66 & 11 & 24 & 36 & 22 & 27 & 22 & 22 & 11 & 12 & 11 & 22 \\
\hline 39 & 52,4 & 179,8 & 66 & 11 & 24 & 36 & 22 & 27 & 22 & 22 & 11 & 12 & 11 & 22 \\
\hline 40 & 61,5 & 184,4 & 66 & 11 & 24 & 36 & 22 & 27 & 22 & 22 & 11 & 12 & 11 & 22 \\
\hline 41 & 94,7 & 156,5 & 66 & 11 & 24 & 36 & 22 & 47 & 22 & 11 & 12 & 22 & 11 & 22 \\
\hline 42 & 135,9 & 141,1 & 66 & 11 & 25 & 38 & 24 & 47 & 22 & 11 & 12 & 12 & 11 & 22 \\
\hline 43 & 153 & 146,7 & 66 & 11 & 25 & 38 & 24 & 47 & 22 & 11 & 12 & 22 & 11 & 22 \\
\hline 44 & 156,4 & 150,7 & 26 & 11 & 58 & 68 & 34 & 27 & 22 & 11 & 22 & 12 & 11 & 12 \\
\hline 45 & 220,3 & 173 & 16 & 13 & 48 & 55 & 37 & 47 & 22 & 11 & 12 & 12 & 11 & 12 \\
\hline
\end{tabular}


Tabelle 3: (Fortsetzung)

\begin{tabular}{|c|c|c|c|c|c|c|c|c|c|c|c|c|c|c|}
\hline \multirow[t]{2}{*}{$\mathrm{Nr}$} & \multicolumn{2}{|c|}{ Polarkoordinaten } & \multicolumn{6}{|c|}{ Mikrosatelliten-Loci } & \multicolumn{6}{|c|}{ Isoenzyme } \\
\hline & $\mathrm{x}$ & $y$ & UDP96-005 & UDP98-021 & UDP98-410 & UDP98-412 & ВРРСТ034 & ВРРСТ 040 & PGM & IDH & 6PGDH & SKDH & GOT & $\mathrm{ACO}$ \\
\hline 46 & 225,3 & 154,5 & 26 & 11 & 55 & 66 & 46 & 12 & 22 & 11 & 22 & 12 & 11 & 12 \\
\hline 47 & 224,4 & 175,6 & 16 & 13 & 48 & 55 & 37 & 47 & 22 & 11 & 12 & 12 & 11 & 12 \\
\hline 48 & 221,2 & 181,4 & 16 & 13 & 48 & 55 & 37 & 47 & 22 & 11 & 12 & 12 & 11 & 12 \\
\hline 49 & 223,7 & 183,7 & 16 & 13 & 48 & 55 & 37 & 47 & 22 & 11 & 12 & 12 & 11 & 12 \\
\hline 50 & 228,1 & 178,8 & 16 & 13 & 48 & 55 & 37 & 47 & 22 & 11 & 12 & 12 & 11 & 12 \\
\hline 51 & 249,2 & 173,3 & 16 & 13 & 48 & 55 & 37 & 47 & 22 & 11 & 12 & 12 & 11 & 12 \\
\hline 52 & 248,1 & 176,2 & 16 & 13 & 48 & 55 & 37 & 47 & 22 & 11 & 12 & 12 & 11 & 12 \\
\hline 53 & 249 & 176,3 & 16 & 13 & 48 & 55 & 37 & 47 & 22 & 11 & 12 & 12 & 11 & 12 \\
\hline 54 & 250 & 185 & 16 & 13 & 48 & 55 & 37 & 47 & 22 & 11 & 12 & 12 & 11 & 12 \\
\hline 55 & 250,4 & 191,4 & 16 & 13 & 48 & 55 & 37 & 47 & 22 & 11 & 12 & 12 & 11 & 12 \\
\hline 57 & 238,9 & 193,2 & 16 & 13 & 48 & 55 & 37 & 47 & 22 & 11 & 12 & 12 & 11 & 12 \\
\hline 58 & 238,6 & 196,6 & 16 & 13 & 48 & 55 & 37 & 47 & 22 & 11 & 12 & 12 & 11 & 12 \\
\hline 59 & 235,5 & 201,7 & 16 & 13 & 48 & 55 & 37 & 47 & 22 & 11 & 12 & 12 & 11 & 12 \\
\hline 60 & 241,5 & 205,4 & 16 & 13 & 48 & 55 & 37 & 47 & 22 & 11 & 12 & 12 & 11 & 12 \\
\hline 61 & 252,8 & 193,5 & 16 & 13 & 48 & 55 & 37 & 47 & 22 & 11 & 12 & 12 & 11 & 12 \\
\hline 62 & 202,1 & 158,8 & 26 & 11 & 55 & 66 & 46 & 12 & 22 & 11 & 22 & 12 & 11 & 12 \\
\hline 63 & 140,9 & 183,9 & 66 & 13 & 55 & 57 & 14 & 27 & 22 & 11 & 22 & 12 & 11 & 12 \\
\hline 64 & 140,5 & 186,2 & 26 & 11 & 55 & 66 & 46 & 12 & 22 & 11 & 22 & 12 & 11 & 12 \\
\hline 65 & 180,2 & 268,2 & 12 & 13 & 22 & 77 & 24 & 23 & 22 & 12 & 12 & 22 & 11 & 22 \\
\hline 66 & 236,8 & 258,3 & 26 & 15 & 27 & 18 & 24 & 13 & 22 & 11 & 12 & 11 & 11 & 12 \\
\hline 68 & 189,8 & 272 & 12 & 13 & 22 & 77 & 24 & 23 & 22 & 12 & 12 & 22 & 11 & 22 \\
\hline 69 & 201,5 & 291,3 & 26 & 13 & 22 & 18 & 46 & 22 & 22 & 12 & 22 & 12 & 11 & 22 \\
\hline 70 & 191 & 307,2 & 26 & 11 & 48 & 38 & 34 & 24 & 22 & 12 & 22 & 22 & 12 & 12 \\
\hline 71 & 195,7 & 308,4 & 26 & 11 & 28 & 38 & 34 & 24 & 22 & 22 & 22 & 12 & 12 & 12 \\
\hline 72 & 189,4 & 313,2 & 26 & 11 & 28 & 38 & 34 & 24 & 22 & 22 & 22 & 12 & 12 & 12 \\
\hline 73 & 206,1 & 330,1 & 23 & 11 & 58 & 16 & 13 & 34 & 22 & 22 & 22 & 12 & 12 & 12 \\
\hline 74 & 209,3 & 333,1 & 23 & 11 & 58 & 16 & 13 & 34 & 22 & 22 & 22 & 12 & 12 & 12 \\
\hline 75 & 210,8 & 332,7 & 23 & 11 & 58 & 16 & 13 & 34 & 22 & 22 & 22 & 12 & 12 & 12 \\
\hline 76 & 183,4 & 355,6 & 12 & 12 & 25 & 66 & 18 & 27 & 22 & 11 & 22 & 12 & 12 & 22 \\
\hline 77 & 181,9 & 357,1 & 12 & 12 & 25 & 66 & 18 & 27 & 22 & 11 & 22 & 12 & 12 & 22 \\
\hline 78 & 181 & 353,6 & 12 & 12 & 25 & 66 & 18 & 27 & 22 & 11 & 22 & 12 & 12 & 22 \\
\hline 79 & 185,1 & 347,1 & 12 & 12 & 25 & 66 & 18 & 27 & 22 & 11 & 22 & 12 & 12 & 22 \\
\hline 80 & 178,3 & 354,2 & 12 & 12 & 25 & 66 & 18 & 27 & 22 & 11 & 22 & 12 & 12 & 22 \\
\hline 81 & 153,3 & 22,8 & 25 & 11 & 22 & 58 & 24 & 17 & 22 & 11 & 12 & 12 & 12 & 22 \\
\hline 82 & 151,9 & 24,3 & 25 & 11 & 22 & 58 & 24 & 17 & 22 & 11 & 12 & 12 & 12 & 22 \\
\hline 83 & 169,1 & 22,8 & 25 & 11 & 22 & 58 & 24 & 17 & 22 & 11 & 12 & 12 & 12 & 22 \\
\hline 84 & 170,6 & 2,60 & 16 & 11 & 45 & 18 & 34 & 17 & 22 & 11 & 22 & 12 & 11 & 22 \\
\hline 85 & 188,8 & 29,9 & 26 & 11 & 24 & 67 & 14 & 37 & 22 & 11 & 12 & 12 & 12 & 22 \\
\hline
\end{tabular}




\section{Curriculum vitae}

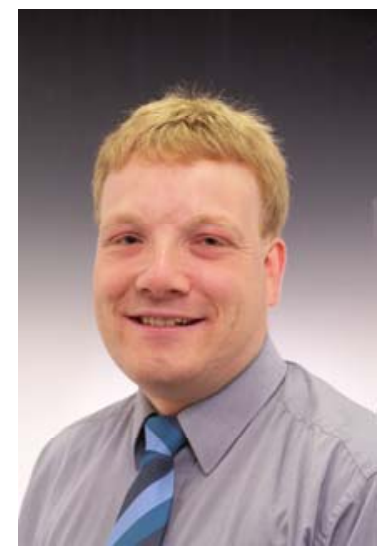

\section{Persönliche Daten}

Name:

Geburtsdatum/-ort:

Staatsangehörigkeit:

Familienstand:

Wohnort:

Arbeitsplatz:
Aki Michael Höltken

29.03.1971 in Oldenburg / Oldbg. deutsch

ledig

Stadtstieg 44, D-37083 Göttingen

Georg-August-Universität Göttingen, Institut für Forstgenetik und Forstpflanzenzüchtung, Büsgenweg 2, D-37077 Göttingen

\section{Ausbildung}

1981 - 1990 Gymnasium Wermelskirchen, Abschluß: Abitur

\begin{tabular}{c} 
1990 - 1991 \\
\hline---------- \\
\hline 1991 - 1992 \\
1992 - 1995
\end{tabular}

Wehrdienst (Bundeswehr)

Praktikum am Forstamt Lüdenscheid (6 Monate)

Grundstudium an der Ludwig-Maxin -1995 Fakultät für Forstwissenschaften

Abschluß: Vordiplom

1995 - 1999 Hauptstudium an der Georg-August-Universität Göttingen, Fakultät für Forstwissenschaften und Waldökologie; Diplomarbeit am Institut für Forstgenetik und Forstpflanzenzüchtung: 'Genetische Strukturen der Fichte (Picea abies) in der nördlichen Marginalzone ihres Verbreitungsgebietes in Finnland' Abschluß: Diplom-Forstwirt

\section{Berufliche Laufbahn}

8/1990 - 1/2005 Handelsvertretung sowie Bau und Vertrieb biologisch-technischer Geräte (Fa. LIMNOS, selbständige Tätigkeit)

10/1999 - 10/2001 Wissenschaftlicher Mitarbeiter an der Universität Helsinki, 
Department of Plant and Tree Breeding

Projekt: 'Genetische Strukturen der Esche (Fraxinus excelsior L.) in der nördlichen Marginalzone ihres Verbreitungsgebietes in Finnland'

Projektfinanzierung: Universität Helsinki, Finnische Kulturstiftung, Niemi-Stiftung, Societas pro Fauna et Flora Fennica, Centre for International Mobility

11/2001 - 10/2005 Wissenschaftlicher Mitarbeiter an der Georg-August-Universität Göttingen, Institut für Forstgenetik und Forstpflanzenzüchtung

Projekt: 'Mechanismen zur Erhaltung genetischer Variation in Populationen rezedenter Waldbaumarten am Beispiel der Vogelkirsche (Prunus avium L.)'

Projektfinanzierung: DFG (Deutsche Forschungsgemeinschaft)

6/2005 Promotion an der Fakultät für Forstwissenschaften und Waldökologie (Hauptfach: Forstgenetik, Nebenfächer: Bodenkunde sowie Waldinventur)

\section{Zusätzliche Qualifikationen}

\section{Veröffentlichungen}

HÖltKen A.M., TÄHTINEN J. \& PAPPINEN A. (2003) Effects of discontinuous marginal habitats on the genetic structure of common ash (Fraxinus excelsior L.). Silvae Genetica 52, 206-212.

HÖLTKEN A.M. \& GREGORIUS H.-R. (2005) Is enhanced species diversity in historical forest management systems sustainable? A case study in wild cherry (Prunus avium L.). Verhandlungen der Gesellschaft für Ökologie (Band 35), Bayerische Akademie für Naturschutz und Landschaftspflege (Hrsg.), Laufen/Salzach.

HÖLTKEN A.M. \& GREGORIUS H.-R. (2005) Genetic characteristics of the mixed reproduction system of Prunus avium L. (wild cherry), Heredity (eingereicht)

\section{Konferenzen, Kurse, Veranstaltungen}

Metapopulationsökologie und -genetik der Pflanzen - Bedeutung für die Arterhaltung (Metapopulation ecology and genetics in plants - implications for conservation biology), 10.-13.10.2000

Veranstaltung der Universität Oulu (Finnland) an der Biologischen Station des Nationalparks Oulanka

Resistenzzüchtung, 05.-10.02.2001.

Graduiertenkurs der Universität Lettland (Institut für Biologie) in Jurmala, Lettland 
Molekulare Marker in der Pflanzengenetik, 11.-22. 06.2001

Graduiertenkurs, Riso National Laboratory, Roskilde, Dänemark

Vermittlung des theoretischen Hintergrunds auf dem Gebiet der Kopplungs- und QTL-

Analyse sowie grundlegende molekulargenetische Methoden; Techniken der DNS-Extraktion aus Pflanzengeweben; Klonierung und Sequenzierung amplifizierter DNS-Fragmente und verschiedene DNS-Markertechniken

Population dynamics in a changing landscape - persistance, dispersal or adaptation, 19.-23.05.2004 Konferenz des Arbeitskreises Populationsbiologie der Pflanzen der Gesellschaft für Ökologie (GfÖ), Lehrstul für Botanik, Universität Regensburg

Eigener Vortrag zu dem Thema 'Spatial separation does not imply reproductive isolation: A case study in wild cherry (Prunus avium L.)'

Landschaften, Ökosysteme und Populationen - Funktionen, Dynamike und Naturschutz, (Landscapes, ecosystems and populations - functions, dynamics and conservation), 19.-24.09.2005

Konferenz des Arbeitskreises Populationsbiologie der Pflanzen der Gesellschaft für Ökologie (GfÖ), Lehrstul für Botanik, Universität Regensburg

Eigener Vortrag zu dem Thema 'Is enhanced species diversity in historical forest management systems sustainable? A case study in wild cherry (Prunus avium L.)'

\section{Sprachkenntnisse:}

Deutsch und Finnisch (Muttersprachen)

Englisch (häufig genutzte wissenschaftliche Sprache)

Latein (Schulkenntnisse) 
